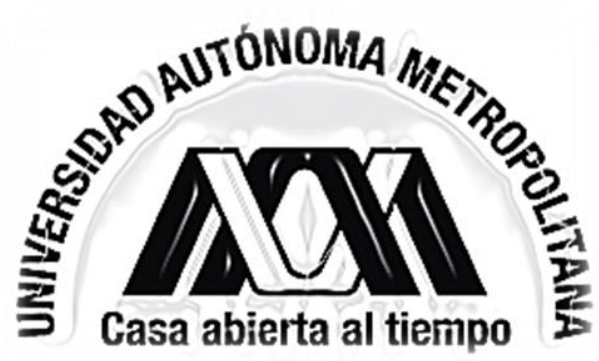

\author{
Universidad Autónoma Metropolitana \\ Unidad Azcapotzalco \\ Maestría en Sociología
}

\title{
MUJERES INDÍGENAS Y MESTIZAS RECLUIDAS EN "SANTIAGUITO", ESTADO DE MÉXICO. PROCESOS DE SOCIALIZACIÓN Y ESTRATEGIAS DE SOBREVIVENCIA: UN ANÁLISIS COMPARATIVO
}

PRESENTA

Yazmín Calderón Heredia

ASESORA

Dra. Karina Ochoa Muñoz

SINODALES

Dr. Jorge Mercado Mondragón

Dr. José Francisco Avila

Castañeda

Diciembre 2020 
"Suele decirse que nadie conoce cómo es realmente una nación hasta haber estado en una de sus cárceles.

Una nación no debe juzgarse por cómo trata a sus ciudadanos con mejor posición, sino por cómo trata a los que tienen poco o nada"

Nelson Mandela, 1994 


\section{ÍNDICE}

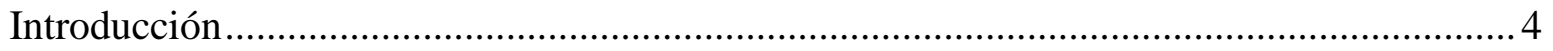

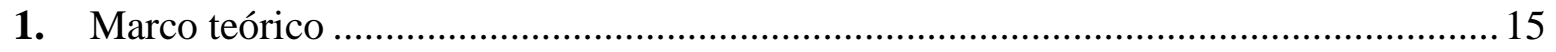

1.1. Los procesos de socialización y su importancia en la conformación de grupos

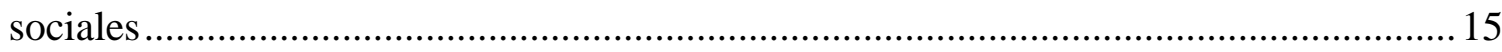

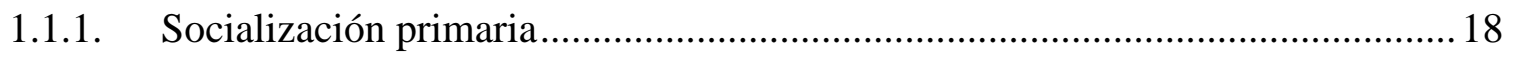

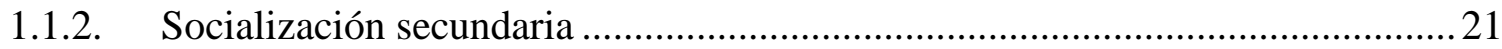

1.1.3. El proceso de socialización terciaria o de resocialización ...............................27

1.2. "Estrategias de sobrevivencia", construcción desde la mirada de las ciencias

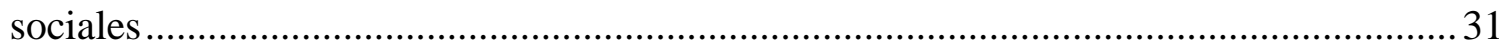

1.3. Sistemas penales y el castigo: del suplicio a la privación de la libertad desde las perspectivas de Durkheim y Foucault ...................................................................... 44

1.3.1. El castigo y el sistema penal de Émile Durkheim ...........................................46

1.3.2. Castigo y sus nuevas modalidades: el sistema penal según Michel Foucault ....54

2. El Estado Nación en México. Antecedentes de un conjunto de desigualdades ............64

2.1. Estado Nación Mexicano y la diferenciación de raza ..........................................67

2.2. Las clases sociales en la constitución de desigualdades ................................... 85

3. Categoría de género: las mujeres en la sociedad ................................................. 103

3.1. La subordinación femenina y la heteronormatividad...................................... 113

3.2. Distinción entre mujeres indígenas y mestizas: aportes desde la

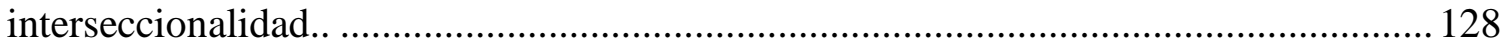

4. El sistema carcelario mexicano: recintos reproductores de racismo, desigualdad social,

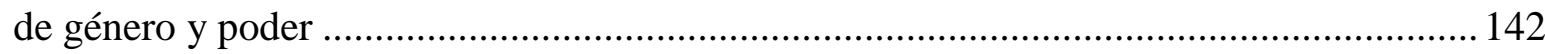

4.1. Tipos de instituciones carcelarias en México ................................................ 152

4.2. Mujeres recluidas en cárceles femeniles y mixtas (panorama general) ............... 157

4.3. Centro Penitenciario y de Reinserción Social "Santiaguito", Almoloya de Juárez,

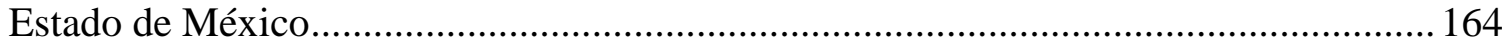

5. Mujeres en el CPRS de Almoloya de Juárez: análisis y comparativo de casos .......... 172 5.1. Diversidad de mujeres y su día a día en "Santiaguito": Subordinación y exclusión en la reclusión 180

5.2. Reclusas de Almoloya de Juárez: los diferentes impactos en los procesos de socialización desde su condición de género, raza, clase social y edad..... 195 
5.3. Producto de una múltiple opresión en el área femenil de "Santiaguito": comparativo de casos y estrategias de sobrevivencia de mujeres indígenas y

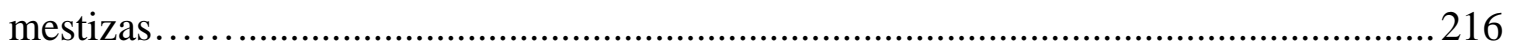

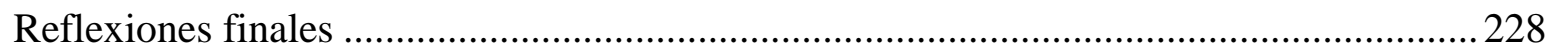

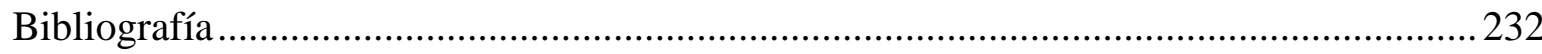

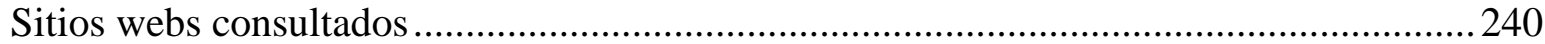

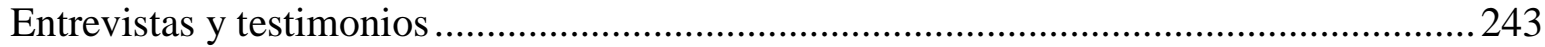




\section{INTRODUCCIÓN}

Hablar de las situaciones que se originan en los sistemas carcelarios, tiene como implicación hacer el recorrido de muchas de las problemáticas que se han vivido o se viven en muchas sociedades. Esto, debido a que dentro de los recintos destinados para el confinamiento de las personas que se dice, presentan comportamientos anómalos y rompen con las reglas establecidas en sus entornos (delincuentes/ criminales), podemos ver el reflejo de la manera como se han ido construyendo las sociedades, dejando en relieve mucho de lo que constituye los fracasos de estas mismas. La manera como actualmente están diseñados los sistemas carcelarios, es lo que da muestras de lo que se vive en el exterior día a día. De este modo, algo que se hace totalmente evidente de instituciones como estas, es la marcada conformación de relaciones altamente diferenciadas, en las que, incluso, las penas se imponen de maneras desiguales, según la condición de cada individuo.

Respecto a esto cabe resaltar que los sistemas penales, desde sus inicios, con antecedentes como el suplicio, exhibicionismo social, y castigos corporales, hasta las maneras "modernas" de castigo, como son, principalmente, las que se representan con la privación de la libertad, se puede ver que las asignaciones de los tipos de penas han sido desde formas disparejas y desequilibradas entre cada tipo de persona. Tal como lo señala Émile Durkheim en el texto: Dos leyes de la evolución penal (1899-1900), en donde las clases sociales más bajas eran blanco de castigos más severos. Por ejemplo, si el infractor era un esclavo, éste recibía una mayor cantidad de azotes. Lo mismo sucede con la privación de la libertad, en donde, si los sujetos pertenecen a una clase inferior su período de encierro puede ser más largo y difícil de sobrellevar. Es por esto que cabe decir que, el carcelario es uno de los sistemas más desiguales en donde tienen un mayor impacto las condiciones de clase, raza, género y edad.

Estas últimas disparidades, actualmente podemos identificarlas muy claramente en muchos países de Latinoamérica, en donde el tema de los sistemas carcelarios se ha vuelto algo muy polémico, debido a las múltiples ineficiencias y limitaciones que se presentan en prácticamente todos los modelos con los que se constituyen en los diferentes sitios de esta región. Se piensa que, en muchas ocasiones, lo que compone a estos sistemas, tiene como uno de sus principales resultados, un impacto muy fuerte en los procesos de socialización de personas implicadas en delitos de cualquier tipo y que se encuentran enfrentando algún 
proceso penal o que ya están cumpliendo algún tipo de sentencia dentro de instituciones carcelarias. Así, el hecho de privar de la libertad a estos sujetos trae como consecuencia que éstos comiencen a desarrollar mecanismos o herramientas que les permitan enfrentarse a las situaciones que se presentan en el día a día durante la vida de encierro. Cada individuo, presenta diferentes estrategias, dependiendo, principalmente, de las distintas condiciones sociales que los conforman.

Es por esto que en la mayoría de los países de esta región podemos identificar entre muchas personas privadas de la libertad, que hay una gran cantidad de casos que son similares entre sí. En muchos de estos, es notable que son algunos grupos o individuos particularmente, quienes reciben una mayor intervención en sus vidas por parte de los sistemas carcelarios, de sus entornos y contextos. Se trata de individuos tales que, por poseer o desposeer ciertas características, bienes y recursos, tienen que enfrentarse a grandes obstáculos cuando son juzgados o se encuentran cumpliendo algún tipo de sentencia. Mientras que, por otro lado, también hay grupos o personas que específicamente son privilegiados dentro de prisión, muchas veces debido a su estatus social o a su poder adquisitivo, pero en otros casos, no son estos los motivos que les otorgan el poder para dominar y la facultad de subordinar a los demás dentro de las cárceles.

En este tipo de instituciones se puede reconocer una diversidad muy amplia de personas que conforman los distintos grupos que los habitan y que ocupan diferentes posiciones de la escala social. Sin embargo, una gran parte de estos suelen ser vulnerados más fuertemente que otros. Por lo que, en este trabajo se resaltan aquellos conformados por las poblaciones femeniles ya que, inicialmente es evidente que, por el solo hecho de ser mujeres, son puestas en desventaja dentro de los sistemas de cárceles. Sistemas que hoy en día podemos definirlos desde la concepción de que son medios que se diseñaron para atender a poblaciones varoniles principalmente, puesto que éstos representan los primeros individuos en ser privados de la libertad en cárceles como medio de castigo "moderno". Lo que no quiere decir que las cárceles hoy en día satisfacen a plenitud las necesidades de los hombres en situación de reclusión, pero, se podría decir que sí poseen "mejores” condiciones a comparación con las de mujeres que se encuentran en esta misma situación. 
En cuanto a las mujeres privadas de su libertad cabe decir que al ser ubicadas en recintos como los mencionados, es importante poderlas caracterizar más allá del termino de solo mujeres, puesto que, al igual que en el exterior, existe una amplia diversidad de éstas. Lo que para esta investigación es de suma relevancia, por lo que, una de las metas de este análisis es identificar algunos de los diferentes tipos de mujeres que se pueden encontrar en los recintos carcelarios puesto que, ninguna es igual. Para comenzar con esta distinción entre mujeres tenemos grupos de mestizas e indígenas. Estas últimas en diversos estudios son presentadas como unas de las personas en enfrentarse a situaciones que, probablemente son más adversas que las de las mestizas, puesto que, en muchas zonas de Latinoamérica, las indígenas son vulneradas y excluidas en casi todos los ámbitos sociales, debido a diversos motivos como son: sus tradiciones, sus lenguas, costumbres, creencias, color de piel, clase social, etc.

Esto no significa que entre estas dos poblaciones solo las indígenas se enfrentan a situaciones complejas, pues, como se desarrollará más adelante, algunas mestizas, también suelen ser posicionadas en lugares de gran desventaja. Por lo que, una vez hecha esta aclaración, si bien, en muchos casos, las afectaciones vividas por las indígenas cuando se encuentran privadas de su libertad, se reflejan en actos de violencia física, burlas o humillaciones por parte de las personas de su entorno, también suelen surgir por parte del Estado. Lo cual es representado en la ineficiente y hasta casi nula aplicación de las leyes específicas para poblaciones de este tipo, las cuales, en materia penitenciaria, se promueven en muchos países de Latinoamérica. La ausencia de estas garantías, podemos atribuirlo, principalmente a que los sistemas de cárceles "modernos" han sido constituidos sobre bases racistas, reproductoras de desigualdades sociales, de género y de poder frente a las diversas poblaciones que los habitan. Cada uno de los grupos existentes dentro de los recintos carcelarios enfrenta situaciones distintas, según su género, raza, clase social y grupo etario. En teoría, las leyes son "aplicadas" de manera distinta para los diferentes casos, considerando la condición de cada individuo. Es por esto que se estima que los sistemas penitenciarios son los primeros elementos en tener un fuerte impacto en los procesos de socialización de las personas privadas de la libertad, pues desde el momento en que las personas, en este caso las mujeres, son imputadas de algún tipo de delito, se van notando las maneras desiguales como se 
procede. Lo que, a su vez, comienza a significar la necesidad de que cada mujer desarrolle mecanismos que les permitan sobrellevar procesos y la vida de encierro.

Estos medios, sin duda, también han de variar según la condición de cada mujer, por lo que no es posible generalizarlos, pero se pueden identificar en diferentes casos. En este trabajo se denomina a estas herramientas "Estrategias de Sobrevivencia", las cuales, generalmente son empleadas en estudios sobre economía campesina y familiar. Pero para esta investigación se le emplea desde una perspectiva social. La cual, se considera que es de gran importancia conocer, por lo que, junto con otros elementos se da vida a este estudio de caso, empleándolo en un recinto carcelario mexicano y específicamente en un área femenil, se trata del Centro Penitenciario y de Reinserción Social (CPRS) "Santiaguito", ubicado en el municipio de Almoloya de Juárez en el Estado de México.

Esta es una institución mixta, lo que significa que está habilitada para ser habitada por hombres y mujeres. Cabe señalar que, dentro de estos dos grupos, existen subgrupos de personas privadas de la libertad, de donde identificamos a las principales sujetas de análisis de esta investigación: mujeres de distinta raza (indígenas y mestizas), de diferentes edades y niveles socio- económicos. Para la obtención de la información necesaria para este trabajo, se ingresó al CPRS, "Santiaguito" por medio de la impartición del Taller de Creación de Figuras con Materiales Reciclados del 12 de octubre al 14 de diciembre de 2018. La actividad se llevó a cabo en el área varonil en las instalaciones del programa denominado $\mathrm{CICA}^{1}$ y en el "Dormitorio Once ${ }^{2 "}$ a un grupo de mujeres que decidieron participar de manera voluntaria. A los internos no se le realizaron entrevistas a profundidad, ni siquiera estructuradas, debido a las restricciones que las autoridades condicionan para poder ingresar al recinto.

\footnotetext{
${ }^{1}$ Centro Integral Contra las Adicciones. Programa en el que se atiende a varones en situación de reclusión que presentan serios problemas de adicción a las drogas y alcoholismo (Toxicómanos). Los participantes son confinados y alejados totalmente del resto de los presos. En este sitio los internos deben cumplir con diversas actividades que favorezcan la reinserción social, distrayéndolos y alejándolos de la necesidad de consumir drogas o bebidas alcohólicas. Las actividades que se realizan aquí vienen de parte de las áreas de psicología, formación educativa y del Departamento de Industria Penitenciaria y Promoción del Empleo (área Laboral). ${ }^{2}$ Se identifica así a la sección femenil, en donde habitan la mayoría de las mujeres. También existe el área cinco, que es el área femenil de castigo.
} 


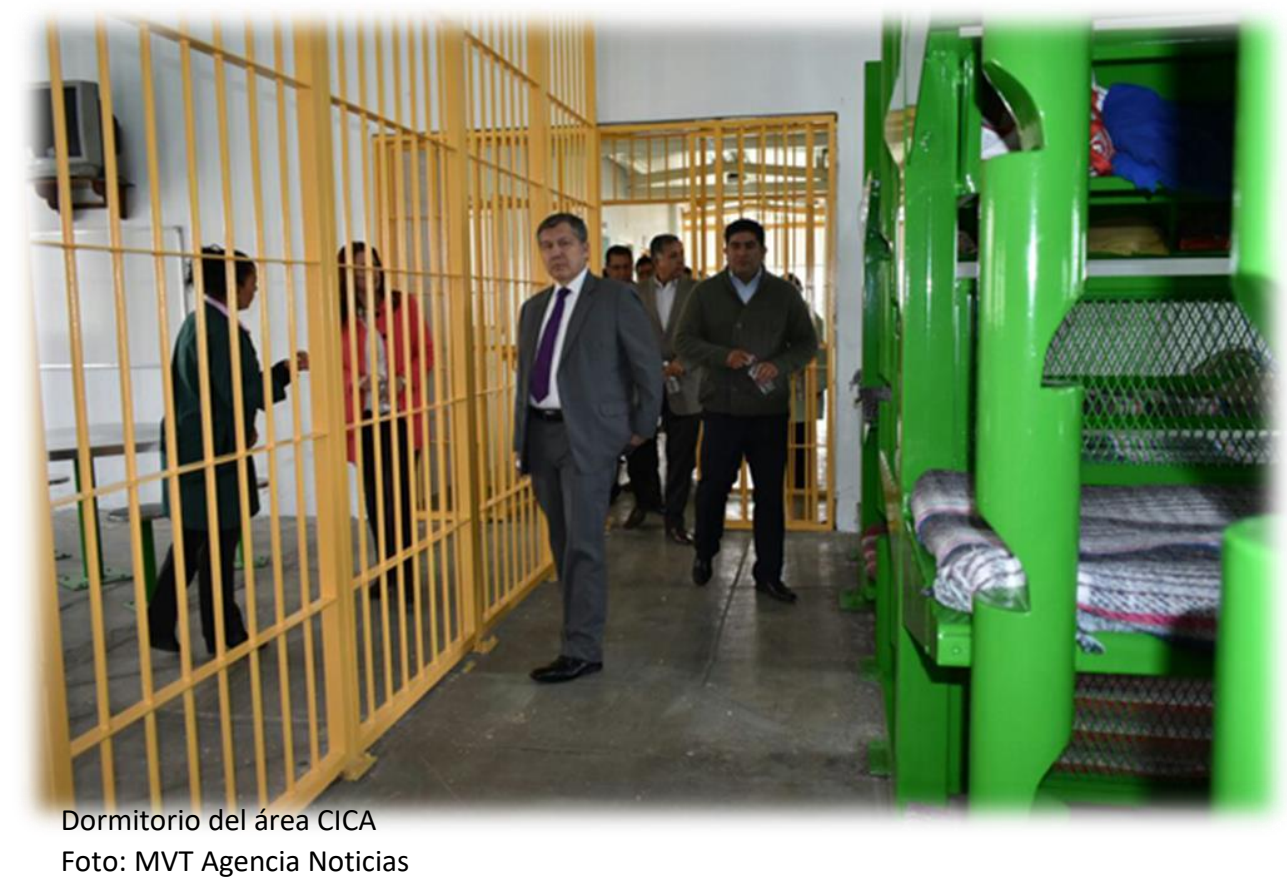

La mayor parte de la información recaudada para esta investigación, fue registrada manualmente en dos diarios de campo y de manera memorística, debido a que tampoco está permitido ingresar a las instalaciones con algún tipo de dispositivo electrónico para grabar audio, vídeos o de captura fotográfica. Los testimonios se recolectaron de forma individual mediante conversaciones casuales en las que, durante su desarrollo, se lanzaron preguntas detonadoras que fueron guiando las conversaciones según los temas requeridos para este trabajo. De los testimonios recaudados, se obtuvieron narrativas de algunos momentos destacados de las mujeres desde antes y durante el encierro, y algunas de ellas hablaron de sus perspectivas a futuro.

Adicionalmente a esto, también se agregó el caso de Dominga Gózales, mujer indígena defensora del agua, quien fue puesta en libertad en febrero de 2019. Esta mujer se encontraba recluida en "Santiaguito", durante los meses que se impartió el taller. Sin embargo, al solicitar a las autoridades que se le permitiera incorporarse a la actividad, la petición fue rechazada. Durante este periodo, la mujer indígena estaba confinada en el área de castigo femenil (dormitorio cinco) de este recinto, desde el momento de su llegada. Además, autoridades y personal penitenciario la describieron como una mujer peligrosa y conflictiva. Es así que, tiempo después, al saber de su liberación, se le visitó en su domicilio, ubicado en la 
comunidad de San Pedro Tlanixco, Estado de México. Durante la visita se le aplicó una entrevista semi-estructurada, la cual tuvo como base los temas y preguntas detonadoras que se abordaron en las conversaciones mantenidas con el resto de las internas dentro del CPRS de Almoloya de Juárez.

De toda la información obtenida durante el trabajo de campo, en esta ocasión, se ha utilizado en mayor medida la de la población femenil, debido a que el objetivo principal que persigue esta investigación cualitativa es documentar desde un análisis comparativo las diferencias y desigualdades que se generan en los procesos de socialización y las estrategias de sobrevivencia que se desarrollan debido a la condición de género, raza, clase social y grupo etario de mujeres indígenas y mestizas (y derivados) recluidas en el Centro Penitenciario y de Reinserción Social (CPRS) "Santiaguito", Estado de México. Para llegar a esta meta, es que este trabajo ha sido dividido en cinco principales capítulos; en el primero se desarrollan, inicialmente, el concepto de procesos de socialización, contemplando especialmente tres etapas: socialización primaria, que es la que parte desde nuestro nacimiento y durante los primeros años de la niñez.

Es durante esta etapa que los individuos comenzamos a adaptarnos y apropiarnos de todo lo que se considera propio de nuestras sociedades. En esta fase es de suma importancia la interacción familiar, pues quienes se encargan de hacer realidad este proceso son principalmente los padres. Por otro lado, también está la socialización secundaria, la cual es una etapa que comienza durante la niñez y la adultez, justo cuando los individuos se hacen parte de entornos distintos a los familiares, tales como la escuela, la iglesia, grupos de pares, equipos deportivos, etc. Además de que, durante esta parte del proceso, los individuos comenzamos a adquirir nuevos roles y funciones sociales con los cuales hemos de adaptar nuestras conductas según las normas de cada grupo social. Este momento de la vida social, se puede decir que es el que perdura por más tiempo, pues sigue su curso durante toda la edad adulta de las personas.

Sin embargo, durante este proceso, cuando la conducta de los individuos llega a presentar un quiebre o ruptura con lo socialmente aceptado y establecido, algunos autores señalan que surge una tercera etapa del proceso. Se trata de la socialización terciaria o de resocialización. Dicha parte del proceso se desarrolla principalmente en casos como en la migración 
extranjera y en la estadía dentro de instituciones geriátricas, psicológicas y en recintos carcelarios. Pues, aparentemente, los individuos son arrancados o separados de lo que llevan interiorizado desde las dos primeras partes del proceso de socialización. Y, además, se piensa que éstos han de adoptar nuevas conductas, creencias, comportamientos y actitudes que vayan acorde con lo instituido y normalizado dentro del nuevo entorno.

No obstante, al respecto, cabe decir que, en esta investigación, se piensa que, de tal manera, no se trata de un desprendimiento de lo procesado en etapas previas, sino que, los cambios generados en los sujetos, más bien, son el desarrollo de "estrategias de sobrevivencia", como mecanismos de adaptación. Las estrategias de sobrevivencia, las encontramos como un concepto que se emplea comúnmente en estudios que refieren a la economía campesina. Sin embargo, en el caso de la presente investigación, no se le ha de entender desde este punto de vista, sino que, se construye desde una mirada social en la que podemos decir que estas son: acciones con las que se persigue un beneficio individual que, para lograrlo, los sujetos suelen apoyarse de otros. Para sobrevivir a las situaciones adversas, la relación con los demás no es precisamente de trabajo en conjunto (al menos no con todos).

Dicho esto, es importante señalar que, para poder identificar este concepto en recintos específicos como las cárceles, hay que conocer cómo es que estos lugares se han posicionado como herramientas de castigo "moderno" y cómo se constituyen las relaciones dentro de estos entornos. Para ello, en el apartado 1.3, se hace un análisis de estos sistemas desde las perspectivas de Émile Durkheim y Michael Foucault, quienes desde diferentes ángulos se plantean cómo es que los individuos con un actuar anómalo han de pagar por sus delitos durante las diferentes etapas del castigo. Según las propuestas de ambos autores, algo que se resalta es, como se mencionó al principio de esta introducción, la desigualdad con la que se han impuesto los castigos, según la condición de cada individuo. Lo cual, es preciso decir que sigue vigente hasta nuestros días. Por tal motivo, en el capítulo 2 se hace un recuento de cómo se han ido conformando las principales disparidades entre individuos en nuestro país. El punto de partida de este momento del análisis se empieza a explicar desde la conformación del Estado Nación en México y cómo es que, durante este, se han ido configurando las distinciones y desigualdades por condición de raza. Lo que más adelante nos lleva al apartado 2.2, en donde se habla de la constitución de las diferentes clases sociales, y con ellas, las 
distinciones que se promueven entre los individuos que conforman cada una de estas. No solo por su adquisición y posesión económica, sino por el status social que cada persona posee, según lo determina la sociedad. Durante el desarrollo de estos dos tipos de desigualdades, notamos que algo de lo que no se habla mucho es acerca del lugar que han ocupado las mujeres durante estos procesos, pero que resultan importantes para la realización de esta investigación, ya que son el eje medular de esta misma.

Es por esto que en el capítulo 3 se comienza con la exposición de lo que significa la categoría de género, describiendo cómo se han ido rescatando los elementos de la presencia femenina en todos los ámbitos sociales. Con lo que más adelante, en el apartado 3.1, se habla de cómo se percibe el lugar de las mujeres desde las normativas sociales compartidas por diferentes culturas y sociedades, lo que se establece desde la heteronormatividad. Esto, nos lleva a la última parte de este tercer capítulo, en donde se describe cómo se han planteado grandes desigualdades entre mujeres de distintas condiciones sociales, destacando que, en las sociedades, no todas las mujeres son iguales, por lo tanto, no se enfrentan a las mismas situaciones. Lo que posteriormente, se trata de interpretar desde la interseccionalidad como un marco que ha sido diseñado para explorar y analizar la dinámica de las relaciones femeninas, su entorno y los sistemas de opresión existentes. Contemplando una amplia diversidad de mujeres dentro de las sociedades: mestiza, negra, indígena, pobre, analfabeta, anciana, etc.

Todo lo contenido en los mencionados capítulos pretende ser identificado dentro de nuestro estudio de caso, en donde específicamente nos interesa conocer ¿cuáles son las diferencias y desigualdades que se generan por condición de género, raza, clase social y grupo etario en los procesos de socialización y estrategias de sobrevivencia entre mujeres indígenas y mestizas recluidas en el CPRS de Almoloya de Juárez? Una vez entendidas las bases de esta investigación, y buscando dar respuesta a la interrogante, en el capítulo 4 comenzamos a contextualizar los elementos propuestos en los primeros tres capítulos para así poder analizar y comparar los casos de mujeres indígenas y mestizas privadas de su libertad en “Santiaguito", Estado de México. Por lo que, en este capítulo se muestra un panorama general que comienza por explicarnos cuántos tipos de recintos carcelarios encontramos en México, cómo son y cómo supuestamente funciona el sistema carcelario en este país. 
Y, más adelante, se hace un recuento de la diversidad de mujeres que podemos encontrar en los distintos tipos de instituciones carcelarias, destacando que son una minoría muy notoria dentro de este sistema. Además, de que lo que viven durante su encierro es muy distinto a lo que encontramos en cárceles varoniles o en las predominantes áreas para hombres. Esto, también nos da herramientas para identificar que las diferencias por género no solo se dan por parte de las autoridades y por los mismos internos, sino que, es común que las mujeres vivan un mayor abandono familiar a comparación de los hombres. Todo esto, sin duda, tiene importantes consecuencias en las vidas de las mujeres privadas de su libertad en "Santiaguito". Posterior a esto y con la intención de ir centrándonos en nuestro estudio de caso, el capítulo 4 cierra con la explicación de qué tipo de institución carcelaria es "Santiaguito", dónde se ubica y los datos generales de la población que actualmente se encuentra hacinada en este lugar.

Cabe decir que no se cuenta con mucha información respecto a este centro penitenciario, y que son pocos los registros que se tienen sobre esta institución, por lo que, los datos que se exponen en este trabajo, se obtuvieron al solicitarlos a la Secretaría de Seguridad Pública del Estado de México, siendo esta la única institución que los posee. Una vez dicho lo anterior, y continuando con el desarrollo de este trabajo, en el capítulo 5 se comienza a describir cómo es la vida en las áreas femeniles de "Santiaguito", contemplando aspectos como espacios físicos, servicios y actividades generales, vistas desde el trabajo etnográfico realizado durante las visitas que se hicieron en este recinto. Además, se exponen algunos otros aspectos como los periodos en que este recinto fue habitado por mujeres, puesto que, inicialmente este era una cárcel exclusivamente varonil.

Posteriormente, en el apartado 5.1, se comienza a hacer una caracterización de la diversidad de mujeres identificadas en las áreas o espacios femeniles. Se exponen algunas de las condiciones generales de estas mujeres, según su condición en relación con lo que, supuestamente, promueve el sistema penitenciario del Estado de México. Lo que, dentro de este mismo apartado, nos lleva a mencionar de manera más específica los casos con los que se hará el análisis comparativo de las desigualdades y diferencias en los procesos de socialización y estrategias de sobrevivencia entre mujeres indígenas y mestizas privadas de la libertad en este recinto carcelario. También, en este apartado se empiezan a exponer 
algunas de las narrativas de las diez mujeres consideradas para esta investigación. Testimonios en los cuales, las mujeres nos comparten el antes de ser imputadas y los porqués han llegado adquirir la condición de mujeres delincuentes.

En este apartado se especifican las condiciones a las cuales pertenecen las mujeres participes del trabajo de campo de esta investigación, ya sea por su distinción de raza o grupo étnico, clase social, edad, situación legal, entre otras. Se exponen, algunas de las problemáticas generales que surgen a partir de estos aspectos con lo que se van identificando los elementos que se han de comparar en apartados posteriores. Inmediatamente de esto, se expone el impacto del cruce generado desde dichas condiciones y qué tanto, y de qué manera se ven alterados los procesos de socialización de unas y otras mujeres. Con lo que se quiere comprobar la hipótesis de que la mala organización y aplicación del Sistema Penitenciario mexicano impacta fuertemente en los procesos de socialización de mujeres privadas de la libertad en el CPRS “Santiaguito”, debido a su condición de género, raza, clase social y edad, lo que resulta en que éstas desarrollen distintas estrategias de sobrevivencia.

Pensando inicialmente que las afectaciones son más grandes en las mujeres indígenas que en las mestizas, pues las primeras, en la mayoría de los casos, se ven obligadas a abandonar mucho de lo que las define, como es: su lengua materna, usos y costumbres, creencias, etc. Y por otro lado tienen que adoptar nuevos elementos como tener que hablar español y aprender a leer y escribir, lo que les ayudará a "evitar" o "disminuir" actitudes de violencia dentro de la institución. Pero, también se destaca que no solo estas mujeres son las mayormente influidas, puesto que, algunas otras desde diferentes condiciones, también perciben impactos fuertes en lo internalizado desde las primeras etapas de sus procesos de socialización. Lo que nos lleva a nuestro último apartado, en el que se identifican y documentan más claramente los mecanismos de sobrevivencia con los cuales se comprueban las diferencias y desigualdades que se generan, desde muchos aspectos, en las vidas de las mujeres consideradas en esta investigación como una representación social.

Al termino de este trabajo se expone que la perspectiva con la que se propone este análisis podría dar la posibilidad de reconocer más escrupulosamente los hechos que promueven actitudes de racismo, discriminación, vulneración y exclusión de mujeres privadas de su libertad, desde sus diferentes condiciones, tales como: el género, raza, clase social y edad. 
Siendo esto un claro reflejo de lo que sucede en nuestras sociedades, no solo desde el confinamiento, sino desde el exterior. Además, se piensa que este trabajo contribuirá a alertar sobre la invisibilización social que existe ante algunos sectores de la sociedad. Poniendo en relieve la necesidad de más estudios enfocados al tema de mujeres en situación de reclusión. La investigación no se puede denominar como concluida, pues la problemática que se aborda se encuentra en constante dinamismo. Además de que, en torno al tema de mujeres privadas de la libertad giran muchas otras problemáticas que merecen ser tomadas en cuenta. 


\section{Marco teórico}

\subsection{Los procesos de socialización y su importancia en la conformación de grupos sociales}

Los seres humanos estamos "naturalizados" a vivir en sociedad, en donde interactuamos unos con otros de manera civilizada. De la convivencia con los otros, el humano cubre las necesidades biológicas y sociales que la vida le demanda. La capacidad que tienen los individuos para interactuar entre sí, no es una predisposición biológica por el solo hecho de ser humanos, sino que desde el momento del nacimiento comenzamos a recibir un "entrenamiento", a partir del cual adquirimos hábitos, habilidades y conocimientos que nos diferencian del resto de los animales. Este proceso se conoce como socialización y sus principales objetivos son la integración de los individuos a la vida social, y favorecer los vínculos y relaciones entre humanos en un mismo entorno.

Gracias a la socialización las personas asimilan los aspectos culturales de la sociedad a la que pertenecen y desde aquí es posible desempeñar diversos roles y funciones en los distintos grupos de los que formará parte cada individuo (hombres y mujeres). El proceso de socialización está presente durante todas las etapas de la vida de los sujetos, permitiéndoles ser miembros funcionales de sus comunidades, además de mantener una adecuada convivencia entre unos y otros dentro de una misma sociedad.

Los diferentes entornos en los que se ubicarán los individuos les exigirán ciertos comportamientos, actitudes y habilidades adquiridos desde la infancia y durante las etapas de vida posteriores que, determinados según el género, clase social, raza y edad de las personas, tendrán que adaptar en los diversos espacios ocupados. Tal es el caso de ámbitos como el carcelario, el cual representa el tema central de este trabajo.

Lo anterior debido a que se piensa que la separación del individuo de su entorno cotidiano e incorporación en otro totalmente distinto, impacta en mucho de lo internalizado durante la vida de personas que actualmente se encuentran en situación de reclusión. Es por ello que en este apartado se define y describe el concepto de procesos de socialización con la finalidad de más adelante reconocer la existencia de dicho impacto, principalmente en la vida de 
mujeres recluidas en el Centro de Penitenciario y de Reinserción Social (CPRS) "Santiaguito", ubicado en el Estado de México.

Para lograr el objetivo mencionado es importante destacar que la socialización a lo largo del tiempo ha sido analizada desde diferentes perspectivas, principalmente desde las ciencias sociales, y desde éstas se le han concedido diversas definiciones en las que se destacan coincidencias de algunos elementos, como la relación que tiene el individuo y la sociedad durante este proceso. Para entender mejor a la socialización es necesario hacer un repaso por algunas definiciones generales de este concepto y, posteriormente, mirarlo desde de la sociología para profundizar en su análisis, identificando cómo es que éste es intervenido en el caso específico de mujeres recluidas en "Santiaguito".

Así, de manera general la socialización se puede definir como "el proceso por cuyo medio la persona aprende e interioriza en el transcurso de su vida, los elementos socioculturales de su medio ambiente, los integra en la estructura de su personalidad, bajo la influencia de experiencias y de agentes sociales significativos, y se adapta al entorno social en cuyo seno debe servir” (Rocher, 1980: 133). En esta definición, la centralidad se encuentra en la actividad que tiene el individuo durante este proceso: el actor interioriza, aprende, integra elementos a su personalidad, y adquiere experiencias para adaptarse a un entorno (Costa y De Juan, 2010).

Por otro lado, la socialización también se ha definido como el "proceso en el cual los individuos incorporan normas, roles, valores, actitudes y creencias, a partir del contexto socio-histórico en el que se encuentran insertos a través de diversos agentes de socialización tales como los medios de comunicación, la familia, los grupos de pares y las instituciones educativas, religiosas y recreacionales, entre otras" (Arnett, 1995. En Simkin y Becerra, 2013: 122). Esta definición incluye elementos que no se especifican en la antes citada, como son algunos de los agentes que intervienen en el proceso de socialización de los individuos, así como los medios con los que los sujetos tendrán una correcta adaptación e integración a su entorno.

Cuando se habla de socialización, los agentes que la componen son importantes, ya que son los grupos o contextos en donde se desarrollan los procesos con los cuales el individuo se constituye como ser social. Estos agentes son diversos y difíciles de enumerar. Sin embargo, 
se reconoce que el principal es la familia, pues a partir de éste comienza el proceso de socialización y, además, siempre tendrá presencia en la vida del individuo. Existen otros agentes, tales como: la escuela, la iglesia, grupos de pares y medios de comunicación que se encontrarán durante cada etapa de vida de las personas y que a su vez intervienen en la adaptación de los sujetos a la vida que exige la sociedad (Ariño y Serra en García, 2005).

En la vida de todo individuo existe una secuencia temporal en la que éste es inducido a participar en la dinámica social de su entorno. Para dicha participación, es la socialización la que determina el comportamiento de los individuos en los diferentes entornos en donde se desarrollan. La conducta de las personas depende de los factores externos que constituyen las situaciones que atraviesan los sujetos, además de factores internos "propios" como son los valores, símbolos y normas interiorizados durante cada etapa del proceso de socialización (Ariño y Serra en García, 2005).

La socialización es un proceso enteramente social por lo que ha sido analizada desde la sociología por autores como Bernard Lahire, quien dice que: "La noción de socialización designa el movimiento mediante el cual la sociedad modela a los individuos que viven en su seno. Si tomamos a los individuos como punto de partida, podemos decir, por consiguiente, que la socialización es un proceso por el que un ser biológico se transforma en un ser social propio de una sociedad determinada" (Lahire, 2007: 25).

Según este autor la socialización es el medio por el cual nos hacemos humanos y con lo que nos distinguimos del resto de los animales, pues, las actitudes, habilidades, conocimientos y comportamientos con los que nos desarrollamos no son características determinadas biológicamente, sino adquiridas y aprendidas a lo largo de nuestra vida. Es así, que la sociedad juega un papel muy importante en nuestra construcción como seres sociales. Es la misma sociedad la que nos dota de los agentes y elementos necesarios para vivir y convivir civilizadamente con los otros en determinados entornos sociales.

La sociología ha hecho un esfuerzo por diferenciar los marcos y los tiempos del proceso de socialización, dividiéndolo en dos principales etapas: socialización primaria y socialización secundaria. Pero, además, en este trabajo se considera una tercera socialización o etapa de resocialización, la cual aparentemente surge de un quiebre o desviación en la conducta de los 
individuos o de la exclusión o alejamiento de estos de su grupo social, tal como en el caso de las mujeres recluidas en el CPRS "Santiaguito".

A continuación, se explican las dos primeras etapas del proceso de socialización desde la consideración de Berger y Lukmann, quienes exponen las características y agentes que intervienen en este proceso durante la vida de los actores desde el momento de su nacimiento. Y posteriormente se desarrolla la socialización terciaria como etapa en la que se reintegran aspectos de las dos primeras socializaciones. Cabe mencionar que en este trabajo se cuestiona la existencia de un proceso de resocialización, pensando que más bien se trata de estrategias que los individuos desarrollan en los nuevos entornos para adaptarse y sobrevivir a las diferentes condiciones de vida a las que se enfrentan, sin que esto signifique la separación de los sujetos con lo adquirido en las dos primeras etapas del proceso de socialización.

\subsubsection{Socialización primaria}

Como se mencionó previamente se revisará a la socialización desde la perspectiva de Berger y Lukmann, quienes de manera general definen este concepto como "la inducción amplia y coherente de un individuo en el mundo objetivo de una sociedad o un sector de él" (Berger y Lukmann, 1999: 164). Es decir, para los autores, con el proceso de socialización se dota a los individuos de los elementos necesarios y aceptados para constituirse como integrantes de la sociedad o de grupos sociales determinados. Los autores analizan este proceso distinguiendo dos principales etapas que se desarrollan a lo largo de la vida de las personas, se trata de la socialización primaria y la socialización secundaria.

La socialización primaria como su nombre lo indica, es la primera etapa por la que el individuo atraviesa desde el momento de su nacimiento y durante toda su infancia. El paso por esta fase de la socialización es el medio por el cual el ser humano se convierte en un miembro activo de la sociedad. Berger y Lukmann la consideran como la etapa más importante de la constitución de los individuos. Además, los elementos de esta primera etapa son los que se arraigan más fuertemente en la conciencia individual de las personas y perduran a lo largo de toda la vida de los sujetos (Ariño y Serra en García, 2005). 
En esta primera etapa el individuo interioriza los elementos socioculturales de mayor relevancia en la sociedad, tales como el lenguaje, la identidad de género y la concepción de clase con la que se estratifica la sociedad. En esta fase, se construye la imagen de un "primer mundo" sólido, real e incuestionable. Es en la socialización primaria en donde durante de la niñez, se asumen las imágenes de los roles ${ }^{3}$ que los otros representan, como es el de la madre o el padre. Además, comenzamos a diferenciar lo bueno de lo malo desde la comprensión e interpretación de las normas con las que se rigen los grupos de los cuales somos parte (Ariño y Serra en García, 2005).

Durante la socialización primaria ocurre el proceso denominado “internalización” que es la “aprehensión o interpretación inmediata de un acontecimiento objetivo en cuanto expresa significado, o sea, en cuanto es una manifestación de los procesos subjetivos de otro que, en consecuencia, se vuelven subjetivamente significativos para mí” (Berger y Lukmann, 1999: 162). Es decir, en algunas ocasiones, podemos interpretar las acciones de los otros, dándoles un significado inmediato acorde con lo que hemos interiorizado, haya o no congruencia exacta con lo que los otros nos están transmitiendo. El proceso de internalización, nos permite generar interpretaciones y significados a las acciones de los demás.

La internalización como parte del proceso de socialización primaria, constituye las bases para interpretar y comprender a los otros, y al entorno como una realidad significativa y social. Esto comienza cuando el individuo asume el mundo en el que ya viven otros y que a su vez son los encargados de adaptarlo e integrarlo a la vida en sociedad (Berger y Lukmann, 1999). Por lo que cabe señalar, que la aprehensión de los elementos que favorecen este proceso, no se constituyen de manera individual, sino que deriva de la interacción con los demás y con el contexto. Durante este proceso, los seres humanos adherimos y normalizamos significaciones compartidas con los otros y de este modo se favorece la convivencia social.

El proceso de internalización en la socialización primaria tiene como punto de partida la interacción con el entorno familiar. "La familia es [considerada] la institución socializadora por excelencia” (Lucas, 1986: 367). Ésta es un elemento central que perdura a lo largo de la

\footnotetext{
${ }^{3}$ Funciones o papeles que desempeña un individuo en cierto contexto social. En sociología se trata de las pautas de comportamiento que la sociedad espera de una persona. Disponible en: https://definicion.de/rolsocial/
} 
vida de los individuos y es uno de los contextos con mayor importancia para el desarrollo de los seres humanos. La etapa familiar de la socialización está representada principalmente en la relación que hay entre los padres y los hijos. Mediante las prácticas familiares, los padres transmiten a los hijos un lenguaje, valores, conocimientos y creencias determinados por su cultura (Ariño y Serra en García, 2005).

En la primera etapa de la socialización la participación de los padres es muy importante para el desarrollo social del individuo. En la etapa de la niñez, los padres dotan de componentes afectivos y emotivos con lo que se ha de constituir la personalidad del individuo. Lo adquirido durante este proceso será muy difícil de modificar en un futuro, ya que los sujetos adaptarán lo internalizado en esta etapa a los contextos en donde se encuentren insertos. Cabe señalar que los significantes familiares (padres, hermanos, tíos, etc.) que componen a la socialización primaria, no los elige el individuo, sino que desde su nacimiento se encuentran determinados. Respecto a esto, Berger y Lukmann dicen que:

En la socialización primaria no existe ningún problema de identificación, ninguna elección de otros significantes. La sociedad presenta al candidato a la socialización ante un grupo predefinido de otros significantes a los que debe de aceptar en cuanto tales, sin posibilidades de optar por otro arreglo. Hay que aceptar a los padres que el destino nos ha preparado. Esta desventaja injusta e inherente a la situación de hijo tiene la consecuencia obvia de que, aunque el niño no sea un simple espectador pasivo en el proceso de socialización, son los adultos quienes disponen las reglas del juego. El niño puede intervenir en el juego con entusiasmo o con hosca resistencia, pero por desgracia no tiene otro juego a mano. [...]Como el niño no interviene en la elección de sus otros significantes como uno de los tantos posibles, se identifica con ellos casi automáticamente. (Berger y Lukmann, 1999:170-171)

Es por medio de la adaptación, aceptación e identificación con el grupo primario que el niño incorpora "el mundo, el único mundo existente y concebible, un mundo a secas" (Berger y Lukmann, 1999), es decir, lo que aprende y aprehende durante esta etapa es lo primero con lo que constituye la realidad de su entorno. En esta etapa, el individuo comienza a asimilar por medio de diversos mecanismos las normas y los valores sociales con los que se rige su entorno, lo cual favorecerá su desarrollo e integración a la vida en sociedad a lo largo de su vida.

Uno de los mecanismos más importantes por los que el individuo adquiere e interioriza los elementos de la socialización primaria es por medio de la imitación y todo ocurre de manera inconsciente en el entorno familiar. Los padres se encuentran predispuestos a "entrenar" al 
niño desde el momento de su nacimiento, pues, éstos en su etapa de la infancia, pasaron por dicho proceso. La socialización del infante no es un hecho planeado por la familia, es decir que cuando un niño nace, los padres no suelen decir que lo socializarán o lo constituirán como humano, el proceso solo ocurre y durante éste le transmitirán al niño los elementos propios del entorno social.

Durante la socialización primaria los niños aceptan los roles y actitudes que los otros significantes les transmiten, es decir, los internalizan y se apropian de ellos (Berger y Lukmann, 1999). Cuando el individuo trasciende a la socialización secundaria, muchos de los aspectos de la primera etapa son difíciles de apartar o abandonar, más bien forman parte de la segunda etapa del proceso. Por ejemplo, se dice que la intervención de la familia sigue latente, actuando como moderador de lo que se puede tomar o dejar, de cuánto se ha de resistir algún hecho y en la vigilancia de cómo se han de constituir los grupos de pares de los individuos.

\subsubsection{Socialización secundaria}

En la segunda etapa de la socialización intervienen nuevos medios, agentes y actores. Se trata de cualquier proceso posterior que induce al individuo ya socializado a nuevos sectores del mundo objetivo de su sociedad. Su estructura básica es semejante a la de la socialización primaria. También se puede decir que es la internalización de "submundos" de valores y normas que el individuo va a ejercer durante su vida de adulto. Su alcance y carácter se determina por la complejidad de la distribución social del conocimiento (distribución social del conocimiento especializado) (Berger y Lukmann, 1999: 172).

Berger y Lukmann definen a esta etapa como:

La adquisición de conocimientos específicos de roles, estando estos directa o indirectamente arraigados en la división del trabajo. Los "submundos" internalizados en la socialización secundaria son generalmente realidades parciales que contrastan con el "mundo base" adquirido en la socialización primaria. Sin embargo, ellos también constituyen realidades más o menos coherentes caracterizadas por componentes normativos, y afectivos a la vez que cognoscitivos (Berger y Lukmann, 1999:175). 
Según los autores en esta etapa desarrollada desde la niñez hasta la edad adulta, el individuo se integra a entornos distintos al familiar. En estos, los sujetos adquieren nuevos elementos que favorecen su incorporación a los grupos sociales, representando roles adicionales a los de la infancia (trabajador, estudiante, ama de casa, etc.). Además, el individuo interioriza nuevas normas y valores, que dependerán del contexto en donde se encuentre. En la segunda fase de la socialización, se adquieren nuevos conocimientos que serán aplicados en la vida diaria, sin que esto implique abandonar los internalizados durante la socialización primaria.

En los entornos secundarios de esta etapa de la socialización, lo individuos adquieren nuevos valores, actitudes y conocimientos que serán aplicados en la vida diaria. Para que esto suceda, en la socialización secundaria no solo han de intervenir agentes como el familiar, sino que participan significantes externos, como son: las escuelas y demás instituciones en donde se conforman los grupos de pares (amigos, compañeros de clase, medios deportivos, instituciones religiosas, instituciones carcelarias, etc.) y, además, hay una fuerte influencia de los medios de comunicación en esta parte del proceso.

Uno de los agentes secundarios más importantes del proceso de socialización es el de la escuela. La presencia de este significante comienza durante la etapa de la infancia y es un medio externo al familiar. Las características y grado de influencia de los componentes escolares pueden ser variadas, dependiendo del contexto, tipo de sociedad y cultura (Arnett, 1995). En el entorno escolar los niños desarrollan actitudes y comportamientos adicionales a los de la socialización primaria.

Dentro de las escuelas los actores deben de regular y adaptar su comportamiento según las reglas y normas establecidas por la institución y con ello generar una convivencia civilizada con los otros. (Simkin y Becerra, 2013). Referente a esto, Michel Foucault (2009), quien se abordará más adelante en este trabajo, encuentra similitudes en tanto las escuelas y las cárceles. Ambas son vistas por el autor como instituciones disciplinarias que a su vez funcionan como herramientas de dominación y poder sobre el cuerpo y además se agregaría la conducta “... se ejerce sobre de él [el cuerpo] una coerción débil, de asegurar presas en nivel mismo de la mecánica: movimientos, gestos, actitudes, rapidez...” (Foucault, 2009: 159). 
Es así, que en este tipo de significante secundario los individuos, no abandonan su socialización primaria, pero moldean algunos de los aspectos interiorizados debido al poder ejercido por quienes están al frente de las instituciones, promoviendo que los actores se adapten a las demandas de su entorno. Siguiendo a Foucault, en la escuela “...el ritmo impuesto por señales, silbatos, voces de mando, imponía a todos, normas temporales que debían, a la vez, acelerar el proceso de aprendizaje y enseñar la rapidez como una virtud" (Foucault, 2009: 179). Durante esta parte del proceso, cabe agregar que, en las escuelas, la relación con los docentes y demás actores es más distante y no afectiva como lo es con los integrantes del ámbito familiar desde la primera parte de la socialización.

Además de la escuela otro agente de socialización secundaria es el de los grupos de pares, definidos como; "un conjunto de individuos que comparten categorías sociales comunes y ciertos ámbitos de interacción en tanto grupo" (WolfSun, 2008 en Simkin y Becerra, 2013: 130). Generalmente estos grupos se constituyen en lugares públicos como principalmente serían: el vecindario, plazas, iglesias, en el ámbito laboral, etc. La socialización en estos grupos es restrictiva respecto a la selección de los miembros del grupo, muchas veces se conforman según el género, edad, clase social y condición racial. Las restricciones se incrementan durante la juventud y la adultez (Simkin y Becerra, 2013).

Mientras más edad tiene el individuo las exigencias de los grupos se incrementan, se espera que éste cumpla más cabalmente con las normas que su entorno le demanda y que a su vez se encargue de transmitirlas a los miembros más jóvenes del grupo. Según Berger y Luckmann los individuos no solo habitamos el mismo mundo, sino que también cada uno participa en la constitución del ser del otro. La socialización en estos grupos ocurre mediante tres principales mecanismos: interaccional, comparación grupal e influencia normativa. El primero tiene que ver con la semejanza que hay entre los integrantes en cuanto a ideas y maneras de actuar, lo cual influye de manera positiva o negativa en la conducta de los individuos del grupo (Simkin y Becerra, 2013).

En la comparación grupal los individuos tienden a relacionar sus habilidades, ideas y opiniones con las de otros grupos o personas, lo cual genera la necesidad de adaptarse y por ende, el individuo puede llegar a modificar elementos que conforman su carácter. El tercer mecanismo de socialización en los grupos de pares es la influencia normativa, se trata de los 
medios por los cuales el individuo adhiere a su personalidad normas internas del grupo, que moldean su comportamiento y emociones (Simkin y Becerra, 2013).

Los grupos de pares se conforman en los diferentes entornos en donde se sitúen los individuos, incluso en ámbitos como el carcelario en donde los sujetos son ingresados debido al rompimiento entre su conducta y las normas establecidas por la sociedad. En este tipo de instituciones, los grupos de pares se constituyen a partir de los tres mecanismos mencionados. Por ejemplo, los grupos de mujeres dentro del CPRS "Santiaguito", se crean a partir de la edad, ideologías, actividades con intereses a fin, origen racial, clase social, conducta y respuesta ante las normas y políticas establecidas por la institución. Durante este proceso se puede generar en las mujeres alteraciones en lo internalizado durante las etapas previas a la reclusión y desde esto, ellas desarrollan estrategias que les permitirán "sobrevivir" a la pesada vida en la cárcel.

Por otra parte, además de agentes secundarios como la escuela y grupos de pares, existe otro importante, se trata de los medios masivos de comunicación, considerados los principales manipuladores de la conciencia de los individuos (Lucas, 1986: 327). La forma en la que influyen estos medios es diferente a la comunicación personal con la que generalmente se identifica a la socialización primaria. Este tipo de medios durante la segunda etapa del proceso de socialización pueden llegar a promover valores y conductas diferentes a los que los individuos han internalizado durante la socialización primaria. Sin embargo, no logran alterar lo adquirido desde la infancia.

Los principales medios que intervienen en los individuos son: los libros, la prensa, radio, televisión y más recientemente internet. La manera en que éstos influyen en las personas es distinta a la interacción personal (Lucas, 1986). Desde estos medios, "el mensaje tiene un código amplio, debe pasar unos filtros, da lugar a unos procesos de comunicación personal secundarios y tiene dificultades en la comunicación de retorno" (Lucas, 1976: 68-69).

Los elementos que los individuos internalizan por parte de los medios de comunicación, se pueden ver distorsionados por los filtros que el mensaje debe atravesar, además de que cada persona dará una interpretación distinta a cada mensaje. Los medios de comunicación intervienen en el comportamiento de los individuos dentro de los grupos de pares. Por ejemplo, muchos jóvenes pueden cambiar su manera de vestir o su corte de cabello, con la 
finalidad de "encajar" en su entorno, pues las imágenes que reciben de los principales medios de comunicación (televisión e internet) son las aceptadas por la sociedad y su contexto.

A consecuencia de los medios de comunicación se pueden ver afectados algunos elementos adquiridos durante la socialización primaria como lo es el lenguaje, pues el individuo lo puede llegar a alterar de tal manera que le permita integrarse a nuevos grupos. Hay quienes consideran que la manera de influir de estos medios, favorecen al desarrollo de la identidad, poniendo a disposición de los individuos nuevas formas de interacción que brindan la oportunidad de crear grupos o comunidades en los que los individuos se incorporan de manera civilizada (Simkin y Becerra, 2013).

La descripción de estos significantes (escolar, grupos de pares y medios masivos de comunicación) es importante, ya que, por medio de ellos, el individuo cubre los roles que ha internalizado durante todo el proceso. Todos los elementos que influyen en el individuo determinan el comportamiento, las interpretaciones y significaciones que éste atribuye a su entorno, y que a lo largo de su vida podrán ser modificados. Berger y Lukmann expresan que, dependiendo del contexto, el individuo se verá obligado a dar una nueva interpretación de las cosas, aun cuando en la infancia se les haya atribuido una significación. Puede ser que, a la edad de adulto, en un ámbito externo al familiar, un objeto sea reconocido de manera distinta a como fue internalizado durante la socialización primaria, por lo que, aunque habrá un choque dentro de la conciencia del individuo, éste terminará por adoptar la nueva interpretación del objeto (Berger y Lukmann, 1999).

Durante la segunda etapa de la socialización, el individuo no solo necesita adaptarse a las significaciones del grupo, sino que debe de lograr identificar las nuevas interpretaciones con el rol que desempeña y con las normas con las que se rige su entorno. Este proceso representa la transición de la socialización primaria a la secundaria. El camino que conduce hacia la socialización secundaria depende de la construcción de un "yo" formado con anterioridad y con un mundo internalizado previamente (Berger y Lukmann, 1999). Es decir, un individuo no puede adquirir significaciones nuevas sin tener unas de base constituidas desde la infancia.

Esto puede implicar un problema de coherencia entre las dos etapas de socialización, ya que la influencia de la primera adquirida, podría chocar con las nuevas. La socialización secundaria tiene cierta dependencia de las disposiciones sociales internalizadas en la primera, 
pero no se puede comprobar si las modificaciones que se generan a partir de la segunda sean fuertes o débiles, ni qué capacidad de inducir nuevas disposiciones mentales y de conducta se pueden incorporar en el individuo. Según el ámbito de prácticas, los individuos echan a andar disposiciones que adquirieron durante su proceso familiar. Berger y Lukmann explican la relación entre ambas etapas, mencionando que, para poder aprender cálculo matemático, primero hay que aprender algebra. Es así que el proceso es secuencial.

Además de la importancia de los elementos que integran la transición entre la primera y segunda socialización, cabe mencionar que el proceso presenta efectos distintos en cada individuo y dependerá mucho de sus contextos. Es así que Berger y Lukmann mencionan que en la socialización pueden influir factores como la clase social, ejemplificando con la situación de un niño de clase baja que ha sido socializado desde esta condición. El niño llega a normalizar su vida desde una clase baja y la interioriza como la realidad, creciendo con un estado de ánimo resignado, resentido y hasta satisfecho (Berger y Lukmann, 1999:165).

Durante la socialización secundaria, el individuo ha de contraponer algunos de los elementos de su concepción primaria con los de la segunda etapa del proceso. La influencia de los agentes secundarios, hacen cambiar en cierta medida la realidad que se ha internalizado y promueve la búsqueda de otras posibles. "La socialización es el mecanismo del que disponen tanto el individuo como la sociedad para la reciproca adaptación que su supervivencia exige" (Costa y De Juan, 2010: 110). El ser humano, ya como ser socializado pasará toda su vida aprendiendo, descubriendo y desarrollando habilidades con el fin de adaptarse e integrarse a las condiciones de su entorno.

Conforme se desarrollan ambas etapas de la socialización puede haber rompimientos en lo que se ha internalizado durante la primera y segunda etapa, lo cual promueve la incorporación del individuo a ámbitos muy diferentes a los acostumbrados. Se dice que esto conduce al sujeto a apartarse de muchos de los elementos adquiridos durante su proceso de socialización, desarrollando e interiorizando, nuevos significantes, habilidades y actitudes como mecanismo de adaptación e integración al nuevo contexto. Esta parte del proceso es considerada por algunos como una socialización terciaria o "resocialización", la cual se presenta en entornos como los asilos, instituciones psiquiátricas, instituciones carcelarias, procesos migratorios, etc. 
En este trabajo es importante conocer parte de lo que se dice respecto a la tercera etapa de la socialización, primero desde una mirada general y posteriormente enfocada en entornos carcelarios. Con la descripción de las tres fases que componen este proceso, en capítulos posteriores, se pretende analizar y comparar la intervención en los procesos de socialización de mujeres recluidas en el CPRS "Santiaguito", considerando su género, condición de clase y raza. Pensando en que estas condiciones influyen e intervienen de distinta manera en lo internalizado por las mujeres, y que la situación de reclusión no implica una resocialización como tal, sino que se trata de la continuidad de la segunda etapa en la que las imputadas desarrollan diversas estrategias para sobrevivir dentro del penal. Es así que en seguida se describirá a la socialización terciaria.

\subsubsection{El proceso de socialización terciaria o de resocialización}

Como se explicó previamente, durante la primera y segunda etapa de la socialización, los individuos interiorizan normas, costumbres, valores, conocimientos y creencias con los cuales generan las capacidades necesarias para una correcta convivencia e interacción entre los integrantes de una misma sociedad. Sin embargo, cuando las conductas de los sujetos no se adecuan a las aceptadas por el grupo social, se considera que hay un quiebre en el proceso de socialización. Este quiebre puede llevar a los individuos a integrarse a entornos distintos a los naturalizados y dentro de estos se dice que se desarrolla una tercera etapa del proceso de socialización, también conocida como “proceso de resocialización” (Martínez, 2014).

La socialización terciaria no posee una definición formal, sin embargo, puede ser entendida como "el proceso de resocialización por el cual un [individuo] dis-socializado se convierte en socializado" (Petrus, 1996: 92). En esta definición el término "resocialización" es clave para poderla comprender. Éste se deriva del prefijo "re" que significa "volver a", por lo que en conjunto con el término "socialización" implicaría "un nuevo intento de socialización" (Martínez, 2014). Es así, que esta tercera etapa se puede ver como el proceso por el cual un individuo con un comportamiento "desviado" o que ha sido excluido de su entorno es reentrenado y reintegrado a su mismo o nuevo grupo social.

Este proceso se constituye generalmente en situaciones y entornos específicos en donde los individuos ya socializados (principalmente adultos y adolescentes), son alejados o excluidos de sus grupos sociales o de los ámbitos que han naturalizado, y como consecuencia se ven 
obligados a vivir en contextos en donde la cultura, costumbres y normas son diferentes o tienen fuertes distinciones a las internalizadas durante las primeras etapas de la socialización. Se trata de casos como en la migración en donde los sujetos se enfrentan a una nueva adaptación sociocultural que implica adoptar el lenguaje, normas, valores y costumbres del entorno receptor, apartándose en cierta medida de lo adquirido en etapas previas (Ariño y Serra en García, 2005).

Sin profundizar en el tema migratorio, debido a que no representa la centralidad de este trabajo, cabe mencionar que otro de los ámbitos en donde se desarrolla la socialización terciaria (y que es lo que nos interesa conocer) es en las instituciones carcelarias. En estos recintos, se piensa que los individuos son separados de las concepciones interiorizadas durante las dos primeras etapas del proceso de socialización (principalmente de lo adquirido durante la segunda etapa). Además, dentro de este tipo de instituciones, los sujetos deben integrarse a las subculturas que caracterizan a los grupos constituidos dentro de estas, adaptándose a las reglas y normas que cada sistema carcelario ha de promover (Amariles, 2007).

La resocialización en los entornos carcelarios se supone que es generada por medio del aprendizaje de capacidades, habilidades, normas y valores que se consideran adecuados para preparar la reincorporación de los imputados a la adecuada vida en sociedad. Esto para cumplir con la función de instituciones disciplinarias que como expone Michel Foucault (2009), por medio del ejercicio de poder de quienes están al frente de los recintos, los individuos adhieran a su personalidad lo necesario para "favorecer" la correcta convivencia y participación dentro de los diversos entornos sociales.

Es así, que la socialización terciaria es vista como la herramienta con la que se reeduca al individuo infractor y que, con ello, éste reaprehenda los elementos necesarios para ser parte activa de la sociedad. Según Raúl Guillamondegui ${ }^{4}$ la resocialización en contextos de este tipo "comprende el proceso que inicia con la estancia del condenado en prisión, mediante el cual el equipo interdisciplinario profesional, con la colaboración del personal penitenciario y previo conocimiento del interno, procura que este pueda tomar conciencia de la génesis de su comportamiento delictivo pretérito y de sus implicancias personales, familiares y sociales

${ }^{4}$ Doctor en Derecho Penal y Criminología por la Universidad Pablo de Olavide, Sevilla, España. 
presentes y futuras con el propósito de fomentar y consolidar su capacidad de convivir en sociedad respetando la ley penal en lo sucesivo" (Guillamondegui, 2010: 13).

Es decir, el proceso de resocialización es visto como el instrumento con el que las autoridades y todo el personal de los recintos serán los encargados de preparar al individuo infractor para reintegrarse a la sociedad de manera satisfactoria después de haber delinquido. Y, por otro lado, que éste conozca las consecuencias de infringir las normas sociales, previniendo la reincidencia de los delincuentes. En este sentido, los otros son los encargados de resocializar a los individuos. Es por ello que, al igual que en las dos primeras etapas, este proceso no es individual, sino que se desarrolla con la interacción con los que encabezan y componen el nuevo contexto.

La relación sujeto- sociedad durante la socialización terciaria tiene como objetivo principal el "incorporar al individuo a la sociedad para inculcarle conservación de los valores de una manera dinámica y activa" (Amariles, 2007: 53). Esto significa que la resocialización pretende orientar el comportamiento del individuo excluido o desviado por medio de actividades y prácticas para lograr que éste incorpore a su conciencia individual los nuevos elementos (principalmente en el caso de los sujetos excluidos) o que logre reinteriorizar todo aquello que abandonó debido a su conducta inaceptada.

Al igual que en las dos primeras etapas de la socialización, la relación entre sociedad e individuos es muy importante durante la resocialización, pues es desde este vínculo que los sujetos han de interiorizar y adaptar los elementos componentes del nuevo entorno social y los propios del cual se les pretende reincorporar. Cabe recalcar que con los elementos promovidos durante esta tercera etapa no se despoja a las personas de lo adquirido durante la socialización primaria y secundaria. Por ejemplo, el lenguaje, aun cuando el individuo interiorice un nuevo idioma, éste no se eliminará de su conciencia su lengua materna, sino que adaptará ambas y las usará dependiendo del contexto en donde se encuentre.

Un ejemplo de lo anterior es el caso de mujeres indígenas recluidas en "Santiaguito". Dentro de la cárcel éstas se adaptan a la lengua predominante (español), y aunque no borran de su conciencia su lengua materna, sí dejan de usarla debido a las críticas y burlas que se puedan generar por parte de las demás internas e incluso de las autoridades encargadas. En casos como este, los grupos dominantes son quienes imponen y promueven cambios en lo que las 
mujeres indígenas han internalizado desde su socialización primaria. En este trabajo se piensa que estas mujeres se adaptan a los elementos que su nuevo entorno les demanda, pero no como parte de un proceso en el que se les esté volviendo a socializar, sino como una estrategia que favorezca su estancia dentro del penal.

Ante lo dicho podemos ver que la función de la relación individuo- sociedad en entornos como el carcelario, hace cuestionar la existencia de una tercera etapa del proceso de socialización, pues las características de este son bastante cercanas a lo expuesto sobre la socialización secundaria. En los recintos carcelarios puede que no se desarrolle una nueva socialización, ya que las actividades con las que se pretende lograr la reinserción social, son parte de un entrenamiento que no garantiza que los individuos infractores no volverán a reincidir, y tampoco significa que los sujetos sustituyen a la totalidad sus conocimientos previos por los nuevos. En muchas ocasiones lo interiorizado antes de la reclusión es moldeado a su nuevo entorno, lo que le permite a los imputados sobrellevar su estancia en la cárcel.

Lo anterior no significa que las personas en situación de reclusión no adquieren nuevas características en su personalidad, sino que las adaptan a la vida del nuevo entorno. Esto se trata principalmente del desarrollo de estrategias específicas para la sobrevivencia dentro de los nuevos contextos y que no implican el abandono o el despojo total de lo internalizado durante el proceso de socialización. Más bien se trata del desarrollo de medios individuales con los cuales adaptarse a un nuevo entorno y a su vez apropiarse de éste. En este trabajo, estos medios se denominan "estrategias de sobrevivencia", considerando que, durante toda la vida, además de lo internalizado, los sujetos realizan actividades, y desarrollan actitudes y habilidades de manera individual que les permitan acoplarse a los distintos entornos que la vida social les demanda.

Las "estrategias de sobrevivencia" pueden ser variadas y dependerán del entorno en donde se sitúen los individuos, así como de su edad, condición de género, raza y clase social. En el caso de mujeres en situación de reclusión, estas condiciones son importantes en el desarrollo de estrategias para sobrevivir, ya que esto implica que cada tipo de mujer tendrá diferentes necesidades, se enfrentará a distintas circunstancias y sus procesos de socialización se verán 
alterados de diferente manera, por lo que los medios que desarrollará para su sobrevivencia serán de distinto tipo.

En este trabajo se pretende construir el concepto "estrategias de sobrevivencia" principalmente desde una concepción social, ya que se ha empleado en mayor medida en la economía campesina y no en entornos sociales como el carcelario. Para que esta construcción sea posible es necesario acercarse a las definiciones, antecedentes y usos que se han dado al concepto. Esto nos permitirá que en capítulos posteriores podamos identificar las alteraciones que se generan en los procesos de socialización de mujeres recluidas en el Centro penitenciario "Santiaguito", y a partir de esto comparar desde su edad, condición de género, clase social y raza, cómo y de qué tipo son las estrategias que desarrollan para adaptarse y sobrevivir dentro del penal.

\section{2. "Estrategias de sobrevivencia”, construcción desde la mirada de las ciencias sociales}

Como se ha venido diciendo, en este trabajo se piensa que los procesos de socialización de distintos tipos de mujeres recluidas en el Centro Penitenciario y de Reinserción Social "Santiaguito", se ven alterados dentro de la institución. Lo cual promueve (más allá de la interiorización de nuevas formas) el desarrollo de tácticas que favorezcan la adaptación de estas mujeres, permitiéndoles sobrevivir a las diferentes circunstancias de vida a las que allí se enfrentan. Como se mencionó en líneas previas, en esta investigación a esas tácticas se les denomina "estrategias de sobrevivencia", a las cuales, en este apartado se les pretende dar una definición principalmente social.

En las ciencias sociales la significación de este concepto ha pasado por diferentes apreciaciones derivadas de cuatro principales enfoques: Sociodemográfico, SociológicoAntropológico, Antropológico, y desde la Pobreza y el Género. En cada una de estas

perspectivas el concepto se constituye de diversos elementos (que se explicarán más adelante), pero algo en lo que las cuatro coinciden es que se le ha empleado principalmente en aspectos de la economía, ya que se consideran acciones que las personas en situación de pobreza y marginalidad desarrollan a consecuencia de la necesidad de sobrevivir. 
Sin embargo, en este trabajo consideramos, que los individuos no solo desarrollan estrategias de sobrevivencia por motivos económicos, sino también por las adversidades sociales que enfrentan en diferentes entornos a causa de su condición de raza, género, clase y edad. Para mirar este concepto desde una perspectiva social y no solo económica, es preciso ahondar más extensamente en cómo surgió, las definiciones generales que se le han otorgado y la manera como se ha concebido a partir de los cuatro enfoques mencionados arriba.

Una vez hecho este recorrido se mirará al concepto en contextos específicos en donde las condiciones del entorno, la interacción y las relaciones con los otros, promueven en los individuos la necesidad de generar medios que les permitan adaptarse o "sobrevivir" en los ambientes en los que se sitúen. Esto nos ayudará a identificar, analizar y comparar las "estrategias de sobrevivencia" que desarrollan mujeres recluidas en el CPRS "Santiaguito". Por lo que la construcción de este concepto comienza por dar conocer cómo se ha constituido y aplicado en Latinoamérica, en donde las condiciones de vida y los entornos de muchas personas promueven la búsqueda de recursos alternos para adaptarse o "mejorar" su calidad de vida.

Es así que, autores como Mónica Vargas Jiménez ${ }^{5}$, Martha Arredondo Velásquez ${ }^{6}$ y José Ricardo González Alcalá7 coinciden en que el concepto "estrategias de sobrevivencia" aparece en Latinoamérica ya entrados los años setenta. A principios de los setenta no era común hablar de estrategias de sobrevivencia, más que cuando los estudios se centraban en los grupos sociales de escasos recursos que invadían tierras para establecerse en ellas. Estos grupos organizaban sus recursos y esfuerzos para alcanzar y conservar cierto nivel en su calidad de vida, actuando fuera de las normas legales de la posesión de las tierras (Arredondo

\footnotetext{
${ }^{5}$ Maestra en Ciencias Sociales con especialidad en Desarrollo Municipal. Investigadora del CIEAP-UAEM. "Estrategias de Sobrevivencia, alternativas económicas y sociales de la unidad campesina" (1996)

${ }^{6}$ Maestra en educación y en Metodología de las Ciencias Sociales. Profesora-investigadora de la Facultad de Trabajo Social de la Universidad Autónoma de Coahuila (UAC). "Las Estrategias de Sobrevivencia de los pobres: un repaso a su estudio en las ciencias sociales (concepto, perspectivas teóricas y acciones que implican)" (2013)

7 Doctor en Filosofía con Especialidad en Trabajo Social y Políticas Comparadas de Bienestar Social, por la UANL. Profesor-investigador de la Facultad de Trabajo Social y Desarrollo Humano (FTSDH) de la UANL. "Las Estrategias de Sobrevivencia de los pobres: un repaso a su estudio en las ciencias sociales (concepto, perspectivas teóricas y acciones que implican)" (2013
} 
y González, 2013: 21). A este tipo de acciones se les conocía como "estrategias de sobrevivencia de los pobres".

Más adelante, en 1980 el uso del concepto es formalizado e institucionalizado dentro de las ciencias sociales cuando el Programa de Investigaciones sobre Población en América Latina (PISPAL) y el Centro de estudios Urbanos y Regionales, organizan el Taller Sobre Estrategias de Sobrevivencia en la ciudad de Buenos Aires, Argentina. Tiempo después, en los años noventa, el concepto adquiere una definición formal, siendo éstas el "conjunto de acciones típicas que permiten a los pobres acceder a un umbral material mínimo indispensable para mantener su existencia tanto en lo individual como en lo familiar y social" (principalmente se alude a una concepción social más que a la individual) (Arredondo y González, 2013: 19). Actualmente, existen más definiciones para este concepto, por lo que antes de profundizar en ellas, cabe hacer la aclaración de que en materia económica se suele emplear a la palabra "sobrevivencia" como sinónimo o equivalente de "supervivencia" (López y Díaz, 2015: 218), en donde se le da un mayor uso a la segunda.

El estudio de las estrategias de supervivencia tiene como actores principales a los grupos marginados, población excluida de los beneficios del desarrollo político, económico y social del entorno latinoamericano (COPLAMAR, 1982 en Vargas 1996: 40). Además, se piensa que su aspecto central "consiste en la reordenación de las unidades familiares, enfatizando la participación económica de todos o la mayoría de los miembros componentes" (Duque y Pastrana, 1973 en Vargas 1996: 40). Se puede entender, que este tipo de estrategias es un medio principalmente familiar, en donde el conducto para generar una mayor cantidad de ingreso económico es el trabajo o actividades adicionales que desarrollan los integrantes del grupo familiar. Son varios los elementos que componen este tipo de estrategias, por lo que se le han dado diversas definiciones como son las siguientes:

\footnotetext{
${ }^{8}$ Según el Diccionario Panhispánico de Dudas de la Real Academia Española, la "sobrevivencia" refiere a seguir existiendo después de la muerte de alguien, de la desaparición de algo o de un suceso. En la mayoría de los casos, este término no es utilizado y se le sustituye por el concepto de "supervivencia". Definición disponible en: http://lema.rae.es/dpd/?key=Sobrevivir. Consultado el 15 de julio de 2018.

9 La "supervivencia", según el diccionario de la Real Academia de la lengua Española (RAE), se define como Acción y efecto de sobrevivir. Este término a triunfado en aplicación frente al de Sobrevivencia, sin embargo, en el Diccionario Panhispánico se considera que es incorrecta la forma "supervivencia". Disponible en: http://dle.rae.es/?id=YlFjai2 y http://lema.rae.es/dpd/?key=Sobrevivir. Consultado: 15 de julio de 2018
} 
En primer lugar, las estrategias de sobrevivencia se pueden entender como las "actividades desarrolladas por diversos sectores sociales que operan a nivel nacional, local o barrial con el objetivo de facilitar el acceso a bienes y servicios básicos a los grupos sociales que carecen de los mismos. Estas actividades se implementan a través de un amplio espectro de tipos de organizaciones, técnicas e interacciones entre individuos, grupos o instituciones implicadas en las mismas" (Finquelevich, 1993). En este sentido, se trata de actividades que los individuos de manera conjunta (ya sean grupos grandes o pequeños), desarrollan con la finalidad de enfrentar la escasez de los bienes básicos que les permitan vivir.

Por otro lado, las estrategias de sobrevivencia son consideradas un "dispositivo provisional, transitorio, que permite resistir [...] mientras pasa la chaparrón. Los campesinos saben que el chaparrón es permanente y no configuran sus dispositivos en términos transitorios" (Esteva, 1988). Los individuos desarrollan mecanismos con los cuales enfrentar los largos periodos de crisis, estos mecanismos, no son medidas definitivas, solo son funcionales por cierto tiempo, por lo que los actores estarán generando estrategias constantemente. Estas acciones se atribuyen principalmente a los campesinos, por lo que se muestra su aplicación dentro del entorno rural.

Con base en estas dos primeras definiciones, es importante recalcar que la mayoría de las definiciones que se dan acerca de las estrategias de sobrevivencia, se ubican en el ámbito económico y los campesinos son sujetos centrales para su estudio. Las estrategias de sobrevivencia o supervivencia son "mecanismos que utilizan los campesinos para lograr un equilibrio frente a las demandas de la sociedad de la cual forman parte" (Lara, 1988). Además, estos mecanismos se constituyen como un "conjunto de labores realizadas por la unidad doméstica campesina para contrarrestar su posición desventajosa frente al mercado y permitir su sobrevivencia" (Lehauller y Rendón en Vargas, 1996: 40).

Según lo expuesto hasta ahora, las estrategias de sobrevivencia se atribuyen principalmente a los sectores considerados más pobres y a quienes enfrentan situaciones de escasez económica. En las definiciones anteriores, son los campesinos y trabajadores del ámbito rural quienes integran dichos sectores (aunque no necesariamente debe de ser así), viéndose motivados a desarrollar medios que les permitan, si bien, no mejorar su calidad de vida, al menos satisfacer las necesidades básicas. 
Desde la perspectiva económica con que se define a los mecanismos de sobrevivencia, se destaca la participación y división del trabajo con la que los individuos se esfuerzan por generar ingresos $\mathrm{u}$ obtener los bienes y servicios necesarios para satisfacer las necesidades del grupo. La distribución de actividades para la sobrevivencia familiar o grupal, puede ser de tres diferentes tipos; los primeros enfocados a la producción de servicios de autoconsumo, los segundos tratan de la producción de bienes y servicios vendidos al mercado, y por último la venta de fuerza de trabajo fuera de su propio predio (Vargas, 1996). Respecto a esto, hablando solo del aspecto económico, pensamos que estos mecanismos no solo se desarrollan de manera grupal, sino individual y en entornos no rurales, pero sí derivados de una situación de pobreza.

Por ejemplo, dentro de recintos como "Santiaguito" (institución carcelaria), la gran mayoría de la población posee recursos económicos extremadamente limitados, por lo que los internos buscan alternativas para ganar dinero. De esta búsqueda surgen estrategias de sobrevivencia para favorecer la economía individual de los sujetos, y éstas pueden ser variadas. Según un interno: "Para ganarse la vida, hay muchas cosas que uno puede hacer aquí (dentro del penal). Puedes lavar ropa, ayudar en cocina, ser el gato de los que tienen lana o vender drogas...Pero casi siempre me pagan por hacer el trabajo de los demás, ya con eso te la vas llevando" (Persona en situación de reclusión, 2018).

Este testimonio va más enfocado a la venta de la fuerza de trabajo del interno, pues en general se emplea en actividades que otros con la capacidad económica de pagar, no quieren realizar. Ocuparse en estas actividades, favorece en cierta medida al individuo, pues el dinero que recibe a cambio de su trabajo, le permite satisfacer algunas de sus necesidades básicas como la alimentación. Cabría mencionar que, en este caso, al igual que en las intervenciones que se generan en los procesos de socialización, las estrategias de sobrevivencia también se ven relacionadas con el poder que tienen unos sobre de otros. En esta parte del trabajo, se trata de un poder económico, pero más adelante se hablará de un poder social.

Retomando la generalidad del concepto "estrategias de sobrevivencia", cabe mencionar que los mecanismos en donde situamos el ejemplo anterior y las definiciones expuestas previamente, derivan principalmente de cuatro enfoques de las ciencias sociales: 
Sociodemográfico, sociológico-antropológico, antropológico y desde la pobreza y el género. Estas perspectivas se describen a continuación:

El primer enfoque de análisis de las estrategias de sobrevivencia es el sociodemográfico, este "surge a partir de las discusiones y consensos de un grupo de demógrafos en México, en el año de 1978, durante el PISPAL. En este enfoque se consideran estrategias familiares de sobrevivencia actividades como: la procreación, la división de trabajo familiar, organización de consumo familiar, cooperación familiar y migración laboral. Esta perspectiva pretende vincular la reproducción material y biológica para demostrar que existe relación entre las esferas de producción, la reproducción social y la económica" (Torrado, 1980 en Arredondo y González, 2013: 23).

El análisis que hace esta perspectiva considera estrategias de sobrevivencia que pueden ir desde aspectos biológicos hasta lo familiar-laboral. Por ejemplo, la procreación como mecanismo de sobrevivencia, indica que habrá individuos que consideren que el tener una mayor cantidad de hijos podría favorecerlos, pues tendrían un número mayor de mano de obra, con la cual se beneficiaría la distribución del trabajo y se obtendría un mayor ingreso económico familiar (esto sucede principalmente en entornos tradicionales). Por otro lado, la migración también es considerada una estrategia de sobrevivencia, ya que el individuo que migra, beneficiará a la economía comunitaria y familiar con el envío de divisas, lo cual supone que la calidad de vida del grupo social, mejorará.

Por otra parte, tenemos al enfoque sociológico-antropológico "se define en función de la reproducción de los sujetos sociales, contextualizándose en una comunidad en particular, generalmente en comunidades tradicionales, relacionadas con la producción agrícola, la tierra, y las relaciones socio-productivas y culturales que giran en torno a ellas" (Massa, 2010 en Arredondo y González, 2013:23).

Este enfoque está mayormente relacionado con las definiciones dadas anteriormente. Se trata del desarrollo de mecanismos, principalmente familiares y comunitarios de los contextos rurales (no son esfuerzos individuales). A diferencia del enfoque sociodemográfico, los individuos generan actividades para mantener o mejorar su calidad de vida, sin considerar acciones como el abandono del entorno (migración) o el incremento poblacional. La economía funciona a partir de la interacción y trabajo dentro del mismo grupo. Se trata de 
actividades realizadas en el campo como la siembra y cosecha, así como la crianza de animales para el autoconsumo y el intercambio. Este tipo de estrategias se limitan a ciertos entornos sociales en donde se encuentra el grupo familiar y no el individuo solo.

Un tercer enfoque es el antropológico, en este, las estrategias de sobrevivencia son vistas como comportamientos sociales y demográficos de las unidades familiares que responden a situaciones concretas de acuerdo con su posición en la división social del trabajo. En este enfoque los mecanismos de sobrevivencia se definen de manera general como "conjunto de prácticas fenomenalmente muy diferentes, por medio de las cuales los individuos y las familias tienden de manera consciente o inconsciente a conservar o aumentar su patrimonio, y correlativamente a mantener o mejorar su posición en la estructura de las relaciones de clase" (Gutiérrez, 2009 en Arredondo y González, 2013: 23). Esta perspectiva propone revisar a los sectores más pobres para poder hacer un análisis de las estrategias que los individuos desarrollan para sobrevivir.

En la economía campesina el enfoque antropológico es el que más se utiliza para entender cómo y cuáles son las estrategias familiares de sobrevivencia de los individuos. Estas son actividades que los pobres o marginados generan principalmente de manera grupal con la finalidad de generar ingresos extras que les permitan mantener su calidad de vida o mejorarla considerablemente. La perspectiva antropológica está mayormente relacionada a la condición de clase y el lugar que los individuos ocupan a partir de los recursos económicos que poseen. Desde la antropología no se especifica el ámbito en el que se estudia a las estrategias de sobrevivencia de los pobres (rural o urbano). Sin embargo, sí se plantea una relación de la marginación, pobreza y exclusión con la vida en entornos rurales.

El último enfoque de análisis de las estrategias de sobrevivencia es el de la pobreza y el género, éste se vincula con los estudios sobre las formas de reproducción social en donde las mujeres son el centro de atención. Las mujeres son las protagonistas del "proceso de reestructuración de la unidad familiar bajo el sistema capitalista dominante" (Massa, 2010 en Arredondo y González, 2013:24). Sin embargo, cuando se analiza a la economía campesina (y muchos otros ámbitos) es común referirse al trabajo de los varones y no de las mujeres.

Por lo que este enfoque considera que la participación de las mujeres en la esfera pública es motivada por las crisis económicas y otros factores que impactan en el acceso a alimentación 
y salud de ellas y de sus familias, lo que las orilla a generar estrategias de sobrevivencia con las cuales enfrentar la marginación y pobreza en las que viven, promoviendo una resignificación de la concepción de "trabajo" de la unidad doméstica de producción familiar (López y Díaz, 2015: 214-215).

El análisis que hace esta perspectiva se centra en el vínculo que existe entre el contexto sociocultural de los individuos y la forma en que se distribuyen las actividades que realiza cada miembro de la familia con la finalidad de mantener un nivel de vida "normal". En la mayoría de los casos se piensa que las mujeres únicamente ocupan actividades relacionadas con el hogar y que el mayor ingreso proviene del esfuerzo de los varones. Esto debido a que las estrategias de sobrevivencia se han condicionado a aspectos culturales y tradicionales del entorno campesino en donde los hombres son los proveedores económicos (Errázuriz y Urzúa, 1984).

No obstante, el enfoque de la pobreza y el género, considera que las mujeres son quienes en verdad desarrollan estrategias para la sobrevivencia de sus familias y sus comunidades, realizando actividades alternas a las que socialmente se les ha asignado. En este tipo de análisis, no solo se relaciona a la pobreza con el hecho de ser campesino o trabajador rural, sino que se relaciona con el ser mujer en diferentes contextos. Para esta perspectiva es importante la idea de que las mujeres no solo participan en actividades extras para la generación de recursos económicos, sino que, además, como elementos socializadores, se encargan de transmitir a las nuevas generaciones un hábito de búsqueda de acciones alternas que favorezcan la subsistencia familiar.

Este enfoque puede ser funcional para identificar estrategias de sobrevivencia en entornos diversos, no solo en los del ámbito rural y familiar. Por lo que conocerlo es de utilidad para el análisis que se propone en esta investigación. En los entornos carcelarios como el CPRS "Santiaguito", las mujeres a partir de su edad, clase social o raza y de manera individual, generan diferentes estrategias para sobrevivir dentro del penal. Por una parte, algunas de las estrategias son para la percepción de recursos económicos y, por otro lado, otras que les permitan protegerse o sobrellevar situaciones en donde se pueda atentar en contra de su integridad (estas se exponen más adelante). 
Es importante destacar que como bien se expone en el enfoque de la pobreza y el género, a diferencia de los otros cuatro, no solo los hombres generan este tipo de tácticas para la sobrevivencia e incluso, las mujeres son quienes desarrollan una mayor cantidad de mecanismos para favorecer su subsistencia y estadía en los entornos en donde se ubican. Por ejemplo, en las instituciones carcelarias, pese a conservar un diseño marcadamente varonil, las mujeres buscan medios alternos para sobrevivir a las imposiciones de los sistemas carcelarios. La gran mayoría de la población femenil realiza labores manuales, con iniciativa personal e individual que les permitan generar ganancias.

Aun cuando en este trabajo nos interesa conocer el impacto y los mecanismos que desarrollan las mujeres de forma individual en el Centro Penitenciario, explorar antes las definiciones y enfoques con que se analiza a las estrategias de sobrevivencia, permite que encontremos un común denominador en la mayor parte de lo expuesto previamente: La sobrevivencia es una lucha de los pobres por alcanzar mejores niveles de bienestar económico o mantenerse en cierto nivel (Arredondo y González, 2013:24). Además, muchos de los autores que analizan las actividades que emprenden los pobres para sobrevivir, afirman que las principales motivaciones son en materia económica (aunque se pueden considerar otros aspectos como culturales, sociales y políticos, como se ha intentado ejemplificar en algunos fragmentos previos).

Respecto a lo anterior, en este trabajo se considera que las aplicaciones económicas que se le atribuyen al concepto "estrategias de sobrevivencia" en las ciencias sociales son limitadas, porque una mala condición de vida no solo puede derivar de aspectos económicos, sino también, de hechos como las relaciones y luchas de poder que se presentan en entornos determinados (ya sea en la zona rural o urbana), en donde, como se ha mencionado, intervienen la condición de género, raza, clase social y edad. Muchos individuos en situación de vulnerabilidad se ven en la necesidad de desarrollar habilidades, actitudes y acciones con las cuales integrarse a entornos nuevos en donde la lucha por sobrevivir no hace referencia únicamente a la adquisición de recursos y bienes materiales. Tal es nuestro caso de estudio.

Para poder entender los diferentes tipos de estrategias de sobrevivencia de mujeres recluidas en "Santiaguito", es necesario separarnos un poco de esa concepción que nos las muestra como medios que se desarrollan únicamente en la economía y con ello dar un significado y 
aplicación más amplios. Por lo que es necesario hacer la revisión de percepciones que no sean solo las relacionadas a los aspectos de la economía familiar campesina, sino que hay que entender lo que es la "sobrevivencia" como práctica mayormente social. Es por eso que se revisa el enfoque de otros autores como el Dr. Elias Canetti. Con esto se pretende ampliar el uso del concepto en contextos sociales como el CPRS de nuestro estudio de caso, en donde el poder adquisitivo no es lo único que determina quién es el sobreviviente.

Para un mejor entendimiento, como se ha adelantado en líneas previas, es común relacionar o sustituir a la "sobrevivencia" por el concepto de "supervivencia". Ambos conceptos están relacionados, pero no significan lo mismo. La supervivencia es defina como "acción de sobrevivir", lo cual no dice mucho y se hace necesario consultar la definición de sobrevivir. Según el Diccionario Panhispánico de Dudas de la Real Academia Española, la sobrevivencia refiere a la "acción de seguir existiendo después de la muerte de alguien, de la desaparición de algo o de un suceso ${ }^{10}$ ".

Por otra parte, según el Diccionario de Oxford, hay tres definiciones del concepto; la primera hace referencia a la "conservación de la vida, especialmente cuando es a pesar de una situación difícil o tras de un hecho o un momento de peligro" ${ }^{11}$. Otra manera de entender a la sobrevivencia es como la "vigencia de una cosa, en especial de algo que pertenece a otro tiempo o es propio de otra época" ${ }^{" 12}$. Por último, la tercera definición dice que se trata de la "acción de salir adelante con los medios mínimos necesarios para vivir"13, esta última va en relación con las consideraciones de la sobrevivencia desde la economía tales como las acabamos de abordar.

Estas definiciones tienen que ver principalmente con el vivir después de la muerte o mantenerse vivo aun después de las adversidades del entorno que se presentan a lo largo de la vida (en todos los ámbitos, no solo el económico). Es así que los individuos constantemente estamos generando estrategias de sobrevivencia en los diferentes entornos y contextos en donde nos ubiquemos, y más aún si en el entorno se atenta en contra de la integridad de la

\footnotetext{
${ }^{10}$ Definición del Diccionario Panhispánico de Dudas de las Real Academia Española. Disponible en: http://lema.rae.es/dpd/?key=Sobrevivir. Consultado: 15 de julio de 2018

${ }^{11}$ Diccionario de Oxford, disponible en: https://es.oxforddictionaries.com/definicion/sobrevivencia. Consultado: 15 de julio de 2018

12 Ibíd.

13 Ibíd.
} 
persona. Respecto a esto, según Elías Canetti (2013) la supervivencia se puede reflejar en distintos contextos, el primero de estos puede ser en un campo de batalla, en donde el sobreviviente es aquel que se mantiene vivo y que permanece de pie ante uno o muchos muertos, se trata de aquel que triunfa ante el peligro que los otros pueden implicarle (Canetti, 2013).

En el caso de este autor, a diferencia de las concepciones de la economía, el sobrevivir no solo es una acción colectiva, sino que en la mayoría de los casos se trata de acciones con las que se persigue un beneficio individual, pero para lograrlo, el individuo suele apoyarse de otros sujetos. Para ser sobreviviente, la relación con los otros no es precisamente de trabajo en conjunto (al menos no con todos), algunos se constituyen como enemigos del otro. La sobrevivencia no solo implica mantenerse vivo físicamente, sino que también a través de la memoria y a través del tiempo. Para ello, el individuo se constituye como un "héroe" por medio de la acumulación de triunfos y actos destacados. Las acciones que el héroe desarrolla pueden ser en beneficio o perjuicio de los otros, el objetivo es destacar, vencer y triunfar ante el enemigo.

En el sobrevivir desde las analogías de Canetti, se implica algo así como un "sacrificio" de amigos, familiares o simpatizantes que luchan junto al que resulta sobreviviente, éstos pueden llegar a perder la vida en beneficio de aquel que logra escapar de la muerte. A pesar del conjunto de caídos (gente a fin o enemigos) que pueda haber después de una batalla, solo el que se mantiene de pie, el que derrotó a los contrarios (aun con el apoyo de un grupo de individuos) o superó las adversidades, ése es el sobreviviente. En este sentido, lo que importa es ser el vencedor y no solo el que posee la mayor cantidad de bienes.

El que sobrevive, además de mantener una posición social, logra saciar deseos y necesidades ideológicas a consecuencia de los sucesos y condiciones de las cuales ha logrado sobrevivir. Muchas veces, antes de los hechos de riesgo, el individuo es solo uno más de entre tantos, pero después, éste se convierte en alguien destacado. Sobrevivir, implica que el individuo posea poder ya sea ideológico, emocional, social, cultural y hasta físico ante los otros por el hecho de que éste se ha mantenido de pie ante las circunstancias. El autor dice que la supervivencia tiene diferentes formas además de la que se presenta durante las batallas. 
Canetti destaca que, para sobrevivir, el individuo no siempre requiere del uso de su propia fuerza física, no siempre necesita tocar, ni ser tocado. Basta con poseer habilidades mentales, características personales como el carisma y buenos argumentos, y con ello desarrollar buenas estrategias. Algunas de estas estrategias pueden ser que el sujeto sobreviviente, logrando un control psicológico sobre los otros, les genere una sensación de miedo, lo que alejará de sí las amenazas de peligro que los otros pueden significar.

El miedo le da poder al individuo sobre la vida de sus enemigos y esto favorece su supervivencia individual. Tener el poder de someter al otro y que este último lo acepte, da una sensación de tranquilidad al sobreviviente. Además del miedo, la persuasión también funciona como medio de sobrevivencia, persuadir no solo a los enemigos, sino a sus propios simpatizantes, convenciéndolos de dar la vida por él o de eliminarse entre ellos mismos en lugar de exponerse a sí mismo.

Otra manera de sobrevivencia es el pasar desapercibido, camuflajeándose con el entorno, pareciendo invisible ante los ojos de los demás, de esos que implican peligro para el individuo. Ésta es una manera de mantenerse a salvo, de sobrevivir a las condiciones y circunstancias del entorno. Actuar cautelosamente, es una estrategia para mantenerse vivo y no significa cobardía, sino inteligencia. Esta manera de sobrevivir es importante en esta investigación, siendo que la encontramos en mujeres en situación de reclusión, principalmente en mujeres indígenas y en aquellas que ingresan durante la etapa de la vejez, ya que en ambos casos se encuentran en situaciones de gran vulnerabilidad.

Respecto a la vejez, según el autor, en algunos pueblos o grupos primitivos, los más viejos poseen privilegios sociales por el hecho no solo de existir, sino de aun existir. En sus grupos, principalmente los varones ancianos, son considerados seres respetados, son quienes poseen el poder, quienes gobiernan por el hecho de ser sobrevivientes ante la vida. Sin duda, para llegar a esta posición privilegiada intervienen diversas condiciones como el género, el tipo de sociedad y el contexto. En ámbitos como el carcelario, tener una mayor edad, ser mujer y ser indígena, hace a las mujeres más vulnerables que los varones, los más jóvenes o los mestizos. Por lo que sobrevivir dependerá de ocultarse del peligro, vencer la batalla siendo invisible ante la mirada de los demás. 
Otra manera de sobrevivir, según Canetti, es aquella en la que el individuo logra alcanzar un objetivo que muchos otros comparten y luchan por conseguir. Es así que entre humanos compiten por alcanzar un mismo fin, lograrlo implica sobrevivir. El autor ejemplifica esto, por medio de una analogía referente al momento de la procreación, en donde un espermatozoide entre millones logra fecundar al óvulo. El que vence al resto, el que alcanza la meta, es el superviviente. En este caso, quienes no logran el objetivo de la fecundación, según el autor, perecerán y solo el que alcanzó la meta, formará al nuevo ser. (Canetti, 2013).

Desde esta representación los humanos en algunos de los entornos en donde nos ubiquemos, competiremos con los otros, si bien, no siempre será para salvar nuestras vidas, pero sí por conseguir o mantener poder sobre los otros o para obtener beneficios y privilegios que los demás no poseen. Por ejemplo, en el día a día de personas en situación de reclusión, hay quienes adaptan sus actitudes, comportamientos y actividades en función de "convencer" al sistema de que son aptos para recibir beneficios como la libertad anticipada ${ }^{14}$. Muchos buscan lograr este objetivo, sin embargo, no todos lo logran, pues algunos no adaptan su esencia a las exigencias del entorno, pero quien lo logra es el superviviente.

Según el autor para que los sujetos logren alcanzar este tipo de objetivos, necesitan satisfacer sus necesidades básicas como comer, además, para sobrevivir hay que defenderse de los enemigos, hay que desarrollar mecanismos que favorezcan la obtención de un lugar de poder. El poder para Canetti es mantener el control sobre los otros, lo cual nos lo representa mediante la analogía de la relación entre un gato y un ratón:

El ratón, una vez atrapado, está bajo el régimen de fuerza del gato: éste lo agarró, lo mantiene apresado, su intención es matarlo. Pero apenas comienza a jugar con él, agrega algo nuevo. Lo suelta y le permite correr un trecho. No bien el ratón se vuelve y corre, escapa de su régimen de fuerza. Pero está en el poder del gato el hacerle regresar. Si le deja irse definitivamente, lo ha despedido de su esfera de poder. Dentro del radio en que puede alcanzarlo con certeza permanece en su poder. El espacio que el gato controla, los vislumbres de esperanza que concede al ratón, vigilándolo meticulosamente, sin perder su interés por él y por su destrucción, todo ello reunido - espacio, esperanza, vigilancia e interés destructivo-

\footnotetext{
${ }^{14}$ La liberación anticipada tiene como propósito facilitar al sentenciado su reincorporación a la sociedad en mejores condiciones y antes de concluir su sentencia, una vez que a juicio de la autoridad, ha logrado desarrollar el perfil apto para su regreso a la sociedad. Disponible en: http://www.lja.mx/2013/05/derechoshumanos-estatal-a-favor-de-la-libertad-anticipada/
} 
podría designarse como el cuerpo propiamente dicho del poder o sencillamente como el poder mismo. (Canetti, 2013: 399)

El poder que el autor representa con esto, lo relaciona con el tema de las prisiones, en donde "el prisionero tiene tiempo por delante y esperanza de escapar o de ser libre; y durante todo el tiempo, percibe el interés destructivo del aparato en cuya prisión se encuentra, aun cuando parezca haber cesado" (Canetti, 2013: 399). En esta analogía, el gato representa el sistema penitenciario y el prisionero sería el ratón. Entre ambos se mantiene una relación de poder, la vigilancia, las reglas y normas a las que los reclusos están sometidos son las herramientas con las que el sistema carcelario pretende reincorporar a los infractores a la sociedad. Pero, además, en los entornos carcelarios, el poder no solo parte de la relación interno-autoridad, sino que, en los grupos creados dentro de las cárceles, habrá quienes posean un poder sobre los otros.

Comprender estas relaciones es indispensable para este trabajo, pues ésta es un factor que interviene en la socialización de personas en situación de reclusión, lo que tiene como consecuencia el desarrollo de las diversas estrategias de sobrevivencia que nos interesa identificar en los diferentes tipos de mujeres recluidas en "Santiaguito". Es así que en el apartado 1.3, desde las perspectivas de Émile Durkheim y Michel Foucault, se describe la evolución de los sistemas carcelarios con la finalidad de exponer más ampliamente lo que Elias Canetti nos introduce referente a la relación de poder que se genera en estos entornos, y que más adelante nos servirá para analizar nuestro estudio de caso.

\subsection{Sistemas carcelarios y el castigo: del suplicio a la privación de la libertad desde las perspectivas de Durkheim y Foucault}

Los sistemas carcelarios y el castigo como herramienta de reformación social han sido estudiados en diferentes ramas de las ciencias sociales, tales como el Derecho, Criminología, Antropología Social, Historia y Sociología. En todas éstas se comparten algunos referentes teóricos para su análisis, entre ellos los enfoques de autores como Michel Foucault, Max

Weber, Émile Durkheim, Carlos Marx, entre otros. Los aportes de estos autores, respecto a los sistemas penitenciarios han sido variados y vistos desde diferentes perspectivas, pero con algunas características en común. 
En este trabajo, desde una perspectiva sociológica y con la finalidad de identificar los aspectos centrales que nos interesa analizar respecto a la situación de mujeres de diferentes condiciones $^{15}$ recluidas en "Santiaguito", solo se abordarán las ideologías de Émile Durkheim y de Michel Foucault. Debido a que con ambos autores se pretende conocer cómo se ha constituido la relación individuo- sociedad y los efectos que este vínculo representa en los internos dentro de los entornos carcelarios.

El primer autor explica al castigo y a los sistemas carcelarios desde una perspectiva más pasional, parte de aspectos tradicionales y pasa a los de las sociedades "modernas", destacando la importancia social del delito y del delincuente. En segundo lugar, el análisis de Foucault pone un mayor énfasis en las relaciones de poder, los mecanismos de sanción y su funcionalidad sobre los individuos a lo largo de la evolución de los sistemas penitenciarios.

En ambos autores hay que destacar que conforme se desarrolla la historia de los sistemas penales, han existido y existen marcadas desigualdades sociales en la manera de castigar a los individuos infractores, esto hace que cada sujeto viva y perciba sus sanciones de distinto modo y con diferente intensidad. Esta es una situación que no ha cambiado mucho hasta nuestros días. La condición de cada individuo sigue determinando el grado con que será castigado y cómo ha de enfrentar la vida dentro de los recintos carcelarios. Los aspectos mencionados se irán identificando desde los procesos que anteceden a los sistemas penitenciarios como herramienta de castigo.

Los sistemas carcelarios son instituciones relativamente nuevas de no más de 300 años. Éstos son propuestos como mecanismos para castigar por medio de la privación de la libertad a quienes actúan fuera de las leyes establecidas en su sociedad. Las cárceles tienen como antecedentes medidas correctivas en las que se involucraba el castigo corporal, el exhibicionismo social y hasta la muerte del infractor (siglo XVI). A quien se le ocurría actuar fuera de las normas morales y políticas de la sociedad, tendría que enfrentar un devastador castigo con el que además de pagar la pena de su actuar anómalo, sería expuesto ante todos como advertencia de lo que sucede si se rompe con las reglas.

\footnotetext{
${ }^{15}$ Mujeres indígenas, mestizas, jóvenes, de la tercera edad y de diferentes clases sociales.
} 
Con el paso de los años la manera de castigar evoluciona, mermando el suplicio y concibiendo una nueva forma de represión en la que la tortura corporal deja de ser la herramienta principal (Foucault, 2009: 11-26), se trata de la privación de la libertad. Con esta herramienta se pretende que el castigo sea el medio para reformar al transgresor o infractor. Sin embargo, mirando más profundamente esta modalidad, alejar al individuo de su entorno cotidiano no es la penitencia total, sino que con el encierro se promueve una dura existencia para el interno, siendo común que dentro de las instituciones carcelarias se reproduzcan actitudes de violencia y desigualdad por parte de las autoridades encargadas y de los mismos presos, lo que promoverá el desarrollo de estrategias para sobrevivir en estos entornos (véase apartado 1.2).

En las actitudes que reproducen quienes dirigen las instituciones carcelarias, es observable que castigar no es el único objetivo perseguido, sino que también implica la reafirmación del poder que tienen los gobernantes (sociedades tradicionales) o el Estado (sociedades modernas). Para tal demostración de poder debe haber un dominante y un dominado, así como nos dice Canetti en el apartado anterior, estos papeles se atribuyen a los individuos a partir de la existencia del delito y el delincuente, los dominantes serán quienes castigan el delito y el delincuente quien comete la falta.

Foucault atribuye la existencia del delincuente a la creación de las instituciones carcelarias, debido a que estas últimas no logran cumplir con su objetivo central de reincorporar a los individuos a la sociedad, creyendo que más bien, se promueve la reincidencia del sujeto infractor. Por otra parte, Durkheim pone un mayor énfasis en la concepción del crimen (delito) y la pena como castigo. Para el autor esto surge desde la concepción que los individuos tienen de lo sagrado, qué es eso que valoran y a lo que se le debe de imprimir respeto. Lo sagrado no está dirigido específicamente a una concepción religiosa, pese a que de ahí parte. Esto lo expone el autor más detalladamente.

\subsubsection{El castigo y el sistema penal de Émile Durkheim}

El enfoque de Émile Durkheim hacia el castigo y los sistemas penales es ambiguo, su consideración respecto al tema parte de la cuestión criminal, en donde la sociedad como un 
concentrado de creencias y sentimientos colectivos ha de definir lo que es aceptado o no dentro del grupo social. Por ello, este autor se centra principalmente en la concepción de lo que las sociedades han de determinado como crimen y la consolidación de las penas para castigar a quienes rompen con las normas que cada grupo establece. Además, Durkheim destaca la importancia del poder que tienen los gobiernos para aplicar los castigos y sanciones a los infractores, así como la relevancia que juega la existencia del delito en las sociedades.

Para este autor el castigo es visto como una institución relacionada con el corazón mismo de la sociedad, siendo éste "la conciencia colectiva"16. Respecto a esto, David Garland en su obra Castigo y sociedad moderna (1999), dice que:

La sanción penal representaba un ejemplo tangible del funcionamiento de la 'conciencia social' en un proceso que expresaba y regeneraba los valores de la sociedad. Al analizar las formas y funciones del castigo, el sociólogo obtenía una perspectiva sistemática del núcleo de la vida moral alrededor del cual se conforman la comunidad y la solidaridad social ${ }^{17}$ (Garland, 1999: 39).

Es decir, según Garland, para Durkheim es en los procesos y rituales penales en donde se encuentra la clave para analizar a la sociedad. Además, el castigo es considerado como una institución social, el cual es un asunto de moralidad y solidaridad social. El castigo en la moralidad se puede entender como una reacción emotiva e irreflexiva que profana lo que la sociedad tiene como sagrado o en más alta estima (Richter, 2010). Dicho esto, hay que hacer notar que el término de "sagrado" es importante en cuanto a la concepción de castigo, pues a partir de éste es que los individuos determinan lo que es un acto criminal y el tipo de pena que se impondrá al infractor.

16 "El conjunto de las creencias y de los sentimientos comunes al término medio de los miembros de una misma sociedad, constituye un sistema determinado que tiene su vida propia, se le puede llamar la conciencia colectiva o común" (Durkheim, 2007: 89). Es decir, todas aquellas creencias que son compartidas por toda la sociedad o la mayoría de esta. Su valor es importante en la colectividad, por lo que los miembros de cada grupo promueven que se respeten dichas ideologías.

${ }^{17}$ Capacidad o actitud de los individuos de una sociedad para ayudarse y apoyarse unos a otros en aspectos puntuales de la vida cotidiana. Según Durkheim, la solidaridad social se encuentra en la conciencia colectiva de las sociedades. En los diferentes grupos de las sociedades se requiere solidaridad social para desarrollar diversas actividades (https://www.significados.com/solidaridad-social/) . Durkheim las divide en dos:

1. Solidaridad Mecánica: Vinculo en el que los miembros del grupo están unidos por semejanzas valorativas y afectivas (Tonkonoff, 2012).

2. Solidaridad Orgánica: Los integrantes del grupo se relacionan por diferencias funcionales, derivadas de la especialización que poseen para diferentes tipos de trabajos (Tonkonoff, 2012). 
Lo sagrado se relaciona principalmente a ideologías de sociedades tradicionales, en donde las leyes y sentimientos colectivos responden a un sentido religioso, son consideradas como algo divino y superior que inspiran respeto, y algunas veces temor (Garland, 1999). Durkheim dice que en las sociedades tradicionales el derecho criminal era inicialmente un derecho religioso, en el que las ofensas en contra de los dioses eran directamente ofensas hacia la sociedad misma. Estas ofensas eran castigadas con penas más "privadas" como es la vendetta ${ }^{18}$ dada en sociedades compuestas principalmente de una naturaleza más familiar, denominadas por el autor como "clans". “...Cuando un atentado se comete por uno o varios miembros de un clan contra otro, es este último el que castiga por sí mismo la ofensa sufrida" (Durkheim, 2007: 101).

En este sentido, las faltas y ofensas cometidas se castigaban de manera pasional y vengativa, las penas eran directamente ejercidas entre los miembros de la sociedad y los criminales. El autor señala que mientras más primitivos eran los grupos, los tipos de sanciones eran aplicados sin estar planificados adecuadamente, Durkheim dice que "... [Los miembros del grupo] hacen sufrir al culpable únicamente por hacerlo sufrir y sin esperar para ellos mismos ventaja alguna del sufrimiento que imponen" (Durkheim, 2007: 95). En estas sociedades, los castigos más que resarcir las faltas cometidas, implicaban generar satisfacción en los individuos al hacer sufrir a aquel que cometió alguna falta.

Más adelante esta modalidad presenta algunos cambios, las sociedades modernas siguen castigando a los delincuentes, pero relegando el poder a un mandatario (Estado) que, según el autor, los castigos irán en función de la satisfacción de los intereses de quien posee el poder, más allá del sentir de la sociedad. En éstas, la concepción de lo sagrado representa autoridad social y legalidad, por lo que existen valoraciones y sentimientos sociales arraigados que si son transgredidos generarán repudio por los individuos. Según el autor, "la cosa sagrada es por excelencia, aquella que el profano no debe, no puede tocar imprudentemente (Durkheim, 1992: 43)”. En este caso, las normas y valores de cada grupo son eso "sagrado" que el individuo no debería de trastocar.

18 Venganza producida por enemistad, especialmente a causa de una muerte o una ofensa. Disponible en: https://es.oxforddictionaries.com/definicion/vendetta 
En las sociedades modernas los valores morales que se conciben como lo sagrado no son tan claros y específicos como en las tradicionales (religiosos). Son los valores de libertad; el respeto por el individuo; la tolerancia y la razón, los que no pueden ser violados impunemente. Ahora la conciencia colectiva está protegida por un código penal, el cual al ser violado será el castigo o la pena el medio con el que se garantiza la fuerza y significación de lo establecido. El castigo penal se constituye como un ritual público y violento con el que se promulga la protección y validez de las normas y leyes que las sociedades establecen (Tonkonoff, 2012).

Para que este tipo de castigo suceda debe de existir la presencia de alguien que transgreda las normas, denominado criminal o delincuente, y de una falta política, moral o social considerada crimen o delito. El criminal según Durkheim "ya no aparece como radicalmente insociable o como un elemento parasitario, un cuerpo extraño e inamisible dentro de la sociedad; es un agente regular de la vida social" (Durkheim, 1986: 96 en Tonkonoff, 2012: 122). Se trata de un individuo con una personalidad patológica ${ }^{19}$, pero que a su vez, su existencia es importante para la sociedad.

Por otro lado, el crimen sucede "cuando [el delincuente] ofende los estados fuertes y definidos de la conciencia colectiva... el crimen hiere sentimientos que, para un mismo tipo social, se encuentran en todas las conciencias sanas” (Durkheim, 2007: 83, 90), “...un acto no hiere la conciencia común porque es criminal, sino que es criminal porque hiere la conciencia común. No lo reprobamos porque es un crimen, sino que es un crimen porque lo reprobamos" (Durkheim, 2007: 91). Es decir, todos aquellos actos que las sociedades consideran criminales, son determinados por el mismo grupo. En algunas culturas habrá acciones que se consideren inadecuadas, mientras que en otras no.

Es la conciencia colectiva la que constituye eso que los individuos deben valorar y respetar, por lo que los delitos no son categorías naturales, sino que su relevancia dependerá según la época y el lugar en donde se hayan consumado, siendo el resultado de las normas y códigos aceptados por el grupo social. Estas consideraciones son constituidas durante el proceso de socialización de cada individuo (véase apartado 1.1), ya que éste es educado bajo un conjunto

\footnotetext{
${ }^{19}$ Individuos (principalmente adultos) que ignoran las reglas fundamentales o no reconocen la autoridad, esto como síntomas de un comportamiento social anormal (Durkheim, 2007).
} 
de creencias, normas y valores que deberá de seguir para tener una adecuada convivencia con el grupo, el no hacerlo significaría cometer una transgresión que la sociedad ha de determinar cómo se castigará.

Otro aspecto importante sobre el castigo en sociedades modernas es que en su concepción, se sigue imprimiendo el sentido de venganza. La esencia de la pena no es directamente racional, sino de motivaciones irracionales determinadas por la profanación de lo "sagrado" y la justa rectificación del actuar anómalo del infractor (Díaz, 2007). Se trata de la comunicación de sentimientos transgredidos que a su vez son la forma ideal para preservar las conductas deseadas socialmente. El castigo en estas sociedades, "es el deseo de venganza, el agravio moral el que impulsa la pena, su motivación emana del interior más que del exterior y es el Estado el que solo asume el control del proceso graduando la pasión espontánea, pero no controla su origen (Ritcher, 2010: 281)".

Desde las motivaciones que dan pauta al castigo, éste se hace necesario para las sociedades, puesto que además de funcionar como medio de control del crimen, también sirve para preservar al sistema. Reaccionar con esta herramienta ante los delitos promueve el orden moral, evitando que colapse o se desgaste la sociedad. Durkheim supone que el proceso social de castigar al delincuente, se trata de un ejercicio de poder, el cual asegura hasta cierto punto, la conservación del orden moral y de la autoridad legal. Para el autor, si no se castigan las transgresiones a la conciencia colectiva, se debilita a la moralidad social, poniendo en riesgo los cánones morales que conforman a la sociedad (Garland, 1999).

Es así que el castigo también puede ser visto como una herramienta de control por parte de las autoridades. Es el Estado el que toma el papel regulador de la vida social. Como se mencionó en el apartado 1.2 (con Elias Canetti), cuando se castiga a los delincuentes las autoridades reafirman su poder, además de que imponen un estándar de conducta para los criminales. "...Una vez que un poder de gobierno se establece, tiene, por sí mismo, bastante fuerza para unir espontáneamente, a ciertas reglas de conducta, una sanción penal. Es capaz, por su acción propia, de crear ciertos delitos o de agravar el valor criminológico de algunos otros" (Durkheim, 2007: 93).

En las sociedades modernas se dice que es la sociedad la que castiga, pero no de una manera directa, sino que concentra el poder en el Estado y éste es el que ha de aplicar las penas a los 
infractores. Según Durkheim, el gobierno tiene la facultad de determinar la magnitud de las faltas cometidas por los delincuentes y las sanciones que han de recibir. Estas decisiones serán aceptadas por el grupo social. Por ello, el autor propone que las penas deben de tener cierta fuerza y eficacia para que se pueda conseguir el objetivo de mantener el buen funcionamiento del sistema. Además, considera que la intensidad y la manera de sancionar reforzarán el orden moral establecido por las autoridades, pudiéndose aplicar en un entorno específico como los sistemas carcelarios.

Centrar lo expuesto durante este apartado en instituciones como las carcelarias, nos ayudará a identificar los elementos que impactan en los procesos de socialización y las estrategias de sobrevivencia que promueven mujeres indígenas y mestizas de nuestro estudio de caso desde su situación de reclusión. Así, los elementos que comprenden al castigo, según Durkheim, se reflejan en la obra Dos leyes de la evolución penal (1899-1900), en donde de manera más específica, se plantea la transición de los sistemas penales pasando por dos etapas: una cuantitativa y otra cualitativa.

La primera etapa surge de los antecedentes de los sistemas penales en donde la pena en sí era el suplicio, castigo corporal y exhibicionismo social. Por lo que la fase cuantitativa se caracteriza por el grado de sufrimiento corporal que el infractor recibirá, fundamentado en dos principales variables: tipo de sociedad y tipo de gobierno, en palabras del autor, "La medida del castigo es mayor en la medida en que la sociedad pertenece a un tipo menos desarrollado y al grado en que el poder central tiene un carácter más absoluto (Durkheim, 1899-1900: 71)". Es decir, que en una sociedad tradicional en donde el gobierno sea de orden absoluto, será común recurrir al suplicio como herramienta de "reformación social".

Esta primera ley aplica principalmente en sociedades tradicionales, en donde, como se ha mencionado en líneas previas, predomina la intensidad de la conciencia colectiva. La moral social es más rígida, exigente y severa, inclinada a ordenamientos principalmente religiosos, por lo que las reglas y castigos son "autorizados" por los dioses o divinidades. Los problemas de los primeros sistemas penales son el resultado de una moral religiosa en la que debe existir temor por los dioses y al colapso de la sociedad.

En esta etapa cualquier ofensa en contra de la conciencia colectiva de una sociedad adquiere el status de "criminalidad religiosa" (Garland, 1999), provocando repulsión y temor hacia las 
consecuencias de dichas faltas, pues como correctivo se tomarán medidas terriblemente violentas en contra del infractor. La etapa cuantitativa del sistema penal, es en donde lo sagrado tiene una importante significación religiosa y que principalmente se centrará en la cantidad y lugar de castigo que se tendrá.

Por otra parte, la segunda ley que Durkheim plantea, refiere a la privación de la libertad como la pena con la que se pretende remediar el actuar anómalo (sistemas carcelarios en sociedades modernas), "El castigo que implica la privación de la libertad y solamente de eso por períodos de tiempo que varían con la gravedad del crimen, tiende crecientemente a volverse el tipo anormal de sanción" (Durkheim, 1899-1900: 79). Los individuos infractores serán confinados en una institución carcelaria por el tiempo que han de determinar las autoridades, según el impacto social que se le haya atribuido a la falta cometida.

El encarcelamiento como pena, en un principio solo era un modo de vigilancia en el que el encierro no era en sí la pena, sino que el castigo recaía en la dura existencia de los presos. En general, la prisión se presentaba como un medio para evitar la huida de los acusados (Durkheim, 1899-1900). Cabe mencionar, que aun cuando la sanción se aplica al criminal, ésta tiene efectos que van más allá del individuo. En muchos casos, los hijos, cónyuge, padres y personas cercanas al infractor, verán trastocados sus sentimientos con la ausencia de uno de sus integrantes. Sin embargo, para el resto de la sociedad ha de parecer justo el castigo que se le atribuye al infractor. Durkheim dice que "no hacemos sufrir al culpable por hacerlo sufrir; no es menos verdad que encontramos justo que sufra". Es decir, la dura existencia del individuo dentro de los recintos carcelarios, aun con un sentido de venganza, parece ser lo más cabal, sin considerar todos los efectos que esto represente.

Más adelante, la cárcel comenzó a ser empleada como la verdadera pena, tal como en nuestros días. Esta segunda ley, se encuentra principalmente en sociedades en donde las creencias colectivas compartidas socialmente no son solo de carácter religioso, ni tampoco se rigen por creencias divinas. En este tipo de sociedades predomina la "criminalidad humana", esto significa que la concepción de lo sagrado va dirigida principalmente hacia las personas y su propiedad, la libertad individual, la dignidad humana, la tolerancia y la razón (Garland, 1999). Las ofensas hacia estos valores, siguen generando indignación social y la exigencia de un castigo. 
Sin embargo, se dice que en esta etapa cualitativa los castigos se han ablandado, pues "la ofensa de un hombre contra otro hombre no provoca la misma indignación que la ofensa de un hombre en contra de Dios (Durkheim, 1982, en Garland, 1999: 56)”. Así, encerrar al individuo en una prisión, es una muestra de benevolencia en comparación con los castigos corporales que se aplicaban en las sociedades tradicionales. En referencia a las sociedades modernas, las primeras instituciones carcelarias, eran recintos en los que se retenía al delincuente mientras esperaba su sentencia, la cual podría estar enfocada a ciertas actividades. Por ejemplo, se podría sentenciar al individuo a realizar trabajos pesados, por lo que el encierro no era el castigo en sí.

Cuando este sistema evoluciona y se establece la privación de la libertad como pena hacia el infractor, las instituciones carcelarias adquieren un carácter preventivo y de confinamiento, formalizándose como la nueva modalidad de castigo. Durkheim considera que las nuevas formas penales están constituidas por una nueva moralidad social. Además, con esta segunda ley trata de explicar las características del castigo en los sistemas penales modernos. Lo cual nos es de utilidad para realizar el análisis de nuestro estudio de caso, pues esta modalidad no ha cambiado mucho desde el siglo XVIII hasta la actualidad.

En nuestros días la privación de la libertad se sigue empleando como herramienta de castigo hacia quienes rompen con las normas, valores y conductas aceptadas por la sociedad. No es la sociedad la que castiga directamente a los infractores, sino que por medio del ente social que los representa (Estado) es que se aplicarán las sanciones. La manera en que las autoridades imponen los castigos, dan cuenta del poder que tienen sobre los individuos. Actualmente, castigar con la cárcel, no solo tiene por objetivo mantener bajo control la tasa social de delitos, sino que se supone, preparan a los individuos que han delinquido para ser reintegrados a la sociedad.

Sin embargo, es bien sabido que los componentes del sistema carcelario actual no favorecen el logro de dichos objetivos, sino que más bien, dentro de las cárceles se promueven diversas actitudes y comportamientos con los que se puede atentar en contra de los mismos internos y por ello, éstos deben de generar los medios para adaptarse y sobrevivir a las circunstancias de la vida en reclusión. Esto se desarrollará más adelante en este trabajo, cuando se conozcan algunos testimonios de diferentes personas en situación de reclusión, pues las formas de 
castigo penal dependen del tipo de delincuente, como se ha venido mencionando, por la constitución de diferencias de género, clase social, raza y edad.

Para que más adelante podamos encontrar los elementos de interés de este trabajo, es importante conocer otra perspectiva de análisis del castigo, además de la expuesta desde las consideraciones de Émile Durkheim. Por ello, con la finalidad de acercarnos más al tema de las cárceles, se expone el enfoque de Michel Foucault. Este autor, explica los entornos carcelarios más detalladamente y hace un recuento de los antecedentes de estos sistemas, describiendo de forma gráfica los primeros tipos de sanciones. Asimismo, también destaca las desigualdades que se producen desde la concepción de poder que caracteriza a los entornos carcelarios.

\subsubsection{Castigo y sus nuevas modalidades: el sistema penal según Michel Foucault}

A diferencia de Durkheim, Michel Foucault analiza los sistemas carcelarios de manera más específica. Para Foucault es importante conocer el proceso histórico, sus instrumentos y la utilidad de los sistemas penales con los que se logra su constitución. El objetivo de estos sistemas de castigo es seleccionar, perseguir y sancionar algunos de los comportamientos con los que se transgrede la vida en sociedad. Para el análisis de las cárceles, el autor no enfatiza su mirada en aspectos como la moral y componentes emocionales o pasionales, como en el caso de Durkheim. Es así, que en la obra Vigilar y Castigar (2009), Foucault analiza las técnicas, instituciones y conocimientos penales desde los principios de la vigilancia y la disciplina, conformados desde un proceso de transición del suplicio hasta el castigo penal.

Al igual que en Las dos leyes de la evolución del sistema penal (1899-1900) de Durkheim, Foucault divide su análisis de los sistemas carcelarios en dos etapas diferentes: la primera denota los castigos que anteceden a las cárceles que son penas principalmente corporales, y la segunda etapa parte de una reforma que se originó debido a que la sociedad comenzó a mostrar repudio por la severidad de los castigos corporales, por lo que se consolidó un nuevo sistema penal, el cual basa el castigo moderno en la privación de la libertad como herramienta reformadora. En ambas etapas, según el autor, existe una relación de poder entre quienes 
castigan y quienes son castigados. En la primera el poder se concentra en mayor medida en el monarca y en la segunda etapa, éste se distribuye en diferentes grupos, pero es el Estado quien define los tipos de sanciones.

La primera etapa es analizada por Foucault desde el siglo XVI, en donde los métodos de castigo hacia quienes transgreden las normas sociales se tratan principalmente del suplicio corporal y el exhibicionismo social. Foucault narra y describe lo devastador de los castigos en donde se pasea desnudo, se tortura, se desmiembra y se quema al delincuente hasta quedar hecho cenizas. Todo esto se llevaba a cabo en plazas públicas y el resto de la sociedad eran los espectadores de lo acontecido, tomando como referencia lo que les podría suceder si se les ocurría infringir las normas sociales (Foucault, 2009). Es así, que el autor narra algunos hechos, en donde se muestra lo aterrador de los castigos:

...Un ayudante, arremangado por encima de los codos, tomó unas tenazas de acero hechas para el caso, largas de un pie y medio aproximadamente y le atenaceó primero la pantorrilla de la pierna derecha, después el muslo, de ahí pasó a las dos mollas ${ }^{20}$ del brazo derecho y a continuación las tetillas [del criminal]. [...El] oficial, aunque fuerte y robusto, le costó mucho trabajo arrancar los trozos de carne que tomaba con las tenazas dos y tres veces del mismo lado, retorciendo, y lo que sacaba en cada porción dejaba una llaga del tamaño de un escudo de seis libras (Foucault, 2009: 12).

El fragmento anterior es un ejemplo de la primera etapa del castigo, presentado como ritual en donde se tortura y se hace sufrir el cuerpo del infractor de una manera escalofriante, y que, a su vez, era una muestra de poder de las autoridades. En las sociedades absolutistas de este periodo, los castigos públicos eran la manera en que los gobernantes imponían su autoridad ante la población, promoviendo miedo en los individuos de cometer faltas, que, si bien no solo transgredían el sentir del resto, rompía con las creencias impuestas por las autoridades de lo que era aceptado y lo que no. El monarca reafirmaba su posición, su poder ante la sociedad, mostrando que nadie podía seguir viviendo después de ser un criminal (Foucault, 2009).

Otra manera de ver las violentas herramientas de castigo en sus inicios es con la práctica del patíbulo $^{21}$ (Garland, 1999), la cual lejos de verse solo como una actividad cruel de tortura, el

\footnotetext{
${ }^{20}$ Partes carnosas o blandas de un cuerpo orgánico. Disponible en: https://www.buscapalabra.com/definiciones.html?palabra=mollas

${ }^{21}$ Del lat. patibŭlum.
} 
autor la describe desde dos principales usos. En primer lugar, era una parte esencial del proceso judicial de investigación, pues con esta se buscaba obtener la confesión del criminal. Esto, como se ha mencionado, se llevaba a cabo en una ceremonia pública, en la que en repetidas ocasiones se lastimaba físicamente al condenado hasta conseguir que éste aceptara su culpabilidad. En estos eventos era indispensable la presencia del pueblo para que todos lo pudieran contemplar, y como en todas las actividades de castigo, dar el ejemplo de lo que le podría suceder a los espectadores en caso de delinquir (Garland, 1999).

El segundo uso de la ejecución pública era de orden político, pues cualquier crimen significaba atentar en contra del soberano (así como las ofensas hacia los dioses en sociedades tradicionales), esto ya que se creía que las leyes se encarnaban en la voluntad soberana (Garland, 1999). Así, en este caso, el castigo incluía ciertas motivaciones vengativas por parte de las autoridades y la sociedad, quienes se sentían ofendidos por los actos cometidos por el delincuente (concepción también propuesta por Durkheim). Castigar de esta manera implicaba usar el cuerpo del criminal como la pizarra en la que se imprimía el legado de autoridad y respeto.

En ambos usos, Foucault destaca que la aplicación de castigos de alta violencia, aseguraban la manifestación de la verdad y el poder. El suplicio y la tortura corporal como medio de castigo y reafirmador de autoridad, según el autor, dependerán de factores como: la cultura y las condiciones demográficas que determinan una actitud histórica frente al valor e importancia del cuerpo y de la vida (derivan del proceso de socialización de los individuos en cada sociedad). Es así, que sucesos sociales que se vivían durante esta época, como el bajo costo de la mano de obra, el menosprecio cristiano por el cuerpo y los altos índices de mortalidad, hacían que se perdiera la sensibilidad por el valor de la vida, normalizando y familiarizando el sufrimiento, y la muerte de los individuos durante estos lamentables rituales de castigo (Garland, 1999).

Con el paso del tiempo, las formas de castigo del siglo XVI comienzan a causar inconformidad y revuelo por parte de la sociedad. La crítica a los privilegios de los gobernantes, la arbitrariedad y arrogancia con que se juzgaba a los infractores, es lo que condujo al pueblo a rebelarse para revaluar las formas de castigo con las que habían sido

1. $\mathrm{m}$. Tablado o lugar en que se ejecuta la pena de muerte. Véase: $\underline{h t t p: / / d l e . r a e . e s / ? i d=S 9 U h O 7 r}$ 
regidos durante muchos años. "Muy pronto el suplicio se ha vuelto intolerable. Irritante, si se mira desde la perspectiva del poder, del cual descubre su tiranía, su exceso, su sed de desquite y 'su cruel placer de castigar'... el pueblo aprende pronto que no puede vengarse sino con sangre" (Foucault, 2009: 85-86).

La gente comenzó a sentir la necesidad que, en vez de actuar vengativamente en contra del infractor, se le castigara en serio, sin recurrir al salvajismo de las torturas corporales. Es así que a finales del siglo XVIII y principios del XIX, las modalidades de castigo toman un nuevo rumbo, en el que se esperaba que las sanciones "tengan humanidad como medida" (Foucault, 2009: 87), dando como resultado los primeros sistemas carcelarios en donde se comenzaría a dar valor y respeto al cuerpo. Con esta medida, desaparece esa tendencia de castigo como espectáculo, como aparato teatral del sufrimiento -dice el autor-.

En esta etapa del castigo se pretende que la manera de castigar sea un proceso discreto, por lo que se comienza mediante el uso de la guillotina, la cual es colocada dentro de las cárceles y al momento de la ejecución de un criminal, ya no se requiere la presencia del público. Las autoridades son quienes se encargan de aplicar la pena al infractor, sin tocar demasiado su cuerpo, sin torturarlo hasta el cansancio, solo colocándolo en el aparato y dándole una muerte casi inmediata. Con este tipo de castigo se conservan rasgos del suplicio, no teniendo el mismo impacto, pero llegaban al mismo fin, siendo este la muerte del criminal.

Más adelante, las cárceles y la privación de la libertad comienzan a tener una mayor relevancia como herramienta de castigo. Con este tipo de sanción se pone énfasis en tocar lo menos posible el cuerpo del infractor, buscando herir algo más que su corporalidad. Sin embargo, con el encierro de los criminales, sus cuerpos aún se veían afectados:

Se dirá que la prisión, la reclusión, los trabajos forzados, el presidio, la interdicción de residencia, la deportación -que han ocupado un lugar tan importante en los sistemas penales modernos- son realmente penas "físicas" que, a diferencia de la multa, recaen, y directamente, sobre el cuerpo. Pero en ellas la relación castigo-cuerpo no es idéntica a la de los suplicios. El cuerpo se encuentra aquí en situación de instrumento o de intermediario y, si se interviene sobre él encerrándolo o haciéndolo trabajar, es para privar al individuo de una libertad considerada a la vez como derecho y un bien. El cuerpo según esta penalidad, queda prendido en un sistema de coacción y de privación, de obligaciones y de prohibiciones. El sufrimiento físico, el dolor del cuerpo mismo, no son ya los elementos constitutivos de la pena (Foucault, 2009: 20). 
El autor dice que con este tipo de castigos el cuerpo se ve afectado por las condiciones de las instituciones carcelarias. Dentro de estas, se racionan los alimentos, se priva sexualmente a los individuos, se genera tensión entre los internos, lo que puede llevarlos a actos violentos en los que se han de golpear entre sí, además de la oscuridad de la vida dentro de las celdas. Aun con todo esto, Foucault, dice que el castigar con la privación de la libertad, refleja condiciones de desigualdad con el exterior, pese a las malas condiciones dentro de las cárceles, los presos "pasan menos hambre, menos frío, se encuentran menos privados, que muchos pobres o incluso obreros" (Foucault, 2009: 25), lo cual genera una fuerte crítica, pues “es justo que un condenado sufra físicamente más que los otros hombres" (Foucault, 2009: 25). Por lo que se ha de pretender que los castigos no sean divorciados a la totalidad del dolor físico, además de esperar que se castigue algo más en el individuo.

Como se ha venido diciendo, las nuevas modalidades de castigo, dejan de ser directamente corporales, teniendo otros efectos. Se dice que, con la privación de la libertad, se remite a castigar el "alma” del individuo: “A la expiación que causa estragos en el cuerpo debe suceder un castigo que actúe en profundidad sobre el corazón, el pensamiento, la voluntad, las disposiciones, ...los jueces, poco a poco, pero en un proceso que se remonta muy lejos, se han puesto a juzgar otra cosa distinta que los delitos: el "alma" de los delincuentes" (Foucault, 2009: 26-28). Con este sistema se pretende aplicar penas que afecten la vida del individuo más que su cuerpo, y a la vez, manteniendo aquella exigencia de castigar con humanidad.

En este nuevo sistema el verdugo que antes se encargaba de torturar es sustituido por grupos de técnicos: vigilantes, médicos, psiquiatras, psicólogos, educadores, etc., que se encargan de hacer cumplir la "reformación" social del infractor, puesto que ya no se pretende desaparecer al individuo acabando con su vida. Se piensa que estos profesionales "garantizan que el cuerpo y el dolor no son los objetivos últimos de su acción punitiva" (Foucault, 2009: 20). Aspectos de esta modalidad, bien los podemos encontrar en nuestro estudio de caso, aun cuando hablamos de contextos diferentes. El control de las personas en situación de reclusión, está en manos de distintos profesionales (quienes rinden cuentas a un mismo organismo), que se supone, se encargan de la readaptación social de los imputados. 
Retomando al autor, se dice que en esta nueva etapa hay ocasiones en las que, dependiendo de la gravedad del delito cometido y la región, se considera que se aplican sanciones que conservan aspectos del suplicio corporal, no con la misma magnitud que en siglos previos, pero sí con el resultado de la muerte del infractor. Por ejemplo, la pena de muerte con inyección letal en Estados Unidos o bien, en algunos casos, en esta misma región hay algunos presos que prefieren culminar su sentencia en la silla eléctrica, en vez de ser asesinados con la inyección letal, pues al parecer el sufrimiento es mayor con esta última.

El objetivo de castigar con estos medios "modernos", según Foucault, ya no parte del sentimiento de venganza como en las sociedades tradicionales, sino que la nueva preocupación es conocer al criminal, comprender los motivos por los que incurrió en la falta, y a partir de esto, intervenir para corregirlo. Se trata de formar individuos "normales", moldearlos y volverlos dóciles, dejando de lado las dolorosas sanciones corporales. "Naturalmente, damos (jueces) un veredicto; pero, aunque haya sido éste provocado por un delito, ya están ustedes viendo que para nosotros funciona como una manera de tratar a un criminal; castigamos, pero es como si dijéramos que queremos obtener una curación” (Foucault, 2009: 31).

Castigar con la privación de la libertad se pretende emplear como remedio para una enfermedad, para corregir una condición anormal por la que los individuos pasan. Actualmente los sistemas carcelarios se dice que continúan persiguiendo este fin como resultado del encierro de individuos infractores. Sin embargo, es cuestionable su funcionalidad, pues, como se irá planteando más adelante al entrar a nuestro estudio de caso, para los sistemas carcelarios no es tan relevante conocer las motivaciones por las que se cometieron las faltas, pero sí señala a los individuos como inadaptados. Y las funciones esperadas de las cárceles quedan solo como objetivos sin cumplir.

Esta nueva modalidad de castigo, más allá del alcance de sus objetivos, como se hizo mención en líneas previas, se trata de una "táctica política", localizada en las relaciones de poder (Garland, 1999). Para Foucault, en las cárceles se promueve "un esfuerzo para ajustar los mecanismos de poder que enmarcan la existencia de los individuos; una adaptación y un afinamiento de los aparatos que se ocupan de su conducta cotidiana [de los criminales], de su identidad, de sus gestos aparentemente sin importancia, y los vigilan; una política distinta 
respecto de la multiplicidad de cuerpos y de fuerzas que constituye una población" (Foucault, 2009: 90-91).

Mediante el poder que tienen las autoridades se controla la vida de los internos, bajo reglas y normas establecidas formal o informalmente dentro de las instituciones carcelarias. Los individuos se ven obligados a reproducir ciertos comportamientos y actividades que son aceptados en el entorno carcelario, y es por ello que, con la finalidad de adaptarse, los imputados desarrollan las diversas estrategias de sobrevivencia que nos interesa identificar en este trabajo. Lo cual no significa que los infractores, al concluir con su sentencia estarían exentos de incurrir nuevamente en actos delictivos que los hagan volver al recinto carcelario.

El poder que tienen las autoridades en los sistemas carcelarios puede llegar a ser demasiado, denominado por el autor como un "sobrepoder". Este concentrado puede llegar a intensificar los conflictos internos dentro de las cárceles, lo que lleva a la no consumación y al fracaso de los objetivos de estas instituciones. Sin embargo, para Foucault paradójicamente sus fracasos son los que mantienen con vida este nuevo medio de castigo (Díaz, 2007). Tal afirmación es justificada por el autor desde dos circunstancias: La primera es que la cárcel está fuertemente ligada a la cultura de los últimos dos siglos, resaltando que los sistemas carcelarios no han percibido fuertes cambios hasta la actualidad (aquí lo aplicamos hasta nuestros días). Las cárceles desempeñan funciones precisas, se destaca la importancia social de la existencia del delito y el castigo (Díaz, 2007).

La creación de la delincuencia es útil socialmente como estrategia política, la cual trata de hacer una división social de las clases trabajadoras, imponiendo el temor por la prisión y enfatizando el poder de las autoridades. Según Foucault, con la creación de la prisión, se hace posible identificar a los presuntos criminales, además, es la misma cárcel la que crea la imagen del delincuente. El autor considera que es útil para la sociedad el poder definir un perfil del delincuente, pues esto permitiría anticiparse al crimen. Esto recae en la estigmatización ${ }^{22}$ de individuos que quizás no sean criminales, pero por sus características podrían llegar a ser señalados.

22 Un estigma, según Goffman son atributos, rasgos, condiciones o comportamientos que excluyen a un individuo. Se pueden mencionar tres diferentes tipos de estigma, el primero refiere a características 
Por último, respecto a este autor, cuestiona el por qué la cárcel se pudo imponer como la nueva medida correctiva, lo cual responde diciendo que:

En mi opinión, la prisión se impuso simplemente porque, era la forma concentrada, ejemplar, simbólica, de todas estas instituciones de secuestro creadas en el siglo XIX [...] En el gran panoptismo ${ }^{23}$ social cuya función es precisamente la transformación de la vida de los hombres en fuerza productiva, la prisión cumple un papel mucho más simbólico y ejemplar que económico, penal o correctivo. La prisión es la imagen de la sociedad, su imagen invertida, una imagen transformada en amenaza (Foucault, 1998: 137, en Díaz, 2007: 153).

Para el autor, el encierro provoca la reincidencia. Cuando los acusados abandonan la prisión, tienen una gran probabilidad de volver a ella.

La prisión no puede dejar de fabricar delincuentes. Los fabrica por el tipo de existencia que hace llevar a los detenidos; ya se los aísle en celdas o se les imponga un trabajo inútil, para el cual no encontrarán empleo, es de todos modos "no pensar en el hombre en sociedad; es crear una existencia contra natura inútil y peligrosa”; se busca que la prisión eduque a los detenidos... La prisión fábrica también delincuentes al imponer a los detenidos coacciones violentas; está destinada a aplicar las leyes y enseñar a respetarlas; ahora bien, todo su funcionamiento se desarrolla sobre el modo de abuso de poder (Foucault, 2009: 308-309).

Es así, que hay que destacar que para Foucault el estudio de los sistemas carcelarios es algo extenso y complejo que se determina desde diversos factores, y que sus efectos no son los esperados. Por lo que, incluso hace una ligera critica a lo expuesto por Durkheim respecto al tema. Foucault advierte que limitarnos a estudiar las formas sociales generales, nos hace correr el riesgo de tener como punto de partida un sentido de suavizamiento de los procesos

corporales, el segundo a defectos en el carácter del individuo y el último a los tribales de la raza, la nación y la religión (Goffman, 1997: 16)

${ }^{23}$ El panoptismo es una figura arquitectónica de control y vigilancia de los anormales. Su principio es conocido: en la periferia, una construcción en forma de anillo: en el centro, una torre con anchas ventanas que se abren en la cara interior del anillo. La construcción periférica está dividida en celdas, cada una de las cuales atraviesa todo el ancho de la construcción. Tienen dos ventanas, una hacia el interior, correspondiente a las ventanas de la torre, y otra hacia el exterior, que permite que la luz atraviese la celda de lado a lado. Basta entonces situar un vigilante en la torre central y encerrar en cada celda a un loco, un enfermo, un condenado, un obrero o un escolar. Por el efecto de contraluz, se pueden percibir desde la torre, recortándose perfectamente sobre la luz, las pequeñas siluetas cautivas en las celdas de la periferia. Tantos pequeños teatros como celdas, en los que cada actor está solo, perfectamente individualizado y constantemente visible. El dispositivo panóptico dispone de unidades espaciales que permiten ver sin cesar y reconocer inmediatamente. En suma, se invierte el principio del calabozo: o, más bien, de sus tres funciones - encerrar, privar de la luz y ocultar-: no se conserva más que la primera y se suprimen las otras dos. La luz plena y la mirada de un vigilante captan mejor la sombra, que en último término protegía. La visibilidad es una trampa (Foucault, 2009: 232). 
penales, lo que, para el autor, en realidad es el resultado de las tácticas de poder desarrolladas por el Estado (Foucault, 2009).

A manera de conclusión de este apartado (1.3), tratar de comprender el tema del castigo y los sistemas penales conforme a estos dos autores, es ser enriquecedor por lo contrastante de algunas de sus propuestas. En el caso de Durkheim, enfatiza sus estudios del tema desde la problematización del castigo en sus diferentes etapas con la concepción de la moralidad y la conciencia social. El autor da un importante peso al reconocimiento de los castigos partiendo de las sociedades tradicionales, en donde la concepción de lo "sagrado" nos da una idea de cómo se formula la percepción de delito y por qué éste se castiga. La división que se hace de las etapas del castigo en el ensayo de las Dos leyes de la evolución penal de este autor, logra dar una idea de la transición de los sistemas penales como castigo en las sociedades modernas, además de estar vinculado con lo que posteriormente plantea Michel Foucault.

Por su parte, Foucault da una mayor importancia al conocimiento de la historia que atraviesa la evolución del castigo y los sistemas penales, que, partiendo de penas aterradoras como el suplicio y el exhibicionismo social, logran cambiar a medios de control individual como la privación de la libertad. Con este autor no es tan relevante la comprensión del castigo desde la moralidad, ni tampoco desde las percepciones sagradas implicadas en los hechos. Desde el enfoque de este autor, es importante entender cómo fue la concepción de lo que se conoce como delincuente, siendo que las instituciones carcelarias no descubren a este actor, sino que lo crean por las condiciones que constituyen a las instituciones carcelarias.

Por otro lado, las ideas de uno y otro autor no están peleadas. Se encuentra concordancia en varios puntos. Por ejemplo, en ambos está la ideología de que para poder analizar a las sociedades resulta prospero comprender la conformación de los sistemas penales, pues en éstos se reflejan y representan varias de las problemáticas que imperan en las sociedades modernas. Por otra parte, los dos autores señalan el sentido de venganza que motiva a las autoridades y/o pueblos a promover castigos con los cuales reivindicar a los transgresores, así como hacer que el resto de la sociedad haga conciencia y adopte temor de las posibles consecuencias de transgredir las normas establecidas.

Es importante advertir que los estudios de ambos autores son en la sociedad francesa, en donde la evolución de los sistemas carcelarios surge desde cierto ritmo, distinto al de las 
sociedades latinoamericanas. En este trabajo, el tema central es enfocado en la sociedad mexicana, pero se irán rescatando algunos de los aspectos propuestos por los autores para localizar los elementos necesarios para el análisis sobre los procesos de socialización y las estrategias de sobrevivencia de mujeres indígenas y mestizas que se encuentran recluidas en el penal de "Santiaguito". Por lo que para este estudio es importante conocer la conformación del Estado Nación Mexicano y con él las diversas desigualdades sociales presentes en nuestra sociedad, cómo se representan y qué efectos tienen éstas en las actoras dentro de los recintos carcelarios, bajo los elementos de control que promueve el Estado moderno. 


\section{El Estado Nación en México. Antecedentes de un conjunto de desigualdades}

En México, así como en los diversos países que conforman América Latina, se concentra una gran cantidad de desigualdades sociales, determinadas principalmente por la clase social, raza y género de cada persona. Estas disparidades las encontramos en todos los ámbitos de la vida social de los individuos, posicionando a una gran mayoría de la población en lugares de mucha desventaja frente a otros grupos que son minoritarios, estos últimos poseen privilegios y poder sobre los otros. Son muchas las personas que se encuentran subordinadas a consecuencia de esto, y que, además, en algunos casos se enfrentan a situaciones de vulneración por parte de las autoridades.

Esta problemática no es un asunto reciente pues su existencia parte de diversos procesos históricos que dieron vida a la consolidación de un Estado Nacional mexicano. Es así, que en este capítulo se exponen inicialmente, algunas definiciones generales de lo que es un Estado Nación. Posteriormente, se describe cómo se fue consolidando esta forma de organización política en nuestro país y cómo se fueron permeando las desigualdades mencionadas durante este proceso en la población mexicana, además de los efectos que pueden llegar a tener en los integrantes de ciertos grupos en diversos entornos.

Hablar del tema es importante para este trabajo pues se considera que uno de los entornos en donde podemos identificar gran parte de las desigualdades mencionadas, es en el sistema carcelario. Medio en donde pretendemos identificar los aspectos de interés en nuestro estudio de caso, pensando en que las diferentes estrategias de sobrevivencia que desarrollan mujeres indígenas y mestizas recluidas en "Santiaguito", tienen mucho que ver con la manera en que impactan en los procesos de socialización las disparidades por condición de género, raza y clase social, consolidadas a partir de la constitución del Estado Nacional Mexicano y que se pueden representar en sistemas como el carcelario.

Dicho lo anterior, respecto al "Estado Nación", existen varias definiciones generales, que comparten algunos elementos para su construcción. Por ejemplo, para Max Weber, se trata de "aquella comunidad humana que en el interior de un determinado territorio reclama para sí el monopolio de la coacción física legitima" (Weber, 2012: 662), es "el monopolio legítimo de la violencia" (Weber, 1919 en Talancón, 2009: 386). El autor destaca que uno de los elementos de esta organización política es la demarcación territorial. Además, en un Estado 
se demanda la concentración de poder en un solo ente, el cual está facultado por la misma sociedad para hacer uso de la fuerza y violencia física sobre los individuos de determinado grupo.

Para el autor el poder que tiene el Estado está por encima del que pueden llegar a tener los individuos. Esta organización política es un medio de dominación, siendo esto último algo de mucha importancia para su legitimidad. Para ello, Weber distingue tres principales tipos de dominación: La primera es la tradicional, se dice que esta sucede cuando el poder recae en el "señor" y sus facultades son heredadas. Se trata principalmente de la relación "soberano"- súbdito, colocando a al segundo en un lugar de desventaja y desigualdad frente al primero. En este caso, es la tradición la que le da fuerza y facultad al dominador (Weber, 2012).

El segundo tipo de dominación es la carismática ${ }^{24}$, ésta adquiere reconocimiento por "corroboración" de las cualidades que se identifican en el sujeto. Este es un reconocimiento psicológico que genera; entrega, fe, entusiasmo y empatía de los seguidores hacia el que domina por este medio. Por último, el tercer tipo es la dominación racional o legal, para el autor este tipo de dominación es la que integra al Estado y obtiene legitimidad a partir de ciertas ideas; una es la aplicación de reglas en casos concretos y para la adecuada convivencia (Weber, 2012).

Otra idea es que debe existir una "persona puesta a la cabeza" (Weber, 2012: 174), es quien ordena y manda a los subordinados. Además, debe haber alguien que obedezca los mandatos del soberano. La obediencia no es personal hacia quien domina, sino que se acatan mandatos conforme a las reglas impuestas y solo dentro del entorno en donde se ubiquen los individuos (Weber, 2012). En este sentido, es el Estado quien representa al ente dominador, quien posee el poder ante los otros, el que ordena y administra, apoyándose de instituciones que poseen legitimidad por el grupo social (instituciones como las cárceles).

\footnotetext{
${ }^{24}$ Carisma: cualidad que pasa por extraordinaria (condicionada mágicamente en su origen, lo mismo si se trata de profetas que de hechiceros, árbitros, jefes de cacería o caudillos militares), de una personalidad por cuya virtud se la considera en posesión de fuerzas sobrenaturales o sobrehumanas, o como enviados del dios, o como ejemplar y, en consecuencia, como jefe, caudillo, guía o líder. El modo como punto de vista ético, estético u otro cualquiera, es cosa del todo indiferente en lo que atañe a nuestro concepto, pues lo que importa es cómo se valora "por los dominados" carismáticos, por los "adeptos" (Weber, 2012: 193).
} 
Otra definición, no tan clásica es la de Silvia Bénard"25 quien dice que "un Estado Nacional presupone la existencia de una población que vive en un territorio delimitado y que se gobierna por un Estado. La vida en nación no se limita a las formas concretas de la cotidianidad; va más allá de los grupos pequeños como la familia, la iglesia o el barrio que se caracterizan por interacciones cara a cara" (Bénard, 1998: 58). Se trata de un medio amplio y externo a los que comúnmente estamos inmersos los individuos.

Desde el momento del nacimiento, como parte de nuestro proceso de socialización (véase apartado 1.1, capitulo 1), iremos interiorizando todo aquello referente al Estado que nos representa, esto, dependerá mucho de la ubicación territorial a la cual pertenezcamos. La relación con este ente no es directa como si conviviéramos con otros individuos, sino que tenemos conocimiento de su existencia y damos reconocimiento de nuestros derechos y obligaciones a partir del sentido de pertenencia que adquirimos y desarrollamos como grupos sociales. Esto, según Bénard es mediado por el Estado y nosotros somos quienes lo legitimamos.

Respecto a lo anterior, Aníbal Quijano, dice que la legitimación del Estado se deriva de "una identidad nacional común de los habitantes de tal espacio de dominación, hasta tanto sean estables los elementos fundantes del Estado- Nación" (Quijano, 2014: 617). Se trata de ideales compartidos e impuestos hacia los integrantes del grupo social, los que dan la legalidad a la conformación de un Estado. Además, los elementos principales que componen esta organización política son: un espacio en donde dominar (territorio) y un patrón de explotación- dominación- discriminación (desde fundamentos capitalistas), esto es, alguien que subordine a los otros.

A partir de las definiciones expuestas, como se dijo antes, podemos encontrar elementos importantes que se comparten para la constitución de un Estado Nación. En los tres casos, tenemos que debe existir un territorio, una población que ocupe este espacio y que además serán los subordinados. Y, por último, debe haber alguien que posea el poder de mandar y organizar a los otros. Se trata de una relación de poder más que una cuestión de identidad

\footnotetext{
${ }^{25}$ Profesora Investigadora en la Universidad de Aguascalientes
} 
(según Quijano). Esta organización es compleja, pues sus efectos y funcionalidad dependen del entorno y el contexto en donde la observemos.

\subsection{Estado Nación Mexicano y la diferenciación de raza}

Los primeros Estados Nacionales modernos se constituyeron en Europa, en un proceso que casi iba a la par con el capitalismo, derivado del patrón eurocéntrico de poder que predominaba en las sociedades de este periodo. Referente a esto, Aníbal Quijano (2014) ubica dos principales etapas: la primera va desde finales del siglo XV hasta fines del siglo XVIII, y la segunda desde este último hasta nuestros días. Según el autor, la primera etapa es un proceso de enfrentamiento de los dominadores de los nuevos intereses sociales con el Sacro Imperio Romano- Germánico y el papado, y la lucha por la definición de los espacios particulares de dominación (Quijano, 2014: 617-618).

Por otro lado, la segunda etapa es la maduración y depuración del patrón del poder, a la constitución de la ciudadanía y de la democracia, a la lucha por la definición final y estabilización de los espacios de dominación frente a los imperios europeos en crisis, en particular desde fines del siglo XIX y las primeras décadas del XX (Quijano, 2014: 618). Esto como la de consolidación de poder mediante un proceso "legal", en el que los dominantes han de aprovechar las debilidades de otros. Es así que, fueron muchos los grupos que intentaron constituir los Estados Nación, sin embargo, pocos lograron reunir las condiciones propias para hacerlo.

En este proceso se enmarcan las desigualdades en las relaciones de poder, del control de recursos, instituciones y mecanismos de poder político, así como distinciones sociales. Las sociedades con mayor homogeneidad racial tuvieron mayor éxito en la conformación de los Estados Nación. En cuanto a esto, Quijano hace referencia a algo que dice Tocqueville, esto es que los individuos que eran difíciles de integrar a esta forma de organización eran "negros" e "indios" (Tocqueville en Quijano, 2014: 619). Como ejemplo de esto, se tiene que en América Latina la distinción de razas tuvo un mayor peso, puesto que se pretendía homogeneizar a la población, lo que implicó un proceso en donde se debía de exterminar a los "indios". 
Es así, que en México como en la mayoría de países del territorio latinoamericano, el proceso se vivió desde la época colonial, contexto en donde se pretendía acabar con el "atraso" que implicaban los grupos indígenas de la zona. Cabe mencionar que estos hechos los seguimos viviendo con gran fuerza hasta nuestros días. Es el mismo Estado mexicano quien aparta y excluye a los grupos indígenas, y no solo a estos, sino que también, a otros que, por diversas condiciones como el género y la clase social, son colocados en lugares de desigualdad y vulnerabilidad característicos de nuestra historia.

Las desigualdades en el territorio mexicano comienzan a enmarcarse intensamente desde la invasión europea en nuestro país. Al principio, como parte de este proceso se desmantelaron las instituciones políticas y religiosas con que estaban organizadas las poblaciones indígenas. En lugar de éstas, se impusieron las de origen europeo y cristiano que se combinaron con lo que quedaba de las ideologías tradicionales (Florescano, 1996). Estas arbitrariedades derivaron desde la creencia española de que su cultura era superior a las del territorio americano y por ello debían de civilizar a los pueblos indios, exterminando todas aquellas costumbres y pensamientos que implicaran atraso.

Al respecto, Enrique Florescano (1996) explica que un elemento importante que impulsó la colonización en nuestras tierras fue la propagación de la fe, creencias impuestas por medio de órdenes religiosas como: los franciscanos, jesuitas, agustinos y dominicos. De estos, son varios los llamados misioneros encargados de evangelizar a los indios, bajo la idea de que España solo cumplía con la tarea providencial de hacer de estos seres gente civilizada. Algunos de los propagadores religiosos, consideraron a los indígenas con cualidades adánicas $^{26}$, seres dóciles, simples y conformes con una vida de pobreza (Florescano, 1996).

Esta imagen del indio es definida por el fraile Pedro Juan de Escobar, quien dijo que "Todos los indios son como pajarillos en el nido, a quienes no han salido alas, ni les saldrán del todo para que por sí puedan volar. De donde tienen necesidad que sus padres les lleven al nido cuanto han menester...” (Florescano, 1996: 160). En este caso, los padres de las aves son aquellos religiosos quienes supuestamente se harán cargo de evangelizar a los pueblos del territorio dominado y, además, los misioneros han de implantar una falsa idea de protección

\footnotetext{
${ }^{26}$ De Adán en su categoría de primero, que estrena el mundo, según la Biblia, o relacionado con él. Véase: https://es.oxforddictionaries.com/definicion/adanico
} 
de defensa y seguridad. Haciendo creer que su dios cristiano traerá a los indígenas orden y armonía a sus vidas.

La tendencia paternalista con la que solo los frailes podían educar a los indios, representando la imagen de padres y maestros que por derecho natural, divino y humano estaban facultados para profesar su religión y con ello crear la "perfección nunca antes alcanzada por alguna raza en la tierra" (Phelan, 1972 en Florescano, 1996: 161), colocaba a los indígenas como si fueran la arcilla perfecta para moldear seres correctamente cristianos. Para esta adaptación, Florescano dice que, en lo general, en los pueblos había dos tipos de habitantes: unos eran pobladores fijos como: sacerdotes, algunos soldados, indios lugareños y niños que se encontraban a cargo de los misioneros. Y, por otro lado, indígenas que solo iban de paso, permanecían unos días y después volvían a sus lugares de origen a ocuparse en actividades en las que se les había congregado.

El autor dice que este fue un proceso que implicó la fragmentación y desajustes de la estructura social de las poblaciones originarias. Se pretendía terminar con estas, cambiando todo aquello que era propio de las comunidades. Un cambio tal que le permitiera a los invasores obtener beneficios de la región que se estaban apropiando. El exterminio de la población indígena no solo provino del despojo de sus creencias, sino que, oportunamente, durante el siglo XVI se vivieron sucesos como la llegada de múltiples epidemias, que, sin el uso de violencia física por parte de los invasores, acabaron con la vida de muchos indígenas, implicando la extinción de varias de las antiguas aldeas (Florescano, 1996).

Los indígenas sobrevivientes a las graves enfermedades fueron colocados en nuevos sistemas de trabajo impuestos por los españoles. Lo que provocó que gran parte de los pobladores abandonaran sus comunidades para ser empleados en actividades agrícolas, mineras, artesanales y urbanas, que más bien eran una forma de esclavizar a esta población (Florescano, 1996). Para esto, además de ser arrancados de sus tradiciones y de verse obligados adoptar ideologías religiosas extranjeras, muchos se tuvieron que adaptar a las labores impuestas con el fin de recibir alimentos, aun cuando no percibían un salario y además debían dejar de lado sus propias reglas, normas y valores para cumplir con lo establecido por los invasores. 
Además, otro supuesto beneficio para la población indígena en las congregaciones era que los misioneros ponían a laborar a las personas al cuidado y maquila de sus rebaños de vacas, mulas, borregos y chivos. De estos, además de obtener productos alimenticios, se aprovechaban más productos derivados. Se crearon talleres para tejer lana y algodón, con lo que también se vestía a los frailes y a los indígenas, y el resto de la producción era vendida en los reales de minas cercanas, poblados mestizos y sitios de presidio. Los beneficios de estas actividades, tales como la alimentación, así como se mencionó líneas previas, fueron el anzuelo para atraer a los indígenas a acercarse a las misiones (Florescano, 1996).

En este mismo siglo, además de las misiones, otro de los principales elementos del proceso de dominación, fue que las autoridades dispusieron que se agrupara a los indígenas en asentamientos urbanos con características europeas. Respecto a esto, Florescano cita a Bernardo García Martínez, quien dice que "las congregaciones de la población india fueron una de las manifestaciones más visibles, y sin duda la más espectacular, de la voluntad de los españoles por imponer e inculcar sus principios y valores en la sociedad que habían logrado dominar" (García, 1987 en Florescano, 1996: 151). Otros personajes durante el proceso dieron un sentido diferente a las concentraciones indígenas, esperando que no solo se tuvieran efectos positivos para los invasores, sino que también en los indios.

Es así que, Vasco de Quiroga desde una perspectiva algo utópica, propone en 1531 que se congregara a los indígenas en poblaciones, "donde trabajando e rompiendo la tierra, de su trabajo se mantengan y estén ordenados en toda buena orden de policía y con santas y buenas católicas ordenanzas... hasta que por tiempo hagan hábito en la virtud y se les convierta en su naturaleza" (Quiroga en Florescano, 1996: 162). El plan propuesto consistía en que el control de las poblaciones indígenas fuera mayormente pacífico y su éxito recayera en la promoción e implantación de pensamientos, hábitos y actitudes distintos en los pueblos indígenas, que al final de cuentas continuarían siendo la muestra evidente del poder de los invasores en las "nuevas tierras".

De este modo, en las congregaciones, según Quiroga, la organización de las comunidades se completaría con la debida doctrina y práctica del cristianismo. Así, se suministraría de los valores necesarios para que "esta primitiva, nueva y renaciente iglesia de este Nuevo Mundo, una sombra y dibujo de aquella primitiva iglesia de nuestro conocido mundo del tiempo de 
los santos apóstoles" (Quiroga en Florescano, 1996: 162). Es decir, con la adopción de nuevas características en lo político, laboral, social y religioso, se acabaría con todo lo "atrasado" que las comunidades tradicionales preservaban y que no eran compatibles con el proyecto de los dominantes españoles, pero con la ideología de Quiroga sería por medio de herramientas de reeducación y no de la aplicación de violencia directa.

Se dice que el proceso que se desarrolló en estas concentraciones fue de hispanización de la vida individual, familiar y colectiva de los pueblos indígenas. Sin duda, se pretendía arrancar a los indios de todo lo que distinguía a sus culturas, o al menos eso se esperaba. Los invasores buscaban que los indígenas adoptaran nuevos hábitos alimenticios, ideologías religiosas, gobierno y modos de vestir, todo al estilo europeo. Sin embargo, es preciso mencionar que, aunque fue fácil someter a algunos grupos, otros cuantos se resistieron a vivir bajo la tutela de los españoles y a adquirir todo eso que se les quería imponer. Es esta resistencia la que llevó a la sobrevivencia (véase capítulo 1, apartado 1.2) de los pueblos tradicionales.

La preservación de estos pueblos consistió en mantener con vida muchos de los conocimientos y la sabiduría que por tradición caracterizaba a estas comunidades y que resaltaba la calidad de sus trabajos. Florescano dice que: "Los agricultores indígenas, herederos del saber ancestral sobre los ciclos climáticos, tipos de suelo, uso de plantas y bosques, selección de semillas, técnicas de cultivo, manejo del agua y preparación de alimentos, fueron el sostén de la primera sociedad colonial" (Florescano, 1996: 156). Todo el saber de estos pueblos fue lo que dio un gran valor a su trabajo, incluso, el autor considera que, de todo el reino, los indios eran quienes se esforzaban más.

Los conocimientos de la gente de los pueblos fueron despojados y robados, ya que pese a la consideración española de que su cultura era avanzada, en momentos de crisis recurrían a saberes de los pueblos. Adaptándolos al grupo dominante, haciéndolos propios y sin dar reconocimiento a los orígenes, sino todo lo contrario, se negó la importancia de los aportes indígenas, haciéndolos ver como actividades negativas. Además, se propagó la imagen de "un indio vicioso, reacio al trabajo, apático a los estímulos externos e ignorantes" (Florescano, 1996: 157). Según los invasores, ellos se encargaban de recrear y mejorar las culturas del "Nuevo Mundo" y si los indígenas tenían progresos era gracias al buen trabajo civilizador de los actores españoles. 
Las misiones y las congregaciones aun con sus amplias similitudes, hay que mencionar que, en las primeras, los indígenas no sufrían malos tratos, ni maltrato físico directamente, pero vivían bajo la cotidiana coerción de adoptar en sus vidas el conjunto de nuevas costumbres, maneras de vestir, formas de hablar y de trabajar, acostumbrarse a formas distintas de alimentación al estilo europeo de los invasores. El autor dice que todo esto tenía como finalidad "reproducir la vieja Europa en el Nuevo Mundo" (Florescano; 1996: 168). Se quería reflejar la cultura española en tierras americanas como si se tratara de la extensión o ampliación del territorio europeo. Sin embargo, las imposiciones no fueron totales en la población indígena como se esperaba.

Durante el proceso los indígenas no abandonaron por completo lo adquirido en sus culturas, pero sí se apropiaron de técnicas de los invasores. Esto debido a que se vieron obligados a construir iglesias, monasterios, casas reales y señoriales, y ciudades completas, que además decoraron con pinturas, esculturas y mobiliarios al gusto de los españoles. Hechos como este se siguen presenciando actualmente en nuestro país, solo que ahora somos los mestizos (la diferenciación de castas se describe más adelante) quienes principalmente imponemos comportamientos y valores a los grupos indígenas, según los entornos en donde se les identifique, y estos en vez de abandonar sus saberes los combinan con los nuevos, un ejemplo de esto es el lenguaje, el cual han de emplear según el entorno en donde se encuentren. Este tipo de implantaciones tuvieron y tienen un fuerte impacto en los procesos de socialización y en la cultura que caracterizaba a los pueblos indígenas de lo que hoy es México.

Congregar a los indígenas como se hizo provoca que se identifiquen tres principales consecuencias en los pueblos. La primera implicó, según Florescano, una triple barrera: territorial, étnica y lingüística, debido a que en los territorios en donde se les concentró a los indígenas no se incluía a personas blancas, negros y de nuevas castas, sino que solo eran espacios de exclusión social específicos para la comunidad indígena (Florescano, 1996). La segunda consecuencia parte de que los "nuevos gobernantes" expidieran leyes, nombraran jueces y constituyeran tribunales especiales, dirigidos a la supuesta protección de los pueblos con un sentido paternalista. Que más bien, eran herramientas para validar y reafirmar su poder y autoridad con la población de las nuevas tierras. 
Por último, la tercera consecuencia se debió a la disminución de los indígenas en los pueblos, lo que determinó y sustentó su existencia como mecanismos de fuerza de trabajo que estaría subordinada a los mandatos de los invasores, lo que se dirigiría a impulsar y beneficiar a la economía española, principalmente (Florescano, 1996). Con el desarrollo de este proceso, se hizo notorio, además de la merma de la población indígena, el incremento de nuevos grupos, con los que se enmarcaron cada vez más las diferencias sociales de cada uno de estos.

Había grupos superiores y otros inferiores, estos últimos sometidos a la voluntad de los de más alta escala. Florescano citando a Luis Villoro, dice que "El indio queda plasmado en distintas formas según sea el grupo que solicita su ayuda. Está entregado al otro, a su merced. Lo aderezan desde fuera, desde fuera lo arreglan, lo presentan, le hacen decir discursos y representar papeles" (Villoro, 1950 en Florescano, 1996: 168). Aun cuando en esta parte del proceso se comenzaron a enmarcar ciertas desigualdades, no significa que antes no las había.

Florescano señala que en este periodo se acentuaron algunas diferencias ya existentes en la organización social de los pueblos. Ejemplo de esto es el lugar en la jerarquía social que ocupaban las mujeres y los hijos en los grupos. "La estructura familiar y social de los pueblos de indios nunca tuvo rasgos igualitarios y armoniosos que más tarde le descubrirían algunos anarquistas... nada en las fuentes nahuas o españolas justifica la interpretación de que la sociedad indígena fue igualitaria en el pasado" (Florescano, 1996: 153). Se dice que la desigualdad y la miseria ya eran condiciones comunes de muchos de los pueblos indígenas de ese siglo, pero se vinieron a hacer más fuertes a lo largo del proceso de consolidación de un Estado Nacional debido a la creación de los diversos grupos de castas.

Desde el siglo XVI con la invasión europea la estructura social existente se fue modificando por la llamada distinción de $\operatorname{castas}^{27}$, teniendo efectos incluso hasta nuestros días. Florescano dice que la creación de estas diferencias en la población de la "Nueva España", fue el fruto de relaciones sexuales no formalizadas. El resultado de la mezcla de los genes de diferentes culturas llevó a la conformación de prácticas como la discriminación de grupos y la acentuación de nuevos prejuicios sociales. A la par con la consumación de estas distinciones

\footnotetext{
27 Seres humanos vistos como cuerpos humanos anómalos, forzados a presentarse y representarse por sus rasgos físicos como: color de piel, tipo de cabello, la carnosidad de sus labios, los pliegues de sus parpados etc. (López, 2008: 209).
} 
raciales, se desarrolló una ideología de blanqueamiento, recordando que se consideraba que la cultura europea era superior por características como el color de piel claro.

Con la mezcla de genes se pretendía "purificar" las ramas familiares, se aspiraba revertir o acabar con las tonalidades oscuras de la piel de los grupos "primitivos", mejorando su calidad haciéndola cada vez más clara. Es así que la distinción de castas tuvo un impacto muy fuerte en la organización social de la "Nueva España" y durante todo el proceso de conformación del Estado Nacional Mexicano. Las distintas razas se fueron creando dependiendo de la combinación cultural sucedida en este territorio. Alexander Humboldt (1966), describe el resultado de estas mezclas de la siguiente manera:

La población mexicana está compuesta de los mismos elementos que la de las demás colonias españolas. Hay siete castas distintas: 1) Los individuos nacidos en Europa, llamados vulgarmente gachupines; 2) Los españoles $\operatorname{criollos}^{28}$, o los blancos de raza europea nacidos en América; 3) los mestizos descendientes de blancos y de indios; 4) los mulatos descendientes de blancos y de negros; 5) los zambos descendientes de negros y de indios; 6) los mismos indios, o sea la raza bronceada de los indígenas, y 7) los negros africanos (Humboldt, 1966 en López, 2008: 293).

Humboldt explica que, al hijo de un blanco, ya sea criollo o español con una indígena era denominado mestizo (grupo predominante en nuestro país). El color de éste es casi perfectamente blanco, poca barba, manos y pies pequeños, y una ligera oblicuidad en los ojos. Si una mestiza se casaba con un europeo, el resultado de la unión sería muy cercano a la raza española. Por otro lado, los hijos de blancos con negras son conocidos como mulatos. A los hijos de negros con indígenas se les llamó zambos. De la mezcla de una mulata con un blanco resulta un cuarterón. Si una cuarterona se une con un blanco nace un quinterón. El hijo de una quinterona con un blanco resulta blanco. Por último, de las mezclas en que los hijos resultaban con un color de piel mucho más oscuro se les nombró salta pa' tras, considerados la raza más inferior de la escala (Humboldt, 1966 en López, 2008: 294).

La ideología de blanqueamiento, según Carlos López ${ }^{29}$ en la Nueva España no tenía leyes que impidieran que se consumaran los casamientos, concubinatos, violaciones o comercio sexual entre personas de distinta condición racial, por lo que tampoco se podía impedir el nacimiento de "individuos inclasificables o indefinibles". A lo largo del proceso de

\footnotetext{
${ }^{28}$ Hijo de padres europeos nacido en "Nueva España".

${ }^{29}$ Investigador en el Instituto de Investigaciones Filosóficas de la UNAM.
} 
formación del Estado Nación mexicano, debido a la manera como se comenzaron a desarrollar las diferentes castas es como se fueron redefiniendo las estructuras de poder en el territorio americano. Lo que no cambió fue que quienes poseían los privilegios económicos, políticos y sociales no dejaron de ser los europeos invasores. El resto de los grupos inferiores fueron distribuidos en las diversas actividades según el lugar que ocupaban en la escala social por su color de piel, quedando al servicio de las razas dominantes.

Cada uno de estos grupos se encontraba en un lugar distinto de la jerarquía social, lo que puede representarse con el esquema de una pirámide. En la cúspide se encontraba una minoría de la población ocupada por los extranjeros invasores, es decir, todos aquellos que se diferenciaban por su piel blanca, "cultura avanzada", y con una

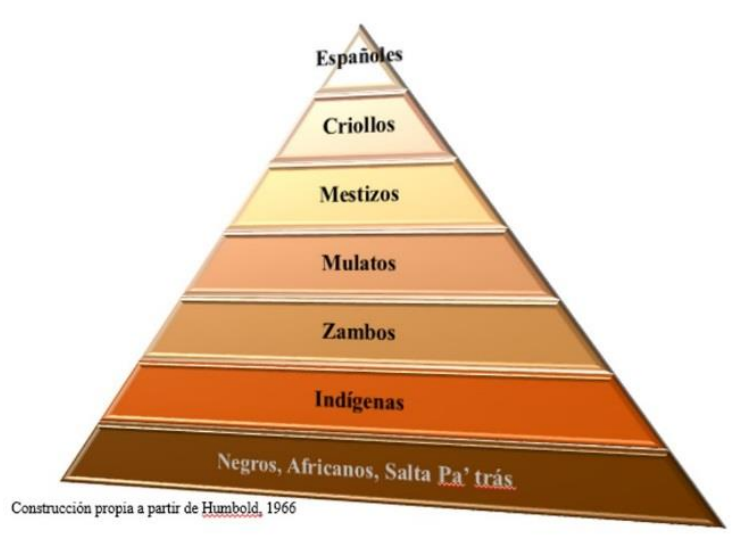
posición económica y social elevada. Según Florescano, en este lugar se ubicaba al Virrey, a los funcionarios de la Real Audiencia, los altos dignatarios de la Iglesia y de la Inquisición. En posiciones secundarias se encontraba a los grupos de criollos y mestizos, y conforme se bajaba más en la jerarquía, se encontraba a los indígenas, y en los últimos eslabones a los mulatos y negros, considerados seres cercanos a la bestialidad.

De la relación entre los diferentes grupos sociales lo más notorio era la división entre los gobernantes, extranjeros poseedores del poder y el resto de la población que no contaban con privilegios en ningún ámbito. Fragmentar a la sociedad de este modo, fue importante debido a que esto llevó a la creación de un sistema de pesos y contrapesos, regulados por el monarca y sus representantes en la Nueva España. Con ello se otorgaba fuerza a la autoridad española, subordinando y haciendo a la sociedad "dependiente" de los gobernantes. Para los invasores era necesario mantener el control con esta modalidad, debido a la distancia que había entre América y la corona española. Además de que la población "inferior" a dominar era numerosa y el mantenerlos sometidos desde la concepción de respeto a la superioridad, fue un mecanismo practico para los españoles (Florescano, 1996). 
El respeto otorgado a ciertos niveles de la jerarquía social se constituyó como un elemento de reconocimiento y aprobación por los diferentes grupos sociales. Aparentemente, la población no rechazaba la aplicación de las reglas y normas que establecieron los invasores dominantes, aun cuando en éstas se mostraban fuertemente las imágenes de desigualdad entre grupos. Como ejemplo de la representación de las desigualdades, Florescano hace referencia a las procesiones que se llevaban a cabo durante este periodo. Estos eventos eran el reflejo de los diferentes niveles de la pirámide de grupos de castas en la Nueva España.

En las procesiones se podían identificar rasgos del exhibicionismo social dado durante el siglo XVI en el que se mostraba el castigo de los individuos identificados por su conducta desviada (véase capítulo 1, apartado 1.3). Solo que en el caso de las procesiones no se trataba de eventos en donde la violencia física era la herramienta central, pero sí se trataba de la exposición pública de la estigmatización de grupos que con ello se reafirmaba el poder que tenían las autoridades ante la población. En estos desfiles se remarcaba la "inferioridad" y "superioridad" de los grupos por condición racial, el objetivo central era hacer una dedicatoria y tributo hacia el monarca.

La manera en que se exhibía a los grupos seguía un orden se comenzaba con las razas inferiores, como los negros y mulatos. En seguida, caminaban grupos de algunas comunidades indígenas, estos pasaban según la antigüedad de cada comunidad. Para cerrar el evento, desfilaban los grupos dominantes, que principalmente se integraba por pobladores españoles de piel blanca, eran los ministros de la Real Hacienda y la Audiencia, altos jueces, magistrados y el virrey. Estas representaciones, según Florescano se podían apreciar en tres eventos principales, cada uno con distintos actores centrales, pero las tres compartían y remarcaban el poder que los invasores poseían.

La primera celebración era en mayor medida religiosa, se trataba de Corpus Cristi, en ésta los grupos indígenas tenían una importante participación, eran quienes daban vida y color a la procesión, "los indios tapizaban el camino con flores y yerbas de olor y construían multitud de arcos de ramas, flores y aves de variados colores" (Florescano, 1996: 194). Sin embargo, en este desfile se celebraba a la iglesia, a la religión impuesta por los invasores, ignorando las tradiciones de los primeros pueblos. Una segunda celebración era la llamada Fiesta del Poder que a diferencia de Corpus Cristi era una celebración política, en esta se festejaba la 
entrada de un nuevo virrey poseedor del poder y autoridad. Éste hacía un recorrido por la ciudad y todos le rendían honores, incluso paralizando todas las actividades de la sociedad, esto como muestra de obediencia y respeto (Florescano, 1996).

Por último, la celebración de San Hipólito, en la que se conmemoraba y homenajeaba a los conquistadores caídos, era una fiesta en honor a la dominación de las tierras de América. Esta fiesta más que un evento religioso, era una representación teatral de cómo se vivió la invasión española, por lo que al igual que en los dos eventos antes mencionados, se sobrevaloraba la autoridad que tenían los europeos en la Nueva España (Florescano, 1996). En las tres celebraciones se utilizaba la presencia de los grupos "inferiores", éstos hacían funcionar los festivales con su participación y trabajo como si también tuvieran motivos para festejar. Aun cuando los diversos grupos se hacían presentes en dichos eventos y parecía que todas las imposiciones eran aceptadas, en realidad no fue así.

Lo cierto es que, durante todo este proceso había tensión entre conquistadores y conquistados. Se produjeron diversas contradicciones étnicas, sociales, económicas, políticas y culturales. Ante estos choques, se hizo notar la resistencia de los pueblos indígenas por hacer prevalecer sus tradiciones y creencias, adaptándolas con las imposiciones españolas, "los grupos étnicos de Nueva España revitalizaron una y otra vez sus antiguos lazos de identidad. Al verse obligados a convivir con sus dominadores, desarrollaron nuevas formas de solidaridad y lograron hacer pervivir, mediante una dinámica de intercambio y adaptación con la cultura dominante, sus propias tradiciones" (Florescano, 1996: 267).

La adaptación de lo tradicional con las nuevas formas se debió a que los lugares en donde se asentó la nueva cultura estaban antecedidos por el altépett ${ }^{30}$, antes de la invasión eran el centro de los pueblos prehispánicos. Para lograr la integración de esta unidad con las imposiciones políticas, religiosas, económicas y culturales, se pasó por dos principales fases: la primera en la que el Tlatoani adquiría todo el poder, además gozaba de beneficios como

\footnotetext{
30 Palabra nahua compuesta. Viene de in atl, in tepetl, el agua, la montaña. Se representa como un cerro con agua en su interior. Fue sinónimo de estado territorial, de gente asentada en suelo propio. El altépetl (plural altepeme) es una unidad territorial y política presente en las distintas regiones de Mesoamérica. Los españoles lo llamaron pueblo, un vocablo que le sentaba bien porque cada altépetl se imaginaba a sí mismo como un pueblo separado en forma radical de los demás. Esta unidad se distingue por tres rasgos: 1. Disponía de un territorio propio, 2. Albergaba en él una o más etnias que compartían un pasado y tradiciones comunes, y 3. Estaba gobernado por un señor dinástico; el Tlatoani (Florescano, 1996).
} 
tener a su servicio y recibir tributo de los pobladores. La segunda fase surge cuando se instala el gobierno colonial y el Tlatoani pierde sus derechos, sin embargo, el altépetl conservó su estructura social y territorial (Florescano, 1996).

Al principio la estructura del altépetl no tuvo grandes alteraciones puesto que, la Corona española reconoció los derechos territoriales de los antiguos mandatarios y de los pobladores, pero se concentró en el gobierno español la justicia, el derecho a las encomiendas y el nombramiento de caciques o "gobernador" que seguiría siendo un individuo indígena asignado por los invasores. Más adelante esto cambió y se concentraron más fuertemente el poder y la autoridad del gobierno español, imponiendo un nuevo modelo de gobierno que otorgaba menores facultades a la gente de los pueblos indígenas (Florescano, 1996).

A finales del siglo XVII, hubo cierta contradicción con lo esperado por la política de blanqueamiento, la población indígena se incrementó. Los pueblos comenzaron a pedir que se les devolviera su autonomía robada, logrando que se conformaran múltiples comunidades. Incluso se nombraron puestos importantes en el cabildo ${ }^{31}$ indígena y entre la misma población se constituyeron diferencias por adquisición de poder y riqueza. "Era común que hubiera un pequeño grupo hereditario que acaparara la riqueza, el prestigio y la educación, el cual tenía en sus manos la mayoría de los cargos de la comunidad" (Lockhart, 1992 en Florescano, 1996: 274).

Los rasgos de poder entre individuos se hacían presentes en las comunidades e incluso se honraba a quienes tenían el mando interno. Esto sucedía en las plazas y templos de los pueblos indígenas, lugar en donde se celebraba ceremonias religiosas y fiestas en honor, no solo de los altos mandos, sino también del santo patrono, algo parecido a como se hacía en la época prehispánica. Los festejos, a su vez eran un intento por conservar las tradiciones, la identidad de los pueblos y la defensa de las tierras. Además, se pretendía que las nuevas generaciones de las comunidades indígenas no abandonaran su pasado, así, los más viejos difundían sus conocimientos desde la memoria oral, incorporando a este proceso lo adquirido

\footnotetext{
${ }^{31}$ Es un término que procede del latín capitulum y que tiene varios usos. Puede tratarse del ayuntamiento o la municipalidad, de la junta que celebra esta institución y del edificio donde tiene lugar la junta. Esta utilización del concepto era muy frecuente en la época colonial, cuando los países americanos eran gobernados por España y el cabildo era la institución y el edificio que albergaba a las autoridades municipales enviadas por el imperio. Disponible en: https://definicion.de/cabildo/
} 
de la nueva cultura. Florescano dice que con esto se creó una nueva memoria histórica de la vida de los pueblos.

Sin embargo, para las comunidades indígenas, la nueva memoria incluía en mayor medida conocimientos de las culturas prehispánicas y era menor lo que se sabía y poseía de los antecedentes de la cultura española. Los pueblos parecían ser ajenos a la historia de sus dominantes, a diferencia de otros grupos como los mestizos, quienes tenían una nueva concepción histórica que se mostraba algo indiferente con la de los pueblos indígenas. Con todo esto se puede decir que aquellas campañas para desaparecer a los grupos nativos, evangelizándolos y culturalizándolos, no logró alcanzar éxito absoluto. Los grupos de mestizos que se conformaron fueron los primeros resultados favorables para la colonización española, puesto que estos grupos implicaron la creación de una "mejor raza" en la Nueva España (Florescano, 1996).

La presencia y resistencia de los grupos indígenas perduró a lo largo de muchos años pese a que los dominantes europeos buscaban erradicar todo lo referente a estos pueblos. Estos, sin embargo, no habían tenido presencia en movimientos políticos a nivel nacional, sino que, mayormente solo en el ámbito local. Fue hasta el siglo XIX cuando estos grupos intervinieron en el proceso de Independencia de la Nueva España, lo que sería un elemento clave de la conformación del Estado Nacional mexicano. Es así que, durante la guerra de Independencia, gran parte de los contingentes que participaron se conformaban por población indígena.

Los indígenas y campesinos durante este proceso fueron muy importantes, debido a que su irrupción hizo que se notara la existencia de esta población como un sector vivo y fuerte a nivel nacional, aun cuando se les había concentrado en espacios apartados de los ocupados por otros grupos. En esta lucha la participación indígena fue motivada por las intenciones de construir una nación soberana y un Estado republicano. Según el pensamiento de Servando Teresa de Mier y Carlos María Bustamante el nacionalismo que se pretendía construir trataba de una nación independiente que considerara la antigüedad indígena como la raíz de lo constituido por la nación europea. También, utópicamente se pretendía que los grupos nativos fueran legitimados por el conjunto social (Mier y Bustamente en Florescano, 1996: 286).

En cuanto a estos ideales referidos a la guerra de Independencia se habla de la difusión de tres imaginarios de lo que se podía esperar del movimiento insurgente: primero, se creía en 
la posibilidad de restaurar un imperio mexicano. El segundo, habla del repudio hacia la invasión española, y por último se concibió a esta lucha como si fuera la venganza contra las injusticias vividas durante el periodo de colonización. Estos ideales se promovieron, generando mayor rechazo por muchas de las imposiciones de la vida colonial. Sin embargo, autores como Mier y Bustamante, en su ideal de nacionalismo, integran elementos europeos que deberían permanecer y estar equilibrados entre sí.

Según estos autores una característica que les parecía importante era la posibilidad de unir la religiosidad tradicional con la impuesta durante la colonia, no se debía abandonar el catolicismo, supuestamente por ser ésta la religión que articulaba a la sociedad. Incluso se dice que la misma declaración de independencia proclamaba que era inaceptable la existencia de una religión distinta a ésta (Florescano, 1996). Aun con las demandas en favor de la comunidad indígena durante esta guerra, era notorio que se estaba procurando mantener el poder en ciertas cosas, con la permanencia de las características de la hibrida sociedad que se había conformado.

Con lo anterior, cabe mencionar que existían contradicciones en las proclamaciones de independencia. Como muestra de esto es parte de lo que decía el artículo 24 de la Constitución de Apatzingán 32 "La felicidad de la nación y de cada uno de los ciudadanos consistía en su derecho a la igualdad, a la seguridad, a la propiedad y a la libertad... la conservación íntegra de estos derechos es el objeto del gobierno, y el único fin de las asociaciones políticas" (Florescano, 1996: 288). No se podía tener igualdad y libertad, cuando se pedía mantener como única a la religión católica.

En esta Constitución también se incluyó la creación de los elementos organizativos del Estado como sistema político de México. La organización incluye el desarrollo de un Congreso que funcionara como organismo de representatividad de la nación. Además, se crea la separación de poderes políticos (ejecutivo, legislativo y judicial), con esto, el poder se dejó de concentrar en un solo individuo y supuestamente, se asignaron diferentes responsabilidades a cada uno de los tres poderes, pero el mando era del Estado y la población no participaba en la elección de quienes se encontraban a cargo.

\footnotetext{
32 Formulada y aprobada por el Congreso de Chilpancingo 1814, en la ciudad de Apatzingán. También se le nombró Decreto Constitucional para la Libertad de la América Mexicana.
} 
Años más adelante, en 1824, ya consumada la independencia del territorio mexicano, la población participó en la legitimación de los cargos que conformaban al Estado (la participación no fue general, solo unos sectores). "[Los ciudadanos] asignaron al Estado la tarea de administrar las funciones públicas y regular las relaciones y los órganos de gobierno" (Florescano, 1996: 289), con esto se puso fin a las formas de gobierno colonial, arrancando el poder al monarca, virreyes y de la Iglesia católica (esta última no perdió todo el poder). Con esto como primeros pasos de la liberación del país, se siguieron formulando ideas utópicas y esperanzadas sobre la nueva forma de gobierno. Esto es importante mencionarlo, debido a que se trata de las bases de la conformación de instituciones y sistemas que caracterizan la organización actual del país. Entre estos, el carcelario en donde, incluso en nuestros días se aprecian las desigualdades que se promueven desde estas bases.

Las instituciones como hoy las conocemos, formaron parte del proceso de conformación del Estado Nación, su desarrollo no dejó de enmarcar las disparidades entre la población por diferentes motivos, pero principalmente por la condición de raza. La construcción de la nueva forma de gobierno, ha sido un proyecto en el que durante su proceso se han ido excluyendo a grupos como los indígenas, además de mantener una jerarquía social en la que este sector de la población ha continuado en las posiciones más bajas. Desde la Independencia se marcaron muy fuertemente ideologías de racismo y xenofobia en la población mexicana, y en acontecimientos precedentes se fueron manteniendo.

Por ejemplo, previo a la Guerra de Reforma (1858-1861) como parte de los resultados de la Ley Lerdo ${ }^{33}$, "se empobreció aún más la vida de los pueblos que ya estaban al borde la miseria [...] En toda la república, durante el verano y otoño de 1856, los pueblos indígenas sufrieron la catástrofe de perder sus tierras arrendadas... “(Florescano, 1996: 317), los despojos de las comunidades nativas continuaron. Algunos indígenas poseedores de tierras, arrendaban partes de sus terrenos y el dinero obtenido era utilizado para apoyar en los gastos municipales

\footnotetext{
${ }^{33}$ La Ley Lerdo es el sobrenombre con el que es mejor conocida "La Ley de desamortización de las fincas rústicas y urbanas de las corporaciones civiles y religiosas de México" y fue expedida el 25 de junio de 1856, por el presidente Ignacio Comonfort. Esta ley tenía como objetivo reactivar la economía y sanear las finanzas públicas del estado. Tiene un origen plenamente liberal y ante la gran cantidad de bienes inmuebles en poder de la Iglesia Católica deciden recuperarlas para el Estado y venderlas para obtener recursos. Esta ley tuvo como consecuencia que muchas de las fincas quedaran en manos de extranjeros y dieran origen a los latifundios o grandes extensiones de tierra en años posteriores. Disponible en: https://sites.google.com/site/laepocadejuarezysusreformas/-leyes/ley-lerdo
} 
y religiosos que se les habían impuesto durante muchos años. Con la aplicación de esta ley dejó de percibirse este ingreso, lo cual dificultó aún más la generación de recursos económicos de los pueblos. Además de remarcarse una gran dificultad para que los indígenas y campesinos se hicieran dueños de tierras que eran confiscadas de las instituciones religiosas por mandato de ley.

Se dice que esto se debió a la difícil integración de los indígenas a la nación. Esta desvalorización, incluso formó parte del pensamiento de autores como Francisco Pimentel, quien propuso que "debe procurarse [...] que los indios olviden sus costumbres y hasta su idioma mismo, si fuere posible. Solo de este modo [...] formarán con los blancos una masa homogénea, una nación verdadera" (Florescano, 1996: 319). En esta parte del proceso de conformación del Estado mexicano se mantuvieron muchos ideales de este tipo, en los que se desprestigiaba y se le restaba oportunidades a la población indígena.

Posterior a la aplicación de la Ley Lerdo, durante la etapa de Reforma, las contradicciones ideológicas continuaban. Según Richard Simkin, el mensaje de los reformadores era que "ningún individuo, corporación, clase o fracción podría gozar de un poder superior al del Estado nacional secular" (Florescano, 1996: 400) y con ello se planteaba que uno de los principales objetivos de las Leyes de Reforma era restar poder a la Iglesia católica, otorgándolo a los organismos estatales supuestamente legitimados por la población. Además, se proclamaba que la Iglesia estaba obligada a vender las propiedades rurales y urbanas acumuladas a lo largo de los años.

Estas medidas no significaron que la Iglesia perdiera completamente el poder que le había caracterizado por muchos años. En el ámbito económico esta institución siguió representando uno de los medios más poderosos de la época. Sin embargo, en lo social el nuevo gobierno no aceptaba que se siguiera compartiendo con la misma fuerza la autoridad entre religión y Estado. En 1857 con la proclamación de una nueva Constitución, la religión católica se vio aún más golpeada, ya que se establecía que el gobierno federal concentraba el poder de decidir sobre todos los asuntos referentes a la religión, y además que la católica no sería más la religión del Estado (Powell, 1972).

Como era de esperarse todas estas disposiciones generaron inconformidad por parte de la Iglesia católica, quien comenzó a amenazar con excomulgar a todos aquellos que valoraran 
estas proclamaciones. El descontento de ésta continuó al paso de los años, por lo que, en 1859 el gobierno expidió un manifiesto en el que se dijo que la Iglesia financiaba una guerra civil con el objetivo de mantener sus privilegios. Para poner fin a esta disputa el Estado echó a andar un programa que pretendía la "separación entre Iglesia y Estado, supresión de las órdenes mendicantes, nacionalización de la propiedad de la Iglesia, tolerancia de otras religiones, prohibición a las mujeres de ordenarse en los conventos y secularización de las ceremonias religiosas que sancionaban los pasajes de la vida humana" (Florescano, 1996: 399). Con esto se esperaba que, aparentemente, el Estado recuperara el derecho a gobernar la sociedad, puesto que nadie podía poseer un poder superior al de éste.

Restar poder a la Iglesia y concentrarlo en el Estado, aun con el paso de los años no hizo que mejoraran las condiciones de los pueblos indígenas, sino que, por lo contrario, éstos seguían siendo desvalorizados. Así, durante el mandato de Porfirio Díaz (1876-1911) se mantenía con vida aquella campaña que pretendía desaparecer a los pueblos nativos, incluso podría decirse que tomó mayor fuerza. Esto se reflejó en la opinión de personajes como Alfonso Luis Velasco quien consideraba que "las razas aborígenes era un obstáculo para la civilización”. Y como esta, había muchas otras opiniones en las que se inferiorizaba a los indígenas, se pensaba que este grupo solo servía como mano de obra, mientras que la población blanca (principalmente españoles) conformaban la elite intelectual. Por su parte y en apoyo de dichas afirmaciones, miembros del gabinete de Porfirio Díaz calificaron como una raza degenerada con poca capacidad intelectual a los indígenas (Florescano, 1996).

Durante este período se intensificó la idea de que "los indios eran el mayor lastre que impedía el desarrollo en México, y con esa convicción no cesaron de rebajarlos e injuriarlos en una campaña racista” (Florescano, 1996: 320). El gobierno de Díaz, pretendía mostrar la imagen de un México cambiado, uno blanqueado y amestizado. Los europeos y mestizos eran puestos como los sectores más importantes y dominantes de la sociedad mexicana. Ninguna lengua indígena era aceptada como idioma oficial nacional, mientras que lo correcto era hablar la lengua impuesta por los invasores: el español (Florescano, 1996).

Pero la situación fue mucho más allá de lo ideológico, desaparecer a los grupos indígenas volvió a ser un hecho de exterminio violento. Durante el gobierno de Díaz, los pueblos que no aceptaban las políticas de "modernización" como la creación de nuevas vías de 
comunicación (extensión de caminos, construcción de puentes, correo, teléfono, vías de ferrocarril, etc.) fueron despojados de sus tierras y concentrados en las zonas más apartadas y de peores condiciones en las diversas regiones en donde se pretendían construir las "mejoras" sociales. Permitir que los pueblos ocuparan los espacios importantes era truncar el desarrollo del país e impedir el incremento de la riqueza nacional (Florescano, 1996).

Los cambios que se promovieron desde la invasión española hasta los procesos posteriores (como en la Reforma y el Porfiriato) fueron hechos que marcaron la vida de nuestro país, puesto que se definió muy fuertemente la división entre grupos debido a la condición racial, afectando en gran medida a los pueblos indígenas. "[...] el ataque contra las comunidades indígenas fue general. Comprendió la afectación de tierras, lenguas, tradiciones y herencias culturales de los pueblos y dislocó las formas de relación que mantenían con el Estado y la nación [...] El proyecto de nación excluyó a los indígenas de sus filas y el Estado les declaró una guerra sin cuartel” (Florescano, 1996: 445).

Durante todo este proceso se fomentó el repudio por la población nativa desvalorizándola frente a otros grupos y reafirmando el poder que descansaba en las autoridades del nuevo gobierno. Esto es algo que perdura hasta nuestros días, podemos decir que las instituciones del Estado mexicano no garantizan la igualdad entre grupos, tal como veremos más adelante cuando nos centremos en nuestro estudio de caso, en donde, como se ha comentado antes, se comparan los procesos de socialización y las estrategias de sobrevivencia de mujeres indígenas y mestizas privadas de la libertad en el CPRS Santiaguito (institución del Estado mexicano).

En dicho comparativo no solo se destacan las diferencias por condición de raza, sino que también las de clase social. En este sentido, cabe decir que son muchos los grupos sociales que se encuentran en condiciones económicas desfavorecidas, pero comúnmente se suele identificar a los indígenas como una de las poblaciones más pobres del país. Es así, que las clasificaciones de este tipo se deben principalmente a la desequilibrada adquisición económica, niveles de alfabetización y desvalorización cultural. Aquellos que cuentan con más recursos (económicos y sociales) ocupan una posición más alta en la jerarquía social, lo que implica, en la mayoría de los casos, la obtención de privilegios y poder en los diferentes ámbitos sociales. 
Al igual que las distinciones por condición de raza, las clases sociales se han ido constituyendo a lo largo de todo el proceso de conformación del Estado nación mexicano. Durante cada etapa se fueron definiendo las características de las diferentes posiciones que han de ocupar los individuos en nuestra sociedad y con ello el impacto que tienen en la vida de éstos en sus diferentes entornos. Existe una fuerte relación entre ambos tipos de desigualdades, pues como veremos en el siguiente apartado, con las determinadas por condición de raza se comenzaron a identificar las de clase, y ya más adelante se fueron integrando otros elementos que definirían una estructura de clases como hoy la conocemos.

\subsection{Las clases sociales en la constitución de desigualdades}

Las disparidades que se generan en las relaciones sociales no solo se han determinado por condiciones culturales y raciales existentes entre grupos, sino que también se deben a la clase social $^{34}$ a la cual pertenezcan los individuos. Se dice que las distinciones de este tipo se comienzan a definir debido a la distribución de las tierras como medio de producción, relaciones de trabajo y comercio como vínculos entre una parte de la sociedad y otra. Más adelante se han de considerar otros factores con los que ciertos sectores tendrán poder sobre de algunos otros (Stavenhagen, 1985). La distinción por clase se ha representado como una mayor segregación de los grupos sociales, situándolos en distintos niveles de la jerarquía social. Así, cabe mencionar que el fuerte impacto de este tipo de desigualdades tiene antecedentes históricos que en este trabajo comenzaremos a ubicarlos desde la época colonial.

La llegada de los europeos a territorio mexicano tuvo importantes consecuencias en la población nativa, una de estas fue que se asentaron las bases de una estructura de clases. En

\footnotetext{
${ }^{34}$ Concepto que surge con el pensamiento social y económico de la modernidad europea, y expresa una de las dimensiones fundamentales en la dinámica de la sociedad capitalista surgida de la descomposición del sistema feudal. Según Vladimir Ilich Lenin "las clases sociales son grandes grupos de hombres [y mujeres] que se diferencian entre sí por el lugar que ocupan en un sistema de producción social históricamente determinado, por las relaciones en que se encuentran con respecto a los medios de producción (relaciones que las leyes refrendan y formulan en gran parte), por el papel que desempeñan en la organización social del trabajo, y, consiguientemente, por el modo y la proporción en que perciben la parte de la riqueza social de que disponen. Las clases son grupos humanos, uno de los cuales puede apropiarse el trabajo de otro por ocupar puestos diferentes en un régimen determinado de economía social" (Lenin, en Marx y Engels, 1996: 479)
} 
esta estructura, nuevamente los grupos indígenas fueron puestos en los niveles más bajos. Las políticas indigenistas del periodo colonial, podría decirse que permitieron la permanencia de características sociales y culturales de los grupos indígenas, pero éstos últimos se veían obligados a pagar tributo y prestar diversos servicios a los españoles, además de no poseer, en ningún sentido, derechos como los de los grupos invasores. Esta situación poco a poco fue empeorando, debido a que, como se mencionó antes, los sistemas de tenencia de la tierra cambiaron, siempre en beneficio de los grupos dominantes, quienes se adueñaron de la mayor parte de las tierras, dejando a los indios con pequeños terrenos comunales en los que éstos ejercían derechos de usufructo (Stavenhagen, 1985).

Debido a una mala integración a la vida colonial, los indígenas ocupaban una de las posiciones más bajas de la sociedad y, además, por su condición de inferiores, se veían obligados a vivir casi siempre apartados de los españoles. Sin embargo, la conexión que había entre un sector y otro era en mayor medida derivada de la relación de dominación y subordinación que se había generado en esta época. Fue de hechos como el cobro de tributos y la imposición de trabajos forzados con los que los españoles se apropiaron de los excedentes económicos de las comunidades indígenas, haciéndolas perder algunas de las bases con las que se definía el lugar ocupado en la jerarquía social de clases (Stavenhagen, 1985).

Durante este periodo las distinciones por condición de clase, también se vieron reflejadas dentro de los mismos pueblos tradicionales. Esto como resultado de las actividades en las que se ocupaban para su subsistencia personal y doméstica. Los indígenas empleados como mano de obra de los españoles formaban parte de la clase trabajadora. Mientras que los que se dedicaban a la creación y venta de artesanías eran considerados comerciantes e incluso, según Rodolfo Stavenhagen ${ }^{35}$, constituían la categoría de "empresarios” dentro de sus comunidades, es decir, ocupaban una posición interna más alta. Aun con las estratificaciones dentro de las comunidades, en el exterior era difícil, casi imposible que algún grupo nativo ocupara una posición social más elevada, esto se debía a lo limitantes que eran las leyes coloniales. Parecía ser que conservar la calidad de indígenas y subir en la escala social era algo incompatible.

\footnotetext{
${ }^{35}$ Doctor en sociología por la Universidad de París, defensor de los derechos de los pueblos indígenas.
} 
El mantenimiento de las características culturales del indio (lengua, vestido, participación en la estructura corporativa, etc.) solo era posible si se mantenía separado de la nueva estructura de clases y conservaba su status jurídico de indígena, es decir, su posición de inferioridad social y de incapacidad jurídica. Aquellos otros que lograban separarse de su comunidad, o que eran obligados a separarse por los españoles, perdían paulatinamente estas características, y se integraban a una sociedad nacional en formación, participando en el proceso de mestizaje biológico y cultural (Stavenhagen, 1985: 118).

Aparentemente, un importante requisito para ubicarse en una mejor posición social durante la colonia, se trataba del abandono de todo aquello que por tradición caracterizaba a los pueblos nativos. Es decir, de acciones propias que favorecían a las llamadas políticas de blanqueamiento de los pueblos indígenas, promovidas desde la llegada de los invasores al territorio. El arrebato de las costumbres y tradiciones de las comunidades indígenas, así como la sustitución de éstas por las de la nueva cultura, daban la falsa idea de que no solo mejorarían su status, sino que sería algo favorable para la integración de estas comunidades a la sociedad de la cual estaban siendo excluidos. Sin embargo, más que mejorar la condición de clase, esta supuesta integración formaría parte del proceso de homogeneización de la sociedad con la que se constituyeron las llamadas castas.

Con las nuevas categorías sociales creadas durante la colonia el color de piel no solo marcó distinciones raciales, sino que también económicas. Los nuevos grupos ocuparon un sitio en la jerarquía de clases según el rol que desempeñaban en la sociedad (véase pág. 68). Es así, que, en la conformación de la estructura social de clases, los españoles poseedores del poder social y económico, ocupaban el lugar más alto. En posiciones más bajas se iban colocando a los criollos, mestizos y más abajo a los indígenas. Ya en los últimos peldaños, se ubicaba a la población negra, quienes al parecer no eran plenamente considerados como parte de una clase social, puesto que eran comercializados como mercancía y obligados a ser esclavos de los españoles. Incluso, de estos últimos, quienes poseían más esclavos adquirían un mejor status social.

Tanto las poblaciones negras como las indígenas se vieron inmersas en una relación con sujetos que los subordinaban, diferían de sus tradiciones y costumbres, y los repudiaban por su color de piel, lo que, por consecuencia, generaba el impedimento para desarrollarse en ámbitos económicos. Esto no significa que, en las sociedades indígenas, antes de la colonia, no existieran las diferencias de clase, pues la población de las comunidades se encontraba 
estratificada. Pero es en la Colonia en donde estos grupos comienzan a ser segmentados y separados de unos otros que pregonaban superioridad (Stavenhagen, 1985).

Así, las relaciones sociales interétnicas durante este periodo, se basaron en un vínculo entre colonizadores y colonizados, en donde los últimos fueron llevados a la exclusión y marginación, lo cual ha ido perdurando durante todas las etapas del proceso de conformación del Estado nación mexicano, y que, además, sigue vigente hasta nuestros días. Por lo que, mencionando sucesos posteriores como en la Independencia de México, cabe decir que se mantuvieron algunos de los efectos de la segregación social constituida. Esto se debió a que, aunque parecía que se pretendía obtener la igualdad jurídica de todos los ciudadanos, las poblaciones subordinadas e inferiorizadas no lograron posicionarse en lugares sociales más altos, ya que no se eliminó la presencia de grupos dominantes poseedores del poder económico, cultural y social.

En el periodo de Independencia pese a las ideas que se habían planteado referente a la lucha por la integración de las comunidades indígenas, la condición de inferioridad económica y social que estas enfrentaban no se terminó, sino que por lo contrario fueron colocadas en una desventajosa desigualdad jurídica, lo que agravó su situación. Se dice que las consecuencias inmediatas de las políticas independentistas fue que los indios tenían la libertad de disponer de sí mismos en el mercado de trabajo, además, las tierras que ocupaban podían pasar a ser propiedad privada. Es decir, los indígenas fueron "liberados" de los trabajos forzados y podían elegir a qué dedicarse, pero por otro lado las tierras comunales que ocupaban pasaron al libre mercado (Stavenhagen, 1985).

Referente a las tierras, en este periodo fue que se crearon una gran cantidad de latifundios ${ }^{36}$, lo que significó que "los títulos de propiedad de los indios pasaron pronto a manos de [propietarios únicos], y aun sin cambios legales de la propiedad de la tierra los indios fueron despojados progresivamente de sus tierras comunales. La falta de tierras obligó a [éstos] a transformarse en peones en las grandes fincas" (Stavenhagen, 1985: 120). La supuesta liberación de los grupos nativos no se consumó, sino que al igual que durante la colonia, se

\footnotetext{
${ }^{36}$ Un latifundio es una finca o hacienda rústica, de extensión superior al centenar de hectáreas, que pertenece a un único dueño. En este sentido, implica la explotación agraria de grandes extensiones de terreno por un solo propietario, de lo cual han derivado gran cantidad de conflictos sociales. Disponible en: https://www.significados.com/latifundio/
} 
les impidió la posibilidad de ser propietarios de tierras y generar ingresos propios para beneficios domésticos e individuales. En relación con la estructura de clases que se venía arrastrando, seguía siendo casi imposible que los grupos indígenas se posicionaran en un peldaño más alto, ya que seguían estando subordinados por otros grupos.

Más adelante, durante este mismo proceso, llegó a zonas indígenas un nuevo producto para cultivar: el café. En estas tierras se constituyeron fincas de este producto que se posicionaron como centros de trabajo, en donde se empleaba legal o ilegalmente a una importante cantidad de indígenas. De este modo se comenzaron a establecer nuevas relaciones económicas entre los indígenas y el resto de la población que ya no se trataba únicamente de los españoles, pero sí de poblaciones derivadas como los mestizos, quienes representaban a los nuevos dominadores. En este sentido, los vínculos entre los diversos grupos de la población, dejaron de ser solo relaciones raciales y culturales, tomando gran relevancia las económicas, se trató de propietarios y trabajadores (Stavenhagen, 1985).

Desde la conquista hasta una época reciente [independencia] se ha establecido una tendencia constante, con algunos fracasos, a la destrucción de la propiedad de las grandes extensiones de tierras del indio, la base física y económica de la solidaridad de la tribu y de su libertad de abstenerse de trabajar para los no indígenas... en consecuencia, para disponer de la gran fuente de mano de obra de las tierras altas, se emplearon dos métodos: la violencia y la destrucción de la base económica que permitía que los indios se rehusaran a ir a trabajar en forma voluntaria a las tierras bajas (La Farge, 1959, citado por Stavenhagen, 1985: 120-121).

Así, los grupos dominantes (no solo conformados por españoles) de manera no tan directa pero sí arbitraria, continuaron forzando a las poblaciones nativas a servirles y mantenerse subordinadas con la intención de que quienes estaban al poder, conservaran su lugar en los niveles más altos de la escala social. Las oportunidades que los grupos indígenas tenían para subir en esta estructura de clase, no dejaron de estar limitadas, ni siquiera durante procesos posteriores de la historia del país. Ejemplo de ello, es lo sucedido en el porfiriato (18761911), en donde las políticas e ideologías del nuevo gobierno no se dirigían precisamente al bien de la población indígena, sino que, como se mencionó en el apartado 2.1 de este capítulo, pretendían desvanecer a estas poblaciones bajo un discurso que señalaba la búsqueda de la modernización del país, en donde la existencia de pueblos tradicionales representaba una gran limitante o retroceso para el logro de dicho objetivo. 
Durante el Porfiriato, cabe decir que las clases sociales comenzaron a delinearse aún más, iniciando este periodo en un contexto internacional favorable. En Europa se gozaba de tiempos de paz y crecimiento económico, lo cual incrementó sus inversiones y comercio exterior. Por otro lado, nuestro vecino Estados Unidos, se encontraba viviendo un momento de gran desarrollo industrial y de modernización en su zona fronteriza con México, lo cual favorecería la economía de la región norte de nuestro país. Con todo esto, las "mejoras" sociales que se empezaron a desarrollar en este periodo fueron muchas y en diversos ámbitos de la sociedad. Por ejemplo, la construcción de nuevas vías de comunicación como el ferrocarril, el establecimiento de instituciones bancarias, el comienzo de la recepción de inversiones extranjeras, y el surgimiento de la agricultura de exportación y la minería industrial (Garciadiego, 2014).

Con la aplicación de acciones como las mencionadas se esperaba que la calidad de vida de la población en general se beneficiara y, además, que se desarrollara un equilibrio en tanto las posiciones de clase, sin embargo, esto no sucedió. Como se ha venido diciendo, las políticas porfiristas no tenían como prioridad mejorar las condiciones de vida de los pueblos indígenas (siendo este uno de los grupos mayormente desfavorecidos), pero sí se promovía la importancia de atraer grupos externos para invertir en nuestro país. Así, las jerarquías de clases en este periodo tuvieron algunos cambios en los que los extranjeros mantenían una fuerte importancia frente a los grupos nativos.

Ya desde los procesos previos los grupos de extranjeros se presentaban como elementos fundamentales para el desarrollo del país, siendo estos quienes poseían poder y beneficios que no tenían los demás grupos. Durante el porfiriato los españoles dejaron de ocupar completamente la posición más alta de la jerarquía social, pero sí seguían teniendo gran relevancia por el hecho de ser extranjeros blancos y con importancia económica internacional. Además, se integraron a esta estructura de clases los norteamericanos, quienes se constituyeron como uno de los estratos más importantes en la sociedad mexicana.

...El elemento extranjero tiene entre nosotros el carácter de huésped invitado, rogado y recibido como quien da favor y por su parte no lo recibe. De allí que nos esforcemos para hacer grata su visita, con la esperanza, por una parte, de los provechos que de esa visita nos resulten, y por otra, de que esa misma visita, dé por final resultado, la definitiva incorporación del huésped a nuestra familia nacional (Molina, 1985: 61). 
La relevancia de los norteamericanos en nuestro país no solo fue por el beneficio económico que pudiera implicar su estancia en el territorio, sino también, para evitar dificultades y roces con ellos, puesto que el vecino del norte se había constituido como un ser fuerte y poderoso a nivel internacional, y para los mexicanos era mejor aprovechar su cercana presencia. En este periodo, era notorio a simple vista que el extranjero era un elemento privilegiado de nuestra sociedad, europeos y norteamericanos, principalmente, ocupaban el peldaño más alto de la estructura de clases. Incluso, cabe decir que las leyes internas de México no producían los mismos beneficios para los mexicanos que para los extranjeros (Molina, 1985).

Es así que, una vez identificado el grupo que encabezaba la estructura de clases en este periodo, es preciso decir que se comenzaron a asentar las bases para la constitución de un nivel medio en la estratificación social de clases (aún no se hablaba de una clase media como tal). Las posiciones secundarias eran ocupadas por los llamados grupos de criollos y mestizos, quienes concentraban pequeñas fortunas derivadas de la gran propiedad y de sus influencias en el ámbito religioso (en algunos casos). En esta sección media, se encontraban en primer lugar los criollos y en segundo los mestizos, pero ambos grupos estaban segmentados internamente según rasgos que no solo eran los económicos y por lo que ocupaban una posición distinta. Algunos de los sectores secundarios se encontraban cercanos a los estratos de clase más bajos de la sociedad en general (Molina, 1985).

Las subcategorías de clase, inicialmente de los criollos, estaban compuestas por los llamados "criollos nuevos", grupo dividido principalmente en dos: conservadores (clero y políticos) y liberales (intelectuales con estrechas relaciones con extranjeros). Este grupo mantenía una alta posición gracias a sus riquezas que, dicho antes, eran derivadas de la propiedad de tierras y también debido a sus buenas relaciones con las autoridades religiosas, lo cual les aseguraba un buen status social. Se les consideraba menos que los extranjeros, pero mucho más que los mestizos. Políticamente, las leyes mexicanas no brindaban para estos grupos los mismos privilegios que para los extranjeros, pero sí les permitían escapar de una gran parte de las cargas que implicaban éstas, además tenían mayores beneficios que la categoría de mestizos (Molina, 1985).

En segundo lugar, en esta clase intermedia estaban los grupos de mestizos, quienes se dividían en varias subcategorías, no como en el caso anterior que eran principalmente dos. 
Éstas eran encabezadas, primero por el grupo director integrado por funcionarios y jefes del ejército, después seguían los profesionistas, trabajadores del ejército, obreros superiores, pequeños propietarios individuales, rancheros y por último empleados. Se dice que el elemento mestizo profesaba gran devoción y estaban sometidos completamente a las leyes proclamadas en la época, principalmente a aquellas que se dirigían a sanciones que las hacían obligatorias. Esto derivado de la disciplina que partía de su conciencia patriótica y moral necesaria para favorecer la creación de una "verdadera” nación mexicana (Molina, 1985).

La subordinación y obediencia de los mestizos a las leyes fue uno de los elementos que los colocó en posiciones inferiores frente a los otros dos grupos (extranjeros y criollos), quienes como se mencionó, tenían mayores provechos o estaban exentos de ciertas obligaciones que las políticas mexicanas promovían. Aun así, los mestizos de esta clase social gozaban de algunos beneficios y asumían sus obligaciones sin rebeldía y aparentemente, sin ningún pesar. Una de las principales ventajas que tenía el sector mestizo era el acceso a la educación, el cual no se generalizaba. Por ejemplo, algunos como los profesionistas contaban con preparación por parte de los institutos fundados durante esa misma época (Molina, 1985).

Mientras tanto, otros sectores como el de los empleados no poseían este beneficio de la misma forma que los anteriores, si bien tenían educación básica, no contaban con estudios profesionales, lo que los colocaba en desventaja en diversos ámbitos como el laboral. Así, este tipo de desigualdad posicionaba a algunos grupos en un peldaño más bajo dentro de la categorización social interna. Sin embargo, pese a las desigualdades de este sector medio, el grupo mestizo en general era superior a otros cuantos como el de los indígenas, quienes estaban sometidos no solo por las leyes, sino también por los tres grupos mencionados antes (Molina, 1985).

Según Andrés Molina Enríquez (1985) durante el porfiriato el elemento indígena se ubicó en uno de los últimos eslabones de la jerarquía social de clases, y además, también se encontraba estratificado internamente. Las subcategorías eran: primero el clero inferior, se conformaba por indígenas "privilegiados" que participaban en actividades de las que los mestizos se estaban distanciando. Por ejemplo, en el ámbito religioso, su participación con la iglesia les otorgaba cierto prestigio pese a que percibían ingresos sumamente bajos. La segunda subcategoría era la de soldados, los soldados indígenas recibían sueldos más altos que el de 
los trabajadores de la industria y los jornaleros, pero mucho más bajos que la categoría militar conformada por mestizos.

La siguiente subcategoría se trató de los obreros inferiores, la integraban indígenas asalariados de la industria a quienes se les pagaban sueldos muy bajos, lo que los mantenía en una situación económica angustiosa. El siguiente grupo era el de los indígenas propietarios comunales, estos eran un grupo pequeño, debido a que como se mencionó en el apartado anterior (2.1), desde el proceso de independencia se les despojó de este tipo de tenencia de la tierra. Los propietarios comunales no ocupaban jornaleros, su trabajo era doméstico y familiar, sus ganancias eran muy limitadas y no se veían favorecidos para subir de posición en la estructura social de clases constituida (Molina, 1985).

La última posición de la división social del elemento indígena lo ocupaban los jornaleros, éstos eran quienes vendían su fuerza de trabajo a los grupos dominantes y se empleaban principalmente en actividades relacionadas al campo y a la tierra, se trató de un estrato sumamente subordinado y sometido. Sus ingresos eran mucho menores que los de las subcategorías anteriores y su calidad de vida era muy mala. Cabe decir, que mucha de la población indígena se vio obligada a ubicarse en esta categoría. La estratificación de clases durante el porfiriato da cuenta de una organización social, económica y cultural desproporcionada, Molina Enríquez la describe como “... un cuerpo... [que] del tórax hacia arriba es un gigante, [y] del tórax para abajo, es un niño” (Molina, 1985: 68). Es decir, las diferencias de clases eran totalmente notorias, pues quienes ocupaban las posiciones más altas eran grupos minoritarios, pero con un gran poder sobre los otros.

Las distinciones de clase vistas hasta este momento continuaron su acentuación pasando el tiempo, como fue durante el proceso de la Revolución mexicana (1910-1920). Al principio de este periodo, la mayoría de los indígenas se transformaron en peones que trabajaban por pequeñas ganancias y con prácticamente nulas prestaciones. Su área de trabajo seguía siendo relacionada al campo y a la tierra, bajo un sistema que los ataba y subordinaba por medio de grandes deudas en las llamadas Haciendas ${ }^{37}$. Estos grupos no eran libres de elegir en donde trabajar, pues las deudas les impedían abandonar el lugar en donde se les explotaba a menos

\footnotetext{
${ }^{37}$ Grandes propiedades rurales para la explotación latifundista
} 
de que pagaran todo lo que debían. Esto era casi imposible, pues su trabajo no generaba ningún tipo de excedente y más bien solo permitía a las familias medio vivir (Whetten, 1985).

Aparentemente, las condiciones con las que se contrataba a los jornaleros indígenas, brindaban ciertos beneficios para este sector, pero la realidad se alejaba mucho de este fin:

El jornal del peón rara vez se paga en efectivo. Comúnmente se le da por su trabajo un pagaré o boleto de tiempo que debe negociar en la tienda de la finca, con resultados obvios. Por otra parte, el salario efectivo que gana no es la única compensación que el peón recibe. [...] Así, ocupa una choza de la hacienda sin que se le exija el pago de renta. Se le autoriza comúnmente una milpa, un pedazo de tierra para su uso propio, y de aquí puede obtener por lo menos una parte de su subsistencia. Además, como tiene que recurrir por fuerza a la tienda de la finca, goza en ésta crédito suficiente para salir de apuros en caso de pérdida general de la cosecha. Sin embargo, en realidad es tan mezquina la compensación que recibe, que se le mantiene en la más abyecta pobreza y pocas oportunidades se le ofrecen de escapar a la servidumbre impuesta por el sistema establecido (McBride, 1951: 30, en Whetten, 1985: 75-76).

Con esta forma de trabajo más de la mitad de la población rural estaba anclada a un sistema de esclavitud y servidumbre en donde su principal verdugo eran las enormes deudas. Debido a esto, fue muy difícil pensar que los grupos indígenas trascendieran en al menos una posición media de la jerarquía social de clases. Es así, que el contexto de clases en este periodo seguía estando fuertemente marcado por la concentración de recursos y poder solo en unos cuantos grupos, mientras que el resto se encontraban en una situación desfavorable como había estado sucediendo desde procesos previos (Whetten, 1985).

Durante la Revolución la población mexicana se encontró en un ambiente envuelto por un conflicto armado, en donde se suponía que se estaba persiguiendo la consigna revolucionaria de "Tierra y Libertad". Estos ideales implicaban la lucha para brindar tierras a quienes carecían de ellas, acceso a la educación de la población analfabeta, emancipación del indio, la conformación de un gobierno democrático, y en general la mejoría del bienestar de la sociedad. Con el transcurso de esta lucha, después de 1920, se desarrollaron varias reformas con las que se pretendía dar atención a las necesidades antes mencionadas, y a su vez se buscaba equilibrar la desigualdad social de clases. Sin embargo, los efectos recibidos no fueron precisamente los esperados (Whetten, 1985).

En materia agraria se echó a andar un programa que tenía por objetivo fraccionar las grandes haciendas y redistribuir la tierra a los campesinos e indígenas, quienes constituían el peldaño 
más bajo de la estructura social de clases. Con este plan, casi en el año de 1945 se habían distribuido una gran cantidad de hectáreas de tierra, beneficiando a algunos de los grupos desfavorecidos desde tiempo atrás, pero del total de tierras solo una cuarta parte servía para ser cultivada, la otra parte se conformaba de pastos, bosques, montes y tierra improductiva. Es decir, si bien la tierra se empezó a concentrar en otras manos, no se obtuvo el beneficio pretendido para las poblaciones más pobres, pues la mayor parte de tierra fértil no pertenecía a estos grupos, sino que se constituyeron ejidos y los dueños de estos eran quienes gozaban de al menos la mitad de tierras cultivables, lo que seguía marcando una fuerte desigualdad entre la población (Whetten, 1985).

Por otro lado, en México también se desarrollaron políticas que promovían la educación de las masas. Para lograr los objetivos de estos programas, se crearon miles de escuelas nuevas para la educación básica, y escuelas normales para la capacitación de nuevos maestros que impulsaran la consumación de las metas propuestas en contra del analfabetismo. Los resultados de esto, podría decirse que fueron favorables en cierta medida, ya que incrementó la cantidad de población con acceso a la educación. Lo cual es importante, ya que se notaron algunos efectos de estas políticas en la estructura de clases, mejorando ligeramente la condición de vida de algunos grupos de los estratos bajos de la jerarquía social. Además, se dotaron las bases para la conformación de las clases medias en el país (Whetten, 1985).

Aun con estos cambios no es posible decir que se estaba terminando con la existencia de las clases bajas. Como se había vivido desde sucesos anteriores, la mayoría de la población seguía perteneciendo a las clases más bajas del país, principalmente la población indígena (situación que perdura hasta nuestros días). "En muchos casos [a la población rural] se le ha enseñado a leer frases sencillas; pero la falta de periódicos, libros o revistas en su comunidad aislada le impide ejercer la habilidad recién adquirida que, por prolongado desuso, es posible que llegue a olvidarse por completo" (Whetten, 1985: 82). Se dice que, en materia cultural, los grupos indígenas seguían en un nivel similar a la época colonial, y solo unos pequeños sectores habían mejorado levemente su nivel (Whetten, 1985).

Otro elemento importante en cuanto a la determinación de clases fueron las condiciones de vivienda, gran parte de las construcciones eran consideradas como jacales o chozas que se encontraban cerca de barrancas, en las periferias y zonas marginadas. Lo que traía consigo 
problemas sanitarios graves, esto como resultado de factores como el consumo de agua contaminada, pues el agua potable, generalmente no se suministraba en las zonas rurales, limitando la calidad de vida de una gran parte de la población (Whetten, 1985). Con esto, no se pretende decir que las políticas impulsadas durante la época hayan fracasado, de algún modo, el rompimiento con la posesión monopólica de las tierras, la promoción de programas educativos y para la mejora social, aumentaron muy poco los niveles de vida de los grupos rurales. Esto no significa que se haya reducido el alto grado de pobreza en la que vivía un gran número de la población en México, pero sí se favoreció que la sociedad se segmentara aún más.

La sociedad mexicana ahora se dividía en tres principales clases consumadas: alta, media y baja. La clase media fue un elemento nuevo, el cual no se constituyó, principalmente, por grupos de clase baja que hayan escalado en la jerarquía social. En realidad, mayormente se conformó por algunos sectores que habían ocupado los peldaños más altos y que con la aplicación de las políticas revolucionarias bajaron de nivel, esto debido a seis principales condiciones. La primera tiene que ver con los millones de hectáreas de tierra que habían sido redistribuidas a los grupos rurales, pues estas fueron tomadas de las enormes propiedades que poseían muchos de los grupos de las clases altas. Algunos antiguos hacendados conservaron pequeñas partes de lo que habían sido sus propiedades y con ello se dedicaron a la agricultura de la clase media (Whetten, 1985).

Otros vendieron sus propiedades y con lo adquirido se reubicaron en la Ciudad de México o Guadalajara, viviendo de sus ahorros o de lo que ganaban ocupándose en pequeñas empresas comerciales. Habitar en las grandes ciudades les otorgaba cierto prestigio que los afianzaba en la clase media. Por ello, también existió quienes invirtieron en propiedades inmuebles, en la industria y el comercio en estas mismas ciudades. Las actividades que todos estos realizaban los mantenían muy ocupados ganándose la vida, tanto que difícilmente se les podía seguir considerando como parte de las clases altas de nuestro país (Whetten 1985).

Entre estos grupos hubo otros que se colocaron en puestos administrativos del gobierno. Muchos de éstos utilizaron los ideales de la Revolución para favorecer sus propios intereses. En vez de acatar su responsabilidad de administrar e implementar los programas gubernamentales y de velar por la consumación de las principales consigas de esta lucha, 
ocuparon sus posiciones para generarse prestigio y riqueza. Con reconocidos ingresos moderados, en muy poco tiempo lograron adquirir propiedades de gran tamaño y costosas. Además de subir en sus posiciones laborales, incrementando rápidamente sus ingresos. Así, la riqueza y poder salió de las manos de algunos cuantos, pero continuaron concentrados en grupos pequeños, remarcando los diferentes niveles de la nueva estratificación social (Whetten, 1985).

Una segunda consecuencia para la conformación de las clases medias en México se constituyó del desarrollo de las propiedades agrarias particulares y de administración personal. Esto mediante un programa para el beneficio ejidal, el cual consideró proyectos que promovían sistemas de riego para mejorar la calidad de los cultivos. Este programa quedó a cargo de la Secretaría de Recursos Hidráulicos creada por el gobierno de este periodo. Con este programa algunas de las tierras fueron distribuidas a ejidatarios y algunas otras fueron vendidas como unidades agrícolas de tamaño legal, casi siempre en la zona norte del país. Estas fueron adquiridas principalmente por agricultores que lograban vivir en condiciones similares a las de familias rancheras del occidente de Estados Unidos (Whetten, 1985). Mientras que las propiedades más pequeñas quedaron en manos de familias que "se esfuerzan por conservar un nivel respetable de vida" (Wetthen, 1985: 85), para poder mantener un lugar en la clase social media.

El tercer elemento de las clases medias se centra en el ámbito escolar. El acceso a la educación empezó a considerarse como un conducto para ubicarse en la clase media, principalmente de quienes ingresaban al nivel superior. Entre los años de 1942 al 46 se expidieron 26, 401 títulos profesionales a abogados, ingenieros, médicos, dentistas, maestros, etc. Lo que facilitó que algunos de estos se emplearan en servicios gubernamentales, mientras que los otros tuvieron la capacidad de ejercer independientemente. Gracias a esto, una gran parte de los profesionistas fueron ubicados automáticamente en la clase media (Whetten, 1985).

Con este programa, sí se benefició el desplazamiento de una muy pequeña cantidad de individuos de las clases bajas para subir en la jerarquía social de clases. Por ejemplo, en la Escuela Nacional de Agricultura en Chapingo se aceptaron 400 alumnos becados por el gobierno, de los cuales al menos un $60 \%$ fueron seleccionados de algunas comunidades 
rurales. Quienes eran provenientes de escuelas vocacionales de agricultura, lugares en donde por lo regular, estudiaban jóvenes integrantes de familias que se enfrentaban a importantes dificultades económicas. Estos al momento de egresar de la institución universitaria, fueron considerados como parte de la clase media de la sociedad mexicana (Whetten, 1985), puesto que contar con estudios profesionales implicaba una mejoría de status social.

La cuarta fuente que dio vida a las clases medias descansa en las burocracias gubernamentales. Los programas implementados a partir de la Revolución hicieron necesaria la extensión de varias de las funciones del Gobierno, lo que resultó en la contratación de un mayor número de empleados federales, estatales y municipales, que supuestamente se encargarían de hacer funcionar las diferentes dependencias. Muchos de estos empleados percibían sueldos muy bajos, pero sus cargos les permitían ubicarse en las clases medias de la sociedad. El hecho de que los trabajadores ya no se emplearan en labores manuales como las del campo y la tierra, les hizo ganar una imagen de prestigio y respeto, lo que implicaba un mejor nivel social (Whetten, 1985).

Estos grupos aun con sus ingresos bajos se esmeraban por mantener una imagen que los separara de las clases bajas. Había quienes contrataban empleados domésticos para que se encargaran de las actividades manuales del hogar, tener este personal era índice de pertenencia a la clase media. Otros aspectos que los caracterizaban era su necesidad por adquirir mobiliarios que los diferenciara de las clases bajas, muchos de estos se empeñaban en tener un nivel de vida más alto de lo que les posibilitaban sus ingresos. Por otro lado, la mayoría de los empleados públicos daban gran importancia a los estudios escolares de los hijos, pues como se mencionó líneas previas, el acceso a la educación también se consideró un elemento vital de las clases medias, ya que los grupos mayormente desfavorecidos no tenían las mismas oportunidades (Whetten, 1985).

La quinta condición de la formación de las clases medias se debió a la creciente industrialización de México. Durante este periodo, el índice de producción industrial se incrementó, principalmente en las grandes ciudades como Puebla, Guadalajara y la Ciudad de México. Debido a esto, en 1940 al menos un 10.9\% de la población trabajaba en algún tipo de industria, de los cuales, quienes se encargaban de la dirección, gerencia y demás funcionarios eran ubicados en la clase media. Mientras que el resto de trabajadores, como 
fue el caso de los obreros, se mantenían en los peldaños bajos de la estructura social de clases. Solamente el pequeño grupo de propietarios de las industrias eran de clase alta. Así, este fue uno de los ámbitos en donde se representaba muy fuertemente la desigualdad entre los tres niveles de clase de la sociedad mexicana (Whetten, 1985).

Por último, la sexta fuente de la nueva clase social se ubicó en el desarrollo del comercio. En 1940 un buen número de la población se dedicaba a actividades de este ámbito. Los tenderos y comerciantes constituyeron un sector importante como la pequeña clase media en nuestro país. Este sector creció y se vio favorecido gracias a los proyectos de urbanización que se estaban impulsando, tales como el desarrollo de las vías de comunicación y la extensión de carreteras. Muchos de los propietarios de las empresas comerciales, sin duda, se posicionaron en los niveles medios de la estructura de clases, esto debido al crecimiento de actividades económicas como el turismo. Ésta brinda oportunidades de empleo para vendedores, oficinistas y gerentes, todos parte de la clase media (Whetten, 1985).

Podemos decir que, en la sexta fuente, al igual que en otros aspectos de la vida social de México, se denota la importancia y el lugar que ocupa la población extranjera para la consumación de las clases sociales, en las que se excluye de los niveles más altos a ciertos sectores, tal como hemos visto a lo largo de este apartado. Estos grupos, son esa mayoría de la población del país que se dedicaba a la agricultura en propiedades de extensiones pequeñas, con malas condiciones económicas y dificultad para abandonar la clase baja.

Con los programas de gobierno que se impulsaron durante la época se vio un acelerado crecimiento de las clases medias, pero esto no ha significado que la pobreza en la que viven algunos grupos decrezca, sino que, por lo contrario, se siguen manteniendo las grandes desigualdades de clase a causa de la concentración de recursos y privilegios en algunos grupos pequeños, pero poderosos que por su posición someten a los de las clases más desfavorecidas.

Esta situación es algo que se ha vivido durante muchos años, no solo en periodos específicos como los mencionados en este apartado. Las condiciones de vida de las clases inferiores han sido algo alarmante en cada etapa de la constitución de nuestro Estado mexicano. Por ejemplo, más recientemente, en los años sesenta perduraba un índice de analfabetismo muy elevado, una gran parte de la población no contaba con acceso a la educación, ni siquiera 
básica, pues en muchas zonas rurales se comienza a laborar en actividades agrícolas y domesticas desde una corta edad (González, 1985).

Otro aspecto representativo de los altos niveles de desigualdad social en México, según Pablo González Casanova, era que la pobreza de algunos grupos se veía reflejada en un 38\% de la población total que aún no usaba zapatos. Esto como resultado de la gran escasez de recursos económicos, puesto que era más importante generar ingresos para la subsistencia familiar e individual que adquirir ciertos productos. Además, también podríamos agregar que debido a que a estos grupos han estado excluidos durante mucho tiempo de ciertos ámbitos, no se encontraban asociados con el uso de prendas como estas, persistiendo el uso de sus atuendos propios, sin importarles el status social que esto pudiera implicar.

La alimentación es otro factor en el que se refleja la gran desigualdad de clases. En estos mismos años había sectores que tenían un consumo limitado de productos como carne, pescado, leche y huevos. Esto se debió a los altos precios de los alimentos, que los hacía poco accesibles para que las poblaciones más pobres pudieran adquirirlos. Es así que su alimentación se componía de productos más económicos al alcance de estos sectores. Por otro lado, los grupos que sí tenían la capacidad para adquirirlos se suelen identificar como parte de las clases medias y altas de la sociedad mexicana (González, 1985).

La producción de los alimentos no estaba directamente en manos de las clases privilegiadas, sin embargo, estos son los dueños de las industrias en donde se empleaba a miembros de las clases bajas. González señala que, pese a que México es una sociedad plural y culturalmente heterogénea, han perdurado acciones de explotación, sometimiento y abuso de grupos que viven en condiciones de marginalidad. Estos, para lograr su subsistencia diaria, viven constantes abusos a su calidad humana, vendiendo su fuerza de trabajo por extensas jornadas, realizando labores pesadas y percibiendo ingresos muy bajos que no favorecen el total de sus necesidades básicas, pero que sí mejoran la calidad de vida de sus explotadores de las clases altas.

Otro gran problema que promovió las desigualdades de clases durante los años sesenta fue el hecho de que una gran parte de la población indígena y rural era monolingüe, esto significa que la mayoría solo hablaba una lengua específica que no era el español, algunos otros que eran más jóvenes hablan ambos, pero estos eran una minoría. Así, factores como hablar una 
lengua, dedicarse a trabajos manuales y promover usos y costumbres, suele ser asociado a altos índices de pobreza (económica) y por ende pertenencia a las clases sociales bajas (González, 1985). Este tipo de desigualdad es algo que no trata únicamente de condiciones económicas, sino que combina elementos que hemos mencionado en el apartado anterior, referentes a la condición de raza (véase apartado 2.1).

Las disparidades de clase que se generaron en este periodo debido a la condición racial y sus elementos, se encuentran vinculadas a la vez, con el difícil acceso a la educación que como en etapas previas, se excluía principalmente a las poblaciones rurales. Por ejemplo, según un censo realizado en $1960^{38}$, se estimó que, de la población total, el $43 \%$ había cursado solo tres años de educación primaria, mientras que un $0.4 \%$ contaba con educación profesional. Es esto uno de los motivos por los cuales la mayoría de la población de las zonas rurales no dominaba el idioma español, poniéndolos en desventaja frente a los sectores dominantes como la población mestiza de clase media en adelante (González, 1985). Es así que, podemos decir que las desigualdades entre grupos se deben a múltiples factores.

Actualmente, es evidente que las cifras anteriores han cambiado completamente. Sin embargo, un hecho que perdura es que gran parte de las poblaciones rurales no hablan y no entienden español, algunos otros lo entienden muy poco, lo que tiene graves implicaciones en contextos específicos como lo es nuestro estudio de caso. Algunas mujeres indígenas no hablan y no entienden la lengua dominante al enfrentarse a procesos penales y durante la privación de la libertad. En otros casos, aunque entienden español, sus contextos de vida han limitado su acceso a la educación, por lo que no saben leer, ni escribir, lo que representa un serio problema en situaciones como la de nuestro interés.

Los tipos de desigualdades vistas hasta este momento nos permiten enlistar una serie de elementos que generan el desequilibrio entre grupos. Pero, además, poniendo cierta atención en lo narrado hasta aquí, poco se ha dicho sobre la condición de las mujeres durante el proceso de conformación del Estado Nación mexicano y su papel en la actualidad. Ante esto, es preciso decir que las distinciones de género pueden promover una mayor vulneración, marginación y exclusión. Esto, no solo cuando se habla de las diferencias entre hombres y mujeres, sino que entre grupos conformados por éstas últimas se puede identificar que para

\footnotetext{
${ }^{38}$ VII Censo General de Población, 1960. Dirección General de Estadística. México.
} 
algunos casos se generan situaciones de desventaja, mientras que para otros en privilegios. Lo anterior derivado, además de la condición de género, de la de raza, la de clase social y la edad (generación).

Es prudente aclarar que no todas las mujeres son iguales, no es lo mismo ser mujer indígena, analfabeta y pobre; que ser mestiza, con cierto grado de escolaridad y de clase media o alta. La agrupación de éstas en sitios en donde el poder se concentra en algunos, aunado a los elementos revisados en este capítulo (distinción de raza y clase social), impactan de distinta forma en la vida de las diversas mujeres. Y de ahí que éstas desarrollen estrategias para sobrevivir. Así, para poder realizar el pretendido análisis comparativo de esta investigación, es preciso abordar desde la categoría de género, cómo se han establecido las relaciones y diferencias entre mujeres de distintos tipos dentro de nuestro actual Estado Nación. 


\section{Categoría de género: las mujeres en la sociedad}

La categoría de género es una importante herramienta de análisis y exploración de cómo se consolidan las relaciones de poder, subordinación y vulneración que, en primera instancia, se promueven entre hombres y mujeres. Y que, además, están relacionadas con aspectos culturales, económicos, políticos, psicológicos, jurídicos y sociales. El género, de manera general, según la Real Academia Española, se define de las siguientes formas "conjunto de seres que tienen uno o varios caracteres comunes", "clase o tipo a que pertenecen personas o cosas" y "grupo al que pertenecen los seres humanos de cada sexo, entendido este desde un punto de vista sociocultural en lugar de exclusivamente biológico" (RAE, 2019 $9^{39}$ ).

Partiendo de la última interpretación, cabe destacar que, aun cuando en ocasiones el género suele ser entendido -erróneamente- como sinónimo de sexo, no se trata de lo mismo. Como se señala en la definición expuesta, el sexo hace una distinción desde las características biológicas, físicas, fisiológicas y anatómicas con las que nacen las personas, determinando así, si se trata de hembras o machos/ hombres o mujeres. El sexo es algo que no se elige, ya que es una construcción determinada naturalmente. Las diferencias que se designan según los sexos, no dependen de los procesos históricos y socioculturales de los grupos, mientras que el género sí.

Este último se refiere a las distinciones que dependen de la simbolización de las creencias, atribuciones y percepciones sociales que establecen lo que es "propio" de varones y lo de las mujeres. Desde el momento del nacimiento, los individuos han de interiorizar lo que es aceptado para su género según su entorno social. "Cada cultura otorga significados a esa diferencia anatómica y en cada cultura esta simbolización de la sexuación estructura los usos y costumbres particulares, además de que determina las relaciones de poder entre mujeres y hombres" (Lamas, 2016: 156-157). Es con el género que se manifiestan diversas actitudes y prácticas de dominación y subordinación en los ámbitos cotidianos de los individuos: lo social, familiar, político, religioso, laboral, etc.

Al ser el género una construcción sociocultural los individuos adquieren por medio del proceso de socialización características, sentimientos, prácticas y habilidades que, a su vez,

\footnotetext{
${ }^{39}$ Diccionario de la Real Academia Española. Disponible en: $\underline{\text { https://dle.rae.es/?w=g\%C3\%A9nero }}$
} 
responden a prohibiciones sociales según lo correspondiente para cada sexo. El ser mujer y el ser hombre no es lo mismo para todas las sociedades, pero algo que podríamos decir que se comparte en la mayoría de los casos, son las fuertes desigualdades entre grupos. Y si bien, cabe mencionar que, otras condiciones como la clase social, la raza y la edad se entrecruzan con el género para desarrollar las distintas maneras de vulneración, es este concepto un importante punto de partida para entender qué es lo que genera las desequilibradas relaciones dadas entre seres humanos dentro de las sociedades (Lamas, 2016).

Las demarcaciones de género se perfilan a lo largo de las etapas de la vida de los individuos a través de las funciones económicas, políticas y sociales de las que se van haciendo parte. Se dice que, aunque estas funciones no son fijas, porque en algunos casos se van modificando, no solo operan desde las concepciones culturales, sino que, también dentro de un mundo imaginario. Conway, Bourque y Scott, dicen que: "Las normas del género no siempre están claramente explicitadas; a menudo se transmiten de manera implícita a través del lenguaje y otros símbolos. De la misma manera que un lenguaje específico en cuanto al género influye en cómo se piensa o se dicen las cosas [...], dan por sentado la presencia de un protagonista masculino [e] influyen en la forma en que se arman cuentos acerca de las mujeres" (Conway, Bouque y Scott, en Lamas, 2018: 43). La construcción del ser mujer, se podría decir, ha sido forjada desde una mirada masculina que asigna lo propio de cada persona.

Tradicionalmente en gran parte de las sociedades, los sexos se han diferenciado por las asignaciones de roles, actitudes y comportamientos de los hombres y de las mujeres, las cuales se creía que eran determinadas, en primera instancia, por las características biológicas de los individuos. Por ejemplo, la mujer ha sido vista como frágil, pasiva, obediente, cariñosa y es quien debe de hacerse cargo de las actividades del hogar; como la crianza de los hijos y de dar atención a las necesidades de los varones de las familias. Mientras que, por otro lado, a los hombres se le asignan valores como la valentía, dominación, agresividad, impulsividad, fuerza, es el proveedor del sustento familiar, y la educación de los hijos no depende ellos. Sin embargo, diversas autoras han hecho notar que estas adscripciones son conformadas según las creencias, significados y significaciones que cada sociedad determina. 
A partir de lo anterior, para entender y explicar de modo más congruente la constitución de desigualdades entre individuos (hombres y mujeres), es que en los años setenta, el concepto de género empieza a tomar fuerza en las Ciencias Sociales, en donde se comienza a visualizar a las personas; sus roles, actitudes y comportamientos más allá de características físicas y biológicas. Por esta razón, durante estos mismos años, pensadoras feministas, principalmente, impulsan el uso de la categoría de género para explicar la raíz de las desigualdades entre sexos. Estas mujeres, retoman y analizan las contribuciones de autoras como Margaret Mead (1935), quien plantea la idea de que las concepciones de género eran sociales y no biológicas y que pueden variar según los diferentes entornos (Conway, Bouque y Scott, en Lamas, 2018).

Los planteamientos de Mead parecieran no tener sentido en un inicio, ya que había un fuerte dominio de las creencias que planteaban que lo que diferenciaba a los hombres de las mujeres eran las condiciones naturales (Conway, Bouque y Scott, 2018). Lo cual, esta autora comienza a cuestionar haciendo un análisis de la división sexual del trabajo y las estructuras de parentesco de las etnias arapesh, mundugumor, tchambouli. A partir de esto muestra que, distinto a las sociedades occidentales, las conductas entre los sexos no son adquiridos biológicamente, sino que, son creaciones socio-culturales y que, por lo tanto, pueden ser modificadas según el grupo social de cada individuo (Ochoa, 2020: 99); (Curiel, 2013: 110).

Por otro lado, también se destacan las aportaciones de Simone de Beauvoir (1949), quien a agrosomodo señala que: "la mujer no nace, se hace". Esta autora, dice que, en ciencias como la biología, psicoanálisis y el materialismo histórico, las mujeres son representadas como "lo otro", no como sujetos. Hace una distinción entre "lo mismo", que se representa por los varones y lo "otro absoluto" con lo que identifica a las mujeres en el lado de la opresión. A partir de esto, Beauvoir expresa que el sexo femenino es puesto fuera de lo considerado humano, mientras que lo que sí forma parte de esta categoría, se compone por lo masculino. Las mujeres no son parte, sino más bien, una extensión de un todo masculino (Curiel, 2013: 110-111).

La autora también destaca que lo femenino queda excluido de muchas de las concepciones culturales con las que los individuos crecemos, vamos desde aspectos como el arte y el lenguaje, en donde los hombres son quienes representan el eje central de casi todo. Por 
ejemplo, cuando hacemos referencia de los "seres humanos", muchas veces lo expresamos como "el hombre" o "los hombres", lo que deja fuera a las mujeres de esta concepción (Triglia, 2020). Es así que, son los mismos sistemas culturales los que dan significación y simbolización a las atribuciones de cada sexo, y no es que se determinen por las características biológicas de los individuos. Estos, también se encargan de segregar y subordinar a las mujeres ante los varones. Con lo que señala Beauvoir, lo considerado correctamente femenino o masculino, es adquirido mediante procesos sociales por los que transitamos desde el momento de nuestro nacimiento (Lamas, 2016).

Sobre este proceso socio-cultural la socióloga Ann Oakley (1972), hace uso de la categoría de género para explicar que el ser mujer o ser hombre, y la manera cómo se definen las relaciones de poder entre ambos sexos (al igual que como señalan las otras autoras), son una construcción cultural. La sociedad es la que moldea a los individuos para definirse como varones o mujeres. La decisión de lo que los sujetos tendrán que adquirir tiene como punto de arranque las características biológicas con las que estos nacen para que, posteriormente, se les vayan asignando los aspectos propios para cada sexo. Oakley dice que: "Es cierto que todas las sociedades utilizan el sexo biológico como criterio para la atribución de género, pero tras este simple punto de partida no existen culturas que estén completamente de acuerdo sobre lo que diferencia a un género de otro (Oakley, 1977: 185 en Stolke, 2004: 89).

Esta autora empleaba desde 1972 el concepto de género como el comparativo intercultural de las distintas maneras en que hombres y mujeres son forjados desde lo establecido en sus entornos. Oakley destaca que existe una extensa variabilidad de significados culturales de lo que determina al género, y esto, a su vez, define los modelos de organización, económica, política y social. Con el análisis que hace esta autora, llega a la conclusión, de que el género se define de manera general como la construcción social del sexo; lo femenino o masculino dependerá y ha de variar según lo que cada sociedad y cada cultura otorgue a los individuos desde sus características biológicas (Curiel, 2013).

La concepción de género como una construcción socio-cultural basada principalmente en dos sexos, puede llegar a tomar muchas formas, las cuales impactarán en términos sociales e individuales. Lo que cada sociedad define como apropiado para uno y otro sexo determina muchos aspectos de la vida de los individuos, tal como son las relaciones e interacciones 
entre estos, en todos los ámbitos sociales posibles, como: en el hogar, lo laboral, económico, político, religioso, académico, carcelario, etc. Partiendo de este planteamiento, es que, según la historiadora Joan Scott (1987), tomando en cuenta a las mujeres dentro de los análisis históricos de la sociedad, dice que, a lo largo de los procesos sociales, se han ido estructurando jerarquías sexuales y distribuciones desiguales de poder.

La autora hace referencia a los estereotipos que se marcan en las interacciones de este tipo de relaciones binarias. Estos, se representan en la muy notoria separación y distribución de actividades aceptadas para cada sexo en aspectos como la vida familiar y la crianza de los hijos, en donde las distribuciones de poder son marcadamente desiguales (en el hogar y en todos los ámbitos sociales, pareciera que son los hombres quienes mandan). Scott ejemplifica esto; en primer lugar, durante el periodo de Industrialización de Occidente, en donde todo lo referente al hogar y la vida laboral es separado: las mujeres se ocupan principalmente, de lo privado; como es la crianza y educación de los hijos. Los hombres, por otro lado, son puestos a cargo de lo público: la vida laboral, política y económica (Scott, 1987, en Lamas, 2018).

Otro ejemplo importante que da la autora sobre estas disparidades entre sexos, es en cuanto a los avances de la educación superior en Estados Unidos. En donde en el siglo XIX, las mujeres son excluidas de actividades como la investigación y todo lo relacionado con conocimientos científicos. Las mujeres, son colocadas en actividades que han sido etiquetadas socialmente como propias de las mujeres, tales como: la enseñanza de menores, enfermería y trabajo social. Cabe decir que, las actividades que son bien vistas para las mujeres, en la mayoría de los casos, son remuneradas con una menor paga. Mientras tanto, las actividades que representaban masculinidad, eran las mejor pagadas, entre estas tenemos: la ingeniería, derecho y la investigación científica (Scott, 1987, en Lamas, 2018).

Según lo expuesto previamente es preciso decir que, aun cuando se visualizan estas desigualdades en momentos y lugares distintos a los actuales, encontramos muchas situaciones similares hoy en día. Respecto a esto, acercándonos un poco a nuestro estudio de caso, tal como lo veremos más extensamente en los próximos apartados, en las cárceles habitadas por mujeres y hombres (cárceles mixtas), a simple vista se identifica que la mayoría de sus actividades son estigmatizadas según cada sexo. Por ejemplo, los principales talleres que son impartidos para la población varonil en cárceles de esta categoría son: carpintería, 
herrería y electricidad. Mientras que para las mujeres son, en la mayoría de los casos, manualidades con materiales como fommy y estambre; tejido y bordado.

Gracias a las capacitaciones que reciben los varones dentro de reclusión, algunas veces son contratados temporalmente por el mismo sistema carcelario para dar mantenimiento a las áreas comunes de las instituciones cuando son necesarias. Estos hombres son encargados de las reparaciones o lo que sea necesario "mejorar" en los espacios que componen a las diferentes áreas. A quienes se asignan estas responsabilidades, reciben remuneración económica de parte de las autoridades. Mientras que, por otro lado, las mujeres no son requeridas para ninguna de estas actividades, porque lo que aprenden a hacer no es del todo útil para las instituciones. Así, ellas deben de buscar generar ingresos de manera independiente. En algunos casos, se dedicarán a la venta de los productos manuales que produzcan, y que, en la mayoría de los casos no son bien pagados.

Como podemos ver, así como las mujeres frecuentemente son excluidas de actividades y espacios, también en muchos estudios y análisis que se han hecho para entender las relaciones sociales y de poder, se omite la presencia femenina. La realidad social, mucho tiempo ha parecido ser una realidad formada por los varones y únicamente para ellos. Al respecto, algunas ideas que dan sustento a esta afirmación son trabajos como los de James Stephen y John Stuart Mill, quienes escribieron ensayos sobre la igualdad, de los que, pensadoras feministas como Jill Conway, Susan Bourque y Joan Scott, destacan que aun cuando las aportaciones de Stephen y Mill se posicionaron como importantes referentes clásicos del pensamiento político, estos no incluyen a las mujeres dentro de la identidad colectiva de los hombres (Conway, Bourque y Scott, 1987, en Lamas, 2018).

Debido a esta exclusión es que las autoras que utilizan el género como una categoría de análisis para las principales desigualdades sociales, se cuestionan cómo era entendida la vida política por las mujeres de esa época, lo que difícilmente alguien se había preguntado en un mundo en donde la tendencia era analizar a la sociedad desde la perspectiva de los hombres. Y si no se había considerado a las mujeres para los estudios sociales, mucho menos se habrían de destacar otros tipos de condiciones que también generan vulneración y sometimiento entre individuos de una misma sociedad. Es por ello que Harriet Taylor y Jane Addams, en sus 
aportes para los estudios de género, y desde una visión propia, comparten cómo era entendida la igualdad para hombres como para mujeres, considerando así, la voz femenina.

Aun cuando las mujeres comienzan a ser tomadas en cuenta en los estudios referentes a las conformaciones de las diferencias sociales, George Murdock en 1937, hace un comparativo de la división sexual del trabajo en diferentes sociedades, llegando a la conclusión de que no todas las especializaciones por sexo se pueden explicar con base a las diferencias físicobiológicas entre hombres y mujeres “...eso es especialmente evidente en lo que se refiere a la manufactura de objetos, para lo que no es la fuerza la que determina, por ejemplo, si un varón o una mujer elabora una canasta, sino que esa canasta vaya a ser utilizada en tareas consideradas femeninas o masculinas" (Lamas, 2018: 113). Así, este autor destaca, que la idealización que los individuos adquieren desde la niñez acerca de los usos y aplicaciones de los objetos, también determinan las diferencias temperamentales de éstos según su sexo (Lamas, 2018).

Murdock, señala, además, que otra referencia que enmarca las diferencias entre los sexos es la que él constituye a partir del análisis del concepto de status. El uso de este concepto tiene mayor claridad con los aportes de Ralph Linton, quien señalaba que las personas aprenden su estatus sexual y los comportamientos adecuados para este. En este sentido, la masculinidad y la feminidad son concebidos como estatus instituidos que a la vez conforman las identidades psicológicas de los individuos y estos aceptan de manera natural la posición social en la que son colocados desde su nacimiento. Sin embargo, es cierto que en algunas ocasiones sucede que los individuos no se encuentran conformes con el estatus otorgado y cuando esto sucede, se genera en el debate de género un conflicto.

Es a partir de esto que, desde la antropología, se cuestiona nuevamente si de verdad hay una relación entre lo biológico y lo sociocultural. "Si los papeles sexuales son construcciones culturales, ¿por qué las mujeres siempre están excluidas del poder público y relegadas al ámbito doméstico? Y si los papeles sexuales son determinados biológicamente, ¿qué posibilidades hay de modificarlos?” (Lamas, 2018: 114). Los estudios antropológicos han mostrado que las sociedades construyen sus propias divisiones mediante la ideología que separa la naturaleza de lo cultural, lo salvaje de lo doméstico; lo bueno de lo malo. Es decir, cada sociedad determina todo lo que es propio para cada sexo, el lugar que ocupa cada 
individuo, y de lo que, cabe destacar, lo femenino es puesto en la representación de lo atrasado o de lo incapaz.

En años más recientes las representaciones de género que hasta aquí se han mencionado, comienzan a tomar un sentido más amplio. La participación de las mujeres en este tipo de estudios se comienza a notar aún más con la integración de algunas procedentes de lugares como América, Oriente y África. Quienes, a diferencia de las investigadoras antes expuestas, miraban la problemática desde una ideología más extensa y radical. Al momento de analizar los orígenes de la opresión femenina se basaban en la relación entre el capitalismo y la dominación patriarcal, con lo que descartan que las desigualdades provengan de condiciones naturales, sino de aspectos sociales (Lamas, 2018).

Tal es el caso de lo que expone la antropóloga Gayle Rubin (1975), quien parte de la premisa de que analizar las causas de la opresión de las mujeres es la base de lo que se debe de considerar para identificar lo que debería de ser modificado para constituir una sociedad sin jerarquías de sexos: "si en la raíz de la opresión femenina encontramos agresividad y tendencia al dominio innato en los hombres, el programa feminista requeriría, lógicamente, ya sea el exterminio del sexo delincuente o bien un programa eugenésico para modificar ese carácter” (Rubin, 1975, en Lamas, 2018: 53). Es decir, la autora pretende identificar las causas de la subordinación de sexos, y a partir de esto, generar las condiciones necesarias para mermar sus efectos.

Así, Rubin comienza su estudio analizando la propuesta de capitalismo de Carlos Marx, en donde lo primero que se destaca es la exclusión de las mujeres en los principales procesos económicos y sociales que el autor expone; la mujer es vista como un ser que debe pasar por un proceso de domesticación en donde sus funciones son determinadas según las necesidades de los hombres. Las mujeres por el solo hecho de ser mujeres, son convertidas en domésticas, esposas, madres, y en una mercancía o posesión de los varones. Tal como sería el hablar de otros sectores como los de los hombres negros, quienes, por su naturaleza, durante este periodo, eran señalados como esclavos u objetos adquiridos, y puestos a disposición de sus respectivos dueños (Rubin, 1975, en Lamas, 2018).

A partir de esto es importante decir que son muchos los grupos que ocupan espacios de desigualdad. Sin embargo, para Rubin es fundamental la condición femenina. Por ello, 
continuando con su interesante propuesta, uno de sus mayores aportes para la categoría de género es lo que ella ha denominado el "sistema de sexo/género", definido como: “el conjunto de disposiciones por el que una sociedad transforma su sexualidad biológica en productos de la actividad humana en el cual se satisfacen esas necesidades humanas transformadas" (Rubin, 1975, en Lamas, 2018: 55). Esta propuesta surge, además del análisis del capitalismo, de la revisión de los postulados de Lévi-Strauss.

De este autor, Rubin destaca la idea del intercambio de mujeres, desde la cual éstas son presentadas como objetos y no como personas. Además, cabe decir que, para Strauss, era importante definir dos grupos de sexo dependientes entre sí, basada en la división sexual del trabajo, que no contemplaba sus diferencias en una base fisiológica, sino desde lo que las sociedades percibían y condicionaban para cada uno de estos dos grupos. A partir de esto, de manera general, Gayle Rubin entiende al sexo como el resultado de las relaciones que organizan y producen la sexualidad, por lo que el género no se encuentra en las características biológicas de las personas, sino desde lo que se determina en cada grupo social, lo cual ha definido las posiciones en las que se ubican los sexos y las diferencias de género (Curiel, 2013).

Más allá de estas propuestas son muchas las perspectivas por las que se miran las motivaciones de la subordinación y exclusión femenina, por lo que, hacer una recuperación histórica de las mujeres durante los procesos más determinantes de las sociedades, fue un hecho fundamental (Lamas, 2018). Con la indagación histórica realizada por mujeres antropólogas, frecuentemente se empiezan a cuestionar si en otras culturas y sociedades las mujeres son subordinadas de la misma forma. Esto fue abriendo nuevas interrogantes y aspectos a analizar, como, por ejemplo, si hay sociedades en las que las mujeres sean quienes ocupen posiciones de dominación y poder, y además lo hayan ejercido. Esto condujo a algunas investigadoras a realizar un análisis profundo de la universalidad de la subordinación femenina, lo que dio como resultado que se modificaran y se potencializaran las teorías y conocimientos con los que se contaba hasta el momento (Lamas, 2018).

Algunas de las aportaciones destacadas fueron las evidencias de la existencia de un poder femenino no reconocido antes, sus implicaciones y alcances, y su naturaleza. Se encontraron hallazgos de que las mujeres mantuvieron papeles importantes en los procesos sociales más 
destacados. Además, se detectaron los factores que facilitaron o limitaron los intentos de las mujeres por modificar los lugares o estatus en los que la sociedad las había colocado. El conocimiento de todo esto, motivó a las investigadoras a explorar las formas y las estrategias (del tipo matrimoniales, laborales, económicas, etc.) que las mujeres desarrollaban en los diferentes entornos sociales. Demostrando así, que las mujeres son piezas importantes en la acción social y política, aun cuando se les ha asignado un estatus bajo (Lamas, 2018).

Este tipo de análisis consiguió mostrar que las mujeres han tenido una amplia participación en los procesos sociales de diversas culturas. Pero, aunque se resaltaron hechos de gran importancia, no consiguieron explicar las causas y motivos por los que las mujeres son subordinadas en la mayoría de las sociedades, esto como una variable constante de cultura en cultura. Además, las antropólogas, también lograron destacar que las diferencias biológicas de los individuos seguían jugando un papel importante en la explicación que se daba respecto a las causas de la vulneración femenina, pues una de las diferencias biológicas más importantes era la maternidad como símbolo de fragilidad y subordinación. Son las mismas sociedades las que le han dado un preponderante significado al hecho de que las mujeres tengan como responsabilidad familiar y social el ser madres (Lamas, 2018).

Por este hecho, es que a las mujeres se les considera más cercanas a la naturaleza, supuestamente, por su capacidad biológica de crear vida. Sin embargo, cuando una mujer decide no ser madre, para la mayoría de las sociedades, se considera que se está saliendo de lo natural y que, por lo tanto, no está cumpliendo con su función social. Es decir, a partir de las características biológicas de los individuos, -en este caso de las mujeres- las sociedades definen lo que es "natural" de cada género, y a su vez, se asigna el rol que le corresponde a cada persona según su sexo. El hecho de convertirse en "antinatural" y no cumplir con lo que la sociedad establece, hace que algunas mujeres sean puestas en un estatus mucho más bajo en donde se promueven importantes desigualdades (Lamas, 2018).

A partir de estas ideas algunas antropólogas hacen cuestionamientos más amplios de la relación de lo natural contra lo cultural, pues de cierto modo, ambos tienen un fuerte vínculo cuando de diferencias sexuales y sociales se trata (Lamas, 2018). Sin embargo, existen otras condiciones consideradas "antinaturales" por las que los individuos (hombres y mujeres), son sometidos y puestos en lugares de mucha vulneración. Estas desigualdades entre personas, 
se derivan de procesos que podríamos considerar inconscientes, y que surgen desde las primeras etapas de vida de los individuos. Las sociedades muestran y enseñan los roles, gustos y actitudes que cada quien tendrá que adoptar según su sexo. El rechazo de las obligaciones sociales impuestas, genera un quiebre con el régimen ideológico predominante en muchas sociedades: la heterosexualidad.

\subsection{La Subordinación femenina y la heteronormatividad}

En relación con la categoría de género el análisis de la subordinación femenina está vinculado con la imposición de normas sociales derivadas desde lo que se determina a partir de la ideología de la heteronormatividad. Este concepto lo podemos entender, inicialmente, como: un régimen social, político y económico impuesto por un idealismo dominante $\left(\right.$ patriarcado $^{40}$ ). Es algo que se extiende en los diferentes ámbitos de la sociedad; tanto en lo público como en lo privado. Según el pensamiento heteronormado, la única forma aceptable y normal de la expresión de los deseos sexuales, las afectividades y la identidad individual debe de ser la heterosexualidad, con lo que se supone que, hombres y mujeres son seres que se complementan entre sí, y las relaciones entre estos son las únicas aceptadas socialmente $\left(\mathrm{CEA}[\mathrm{R}], 2009^{41}\right)$.

En teoría, las conductas, preferencias, gustos, comportamientos y roles propios de hombres y mujeres deben de tener coherencia entre sí, con el sexo definido biológicamente, y, además, con la identidad de género de las personas. Según este régimen, cada individuo adquiere obligaciones sociales que deberá de cumplir a lo largo de su vida en todos los entornos de los cuales se haga parte (CEA[R], 2009). Es así que, las personas que presentan características y comportamientos distintos a los establecidos por este pensamiento, muchas veces, son

\footnotetext{
${ }^{40} \mathrm{~m}$. Sociol. Organización social primitiva en que la autoridad es ejercida por un varón jefe de cada familia, extendiéndose este poder a los parientes aun lejanos de un mismo linaje. Disponible en: https://dle.rae.es/patriarcado

El patriarcado es un sistema político que institucionaliza la superioridad sexista de los varones sobre las mujeres, constituyendo así aquella estructura que opera como mecanismo de dominación ejercido sobre ellas, basándose en una fundamentación biologicista. Esta ideología, por un lado, se construye tomando las diferencias biológicas entre hombres y mujeres como inherentes y naturales. Y por el otro, mantiene y agudiza estas diferencias postulando una estructura dicotómica de la realidad y del pensamiento (Vacca, 2012: 60).

${ }^{41}$ Disponible en: https://diccionario.cear-euskadi.org/heteronormatividad/
} 
puestas en lugares de discriminación, exclusión e invisibilización frente a otros grupos. Además, se les estigmatiza mediante diferentes mecanismos que resultan naturalizados e institucionalizados socialmente.

Más adelante se hablará más extensamente de esto y de la relación del régimen de la heteronormatividad con otros factores que intervienen para generar importantes desigualdades entre individuos dentro de entornos específicos. Tal es el caso, como se ha venido diciendo, del comparativo entre mujeres indígenas y mestizas recluidas en el CPRS "Santiaguito" de Almoloya de Juárez. En donde, a partir de los testimonios de diferentes mujeres, se puede decir que parte de lo que constituye a este concepto es determinante en algunas de las diferentes formas de vida de las actoras, pues con las imposiciones de este régimen es que se establecen muchas de las normas sociales que se espera que las internas cumplan por el solo hecho de ser mujeres, no solo durante su encierro, sino desde antes y después de este.

Las instituciones carcelarias, como se expuso en el apartado 1.3.2. de este trabajo, son un mecanismo de control y dominación, no solo de las conductas, sino de los cuerpos. En sistemas como estos, se supone que se regulan y adaptan las acciones y comportamientos según las reglas y normas que se establecen para mantener una convivencia civilizada. Lo cual, podemos decir, se refleja en lo que sucede en algunas sociedades respecto a la heteronormatividad. Esto se puede comenzar a identificar desde la definición con la que se abrió paso a este apartado, el pensamiento heterosexual determina el poder que tienen ciertos grupos o personas sobre los otros (en este caso hombres sobre mujeres). Además, de que, cabe decir, se ha deslegitimizado la diversidad de género, la libertad sexual, se ha subordinado a las mujeres y se ha determinado lo que ha de representar feminidad y masculinidad.

Para identificar un poco más este tipo de representaciones es preciso definir de manera más precisa a la heteronormatividad, por lo que, según el literario Michael Warner, apoyado de las propuestas de algunas feministas francesas, dice que se trata del "conjunto de las relaciones de poder por medio del cual la sexualidad se normaliza y se reglamenta en nuestra cultura y las relaciones heterosexuales idealizadas se institucionalizan y se equiparan con lo que significa ser humano" (Warner, 1991, en Gómez, 2016: 171). Es decir, se trata de 
estatutos sociales y culturales que representan normalidad, naturalidad y que son reconocidos e impuestos por una sociedad heterosexual. El hecho de romper con esta ideología, promueve la persecución, exclusión y marginación de los individuos, que pareciera ser, son expulsados de la categoría de seres humanos.

Además de esto, se constituyen jerarquías sociales en donde, en la mayoría de los casos, las mujeres ocupan lugares más bajos a los de los varones, tal como sucede con las diferencias definidas por condición de género de las que se habló en el apartado anterior, en donde, generalmente se contemplan solo dos categorías de personas. En la heterormatividad sucede algo similar, en un principio, también se asientan sus bases en una ideología de binarismo sexual, puesto que cuando alguien se refiere a los seres humanos, casi automáticamente se piensa en la existencia de solo hombres y mujeres. Quienes están obligados de seguir ciertas reglas y normas que las sociedades esperan de ellos a partir de sus características biológicas.

Dicho esto, es preciso señalar que existen muchas más definiciones de lo que es la heterosexualidad, pero en la mayoría de estas comúnmente se relacionan con las preferencias o elecciones sexuales de las personas. Sin embargo, la heteronormatividad nos dice que hay que ir más allá de los deseos sexuales que hombres y mujeres tienen de manera individual, pues también se contemplan, conductas, comportamientos y acciones que las sociedades determinan según el sexo y el género de cada persona. La imposición de lo que es propio de hombres y mujeres, al igual que en la categoría de género, se determinará según cada cultura y partirá desde la primera etapa vida de los individuos.

Respecto a la categoría de género es desde donde surge el análisis que algunas estudiosas feministas hacen sobre lo que significa la heteronormatividad. Se puede decir que esta surge desde los cuestionamientos que se hacen sobre la naturalidad de las normas sociales y deseos sexuales de los individuos, dejando de contemplar solamente a dos categorías de personas (Gimeno, s/a ${ }^{42}$. Es por esto que, una importante definición sobre este concepto, es la que da la feminista Monique Wittig (1980), quien dice que la heterosexualidad es un "régimen

\footnotetext{
${ }^{42}$ Disponible en: http://glosario.pikaramagazine.com/glosario.php?lg=es\&let=h\&ter=heteronormatividad
} 
político cuya ideología está basada fundamentalmente en la idea de que existe (LA) diferencia sexual ${ }^{43}$ " (Wittig, 1980, en Curiel, 2013: 51-52).

Significa que la heterosexualidad se determina desde el imaginario que plantea que solo existen dos sexos definidos por sus características biológicas. En relación a esto, para la autora, el sexo es una categoría heterosexual, en donde las mujeres son "heterosexualizadas", es decir, son sujetas a las disposiciones normativas de las sociedades. Además, en este régimen, no solo se establece lo propio de hombres y mujeres, sino que, con este se definen todos los grupos oprimidos, ya que las diferencias que se enmarcan entre individuos, parten de un lugar de poder y dominación, por lo tanto, este pensamiento puede ser considerado un acto normativo e impositivo en muchos ámbitos de la sociedad como en el económico, político, familiar, social, etc. (Wittig, 1980, en Curiel, 2013).

Es así que el análisis de Wittig explica a la heterosexualidad considerando dos principales aspectos: el primero es desde un punto de vista materialista (que también se toma en cuenta en la categoría de género en el apartado anterior), y el segundo es una reevaluación y transformación de la acción política (Curiel, 2013). La autora desarrolla su estudio apoyándose de los aportes de algunas feministas francesas. La primera de éstas es Colette Guillaumin con su concepto "sexaje", el cual se define como: "una doble relación social de apropiación: una apropiación privada, física, directa de las mujeres en forma individual por parte de sus padres, maridos, novios; y una apropiación colectiva de la clase de las mujeres por la clase de los hombres" (Guillaumin, 1992 en Curiel, 2013: 50).

Lo que Guillaumin expone es la manera en que las mujeres son sometidas a la voluntad de los varones como si se tratara de algún tipo de objeto empleado para satisfacer las necesidades de quien tiene el lugar de propietario o dueño. Tal como se suscitaron las relaciones de esclavitud en la Edad Media durante el Feudalismo, en donde las mujeres representan a los estratos más bajos (esclavos) y los hombres al señor feudal (dueño de los esclavos) (Curiel, 2013). Este tipo de relaciones, imposibilita que las mujeres tengan libertad de elegir o romper

\footnotetext{
${ }^{43}$ Según la feminista Marta Lamas, la diferencia sexual es entendida como una subjetividad inconsciente y no como anatomía. Los individuos se definen por las prácticas y representaciones simbólicas dentro de formaciones dadas, además de procesos inconscientes relacionados con sus vivencias y simbolización de la diferencia sexual. La diferencia sexual no es cultural como en el caso del género. En términos generales se trata del conflicto del individuo consigo mismo y no se puede reducir a ningún tipo de arreglo social (Lamas, 2000).
} 
con los esquemas que las sociedades les imponen, debido a la asignación de parámetros de conducta, los "usos" para los que son consideradas y el lugar de subordinación en donde son puestas en sus diferentes entornos.

Desde esta consideración -las mujeres como objetos o mercancía- es que Wittig retoma los aportes de Christine Delphy, quien utiliza la noción de "feminismo materialista", con la que se modifica la concepción marxista de "clases sociales", en la cual no se da importancia al trabajo que no genera valor de cambio, como es el que frecuentemente se realiza por el sexo femenino. Las mujeres son definidas como "clase de sexo" debido a la relación de explotación que se reproduce entre hombres y mujeres por medio del contrato matrimonial con el que, indirectamente, conceden su fuerza de trabajo a los esposos. El trabajo que las mujeres realizan, en la mayoría de los casos es no monetizado, pues, supuestamente, es solventado con alimentación, vestido y vivienda. Por lo tanto, esta relación se muestra como la generada en la teoría marxista entre dueños de los medios de producción y obreros como mano de obra (Delphy, 1970, en Curiel, 2013: 51).

Con esto, Wittig afirma que la conciencia de clase existe, sin embargo, esta no se refiere a un sujeto en particular, a menos de que se trate de las condiciones resultantes de la explotación de individuos de las mismas clases sociales, y que comparten los mismos problemas. Según el análisis de la autora, el marxismo niega la existencia de grupos dominados y grupos privilegiados. Lo que ha generado movimientos colectivos que, en general, impiden a todas las categorías de personas oprimidas que se constituyan como sujetos individuales. En este sentido, en el caso de las mujeres, el marxismo no permitió que éstas se pudieran constituir como una clase más de personas subordinadas, sino como algo que pertenece a la clase obrera o a la clase burguesa, dependiendo del estrato en el que se ubiquen los hombres quienes las dominan (Wittig, 1992).

Así, más allá de lo que la autora extrae del pensamiento marxista sobre la subordinación de grupos, al igual que Gayle Rubin, Monique Wittig retoma una propuesta de análisis sobre los estudios de Lévi- Strauss, se trata de "la antropología de los sexos" de Nicole Claude Mathieu, quien hace una crítica de los trabajos de Strauss. En estos se resalta que el intercambio de mujeres es presentado como un proceso heterosexual, inconsciente y necesario para las sociedades. Este, vela por las necesidades e intereses de los varones y no 
de las mujeres, y al igual que en el capitalismo, este tipo de intercambio niega la existencia de una dominación y esclavitud de mujeres, sino que, aparentemente, solo se trata de diferencias entre sexos (Wittig, 1992).

Estas disparidades, como se mencionó en el apartado anterior, se imponen por medio de la simbolización y el lenguaje con el que nos enseñan lo que es propio de cada sexo y cada género. Ante esto, Wittig considera que deben dejar de existir los calificativos "hombre" y “mujer”, denominándolos solo como "clases", pues hay que considerar que existen otros grupos como son los de lesbianas y gays -entre muchos otros-, quienes no deberían de seguir concibiéndose como parte de una categoría de sexo binario, y con esta acción se logre restar poder a las imposiciones heterosexuales de las sociedades. Además de que, para la autora, sería útil que esta propuesta se empleara para eliminar las asignaciones de otros grupos de personas oprimidas como son: hombres negros, mujeres negras y esclavos (Wittig, 1992).

Estos grupos como actores a los que el discurso de la heteronormatividad los acerca a escenarios de violencia que se ejerce en prácticamente todos los entornos, genera humillaciones y los degrada por ser los otros o diferentes, quienes a su vez son necesarios en la formulación de este régimen. "La sociedad heterosexual no es la sociedad que oprime solamente las lesbianas y a los gays, oprime a muchos otros/ diferentes, oprime a todas las mujeres y a numerosas categorías de hombres, a todos los que están en situación de dominados" (Wittig, 1992: 53). El hecho de que se constituyan diferencias entre individuos y que unos sean subordinados por los otros, según Wittig, es un acto de poder. No cualquiera consigue presentar al otro como diferente, lo logra aquel que se muestra dominante (Wittig, 1992).

Es así que el pensamiento heterosexual concibe a las mujeres como los "otros" quienes son oprimidos por los varones. Mientras que la clase de sexo masculino no se percibe como diferente entre sí, a menos de que se trate de los más pobres, esclavos y negros, pues en este caso, éstos sí ocupan el lugar de los oprimidos. Entre hombres blancos y de posiciones sociales altas, casi siempre se distinguen como iguales. Estas adscripciones que promueven diferencias entre individuos, para la autora, son conceptos primitivos que dan vida a una heterosexualidad que debe de ser obligatoria, en la que necesariamente debe de haber una 
relación binaria, como la que se da entre hombres y mujeres, en la que cada quien debe de cumplir con sus obligaciones sociales establecidas (Wittig, 1980, en Curiel, 2003).

La concepción de una heterosexualidad obligatoria es planteada, principalmente, por la feminista Adrienne Rich, quien propone ver a este concepto como una institución y no solo como una ideología. La autora, afirma que la heterosexualidad, así como la maternidad, la explotación económica y laboral, y el modelo de familia nuclear se debe de analizar como instituciones políticas que restan poder a las mujeres y que se lo otorgan a los hombres. Para hacer este planteamiento, Rich hace un análisis histórico, similar al propuesto por las feministas de la categoría de género, pero en este caso, se destacan momentos y actos como el uso del cinturón de castidad, matrimonios infantiles, la supresión de las mujeres lesbianas, entre otros que se han basado en el uso de la violencia (de varios tipos), el uso de la fuerza física y el control de las conciencias para someter a las mujeres a un régimen único e imprescindible (Rich, 1980, en Curiel, 2013).

Uno de los elementos más destacados de la heterosexualidad obligatoria como régimen forzado, es la imposición del matrimonio. Este, es adoptado por las mujeres desde pequeñas como una ideología indispensable y propia de ser mujer. Con esto, se generaliza, además, la orientación sexual que, se supone, cada individuo debe tener para poder culminar con sus obligaciones sociales determinadas y aceptadas desde la infancia. La autora dice que son varias las causas por las que los individuos, en este caso las mujeres, son convencidas de que el matrimonio y la orientación sexual deben de favorecer los deseos de los hombres, aunque con esto ellas no se sientan cómodas y satisfechas, y en casi todos los ámbitos de sus vidas se encuentren oprimidas a la voluntad de los otros (Rich, 1985).

Según Rich, en cuanto a este vínculo de subordinación femenina, como se mencionó con otras autoras, existe una relación con elementos propios del capitalismo. Por lo cual, basándose en los aportes de Catharine Mackinnon, se destaca una intersección entre la heterosexualidad compulsiva y la economía. "Las mujeres están segregadas horizontalmente por su género y ocupan una posición estructuralmente inferior en el trabajo" (Rich, 1985: 16). Lo que en el capitalismo se representa en la necesidad de un conjunto de individuos que ocupen cargos laborales inferiores y peor remunerados, quienes generalmente, se han visto determinados por las características físicas y biológicas de las personas. En este caso, se trata 
de las mujeres, quienes no solo están apartadas de puestos importantes en los roles laborales, sino que se ubican en lo que la autora denomina "la sexualización de la mujer" en el trabajo (Rich,1985).

Esto significa que es común que las mujeres ejerzan actividades como: empleadas domésticas, secretarias, enfermeras, mecanógrafas, cuidadoras de niños, camareras o simplemente, madres, esposas y amas de casa sin la posibilidad de emplearse en entornos externos que sean bien remunerados. Referente a esto, Rich retoma algo de la propuesta de Nancy Chodorow, quien piensa que, el hecho de que principalmente las mujeres sean las responsables de la crianza y cuidado infantil en la división sexual del trabajo, lleva a una organización de género basada en importantes desigualdades. Planteándose el imaginario de que, lo ideal sería que hombres y mujeres se hicieran cargo del cuidado de los hijos, dividiéndose las responsabilidades por igual. Ya que la aplicación de una educación segregada, puede conducir a los infantes a crecer con percepciones sociales estigmatizadas (Rich, 1985).

Aun con la notable desigualdad en el ámbito de la crianza de los hijos, Chodorow denota una mayor importancia de las mujeres que de los hombres, pues, emocionalmente, la madre ocupa un lugar primario en la vida de los menores, mientras que el padre una posición secundaria. Pese a esta trascendencia, las mujeres no dejan de ser vistas como objetos en la sociedad, pues ellas mismas son utilizadas como una herramienta para transmitir los ideales de todo lo que es propio para los individuos. Según la autora, los hijos crecen bajo un modelo de relaciones heterosexuales, en las que tanto hombres como mujeres deben de tener claros los deseos, gustos y preferencias con los que deberán de crecer, y los roles que les corresponden en la sociedad (Rich, 1985).

Durante este proceso las mujeres deben de aprender e interiorizar la idea de que los varones poseen menores limitaciones a las de ellas en todos los entornos sociales, por causas psicológicas, prácticas y físicas. Y es a causa de esto que, en muchos casos, los hombres son quienes se apoderan de lo que determina a las sociedades. Tal como es la conformación de las leyes. Por ejemplo, desde siglos atrás (siglo XIV-XV), se castigaba a las mujeres que rompían con los estándares sociales establecidos por las autoridades (quienes especialmente eran varones), muchas de éstas eran señaladas como brujas, por el hecho de tener 
conocimientos extraordinarios como el uso de hierbas curativas o útiles para remediar diversas situaciones.

Las mujeres en estas situaciones eran condenadas a torturas igual o mucho más severas como las vistas en el apartado 1.3 de este trabajo (el suplicio). A éstas se les castigaba por hechos diferentes a los de los varones, pues ellas no necesariamente tenían que robar o matar, bastaba con tener ideales o comportamientos distintos a los establecidos por la sociedad. Lo que, cabe decir, es la base de lo que actualmente conforma las estigmatizaciones a las que se somete a las mujeres que comenten algún tipo de delito o son implicadas en alguno. Además, de que sus sentencias (no solo penales, sino sociales y familiares), permanecen siendo desiguales. Es común que uno de los principales castigos recibidos por las mujeres provenga de sus familias, amistades y personas de su entorno.

A éstas se les etiqueta de malas e irresponsables, suelen ser abandonadas por sus familias y alejadas de sus hijos, en la mayoría de los casos. Por otro lado, los hombres en la misma situación, no siempre pasan por este castigo, casi siempre hay una mujer que se encuentra al tanto de lo que éste vive durante su proceso y encarcelamiento.

La situación de las mujeres privadas de la libertad, es de abandono y olvido. A los hombres no los olvidan sus familias, y hasta les justifican sus acciones, siempre está la presencia de la mamá, de la esposa, de la hermana, tías o alguna mujer de la familia. En cambio, a las mujeres las abandonan los esposos, padres y demás familiares. Buscan alejar a los hijos porque son tachadas de lo peor, porque dan un mal ejemplo y una mala imagen. Son juzgadas muy duramente, mucho más que los hombres. No es de una "buena mujer", estar en la cárcel, un hombre sí porque es más normal, es común que ellos "se equivoquen" (Testimonio de "Anónimo 24", DGRS ${ }^{45}$ EDOMEX, 2018).

Como podemos ver en casos como estos y según lo propuesto por Rich, se espera que las mujeres actúen como "buenas esposas y madres", sin que importe mucho la conducta que los hombres presenten. Por ejemplo, en "Santiaguito", un joven interno narra haber sido adicto a diferentes drogas durante una etapa de su encierro, al grado de no tener conciencia de ninguna de sus acciones, ni siquiera de satisfacer necesidades básicas como la alimentación. Sin embargo, la preocupación de su madre y hermanas se hizo notar, ellas trataban cada

\footnotetext{
44 Se nombra como "Anónimo" al contacto por petición propia, debido a restricciones impuestas a los funcionarios de la Dirección General de Reinserción Social del Estado de México.

${ }^{45}$ Dirección General de Reinserción Social del Estado de México.
} 
semana de visitarlo y preguntar por él. Al no tener suerte de poderlo ver, llegaron a pensar que él había muerto y no les habían informado.

Según las autoridades tuvieron que mostrar documentos que avalaran que el joven seguía con vida, pero en malas condiciones. "Enrique" (como se le ha nombrado), respecto a esto, dice: “mi mamá se preocupó mucho por saber de mí, sí me avisaron, pero a mí me valía madre. Cuando reaccioné, ella nunca me dejó solo, hasta ahorita, no hay semana que me falle, me trae un taco y me trae mis cositas" (“Enrique”, hombre mestizo privado de la libertad, 2018). Mientras que, por otro lado, en casos de mujeres en la misma situación hay quienes, como "Luna", declaran el abandono y desconocimiento de sus padres y esposo, además del arrebato y separación de sus hijos: "nadie viene a visitarme, bueno, casi cada año viene mi hermana. Mis papás dijeron que yo dejaba de ser su hija... El papá de mis hijos me los quitó y ya se olvidó de mí" (“Luna”, mujer mestiza privada de la libertad, 2018).

Con estos ejemplos y siguiendo lo que dice la autora Adrienne Rich, el hecho de que las mujeres rompan con lo que la familia y sociedad espera de ellas, constituye que éstas sean “castigadas" y sometidas al poder determinado por un pensamiento que no solo es masculino, sino heterosexual, en donde las relaciones entre individuos están ligadas por un sentido de dominación de unos hacia otros. Las sanciones que se determinan para las mujeres, socialmente hablando, según la autora, tienen que ver con ocho principales aspectos que rescata de las propuestas de la antropóloga Kathleen Gough, en donde el primero de estos puntos se refiere a la acción de negar a las mujeres su sexualidad, esto lo podemos ver en prácticas de control que se implementaba en algunas mujeres como con el uso del cinturón de castidad y otros tipos de castigos que eran mucho más severos y que podían llevarlas a la muerte (Rich, 1985).

El segundo aspecto trata de la imposición de una sexualidad predominantemente masculina, lo que alude a que, en algunos casos, por medio de actos violentos como violaciones y maltrato físico, se imponía en las mujeres la idealización de que su deseo sexual debía ser dirigido hacia su sexo opuesto. Esto, aunque actualmente no se lleva a la práctica de la misma manera que en sociedades tradicionales, sigue siendo parte del proceso de socialización, en el que no solo participa la familia, sino que también, de muchos medios de difusión con los que las personas interactúan, como son: la literatura, la música, el cine, la tv y la radio, con 
esto muchas veces se muestra un estándar de actos, romance, amor, sentimientos y sensaciones que las mujeres deben de seguir (Rich,1985).

Un tercer punto es el reclutamiento y la explotación del trabajo femenino para controlar su producción, la autora dice que, por medio de instituciones como el matrimonio y la maternidad como productos gratuitos, es de donde se definen el resto de las actividades de las mujeres. Por ejemplo, en el aspecto laboral en el puesto que éstas ocuparán y el salario que han de percibir. Además de que existe un control masculino de actos como el aborto, la natalidad y el parto, que, de alguna manera, dejan de ser individuales y pasan por la crítica social y hasta jurídica. Es así que, en general, en este aspecto se determina la desvalorización de lo femenino, lo que actualmente no solo se puede atribuir a una dominación masculina, sino que, influyen otros sectores de personas que se colocan en posiciones de "superioridad", como se ha mencionado con anterioridad (Rich, 1985).

Por otro lado, la dominación masculina se deriva del poder que tienen los varones para definir actos como la esterilización forzada, la cosificación de los hijos, el infanticidio sistemático y prácticas (en algunas culturas), como la mutilación genital de niñas o la preparación de las menores para contraer matrimonio. Todo esto, para la autora es una manera de controlar a las mujeres desde el arrebato de los hijos y de la negación de su propia libertad. En relación a esto, un quinto aspecto de sanción femenina es un terrorismo indirecto en el que se encierra físicamente a las mujeres y se limitan sus posibilidades de movilidad. Esto por medio de violaciones para generar temor en éstas e impedir que salgan a las calles. También se limita el desarrollo de cualidades atléticas, se imponen vestimentas y se impone una dependencia económica de las mujeres hacia los hombres (Rich, 1985).

Además de los límites que se promueven en las vidas de las mujeres, éstas también son utilizadas como objetos en transacciones masculinas. Rich hace referencia de las mujeres que son entregadas como obsequios, que son vendidas para contraer matrimonio, las que son alquiladas para el entretenimiento de los varones, en donde, muchas veces también se les impone un código de vestimenta, comportamientos y actitudes específicos para la satisfacción de quienes tienen el control. El séptimo punto que retoma la autora es importante, ya que hace alusión a lo expuesto en líneas previas, sobre la cacería y quema de "brujas" o aquellas mujeres que poseían conocimientos desarrollados o extraordinarios, mujeres que, 
por su amplia creatividad y posibilidades de salirse de lo establecido por las sociedades, eran castigadas de maneras crueles y severas (Rich, 1985).

Por último, y quizá en sociedades más “modernas", las mujeres han sido marginadas de las principales áreas de conocimiento y de los logros culturales de la sociedad. Tal como se ha visto en varios momentos de la historia en donde las mujeres no son incluidas en la formación académica, ya que, principalmente esto se dirigía a los varones de las comunidades. La ciencia y la tecnología han sido lugares constituidos en especial para hombres y no para mujeres. Y así como se ha mencionado antes, las mujeres han sido identificadas en actividades del ámbito privado, mientras que los varones se encargan de lo público. Rich denomina a esto como una "discriminación contra las mujeres en las profesiones" (Rich, 1985).

Sin embargo, cabe resaltar que esto no solo se determina en las diferenciaciones entre sexo binario, ya que existen otros aspectos con los que se formulan las relaciones de subordinación, dominio y exclusión entre individuos. Si bien, cabe aclarar que existen diferentes tipos de mujeres, hombres y personas, que se ven envueltos en relaciones de este tipo. Por ejemplo, Rich habla de las mujeres lesbianas, quienes no solo se enfrentan a la condición de vulneración por el hecho de ser mujeres, sino que, también por no cumplir con las normas heterosexuales establecidas por las sociedades. Muchas de éstas, para afrontar desventajas como las económicas, desarrollan estrategias de vida, como es aparentar ser heterosexual con su forma de vestir, los roles que ocupan, siendo los "propios de mujeres" y adoptando conductas que demuestren feminidad (Rich, 1985)

Son muchas las estrategias de sobrevivencia que mujeres en esta condición suelen adoptar, tal como es el contraer matrimonio. Con esto, ellas pueden escapar o pasar desapercibidas de algún tipo de violencia que se derive del hecho de no cumplir con los estándares sociales. La adopción de este tipo de medios, en muchos casos, ubica a algunas mujeres en lugares que, podríamos considerar, son de esclavitud. Al respecto, Adrienne Rich, retoma parte de la propuesta de Kathleen Barry (1984), quien documenta la existencia de una esclavitud femenina a nivel internacional. Así, algo muy importante del trabajo de Barry es el señalamiento de las condiciones en las que frecuentemente las mujeres son sometidas por los 
varones, como son: la prostitución, incesto, violencia marital, pornografía, compra-venta de mujeres y mutilación genital (Barry, 1984 en Rich, 1985).

La esclavitud a la que hace referencia esta autora, dice: "está presente en todas las situaciones en que las mujeres o las niñas no pueden cambiar las condiciones de su existencia; en que sin considerar cómo llegaron a esas condiciones, por ejemplo, por presión social, por penuria económica, por confianza mal depositada, o por ansias de afecto, no pueden salir de ellas...” (Barry, 1984 en Rich, 1985: 18). Esto, podemos decir, se encuentra muy vinculado con el tema central de este trabajo (mujeres en situación de reclusión), pues es por estos medios que muchas mujeres llegan a los recintos carcelarios y deben de enfrentarse a la vida en espacios donde impera la violencia y la discriminación. Como se verá en el capítulo 5, muchos de los delitos por los que se les imputa tienen que ver con la relación con sus familias y con los roles que éstas ocupan como mujeres en la sociedad.

En entornos como el carcelario, así como en muchos otros y desde diferentes momentos de la historia, suele ser común que se invisibilice que hay una diversidad de mujeres en los distintos ámbitos de la sociedad. Por ejemplo, la existencia de lesbianas ha llegado a ser considerado como un padecimiento mental o una enfermedad en las mujeres, lo que las ha llevado a ser estigmatizadas, violentadas, excluidas y vulneradas por unos otros en muchos contextos sociales. Esto, también suele ocurrir en el caso de varones homosexuales, pues el hecho de presentar conductas, deseos y elecciones sexuales diferentes a las del resto de individuos "normales", significa un rompimiento con lo establecido por la comúnmente institucionalizada heterosexualidad.

Al respecto, Rich considera que es probable que la heterosexualidad no sea en sí una preferencia, sino que, está vinculada al proceso de socialización de los individuos, desde donde adoptan la imposición del reconocimiento, aceptación y propagación de lo que por "naturalidad" deben de acatar. Sin embargo, cabe destacar que el reconocimiento de este régimen social es tan importante para la vida social, tanto como lo ha sido el capitalismo y como lo fue el sistema de castas, los cuales sustentan su razón de ser desde fuerzas como la violencia física, emocional, simbólica y desde la construcción de una falsa conciencia, en donde las relaciones desiguales de poder han de ser imperantes en cada grupo social (Rich, 1985). 
En este sentido la autora destaca la idea de que, en el caso de los vínculos entre sexo binario, se ha llegado a pensar que el dominio de los hombres hacia las mujeres es necesario, ya que con esto ellas adquieren un sentido de protección social, económico y psicológico que les brinda seguridad personal. Por esto, la familia heterosexual se muestra como unidad básica e irremplazable, en la que aquellas mujeres que no forman parte de ello, son condenadas a castigos sociales como la marginalidad. Así, en el caso de las lesbianas, por ejemplo, suelen ser castigadas por la sociedad más fuertemente que en el caso de los homosexuales varones, debido a la presunta debilidad y fragilidad femenina (Rich, 1985).

Esto es, cuando una mujer adopta más de una "anormalidad”, suele enfrentarse a situaciones más complejas, lo que, según Rich, desde la crítica negra feminista lesbiana de Lorraine Bethel "subraya que para una mujer negra -ya dos veces marginal- asumir otra "identidad odiada' es algo ciertamente problemático" (Bethel. En Rich, 1985: 33). Tal situación, destaca Adrienne Rich, es algo que ha dejado grandes marcas en la vida de muchas mujeres negras, en África y en Estados Unidos, aunque tal vez en muchas otras regiones. Siguiendo lo propuesto por Bethel:

Las mujeres negras tienen una larga tradición de vinculación emocional entre ellas [...] en una comunidad de mujeres negras que ha sido fuente de información vital para muestras de supervivencia, y de apoyo psíquico y emocional. Tenemos una cultura de identificación con mujeres negras, basada en nuestras experiencias de mujeres negras en esta sociedad, con símbolos, lengua y modos de expresión específicos de las realidades de nuestras vidas [...] Debido a que las mujeres negras rara vez han estado entre los negros y las mujeres que tuvieron acceso a la literatura y a otras formas aceptadas de expresión artística, estos lazos entre mujeres negras y esta identificación con mujeres negras a menudo han sido escondidos y no se han registrado, salvo en las vidas particulares de mujeres negras por intermedio de nuestros recuerdos de nuestra particular tradición femenina negra (Bethel, en Rich, 1985: 33).

La consideración de otros tipos de mujeres para el análisis de la sociedad, es importante y, según Rich, se debe de ir más allá de lo que se propone desde el pensamiento de mujeres blancas de occidente y de clase media. Esto, debido a que ninguna vive, es vista y es tratada de la misma forma, según su condición física y social. La autora señala que es conveniente que los estudios de las mujeres contemplen diferentes estructuras sociales, raciales, étnicas y políticas. Lo que, desde la perspectiva de otra importante pensadora feminista; Breny Mendoza, de nacionalidad hondureña integra al estudio de la heterosexualidad al mestizaje como dispositivo de poder en sociedades latinoamericanas. 
Respecto a esto Mendoza destaca tres principales elementos para favorecer el análisis de las relaciones de poder generadas desde la heteronomatividad: el primero se relaciona con la llamada Conquista, el racismo y la sexualidad. A través de esto se observa la irrupción y dominación de los cuerpos femeninos desde actos como las violaciones sexuales, dadas por hombres españoles hacia mujeres indígenas y negras durante los procesos de invasión de los pueblos de América. En segundo lugar, tenemos el carácter heterosexual y la normatividad reproductiva de familia patriarcal y de un marcado sistema de castas. Por último, este sistema dirige a los individuos a una condición de "ilegitimidad" y bastardía del mestizo durante la época colonial, lo que repercute, principalmente, a la condición de los individuos de sexo femenino (Mendoza, 2001 en Curiel, 2013).

Para esta autora, el concepto de mestizaje se ha constituido como una categoría heterosexual, puesto que este es el resultado de la mezcla de hombres españoles y mujeres indígenas que se derivó de la apropiación y sometimiento del cuerpo, sexualidad y fuerza de trabajo de éstas. Además, la autora hace referencia al hecho de que la homosexualidad durante los procesos de Conquista y Colonia, en muchas ocasiones, fueron negados e ignorados dentro de la pirámide social constituida principalmente en las sociedades de América (véase apartado 2.1 de este trabajo). Y en otros casos, se destacan actos de "castigo" y "sanción" similares a los crueles y violentos ocurridos durante el suplicio (véase apartado 1.3). Esto, supuestamente, propiciado por la presencia de comportamientos, actitudes y acciones distintas a las normalizadas socialmente, generando horror y desagrado social por ser consideradas "inmorales" y "pecaminosas" (Mendoza, 2001 en Curiel, 2013). La autora señala que:

"No hubo cabida para lo femenino-mestizo, ni para la indígena, la negra o la mulata. Las mujeres fueron suprimidas o representadas como "reposo del guerrero", ausentes en su subjetividad, siempre asumidas como madres, hermanas, abuelas o amantes solidarias, no como entes activos de la vida pública” (Mendoza, 2001 en Curiel, 2013: 146). Si bien, como se mencionó anteriormente con otras autoras, las mujeres fueron puestas como mercancías de los varones, en este caso, durante los principales procesos de dominación en América Latina. Sin embargo, Breny Mendoza destaca que, durante estos momentos, sí hubo un reconocimiento de la nacionalidad indígena por el hecho de haber nacido dentro del territorio 
nacional, aunque esta consideración solo se daba en el ámbito social y jurídico, y no en el político (Mendoza, 2001 en Curiel, 2013).

Mientras tanto, en otros casos como en el de las personas negras no se les otorgó una nacionalidad porque, como se vio en el apartado 2.1 por su color de piel se les asumió como posesiones o mercancías y no como personas o individuos en sí. Es por esto que la autora destaca que las diferencias y desigualdades que se generan entre individuos, no solo se derivan de la condición de género o de lo establecido desde el pensamiento heteronormado, sino que, muchos sectores son subordinados e invisibilizados por los demás debido al cruce de diferentes condiciones, tales como: el género, raza, clase social y edad. Lo que con los aportes de algunas pensadoras feministas es posible analizar desde la perspectiva de la interseccionalidad la cual se expone más ampliamente a continuación y que, además, en el capítulo 5 será de utilidad para analizar nuestro estudio de caso.

\subsection{Distinción entre mujeres indígenas y mestizas: aportes desde la interseccionalidad}

Tal como se ha venido exponiendo, algo que pareciera bastante obvio decir es que todas las personas somos completamente diferentes los unos de los otros, tanto física, social, política y culturalmente. Por ello, establecer categorías cerradas para intentar encajar a cada uno de los individuos en una de estas es una tarea muy compleja, por no decir imposible. Esto debido a que los diferentes elementos que constituyen la identidad de los sujetos, en muchos casos son los determinantes del lugar en donde somos puestos dentro de las jerarquías sociales construidas. Es así que, condiciones como la raza, el género, la clase social y la edad son factores que se cruzan entre sí de tal suerte que el punto en donde estas convergen define los distintos niveles de vulneración y subordinación de los cuales las personas serán víctimas o privilegiados dentro de sus relaciones y grupos sociales.

A lo largo de la historia hemos visto que son muchas las motivaciones por las que las sociedades han de resaltar las características "diferentes" de cada persona y, a partir de esto han de determinar el lugar en donde los individuos son puestos y los roles que han de representar dentro de sus grupos sociales. No obstante, partiendo de estas distinciones es que 
se presentan muchas relaciones desiguales de poder, dominación y vulneración. Es así que según lo presentado desde la categoría de género y la heteronormatividad vemos que se consideran por separado solo algunas de las condiciones que constituyen muchos de los análisis que se han realizado sobre la subordinación y exclusión de algunos grupos y personas. Por ejemplo, algo muy claro son las propuestas en las que las desigualdades nacen desde la confrontación entre las condiciones de hombres y mujeres como entes generalizados. Sin embargo, respecto a esto, como se mencionó en el apartado anterior, desde hace ya varios años, algunas autoras comenzaron a cuestionar la viabilidad de este tipo de estudios puesto que en casos como el mencionado, no contemplan el hecho de que las mujeres no solo deben de ser vistas como mujeres, sino que, entre esta categoría existe una diversidad muy amplia de éstas que la componen. Además, cada una de éstas desde sus diferentes condiciones es que se enfrentan a situaciones muy diversas entre unas y otras. Es así que algunas de ellas desde sus propias experiencias proponen que los estudios sobre las desigualdades sociales se hagan desde una perspectiva con una mirada mucho más amplia a la propuesta por la categoría de género. Y es entonces cuando se comienza a plantear un nuevo enfoque de análisis denominado "interseccionalidad”.

Este concepto, visto desde un contexto más reciente y generalizado podemos definirlo inicialmente como "una herramienta para el análisis, la abogacía y la elaboración de políticas, que aborda múltiples discriminaciones y nos ayuda a entender la manera en que conjuntos diferentes de identidades influyen sobre el acceso que se pueda tener a derechos y oportunidades" (awid.org $\left.{ }^{46}, 2004\right)$. Actualmente se puede ver su uso en un abanico amplio de disciplinas de las ciencias sociales, teniendo como finalidad que a partir de este término se revelen algunos de los sesgos que generalmente encontramos en los estudios de género y de raza, los cuales suelen ser analizados como entes independientes y aislados.

La intersecconalidad, entonces, puede verse en primeros términos como el resultado de un conjunto de procesos distintos, pero con elementos interrelacionados que afectan de diferentes formas a las personas. Los componentes que se contemplan en el entrecruce de

\footnotetext{
${ }^{46}$ Association for Women's Rights in Development. Disponible en: https://www.awid.org/sites/default/files/atoms/files/nterseccionalidad una herramienta para la justicia de genero y la justicia economica.pdf
} 
condiciones de cada individuo depende de sus diferentes ámbitos sociales, puesto que cada uno determina los distintos niveles de opresión en los que son puestos algunos sujetos. Es decir, las construcciones sociales, culturales y políticas son las que enmarcan cada una de las aristas que integran los niveles de dominación y subordinación en las relaciones sociales. La composición de los grupos sociales depende en muchos casos de la división de características e identidades aparentemente concretas que van más allá del género y la raza, puesto que se pueden contemplar algunas otras como la edad, la clase social, etnicidad, preferencias o elecciones sexuales, etc. (Golubov, 2016).

Es así que otra manera más precisa de entender a la interseccionalidad puede ser como: “...una herramienta útil para detectar las múltiples discriminaciones que se entrecruzan de tal forma que cotidianamente producen la subordinación y la marginación de las mujeres, en distintos niveles de la vida pública y privada" (Golubov, 2016: 197-198). En esta definición se da un mayor peso al entendimiento de que son las mujeres quienes en muchos casos, suelen ser las que principalmente se enfrenten a situaciones de desigualdad y opresión, considerando que pueden ser muchos los elementos que influyen para que esto suceda y no solo desde su condición de género. Partiendo desde postulados como estos es que importantes pensadoras feministas negras se dieron a la tarea que desde sus propias vivencias pudieran desarrollar esta herramienta de análisis.

Es importante señalar que este concepto se introdujo inicialmente por la académica afroestadounidense Kimberlé Crenshaw en los años ochenta. La propuesta de esta autora surge al darse cuenta de que la razón por la que muchos de los problemas de justicia que atañen de manera grave a las mujeres son muy variados y además generan muchas injusticias sociales en las vidas de cada una de éstas. Su interés por destacar la manera cómo se abordan las situaciones de desigualdad hacia mujeres de diferentes condiciones comenzó al tener conocimiento del caso de una mujer de nombre Emma Graffery, quien según la sentencia escrita por un juez se rechazó dar seguimiento a la demanda que impuso por haber sido víctima de discriminación por raza y género por parte de la empresa automotriz General Motors (Formacionmzc, 201947).

\footnotetext{
${ }^{47}$ Vídeo "¿Qué es la interseccionalidad? Subtítulada en español”. Disponible en: https://www.youtube.com/watch?v=hBalhImM3ow .Visto: 26/septiembre/2020
} 
La situación comenzó cuando Emma solicitó trabajo en esta industria y fue rechazada. La mujer afirmó no haber sido contratada por ser de raza negra. Sin embargo, la empresa rechazó tal acusación argumentando como defensa que antes ya se habían contratado afroamericanos y mujeres. La defensa de General Motors, se podría decir, se sustentaba en lo que se le conoce como "lagunas legales", debido a la falta de especificidad de las leyes para atender casos como estos. Es por esto que no había ninguna normatividad como tal con la que pudieran castigar o proceder con una demanda como la que se estaba planteando. Ante esto, Graffery resaltó que en el caso de los negros contratados se había tratado únicamente de varones que, además, eran asignados a labores industriales. Mientras que las mujeres empleadas eran solo mujeres blancas a quienes ubicadas en actividades "propias" como secretarias o en donde pudieran dar una "buena” imagen a la empresa (Formacionmzc, 2019).

La inexistencia de leyes que contemplaran tipos de discriminación en donde se estuvieran entrecruzando más de una sola condición se hizo resaltar fuertemente en el caso de Emma, demostrando que era imposible que el juez pudiera entender las demandas de la mujer, al parecer, ni siquiera podían percibir lo que estaba ocurriendo. Por otro lado, Crenshaw narra que este caso tampoco pudo ser tratado como demandas separadas, ya que, según el juez, esto significaría que se le estuviera concediendo a Emma muchos más derechos de los que se podía. Esto significaría tener ventajas que los hombres afroamericanos y las mujeres no podrían tener por ser parte de una sola categoría. Lo que, según la autora, sería algo absurdo puesto que ni los hombres afroamericanos ni las mujeres necesitaban combinar más de un tipo de discriminación (Formacionmzc, 2019).

A partir de esto es que la autora hace hincapié en que las leyes y la justicia no defendían a las mujeres afroamericanas debido a que era algo que no lograban comprender. Puesto que, además, este tipo de mujeres tienen experiencias distintas y pasan por situaciones que no son como las de mujeres blancas en ningún sentido, aun cuando entre éstas comparten la condición de género. Es así que el género resulta ser insuficiente y limitado a la hora de estudiar las desigualdades. Los análisis de este tipo muchas veces llegan a contemplar solo un tipo de discriminación como la raza, el género y la clase social, pero desde una mirada independiente, dejando a la deriva lo que puede llegar a ser el producto del cruce de todas o de varias de estas (Golubov, 2016). 
$\mathrm{Al}$ intentar explicar la subordinación y la marginalidad no basta con hacer una sumatoria de elementos, sino que se necesita la contemplación de lo que en unión pueden llegar a generar. Es por esto que Crenshaw introduce la categoría de la interseccionalidad con la intención de hacer un contraste de la multidimencionalidad de las experiencias de mujeres negras con los estudios que solo enfocan la mirada en un solo tipo de discriminación como generalmente lo ha hecho la categoría de género. La autora señala que la "experiencia interseccional es más que la suma del racismo y el sexismo" (Crenshaw, 1989: 140 en Golubov, 2016: 202), sino que, como se mencionó, se trata de la interacción de diferentes condiciones. Desde la perspectiva de esta autora los hombres negros y las mujeres blancas son grupos privilegiados si los comparamos con el de mujeres negras (Golubov, 2016).

Para entender mejor la propuesta de la interseccionalidad de Crenshaw, ella lo explica desde una metáfora en la que se plantea un escenario como son dos avenidas que se entrecruzan entre sí, en el punto donde esto sucede coloca el imaginario de una mujer negra. Una de las avenidas representa la condición de raza mientras que la otra la de género. Si en ambos trayectos transitan dos automóviles y la mujer es la única en estar en el punto exacto en donde atraviesan los autos, ésta recibirá el doble impacto del paso de ambos vehículos, causando serios daños a la mujer. Para la atención de las lesiones, la autora dice que una ambulancia representaría a las leyes (hablando del caso de Emma), el tratamiento se le daría a la mujer solo si se encontrará del lado del género o de la raza, no en el cruce de ambos. Esto lo vemos cuando se quieren tratar casos de discriminación y opresión desde medios como la categoría de género.

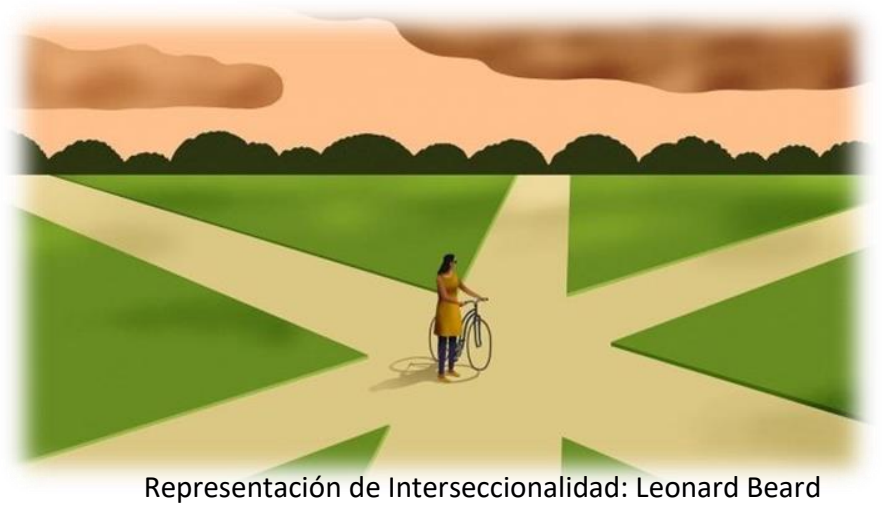

Es por esto que, si pensamos en el estudio de caso de este trabajo, podemos ver que en el sistema penitenciario mexicano se presentan aun importantes omisiones de elementos a la hora de tratar la diversidad de casos de mujeres que son imputadas. Durante los procesos vemos que la problemática se acentúa cuando se trata mujeres con varias condiciones entrelazadas, por mencionar algunas, tenemos a las mujeres indígenas que, por su raza, clase 
social y género, difícilmente son juzgadas de manera adecuada por el sistema penitenciario. Algo muy común es que, aunque las leyes estipulen que los sistemas deben de brindar ciertas garantías a la población identificada como indígena, no siempre ocurre así. Por ejemplo, cuando las mujeres no hablan y entienden español, y no saben leer y escribir pocas veces se les otorga una defensoría legal que cuente con los conocimientos necesarios para generar una buena comunicación con sus defendidas.

Al parecer en estos casos las autoridades consideran que se cumple con las leyes por el hecho de que cuando las mujeres no cuentan con recursos económicos para pagar su defensoría, se les proporciona una de oficio (es decir gratuita), pero la realidad de este servicio es que solo se brinda a medias pues los abogados asignados, no logran romper con las barreras socioculturales generadas a partir de las distinciones raciales. Por lo tanto, a la hora de que se juzga a las indígenas, éstas no logran tener claridad en los procesos, además de que, en ocasiones son violentadas y discriminadas en cada una de las audiencias. Ser mujer indígena en entornos como el carcelario tiene implicaciones notables en las vidas de las mujeres. Esto no significa que en el caso de las mestizas no ocurra esto, sino que se piensa que sucede de manera muy distinta y con un menor impacto, puesto que no requieren el mismo tratamiento que en el caso de las indígenas.

Por esto es muy importante que a los casos como los mencionados se les vea desde una perspectiva interseccional, así como lo propone Kimberlé Crenshaw, pues sería algo funcional porque con ello se pueden tomar en cuenta las muy variadas causas de discriminación que enfrentan los diferentes tipos de mujeres en condiciones tales como las del ejemplo. Además, cabría decir que para analizar las múltiples opresiones vistas en los sistemas penitenciarios se pueden considerar las perspectivas de otras autoras, tales como la académica estadounidense Patricia Hill Collins (1990) quien desde el feminismo estructuralista propone la "Teoría de la traída de opresiones" la cual, aunque no tiene una denominación como tal interseccional, sigue una línea en la que se toma en cuenta el punto de vista de las mujeres negras más allá de lo que se había analizado desde la categoría de género (Viveros, 2016).

En su análisis Collins destaca que el pensamiento feminista negro propone cambios en la manera en que generalmente se estaban estudiando las relaciones de opresión ya que, como 
se mencionó antes, este estaba dejando de lado la noción de que existen más de un sistema de subordinación: el género. Las relaciones de desigualdad tal como lo propone Crenshaw, no se tratan solo de aspectos sumatorios e individuales, sino del vínculo que se genera a partir del cruce de varios de estos, como pueden ser: los grupos etarios (edad), raciales, religiosos, de clase, etc. (Golubov, 2016). Desde la perspectiva de Patricia Hill Collins, para poder entender los sistemas de dominación y subordinación es prioritario contemplar los puntos de vista de todos estos grupos, en su caso, se centraliza en las experiencias de mujeres negras:

Ver las relaciones de dominación contra las mujeres negras de cualquier contexto sociohistórico determinado como algo que se estructura mediante un sistema que entrelaza la opresión de raza, clase y género, expande la perspectiva de análisis de una mera descripción de las similitudes y diferencias que distinguen estos sistemas de opresión y presta mayor atención a cómo se interconectan. Al asumir que cada uno de estos sistemas necesita de los otros para funcionar, se crea una postura teórica distinta que estimula el replanteamiento de los conceptos básicos de las ciencias sociales (Hill, 1991: 222 en Golubov, 2016: 199).

Es de este modo que desde una perspectiva sociológica la autora sustenta el hecho de estudiar las diferencias entre tipos de mujeres desde la contemplación de todas las condiciones que las conforman, y no solo hacer un contraste que interpele las relaciones entre hombres y mujeres. Es importante, además, ubicar las distinciones que se generan por estatus social, económico y político a partir del cruce de las características y condiciones de las sujetas, puesto que como se ha planteado desde el capítulo anterior, los niveles más bajos de las jerarquías sociales constituidas son ocupados por poblaciones expuestas a la exclusión, subordinación y vulneración a causa de su color de piel, origen étnico, clase social y género, considerando que en este último, son las mujeres quienes están en mayor desventaja (Hill, 2012).

En relación a esto, cabe decir que, como parte del análisis de la autora, ésta destaca que las mujeres negras han sido descritas desde estereotipos muy marcados como el hecho de que sean personas violentas, sexualmente agresivas y que principalmente han sido relacionadas con situaciones de esclavitud. Esto último, como se describió en el capítulo anterior las poblaciones negras son aquellas a las que siempre se les ha puesto en los niveles más bajos de las jerarquías sociales, además de que se les ha bestializado, comparándolas con animales y siendo expuestas a situaciones de gran violencia, sometimiento y subordinación. En el caso de las mujeres negras en esclavitud la opresión vivida no fue algo impuesto solo por varones, 
sino que, la autora señala que también han participado mujeres blancas de estatus sociales medios y altos.

Un hecho que se relaciona con esto es lo que expone la activista negra Sojourner Truth quien con el pronunciamiento de su discurso Ain't I a woman (¿Acaso no soy una mujer?) en 1852 durante la Convención de los Derechos Humanos de la Mujer en Akron. Da muestras claras de las diferencias que viven las mujeres negras frente a las mujeres blancas. Haciendo énfasis en lo que aparentemente, según las sociedades es el ser mujer y de lo que se deja fuera a quienes poseen condiciones sociales diferentes. Es decir, aquellas mujeres que a lo largo de la historia han sido abusadas, excluidas y vulneradas por condiciones raciales y no precisamente por su condición de género, ya que esta última, en muchos casos, no resulta ser la de mayor relevancia a la hora de que se constituyen las relaciones de poder y subordinación entre individuos, pues la población negra suele verse en los niveles más bajos de las jerarquías sociales de clases.

Es así que Truth, quien vivió en carne propia la esclavitud durante cuarenta años de su vida y quien fue liberada en 1827 dice que desde lo que se ha apreciado como "normal" en los entornos de los cuales ha sido parte, según su contexto, las mujeres viven situaciones en las que reciben ciertas atenciones o tienen ciertos privilegios por parte de los varones y ocupan algunos lugares frente a estos por el hecho de ser mujeres (blancas) como el que se les ayude a subir a las carrozas, el no ser puestas en actividades que impliquen altos niveles de esfuerzo físico como los que se realizan en el campo y en la tierra como por ejemplo, el arado y el cultivo. Cosas que, aunque ella es mujer ha hecho siempre en su vida, por lo que hace el cuestionamiento de si al estar excluida de lo que aparentemente es el ser mujer, entonces si ella puede ser considerada una de estas (PasionLatinaMontreal, 2015 ${ }^{48}$ ).

Su posición siempre había sido de inferioridad, vivió circunstancias completamente diversas y adversas a las de mujeres de razas "superiores" a la de ella. En este mismo caso, si vemos la situación de esta mujer dando prioridad a su condición de género, pensando en que los varones que son negros también pueden encontrarse en situaciones de violencia y vulneración por parte de otros grupos, entre unos y otras, aun cuando comparten raza, es evidente que hay

\footnotetext{
${ }^{48}$ Vídeo: Sojourner Truth discurso: ¿Acaso no soy mujer? Disponible en: https://www.youtube.com/watch?v=fu9vjEmGFjU . Consultado: 30/09/2020
} 
diferencias muy marcadas. Es decir, aunque los hombres pertenezcan al mismo grupo racial que las mujeres, estas últimas son puestas en las posiciones de subordinación y ellos en el de dominación. Estos, al contrastarlos con otros grupos como de mujeres blancas, la situación se torna distinta, pues los lugares de inferioridad no serán ocupados por éstas, sino por los sujetos de raza negra.

Las relaciones de opresión no siempre dependerán de que los individuos compartan solo alguna condición, sino que visto desde la mirada interseccional, podemos entender que son varias las características que determinan la posición de las personas. Sin embargo, más allá de los análisis individualistas que parten de la categoría de género, analizar la problemática desde el feminismo blanco, según autoras como bell hooks, también implica una omisión de elementos importantes a la hora de entender la vulneración y subordinación de algunos grupos:

A menudo las feministas blancas actúan como si las mujeres negras no supiesen que existía la opresión sexista hasta que ellas dieron voz al sentimiento feminista. Creen que han proporcionado a las mujeres negras $\langle<\mathrm{el}\rangle>$ análisis y <<el >> programa de liberación. No entienden, ni siquiera pueden imaginar, que las mujeres negras, así como otros grupos de mujeres que viven cada día en condiciones opresivas, a menudo adquieren conciencia de la política patriarcal a partir de su experiencia vivida, a medida que desarrollan estrategias de resistencia -incluso aunque ésta no se dé de forma mantenida u organizada (hooks, 2004: 45 en Jabardo, 2012:15)

La autora a partir de sus propias experiencias, por medio de la teoría liberadora destaca que en la formulación de análisis como los que se proponen con la interseccionalidad, es importante contemplar los elementos teóricos y aplicarlos dentro del activismo, no basta solo con pensar en un imaginario de lo que podría pasar. Es por esto que para el estudio de las opresiones no se puede tomar como referente solo las experiencias de las mujeres blancas heterosexuales, de clase media o alta y con modelos familiares estandarizados, ya que estas no son representativas en la vida de las mujeres negras (hooks, 2004 en Jabardo, 2012).

Es por esto que las teorías planteadas desde feminismos blancos o desde pensamientos como la categoría de género, no pueden ser aplicadas para explicar los componentes de las relaciones de poder y subordinación a las que se enfrentan mujeres en condiciones de mayor vulnerabilidad como lo que nos comparte bell hooks. Esta mujer, en relación a las notables diferencias que hay con las propuestas de un pensamiento blanco y la perspectiva del 
feminismo negro, señala que el verdadero problema de las relaciones de opresión, no siempre surge de los vínculos con los varones, sino que parte de un marcado sexismo: "el problema es el conjunto del pensamiento y la acción sexista, independiente de lo que perpetúen mujeres u hombres, niños o adultos" (hooks, 2019: 21).

Es decir, la autora no se refiere a las diferencias que se promueven socialmente específicamente hacia un solo sexo, sino a la interpretación que se le dan a estas diferencias. Por ejemplo, hooks señala que generalmente se ha constituido desde la mirada de los medios de difusión una idealización de lo que es el feminismo, en donde, aparentemente se trata de una batalla entre mujeres y hombres que pretenden tener el dominio de unas sobre los otros. Sin embargo, el verdadero problema no serían los hombres como tal, pese a que se reconoce que poseen privilegios ante las mujeres. Pero en realidad no solo son los varones quienes reproducen actitudes violentas y machistas hacia las mujeres, sino que muchas de estas mismas, también reproducen la dominación y subordinación de otros grupos desde las posiciones de superioridad en las que han sido colocadas, tales como lo que se ha venido diciendo en este apartado (hooks, 2017).

Así, otra de las principales autoras en analizar la intersección entre las categorías de género, raza y clase social es la feminista María Lugones, quien inicialmente hace una crítica al concepto por considerarlo como una herramienta que controla, inmoviliza y desconecta, fragmentando las relaciones sociales en categorías homogéneas. La autora señala que la interseccionalidad resalta un vacío y ausencia de aquellas categorías de mujeres que, como hemos visto, son excluidas de muchos de los estudios que se hacen para entender las desigualdades. Por ejemplo, las mujeres negras que no son contempladas desde la categoría de género al no encajar en los estándares sociales del ser mujer y, tampoco son incluidas en la categoría de negro al no estar ubicadas en posiciones significativas dentro de sus grupos raciales (Víveros, 2016). Por esto es que Lugones propone un análisis desde la fusión del reconocimiento de múltiples opresiones e identidades de mujeres planteando como uno de los ejes centrales de estudio las relaciones de dominación:

La matriz de dominación de una sociedad se encuentra ordenada por intersecciones y esos dominios corresponden con lo económico, político e ideológico. Esos ejes se intersectan de modo que no se pueden pensar los ejes de las mujeres negras en los mismos términos que las de mujeres medievales, bajo el feudalismo. Sin esos ejes de intersección entre raza y género 
no es la misma dominación. De modo que hay que comprender la construcción del estereotipo de la mujer negra en torno de su hipersexualidad y su forma de resistir esa matriz de dominación (Lugones, 2013 ${ }^{49}$ ).

La interseccionalidad según la autora, devela aquellos aspectos que no se ven o no se quieren ver en las relaciones de dominación, tal como se hace desde la categoría de género y la raza que se conceptualizan de manera individual una de otra. Lugones resalta que son varias las feministas negras que se han movilizado conceptualmente para poder constituir un medio de análisis que no invisibilice lo que ellas son y que no pretenda que sus experiencias sean reflejadas y se intenten comprender desde lo que se expone en las propuestas de quienes viven de manera muy diferente las relaciones de poder. Aun cuando todos los individuos comienzan a ser definidos desde el binarismo sexual del que se habló en el apartado anterior, esto no logra explicar el por qué y el cómo es que algunos son dominados y victimizados en mayor medida que otros (Lugones, 2008).

Sin embargo, para esta autora los análisis que parten desde una mirada de intersecciones tienen algunos sesgos importantes como es al hacer el cruce de la categoría de "mujer" con la de "negro", la mujer negra suele quedar excluida cuando se requiere entender sus procesos, pues no se encuentra contemplada en ninguna de las dos categorías centrales. Para Lugones esto es algo de lo que aún falta por trabajar y expandir para dar mayor claridad a la interseccionalidad. Esto pretende que se generen respuestas de cómo surge y cómo se podría dar tratamiento a las relaciones de exclusión y subordinación de algunas categorías de análisis y que no se queden solo en lo descriptivo. La autora dice que: "solo al percibir género y raza como entretramados o fusionados indisolublemente, podemos realmente ver a las mujeres de color" (Lugones, 2008). Además, la aplicación de esta contemplación, cabe decir, es un hecho funcional en el análisis del cruce de otras condiciones como la clase social y la edad en diversos entornos.

Otra de las autoras que destaca en sus estudios la importante necesidad de analizar los sistemas de opresión y subordinación desde una perspectiva que contemple el cruce de las diferentes condiciones de los individuos es la activista afroamericana Angela Davis quien

\footnotetext{
${ }^{49}$ Conferencia ofrecida por María Lugones en el Coloquio Internacional "Reconocer las superficies de nuestras hendiduras. Cartografiar el Sur de nuestros Feminismos". IDAES/UNSAM. Bs As, 15 y 16 de julio, 2013. En Bidaseca, 2014. Disponible en: https://www.scielo.br/scielo.php?script=sci arttext\&pid=S0104$\underline{026 \times 2014000300014 \# n t 17}$
} 
como parte de su trayectoria ha participado en una lucha que busca mejorar las condiciones de vida en las cárceles, destacando las desigualdades que se generan debido a las distinciones de género, raza y clase principalmente. Esta autora, desde su propia posición, hace grandes aportes a las problemáticas dadas en los lugares de confinamiento carcelario. Su lucha en este sentido comienza cuando conoce al activista negro George Jackson quién fue encarcelado con una condena de dieciocho años por supuestamente haber robado 70 dólares en una gasolinera (Villaverde, 2016).

Del caso se sabe que la sentencia de Jackson se incrementó cuando además se le acusó de haber asesinado a uno de los carceleros de donde se encontraba preso, éste se trató de un individuo blanco. La situación empeoró aún más cuando el hermano de este sujeto irrumpió en una de las audiencias, portando un arma de fuego con lo que reclamaba que se pusiera en libertad a su hermano y todos los vinculados a este mismo delito. Durante este suceso muere el joven hermano de George Jackson, dos presos y el juez en turno. Meses después el principal implicado muere ametrallado por supuestamente intentar fugarse del recinto. Ante estos hechos, se acusó a Angela Davis de haber sido cómplice, pues se dijo que ella fue quien entregó el arma a Jackson. Además, la acusaron de delitos muy graves como terrorismo, secuestro, asesinato y conspiración criminal (Villaverde, 2016)

Es así que desde la cárcel Davis centra su estudio en las injusticias de los sistemas penitenciarios. Mostrando que debido a condiciones conjuntas como la raza y el género de las personas pueden llevar a los individuos a vivir procesos de violencia y subordinación. Es por esto que la autora señala que es fundamental reconocer el vínculo existente entre el racismo estructural y el complejo industrial penitenciario, entre el castigo y la economía capitalista. Es decir, es necesario sacar a la luz la forma como se relacionan los principales sistemas sociales y las marcadas desigualdades que surgen de un fuerte racismo en las sociedades. En Estados Unidos, según la autora, las cárceles fueron creadas con el objetivo de privar de la libertad y de los derechos que deberían de ser reconocidos por la sociedad, lo que en realidad no estaba ocurriendo (Villaverde, 2016).

Si la situación se enfoca en la condición de mujeres en prisión, el supuesto objetivo de estos recintos sería permitir a las personas arrepentirse y rehabilitarse para ser mejores ciudadanos, pero las mujeres no entraban en esta definición, ni las personas negras, porque no eran 
personas de pleno derecho. Tal como se expuso con las autoras anteriores, existe un sesgo a la hora de pretender aplicar las leyes para individuos que se encuentran fuera de los estándares de análisis de los sistemas de opresión y aunque en este tipo de casos resalta mucho la condición de género por las diferencias destacadas entre hombres y mujeres en condiciones de confinamientos, también se muestra un gran vacío cuando se presentan casos de mujeres de razas consideradas "inferiores" (Villaverde, 2016).

Según la autora, las cárceles específicas para mujeres en Estados Unidos comenzaron a crearse en el año de 1870. El enfoque que se le dio a estos recintos fue muy distinto al propuesto para los varones, puesto que estos últimos al convertirse en delincuentes se esperaba que como resultado del encierro lograran rehabilitarse y no volvieran a transgredir las normas de la sociedad. Sin embargo, para las mujeres esto no significaba lo mismo pues inicialmente éstas no eran consideradas ciudadanas, por lo que cuando cometían algún delito, eran tachadas de militantes contra la naturaleza, vistas como lo más desagradable de la sociedad por lo que se pensaba que era imposible que se pudieran rehabilitar. De éstas solo se esperaba que pudieran ser reformadas y castigadas por su actuar anormal y distante de los estándares de lo que es ser una buena mujer, una buena madre e hija y, en el caso de las de las clases más bajas, dejando de ser unas buenas sirvientas y empleadas (Villaverde, 2016).

Con esto podemos ver que, en entornos específicos como los recintos carcelarios, son claras las desigualdades que se generan por parte de las autoridades, sin mencionar lo que sucede dentro de las cárceles. Las relaciones de dominación y subordinación que se pueden detectar entre las personas que se encuentran hacinadas en algún recinto penitenciario, constituyen sus diferentes niveles a partir de la construcción de categorías sociales que, podemos decir, tienen criterios particulares para caracterizar a los individuos, en este caso a las mujeres que se encuentran en situaciones como estas. Sin embargo, las categorías planteadas no siempre corresponden con la manera como se definen las personas. Por ejemplo, una persona puede identificarse como indígena por sus orígenes, costumbres y tradiciones, pero sus características pueden no coincidir con lo que las autoridades determinan como pertenencia a algún grupo étnico-racial.

Dicha situación, en relación con la perspectiva de análisis desde la interseccionalidad puede llegar a favorecer los vacíos de los que se habló líneas arriba, puesto que, a la hora de dar 
atención a los casos de la diversidad de mujeres en situación de reclusión, se estarían omitiendo algunos aspectos. Es por esto que, para poder realizar el análisis comparativo propuesto en este trabajo, es necesario conocer parte de las caracterizaciones que hace el sistema carcelario mexicano sobre las mujeres imputadas por algún tipo de delito, lo que se expone de manera extensa en el siguiente capítulo. Y, posteriormente con esto, en el último capítulo será posible identificar cómo es que impactan las condiciones de género, raza, clase social y edad en la vida y entorno de las mujeres consideradas en nuestro estudio de caso y qué tipo de estrategias de sobrevivencia desarrollan a partir de todos estos elementos. 


\section{El sistema carcelario mexicano: recintos reproductores de racismo, desigualdad social, de género y poder}

De la problemática que aborda las desigualdades tocadas en los capítulos dos y tres: por condición de raza, clase social y género. Actualmente podemos identificar muchos de sus aspectos en diferentes ámbitos de la sociedad mexicana, ya sea en lo laboral, familiar, escolar, religioso, deportivo, familiar, etc. En cada aspecto de nuestras vidas nos enfrentamos a relaciones desiguales de poder, en las que unos someten a otros, como resultado de las diferentes condiciones sociales de cada individuo. Estas diferencias, se enmarcan con lo que las personas interiorizamos desde nuestro nacimiento, dependiendo de la cultura de la cual seamos parte (véase socialización, capítulo 1 de este trabajo).

Sin embargo, aun cuando en la mayoría de nuestros entornos sociales podemos mirar y presenciar importantes diferencias entre seres humanos, en este trabajo la intención principal es analizarlas desde un contexto específico como son los recintos carcelarios, vistos estos como un reflejo de lo que sucede en nuestras sociedades. Es así que, en las cárceles, aunque pareciera evidente decirlo, las relaciones que se generan son extremadamente desiguales, por lo que, aquellos que son mayormente desfavorecidos tienen que desarrollar los medios necesarios para vivir y sobrevivir a las diversas circunstancias a las que se deben de enfrentar en su día a día desde que inician sus procesos y durante su estadía en prisión. Ningún individuo vive de la misma manera en estos recintos.

Todo esto es importante mirarlo desde casos específicos, es por ello que el estudio de caso para esta investigación se ubica en una cárcel mexicana específica, siendo el Centro Penitenciario y de Reinserción Social (CPRS) "Santiaguito", en el Estado de México, el lugar en donde se analizan algunos casos de personas privadas de la libertad. En esta ocasión se retoman, principalmente los testimonios obtenidos de mujeres que se encuentran en el área femenil de este centro. Cabe decir que, éste es una institución mixta, lo que significa que está habitada y "habilitada" para hacinar población varonil y femenil, y sus respectivas subpoblaciones (en donde identificaremos a las sujetas de estudio para este trabajo).

"Santiaguito" es un recinto que forma parte del Sistema Penitenciario vigente en nuestro país, en donde, se supone, ingresan personas (de distintas condiciones sociales) señaladas como delincuentes y que dentro de este lugar deberán esperar una sentencia y pagar la condena que 
se les impute. Es así como al parecer, funciona este sistema en nuestro país; una estructura semejante a lo que se expuso en el apartado 1.3 de este trabajo, con lo que podríamos decir que las cárceles son un medio poco evolucionado, en el que muchas de sus características y la manera como son constituidas actualmente, conservan rasgos y persiguen objetivos similares a los pretendidos por los sistemas penitenciarios del siglo XVIII.

Recapitulando, acerca de los objetivos centrales que, en teoría, persiguen las instituciones carcelarias, podemos decir que se trata de los siguientes: inicialmente, con el encierro se pretende castigar y sancionar a los individuos que, debido a un comportamiento anómalo hayan infringido e incumplido con las reglas y normas que el Estado como órgano de poder y representación social promueve. Y, por otro lado, se busca que las instituciones carcelarias brinden los medios para incentivar una adecuada reinserción social de aquellos que, al cometer algún delito son puestos en aislamiento, en donde supuestamente se les facultará de habilidades, valores y conocimiento con los que, al cumplir con una condena puedan "reincorporarse" satisfactoriamente a la sociedad.

Para alcanzar dichas metas, las cárceles en México, se supone que, deben de contar con ciertas características, seguir algunas reglas y normas, así como cumplir con funciones que el Estado asienta según el órgano de gobierno del cual dependa cada Centro Penitenciario. Podemos encontrar todo esto, en algunos artículos de la Constitución Política de los Estados Unidos Mexicanos, además de otras leyes más específicas como la Ley Nacional de Ejecución Penal (LNEP) (2016), principalmente. En estas leyes, pareciera que los sistemas carcelarios poseen una adecuada estructuración, organización y planeación, y que los efectos en las personas privadas de la libertad serán favorables al momento de cumplir sus sentencias.

Sin embargo, la realidad está muy alejada del imaginario de un sistema penitenciario cabal, y en su lugar tenemos uno que promueve las diversas desigualdades de las que hemos hablado en este trabajo y que, a su vez, impactan de manera importante en los individuos privados de la libertad. Es bien sabido, que, en México, las leyes no se aplican de la misma manera para ninguna persona, todo dependerá de la condición social de cada quien. Habrá quienes enfrente procesos menos severos que otros, además, dentro de prisión serán algunos los más desfavorecidos y vulnerados. Ante esto, supuestamente, las leyes contienen apartados que indican que se debe de garantizar la prevención y atención de estos grupos, aunque en la 
realidad, no parecen funcionar debidamente. Y, en cambio, lo que más se hace notar son las marcadas desigualdades entre unas y otras personas.

Es importante, identificar estas disparidades y sus consecuencias en personas privadas de la libertad (ppl) dentro del sistema penitenciario mexicano, lo cual es una de las principales tareas de esta investigación. Por ello, y para tener un mejor entendimiento de lo que se quiere documentar, es preciso hacer una breve descripción general de cómo presuntamente se constituyen los sistemas carcelarios ante la ley, y cómo dentro de esta estructura se van permeando las diferencias entre los individuos que habitan estos recintos, debido a su condición de género, raza y clase social. Lo que más adelante, nos llevará a centrarnos en el comparativo de los procesos de socialización y las estrategias de sobrevivencia que desarrollan mujeres indígenas y mestizas que habitan el CPRS “Santiaguito”.

Así, comenzando a hablar de lo que se establece en la Constitución de México en materia penitenciaria, con el Art. 22 y en la Ley Nacional de Ejecución Penal en el Art. 42, se hace énfasis en la prohibición de prácticas arcaicas y crueles que atenten contra la integridad y la vida de los individuos infractores. Acciones tales como las que se aplicaban en los precedentes de los sistemas carcelarios "modernos" (véase apartado 1.3 de este trabajo): exhibicionismo social, intimidación, tortura, mutilación, azotes, encierro en lugares oscuros y sin ventilación, tratos severos e inhumanos, aislamientos internos indefinidos o por más de 15 días continuos, periodos y penas de muerte (aún vigentes en otros países de América como Estados Unidos) (Constitución Política de los Estados Unidos Mexicanos, 2016 y Ley Nacional de Ejecución Penal, 2016).

Además, las leyes señalan que, durante el aislamiento las autoridades deben de garantizar para las personas privadas de la libertad el contacto con otros seres humanos al menos cada 22 horas $^{50}$. Supuestamente, de no cumplirse estas garantías, los encargados de las instituciones carcelarias serán acreedores de algún tipo de sanción como el pago de multas, revocación de sus puestos y hasta el encarcelamiento por algunos cuantos días. Sin embargo, en la mayoría de casos actuales en nuestro país, estas medidas no son aplicadas debidamente

\footnotetext{
${ }^{50}$ Esto no hace referencia a visitas familiares o personales, puesto que éstas solo pueden ingresar en horarios específicos (Art. 59 de la Ley Nacional de Ejecución Penal). En realidad, esta garantía se refiere al contacto con personal y demás habitantes de las instituciones carcelarias.
} 
o en su totalidad. Incluso, existen recintos en los que, como normatividad, durante el aislamiento, algunos grupos de imputados ubicados en recintos muy específicos, viven en condiciones muy cercanas a las mencionadas.

Ejemplo de esto, es la zona denominada "La Roca" en el Centro Penitenciario y de Reinserción Social "Otumba”, en el Estado de México. La cual, según explica un funcionario de la Dirección General de Reinserción Social de este estado, se trata de un pequeño espacio en donde se encierra a delincuentes varones, considerados de alta peligrosidad y que no han sido ubicados en Centros especializados para casos de esta magnitud (penales de "alta" seguridad). Quienes habitan en esta zona solo tienen permitido permanecer un tiempo muy corto bajo la luz del sol, hablamos de al menos quince minutos al día. Durante su encierro, es importante que en todo momento estén encadenados de pies y manos, de tal manera que pierdan gran parte de su movilidad. Además, su convivencia con otros individuos es totalmente limitada, ya que tienen prohibido recibir cualquier tipo de visita personal, a excepción de su defensa legal.

Sobre las condiciones de vida en este recinto, las autoridades tienen completo conocimiento, no obstante, mencionan que no es posible intervenir en este sistema, pues así es como se ha manejado a lo largo de la existencia de "La Roca". Y, las instalaciones, ya tienen varios años de haber sido acondicionadas de esta manera, no han cambiado, no se les ha modernizado y siguen siendo ocupadas para la misma función. Pese a la existencia de un espacio donde no se garantizan las leyes, las autoridades encargadas no reciben ningún tipo de sanción, como lo señala la ley, al menos no hasta ahora. Según lo declarado por el mismo funcionario; “el trato que reciben estos individuos es inhumano. Sin embargo, no se me ocurre otra manera de controlarlos. Así que, nosotros solo vemos y cumplimos con lo que nos toca" (Testimonio de “Anónimo 1"

Respecto a lo anterior, se supone que las autoridades deben de procurar el cumplimiento de una estructura penitenciaria que se describe en el art. 18 constitucional y en los arts. 4 y 9 de la $\mathrm{LNEP}^{53}$, en donde se explican las bases y principios que dan sustento al sistema penal en

\footnotetext{
51 Se nombra como "Anónimo" al contacto por petición personal de éste, debido a restricciones impuestas a los funcionarios de la Dirección General de Reinserción Social del Estado de México.

52 Dirección General de Reinserción Social del Estado de México.

53 Ley Nacional de Ejecución Penal.
} 
nuestro país. En el caso del primero de estos artículos se establece que cuando un individuo cometa un delito que amerite como pena la prisión preventiva ${ }^{54}$, éste será confinado en sitios apartados del entorno social en el cual haya infringido y atentado a las normas impuestas por la ley. Es decir, el individuo infractor deberá ser ubicado en alguna de las cárceles correspondientes al tipo de infracción que éste haya cometido. Además de que deberá ser confinado en el Centro Penitenciario más cercano al lugar donde compruebe que se encuentra pernoctando. (Constitución Política de los Estados Unidos Mexicanos, 2016).

Los recintos asignados para esta función (instituciones carcelarias), según este artículo de la Constitución, deberán asentar las bases de su organización en el respeto a los Derechos Humanos $^{55}$, el fomento y capacitación para el trabajo, la educación, la salud y el deporte, supuestamente, sin ningún tipo de distinción o discriminación por edad, preferencia sexual, género, clase social o grupo étnico. Además, en relación con esto, según el art. 4 de la LNEP, los principios fundamentales de los sistemas penitenciarios son: la dignidad, la igualdad, legalidad, el debido proceso, transparencia, confidencialidad, publicidad y reinserción social. Esto con la finalidad de garantizar que las personas privadas de la libertad gocen de todos los derechos "promovidos” por el Estado mexicano. Según estas leyes, las principales garantías deberán ser:

En primer lugar, las instituciones carcelarias tienen la obligación de asegurar el principio de igualdad entre todos los imputados, según su género, origen étnico o nacionalidad, edad, condición social y posición económica, capacidades diferentes, creencias religiosas, preferencias sexuales, identidad de género, estado civil, etc. Según estas leyes, el Estado mexicano deberá juzgar a los implicados de delitos haciendo valer las leyes por igual, para todos los individuos. En segundo lugar, el estado debe de proporcionar servicios de primera necesidad como una adecuada asistencia médica, preparada y equipada para atender de la

\footnotetext{
54 “Medida cautelar impuesta al imputado por un juez, la cual consiste en la privación temporal del derecho a la libertad personal con el fin de asegurar la integridad de víctimas o testigos, así como el desarrollo de la investigación o la conclusión del proceso penal. Esta medida cautelar debe aplicarse solo si otras medidas menos intrusivas no son suficientes para asegurar dichos objetivos". Véase: https://imco.org.mx/justiciapenal/blog/definicion/prision-preventiva/

55 “Los Derechos Humanos son el conjunto de prerrogativas sustentadas en la dignidad humana, cuya realización efectiva resulta indispensable para el desarrollo integral de la persona. Este conjunto de prerrogativas se encuentra establecido dentro del orden jurídico nacional, en nuestra Constitución Política, tratados internacionales y las leyes". Véase: http://www.cndh.org.mx/Que son Derechos Humanos
} 
mejor manera la mayor cantidad de problemas de salud que las personas privadas de la libertad puedan presentar. Cada institución carcelaria y sus respectivas áreas deben de contar con servicios médicos, tanto para varones como para mujeres (y sus respectivos subgrupos) en condición de reclusión.

Otra de las principales garantías es que los internos deberían de tener una alimentación nutritiva, suficiente y de calidad que permita un adecuado estado de salud (LNEP, Art. 9). Sin embargo, esta es una de las principales y más notorias deficiencias del sistema carcelario en México:

Son las 3:45 de la tarde, estoy parada en la intersección entre el área varonil y femenil [de "Santiaguito"], estoy esperando a que salgan [las autoridades] por mí e ingresar al área femenil. Muchos presos varones se encuentran inquietos en el pasillo, como si esperaran ansiosos recibir una noticia, algunos esperan recostados en el piso bajo los rayos de sol. Pasan los minutos y nada sucede, al cinco para las cuatro, sale del área femenil un carrito de metal empujado por dos hombres con delantal y cubre bocas.

El carrito tiene dos bases; en la superior hay una charola con bolillos y una olla con lo que parece arroz o algún tipo de pasta, de la cual no se le logra percibir la forma. En la parte inferior, hay dos grandes cazuelas de aluminio con lo que parece ser huevo con salchicha, se mira descolorido, aguado, y húmedo. Los presos detienen el carrito antes de que pueda pasar por completo las rejas y ser llevado al comedor. Quienes esperaban con ansiedad, toman uno o dos bolillos, lo parten por la mitad y comienzan a tomar la mayor cantidad de alimento posible con estos. Comen en el suelo, levantan lo que se derrama y lo comen con desesperación... Si quisieran más y mejor comida, tendrán que comprarla o mandarla hacer en costos algo elevados... (Nota de campo de Calderón, 30 noviembre 2018).

Con esto se pretende resaltar un poco la manera cómo los sistemas carcelarios van impactando en la vida de los internos. Y, como se mencionó en líneas previas, las autoridades son conscientes de este tipo de situaciones. En la ocasión narrada, un funcionario del área laboral dentro de este Centro Penitenciario, menciona que la mala alimentación es uno de los problemas más graves dentro de las cárceles. Algunos y algunas internas de bajos recursos, se ven obligados a consumir sus alimentos de este modo, de lo contrario, pueden quedarse sin comer, pues la comida es insuficiente y limitada. Solo quienes poseen mayores recursos económicos (una minoría de la población), suelen comprar alimentos de mejor calidad que, en el caso de este recinto, son preparados por algunas mujeres del área femenil.

Así mismo, otro tema importante que, en teoría, deben de garantizar los sistemas carcelarios es que a las personas privadas de la libertad se les debe de informar desde el momento de su 
detención y durante todo el proceso, sus derechos y obligaciones, de tal manera que exista un entendimiento claro sobre su situación legal, del proceso que vivirán y cómo será su encierro, aunque como veremos más adelante, no sucede como tal. Por otro lado, una quinta garantía en manos de las autoridades, es que se debe de asegurar que dentro de las instituciones carcelarias haya buenas condiciones de salubridad y un correcto suministro de recursos como agua potable y gas natural. Además, también se dice que debe de haber un suministro diario de artículos de higiene para cada uno de los internos (Art. 9).

Esto último, según lo expuesto por algunos internos de "Santiaguito" es inexistente, ni siquiera están informados de que se les debe de garantizar este derecho. Debido a esto, lo que sucede es que dentro de la institución algunas personas privadas de la libertad comercializan productos de higiene, ya sea que los vendan en precios muy altos o los intercambien por trabajos manuales. En cuanto al suministro de agua potable y gas, muchas veces, en algunas áreas, no cuentan con estos recursos. Esta situación, no solo fue vista en el penal de Almoloya de Juárez, sino que también en el Reclusorio Femenil "Tanivet” en el estado de Oaxaca:

En la parte exterior de la estación de custodios una mujer cortaba vegetales (chayotes, zanahorias y papas), -pregunté: “¿prepara comida para los custodios?”, -la mujer respondió: "no, estoy preparando caldo de pollo para la muchacha que tuvo su crío. Llevamos ya como una semana sin gas, sin agua caliente y nosotras como quiera comemos lo que sea, pero la pobrecita de Beatriz no anda bien, anda mala y tiene que darle leche a su hijo, no puede comer lo que sea. Entonces, ps ya les pedimos permiso de cocinarle un taquito aquí, pero no más me dejaron salir a mí...”. La mujer continuó cocinando, solo le permitirían estar un momento en esa zona y debería regresar a su celda pronto (Nota de campo de Calderón, 9 de mayo de 2018).

En México es evidente como el sistema carcelario va promoviendo desigualdades entre individuos, que, sin duda alguna, se enmarcan por las condiciones sociales de los individuos en situación de reclusión. Es así que, también es importante la interacción con personas del exterior, las instituciones carcelarias deben contar con un régimen de visitas semanales, esto siempre y cuando los visitantes cumplan con las normas internas de cada institución carcelaria, pues dependiendo del tipo de recinto (federal, estatal, municipal, etc.) se establecen las normas y condiciones necesarias. No cualquier persona puede tener acceso a las diferentes cárceles mexicanas, al menos no de la forma legal, pues también es sabido que los custodios ofrecen la posibilidad de acceder, siempre y cuando se cubra con una tarifa, la 
cual varía dependiendo de lo que se quiera ingresar en tal caso y el tiempo que permanecerá la "visita".

Por otro lado, las leyes que aquí se mencionan, también señalan que las personas privadas de la libertad tienen derecho a que se garantice y proteja su integridad física, moral, sexual y psicológica sin excepción alguna, no deberían de recibir ningún tipo de tortura en ninguna de las etapas del proceso, pero como veremos en el análisis de nuestro estudio de caso, las afectaciones suelen generarse de manera "indirecta", por parte de las mismas autoridades y de las mismas internas, mientras se generan las diferentes relaciones de poder.

Por último, otro de los derechos con el que se dice que deben de contar los imputados, se trata de su integración y participación en un plan de actividades que favorezcan las bases mencionadas líneas arriba (trabajo, salud, deporte y educación) (Art. 9), con lo que se pueda lograr una debida reintegración social y familiar al momento de que se haya cumplido con las sentencias impuestas. Esto último, incluso, en algunas páginas digitales como la de la Secretaria de Seguridad Pública del Estado de México señalan como uno de sus principales objetivos: "Proporcionar al individuo las herramientas necesarias para asimilar las normas y valores universalmente aceptados, adquisición de hábitos y valores necesarios para reinsertarse positivamente al núcleo social y familiar” (SSP Edo. Méx., 2018).

Para este trabajo es importante hacer mención de estas garantías porque a partir de los testimonios de mujeres recluidas en "Santiaguito", la etnografía y observación no participante obtenidos del trabajo de campo realizado en este recinto, es posible afirmar que su cumplimiento está muy lejos de ser una realidad. Lo que sin duda impacta de manera significativa en la vida de las diferentes categorías de internos (en este caso, principalmente mujeres) que habitan el CPRS, y que tiene como resultado el desarrollo de algunas de las distintas estrategias de sobrevivencia que nos interesa documentar. Es por ello, que es preciso insistir en el hecho de que, aunque estos principios y derechos se encuentren explícitos en la ley, no significa que en la práctica se llevan a cabo debidamente.

Dicha situación es un problema grave que parte de las deficiencias que caracterizan a las instituciones carcelarias de nuestro país. Esto no parece ser ajeno para las autoridades ya que se muestran conscientes, pero poco sensibles con las problemáticas y con lo que esto pueda implicar en las personas privadas de la libertad. Según un funcionario de la Dirección General 
de Reinserción Social del Estado de México, "Hacen falta muchas cosas; mejorar la seguridad, falta personal de la policía, espacio y buscarle alternativas para que cumplamos con la reinserción social... [pero] hay que acoplarse con lo que hay y sobrellevar la situación" (Testimonio de “Anónimo”, DGRS EDOMEX, 2019).

En las autoridades encargadas de los diferentes recintos carcelarios es en quienes recae el monopolio de poder en materia penitenciaria y de prevención del delito (Art. 21 constitucional). Es por ello que les compete que, en supuesta representatividad social, impongan y apliquen las sanciones correspondientes según cada delito y tipo de persona. Pero, además, como se ha venido mencionando, también poseen la facultad para asegurar y promover diversas garantías para los imputados. Es así que, otro hecho que para esta investigación es muy importante, es que, según las leyes del Estado mexicano, se establece que las diferentes penas deberán ser aplicadas en recintos específicos.

La ubicación de personas privadas de la libertad, retomando lo que nos dice la Constitución de México y la Ley Nacional de Ejecución Penal, en los artículos 18 de la primera y el 5 de la segunda, se llevará acabo según diversos rubros: Por edad (Centros de readaptación para menores), tipo de delito (Régimen de vigilancia), si se trata de procesados o sentenciados y por sexo (instituciones carcelarias femeniles, varoniles y mixtas). Y dentro de estas categorías, supuestamente, se identifican algunas subcategorías como son: origen éticoracial, nacionalidad, personas con algún tipo de discapacidad, con problemas psicológicos, etc.

Además, todos los centros penitenciarios y de readaptación (reinserción) social pertenecen a distinta categoría, pueden ser Federales, Estatales y Municipales. Lo cual se describirá más ampliamente en el apartado 3.1 de este trabajo, con lo que se identificarán con mayor claridad los tipos de personas, las desigualdades y el tipo de institución a la que pertenece "Santiaguito", con esto se documentará el tema central de esta investigación. Habiendo hecho este paréntesis, y siguiendo con lo que establecen las leyes, cabe decir que el primer rubro para la ubicación de imputados es en cuanto a la atención de infractores menores de edad (doce años cumplidos y menos de dieciocho años). Ésta deberá basarse en un sistema integral de justicia para adolescentes. 
Con este sistema, se dice que se tendrán que asegurar las garantías mencionadas líneas previas para las personas privadas de la libertad. Las sanciones serán determinadas por instituciones y autoridades facultadas y especializadas en la materia. Éstas podrán aplicar diferentes medidas de orientación, protección y tratamiento, según lo requiera cada caso. Cuando se determine que la sanción correspondiente para un infractor de este tipo sea la privación de la libertad (solo aplica a mayores de catorce años), se le ubicará en recintos específicos (Art. 18 constitucional). Es decir, no cumplirán sus sentencias en sitios habitados por transgresores que cuentan con la mayoría de edad.

Por otro lado, el segundo rubro de separación de personas privadas de la libertad es según el tipo de delito. La lista de lo que es considerado un acto delictivo en nuestro país es extensa y todos estos poseen sanciones que van de acuerdo a la gravedad que se les atribuya. Estos actos pueden pertenecer al fuero común ${ }^{56} \mathrm{o}$ al fuero federal ${ }^{57}$ y dependiendo de la categoría a la que pertenezcan, se le alojará a los imputados en recintos especiales. Por ejemplo, en el caso de acusados de delincuencia organizada (fuero Federal) o delitos que requieran de medidas de seguridad más específicas. Además, en casos como estos, las autoridades están facultadas para restringir la comunicación de los inculpados y sentenciados, limitando la interacción con familiares, permitiéndola solo con su defensor legal (Art. 18 de la Constitución y Art. 5 LNEP).

Un tercer rubro para la separación de las personas privadas de la libertad es por el sexo de los individuos. El artículo 18 constitucional y 5 de la LNEP señalan que las mujeres deberán compurgar sus penas en lugares separados a los destinados para los varones. Es por ello que en México se han creado recintos carcelarios femeniles en donde, supuestamente, se dará atención especializada únicamente a mujeres infractoras. Y en otros casos, en algunos de los

\footnotetext{
56 Los delitos del fuero común son los que afectan directamente a las personas en lo individual, los más comunes son: Secuestro, robo a transeúntes, robo a vehículos, robo a casa habitación, robo a negocios, lesiones leves, daño en propiedad ajena, cohecho, fraude, homicidio, corrupción de menores, abuso de autoridad, falsificación de documentos, delitos sexuales, entre otros. Véase: http://www.oas.org/udse/cd educacion/cd/Materiales conevyt/VPLD/delitos.PDF

57 Son aquellos que afectan la salud, la economía, el patrimonio y la seguridad de la nación, es decir, el bienestar de la población mexicana. Algunos de estos delitos pueden ser: portación de arma de fuego sin licencia, ataques a las vías de comunicación, narcotráfico y otros delitos contra la salud, daños o robo al patrimonio arqueológico, artístico e histórico, delitos electorales, delitos ambientales, contrabando, defraudación fiscal, robo de bienes de la nación, delitos en materia de derechos de autor, entre otros. Véase: http://www.oas.org/udse/cd educacion/cd/Materiales conevyt/VPLD/delitos.PDF
} 
recintos que se identificaban desde sus inicios como específicos para varones, se dividió el espacio para crear áreas que han de ser ocupadas por cierta cantidad de población femenil.

Con este tipo de segmentación de la población privada de la libertad, podemos comenzar a identificar las desigualdades que se promueven por condición de género. Empezando por la distribución de los espacios, que, a simple vista, son de menor extensión los dedicados para la población femenil, mientras que los que se otorgan para la población varonil son de mayor tamaño, esto es justificado por la existencia de un mayor número de hombres imputados que de mujeres.

Además, las áreas femeniles no cuentan con algunas zonas destinadas para actividades deportivas, espacios de trabajo amplios, específicos y en buenas condiciones, servicios médicos a la mano, lugares especiales para los hijos de las internas (menores de 6 años), etc. Esta modalidad de distribución en todo el sistema penal mexicano, enmarca importantes limitantes no solo para las poblaciones femeniles, sino para muchas de las subcategorías que se ubican en ambos grupos de personas privadas de la libertad (varonil y femenil), y que por consiguiente buscan sobrevivir a las condiciones en las cuales se encuentran en alguno de los diferentes tipos de recintos carcelarios.

\subsection{Tipos de instituciones carcelarias en México}

Los sistemas penitenciarios en México, tal como se ha venido diciendo, se supone que asientan sus bases en el respeto a los Derechos Humanos, el fomento y la capacitación para el trabajo, la educación, la salud y el deporte como principales herramientas para lograr la debida reinserción social de las personas calificadas como delincuentes. Para que esto sea posible, algo que resulta importante destacar de la estructura de estos sistemas es la "planificada" y "organizada" distribución de personas en condición de reclusión, según algunas de las condiciones y características de las personas. La clasificación de población

privada de la libertad se focaliza a partir de diversos rubros regidos en conformidad con la legislación nacional en materia penitenciaria.

Lo referente a la ubicación de los y las internas podemos encontrarlo consultando los artículos 18 de la Constitución Política de los Estados Unidos Mexicanos y en el artículo 5 
de la Ley Nacional de Ejecución Penal. En estos, son cuatro los principales criterios con los que se determina en qué tipo de institución se situará a las personas implicadas en algún delito para, ya sea que deban esperar sus sentencias -en el caso de prisión preventiva-, o para pagar sus condenas. Estos criterios son los siguientes: edad (menores de edad y adultos), situación jurídica (procesados y sentenciados), régimen de vigilancia por tipo de delito (fuero común/ federal) y sexo (hombres y mujeres).

En México, a partir de estos criterios, se supone que, se ubica a una población de 233, 469 personas privadas de la libertad (indiciados, procesados y sentenciados) en los 379 Centros Penitenciarios $^{58}$ de nuestro país $\left(\mathrm{CNS}^{59}, 2016\right.$ : 10). Estos recintos pueden pertenecer a tres diferentes categorías, dependiendo del órgano gubernamental al cual pertenezcan. Es así que, las diferentes poblaciones privadas de la libertad se pueden ubicar en cárceles Federales, Municipales y Estatales, y dentro de estas se han de permear los diferentes criterios de distribución penal. En estos espacios, pese a las diferencias en sus características, en teoría, todos persiguen los principios y objetivos propuestos en las leyes antes mencionadas. Es así que los tres tipos se describen a continuación:

Inicialmente, los centros penitenciarios Federales están en manos del Gobierno Federal (Secretaría de Gobernación) por medio del Órgano Administrativo Desconcentrado Prevención y Reinserción Social (OADPRS). Estos recintos están destinados para albergar personas mayores de dieciocho años que se encuentran indiciadas ${ }^{60}$, procesadas o sentenciadas por delitos calificados graves, ya sean del Fuero Común o del Fuero Federal. Dentro de esta categoría se consideran todas aquellas instituciones penitenciarias preventivas, de ejecución de sanciones penales, de reinserción psicosocial o de asistencia post penitenciaria destinados a la reclusión de personas, tales como: los Centros Federales de Readaptación Social (CEFERESO), los Centros Federales de Rehabilitación Psicosocial (CEFEREPSI) y las Colonias Penales Federales (INEGI, 2016).

\footnotetext{
${ }^{58}$ Considerando en la cifra al Centro Penitenciario Federal Islas Marías y Topo Chico en Nuevo León que se han inhabilitado durante 2019.

${ }^{59}$ Comisión Nacional de Seguridad

${ }^{60}$ Situación Jurídica de un individuo en donde se le señala como responsable de algún delito, a causa de que existen indicios de su participación en el hecho ilícito. Véase:

http://sjf.scjn.gob.mx/SJFSist/Documentos/Tesis/299/299329.pdf
} 
Según los últimos censos del INEGI (2016), en todo el país existen 17 recintos que pertenecen a esta categoría, en la cual se tiene contabilizada una población de 19,904 personas. De las cuales, podemos destacar que solo el 3.2\% se trata de mujeres y el otro 96.8\% son hombres. Del total de recintos de esta categoría, solo dos son específicos para población femenil, y aunque las implicadas son una minoría, estas dos cárceles son señaladas como instituciones con sobrepoblación. Además de que, para este grupo de personas en situación de reclusión, existe un grave desarraigo familiar, ya que las que se encuentran pagando condenas, normalmente son alejadas de su entorno social. Esto se debe a que cuando se trata de poblaciones que requieran de atenciones "especiales", por tipo de delito, no son ingresadas en el centro más cercano a su domicilio (CNDH, 2016).

Como ya se mencionó, en este tipo de cárceles se cuenta con recintos varoniles y femeniles (algunos considerados de máxima seguridad) para la distribución y ubicación de las personas privadas de la libertad. Cabe señalar que, dentro de esto recintos, las poblaciones hacinadas no solo se trata de hombres y mujeres, sino que, existen algunas subcategorías, por mencionar una de estas, podemos nombrar las distinciones por origen étnico- racial. Quienes, por lo general no se contemplan para ser contabilizados en las principales estadísticas de poblaciones privadas de la libertad, en ninguna de las esferas poblacionales. Las únicas poblaciones de las que se habla en estos censos son: la edad, género, situación jurídica y tipo de fuero al cual pertenezcan los individuos (CNDH, 2016).

Pasando a otra escala de gobierno, también existen los Centros Penitenciarios Municipales, estos son los recintos a cargo de los gobiernos, que como su nombre lo indica, son del municipio de cada estado. Estos Centros, se destinan para atender y recibir a personas con la mayoría de edad cumplida (18 años), igualmente, indiciadas, procesadas y sentenciadas por delitos del fuero común, principalmente. En esta categoría se consideran todos aquellos establecimientos penitenciarios preventivos, de ejecución de sanciones penales, de reinserción psicosocial o de asistencia post penitenciaria destinados a la reclusión de personas, recintos tales como: Cárceles Municipales o de cualquier otro tipo que tenga funciones de internamiento para personas que se encuentren sujetas a un proceso penal o en ejecución de sentencia, dentro del municipio donde radiquen los implicados en algún delito (INEGI, 2016). 
En México existen 71 Centros Penitenciarios de esta categoría, los cuales, supuestamente, tienen capacidad para resguardar a 2,511 individuos (aunque son habitados por una mayor cantidad de personas). Este tipo de cárceles cuenta con instalaciones pequeñas en comparación con las de los Centros Federales, es por ello que se aloja a una menor cantidad de imputados. La mayoría de estos recintos son varoniles, pero sí se cuenta con algunos destinados para mujeres o espacios para éstas. Según el último Diagnostico Nacional de Supervisión Penitenciaria de la CNDH (2017), la atención que reciben las poblaciones femeniles y además las indígenas en estos lugares, es muy deficiente, puesto que se cuenta con mayores recursos y "mejores" condiciones para dar atención a los varones mestizos que habitan estos centros.

Esto último es un hecho que se puede generalizar en todos los tipos de recintos carcelarios de México. La situación es más notoria en las instituciones mixtas, ya que en sus inicios fueron construidas para "rehabilitar" a delincuentes varones y no precisamente a mujeres. Con los años, estos lugares tuvieron que ser divididos en espacios desiguales, en los que la zona más pequeña se destinó para recluir a mujeres. Al ser solo adaptaciones espaciales, no cuentan con las características necesarias para cumplir con los principios de readaptación social que, se supone, exige la ley. Por otro lado, las cárceles que son específicamente femeniles tienen "mejores" características para dar atención a las necesidades de esta población, lo que, en el siguiente apartado se explica con mayor profundidad.

Dicho esto, es preciso mencionar el tercer tipo de institución carcelaria que también posee en sus raíces las marcadas desigualdades del sistema penitenciario mexicano. Se trata de los Centros Penitenciarios y de Reinserción Social Estatales, estos son las instituciones carcelarias a cargo de los gobiernos de los diferentes estados y de la Ciudad de México, se destinan para dar atención a personas mayores de dieciocho años que hayan actuado en contracorriente con las normas sociales de nuestro país, y que se encuentran en situación de indiciadas, procesadas o sentenciadas por delitos del fuero común o federal (INEGI, 2016). 
En esta categoría de centros se encuentran los establecimientos penitenciarios preventivos ${ }^{61}$, de ejecución de sanciones penales, de reinserción psicosocial o de asistencia post penitenciaria, estas instituciones pueden ser: Centros de Readaptación Social (CERESOS), Centros Penitenciarios y de Reinserción Social (CPRS), Reclusorios, Penitenciarias, Cárceles Distritales o cualquier otro que tenga funciones de internamiento de personas que se encuentran enfrentando un proceso o pagando una sentencia penal en su Entidad Federativa (INEGI, 2016).

Actualmente existen 278 cárceles estatales, las cuales tienen capacidad para "atender" a 148,902 personas (hombres y mujeres). Sin embargo, la mayoría de estos recintos rebasan su cupo por al menos un $26 \%$ de población. Las instalaciones de estos son de menor tamaño que el de los Federales y de mayor extensión que los Municipales. Los centros penitenciarios de los estados cuentan con instituciones específicamente femeniles o varoniles $\mathrm{y}$, al igual que en los casos anteriores, hay algunas que son mixtas o que se acondicionaron para hacinar los dos tipos de poblaciones, y entre estas, diferentes subgrupos que, como se verá más adelante, viven en condiciones desiguales.

Son diversas las características y acciones del sistema carcelario con las que se trastoca la vida de las poblaciones privadas de la libertad. Ejemplos de esto son: la sobrepoblación, la inadecuada adaptación de los espacios, y la indebida o limitada aplicación de las leyes para el sistema penitenciario. Con esto, es innegable la manera en que se empiezan a alterar los procesos de socialización, en este caso, de las actoras: mujeres indígenas y mestizas, según la categoría de recinto en la que se encuentren recluidas. Y que, a partir de su condición de género, clase social, raza y otros elementos se han de ver motivadas para desarrollar las diferentes estrategias de sobrevivencia de las que se habla en este trabajo.

Como se anticipó en líneas previas, existen importantes diferencias entre los penales femeniles y los que son mixtos, ya que, en estos últimos, se piensa que las carencias y relaciones de poder son intervenidas por más actores que en los primeros. Esto se debe a que las áreas "acondicionadas" para recluir a mujeres, es de menor proporción que la que se

\footnotetext{
${ }^{61}$ Centros destinados a la custodia de detenidos y presos, que cuentan con medidas de seguridad para evitar que estos puedan salir libremente mientras enfrentan sus procesos penales. Disponible en:

https://dej.rae.es/lema/establecimiento-penitenciario
} 
conserva para la población varonil (entendiendo que hay una mayor cantidad de hombres en reclusión que de mujeres). Además, el mismo sistema penitenciario, promueve destacadas desigualdades en la vida de las mujeres. Por mencionar un ejemplo, en el ámbito laboral las actividades mejor remuneradas se ofertan principalmente para los hombres, por lo que las mujeres tienen que dedicarse a más de una actividad para generar un mayor ingreso.

Por otro lado, en el caso de las cárceles femeniles, se puede decir que son recintos nuevos, ya que se diseñaron tiempo después de que ya se habían constituido las varoniles. Se supone que, por esta razón, las condiciones espaciales son mejores que en el caso de los recintos mixtos. Esto no significa que, por ser centros específicos para mujeres, la calidad de vida sea la adecuada, ya que, en cualquiera de los dos tipos de recintos, se promueven bastas desigualdades y el golpe que da el sistema carcelario en los procesos de socialización de las actoras dependerá principalmente de los elementos clave de esta investigación: género, raza y clase social.

\subsection{Mujeres recluidas en cárceles femeniles y mixtas (panorama general)}

Los rubros que se contemplan para la ubicación de las poblaciones privadas de la libertad en México son muy específicos, tanto que, incluso, podríamos considerarlos limitados. Esto debido a que, como se explicó en párrafos anteriores, son cuatro los principales: por edad, situación jurídica, régimen de vigilancia por tipo de delito (Fuero Federal y Común) y por sexo. Todos estos en las distintas categorías de recintos carcelarios: Municipal, Federal y Estatal. Sin embargo, las personas que se encuentran en estas instituciones, no solo se identifican dentro de los cuatro grupos, ya que cada individuo se puede clasificar de manera diversa según su condición social.

Por ello, es posible reconocer perfiles distintos en las poblaciones en situación de reclusión. Es así que, en el caso de la división por sexo, no solo podemos hablar de hombres y mujeres, sino que, dentro de estos, existen subcategorías de grupos de los cuales no todos son contemplados por las leyes vigentes. Por ejemplo, comenzando con uno de los primeros perfiles generales, podemos hablar de la edad, pero no solo en el sentido que las leyes contemplan. Éstas, retomando lo dicho en el apartado 3 de este trabajo, establecen ciertas 
características y normas con las cuales se separa a la población adulta de la que es menor de edad (12 años cumplidos y menos de 18 años). Quienes tienen más de 18 años son ubicados en los centros penitenciarios y cárceles para adultos en las que, en realidad, no existen distinciones generacionales (edades).

En las instituciones carcelarias en donde se encuentran recluidas mujeres mayores de edad, se pueden identificar personas jóvenes, adultas jóvenes y adultas mayores. Todas estas, son ubicadas en los mismos entornos, las mismas celdas y se contemplan en las mismas actividades. La manera de procesar a las personas mayores de edad es muy similar entre sí, no se diferencia por generación. Es decir, se juzga del mismo modo a una mujer de 19 años como a una de 70 años, en el caso de haber incurrido en el mismo tipo de delito. Sin embargo, las experiencias de cada una son muy distintas cuando interviene la distinción de edades.

Con esto, no se pretende decir que las mujeres señaladas como delincuentes en su etapa de vejez, deberían de tener un trato preferencial por esta condición, aun cuando hayan delinquido. Sino que, en algunos casos, la edad es una fuerte limitante para sobrevivir a la vida en reclusión, pues dentro de los centros penitenciarios se sufren diversos abusos por parte de los mismos internos y las autoridades. Además de que, si consideramos su condición y estados físicos, y en algunos casos, problemas de salud que puedan presentar, hacen que la generación sea un elemento importante que determina que algunas mujeres sean puestas en un lugar de mayor vulneración frente a personas con menor edad.

Es así que, centrándonos en los recintos femeniles y mixtos, podemos afirmar que no es lo mismo ser una mujer mayor que una mujer joven. Es común, en muchos casos que, mujeres de edad avanzada requieran de atenciones diferentes a las de mujeres con menos años (no siempre es así). Además de que hay actividades que no pueden realizar con facilidad, y esto las coloca en un lugar de sometimiento frente a otras mujeres (autoridades y demás internas). Hacer estas afirmaciones puede sonar muy obvio, debido a que las necesidades, condiciones y creencias de unas y otras mujeres, claramente son distintas. Sin embargo, para el Estado no resulta ser tan evidente, pues, como tal no existen leyes que se enfoquen directamente en esta situación dentro de las cárceles y durante todo el proceso de mujeres privadas de la libertad.

Lo más relevante que podemos encontrar en las leyes mencionadas en el apartado 3 es que, supuestamente, y de manera general, la Ley Nacional de Ejecución Penal (LNEP) señala en 
su Art. 144 que: "El Juez de Ejecución podrá sustituir la pena privativa de la libertad por alguna pena o medida no privativa de la libertad cuando... esta fuere innecesaria o incompatible con las condiciones de la persona privada de la libertad por senilidad, edad avanzada, o su grave estado de salud, en los casos regulados". Lo que, en muchas de las cárceles del país, esto es difícilmente aplicado.

En las instalaciones de algunos recintos, ya sean femeniles o mixtos, basta con caminar por las áreas comunes para darse cuenta que existen numerosos grupos de mujeres de la tercera edad habitando los espacios asignados, y aunque las autoridades sí tienen un registro generacional, no cambia nada la manera en que estas mujeres viven la privación de la libertad. Algo que también es evidente a primera vista, es que las mujeres de mayor edad se agrupan entre ellas durante el día, incluso, realizan actividades en conjunto, buscando pasar desapercibidas del resto de las mujeres, de manera que puedan evitar conflictos y sobrellevar las situaciones que se vayan presentando. Lo que se describirá más extensamente en el capítulo 4.

Así, otra subcategoría - como las denominan las autoridades ${ }^{62}-$, de mujeres privadas de la libertad en cárceles femeniles y mixtas, es el grado de escolaridad y de alfabetización con que llegan a las instituciones carcelarias. Según estudios hechos por autores como la Lic. Marcela Briseño ${ }^{63}$ en 2006, afirman que la mayoría de las mujeres que ingresan a los Centros Penitenciarios llegan con un nivel escolar básico e incluso menor (refiriéndose a primaria trunca). Otras cuantas tienen educación secundaria y aquellas que recibieron estudios de educación superior, representan una notable minoría. Mientras que, por otro lado, también existen muchas internas que ingresan categorizadas como analfabetas. Es decir, que no saben leer ni escribir (Briseño, 2006: 41).

Esto último, coloca a muchas mujeres privadas de la libertad en un sitio de gran vulneración. Incluso, desde antes de ser ingresadas a las instituciones carcelarias. El analfabetismo, junto con otros factores con los que viven muchas de ellas, puede ser las causas que las llevan a delinquir y, por tanto, a tener que pagar una condena en prisión. En casos como estos, encontramos a muchas mujeres (la mayoría madres de familia) de clases sociales bajas y muy

\footnotetext{
${ }^{62}$ Anónimo, Dirección General de Reinserción Social, Toluca, Estado de México, 2018

${ }^{63}$ Ex-Coordinadora del Programa de Capacitación Penitenciaria de la Secretaria de Gobernación.
} 
bajas que buscan sobrevivir en su día a día, y que, algunas veces, por desconocimiento de las consecuencias que pueden llegar a tener sus acciones, terminan siendo cómplices de actos delictivos. (Briseño, 2006); (Salinas, 2014: 4).

Ejemplo de esto, es que, según el Censo Nacional de Gobierno, Seguridad Pública y Sistema Penitenciario Estatales 2019 del INEGI. Muchas de las mujeres que se encuentran privadas de la libertad ingresaron principalmente por los delitos de: robo, delitos contra la salud, homicidio y secuestro (INEGI, 2019). Muchas de estas incurrieron en estas faltas por diferentes razones, entre las más comunes son: una limitada economía para gasto familiar, en el caso del robo y delitos contra la salud. En otros casos como el homicidio, las razones pueden ser distintas; ya sea como consecuencia de violencia intrafamiliar o de género. También, en este tipo de delito, hay mujeres que han sido juzgadas por haber tenido algún aborto, lo que dependerá de la concepción de las leyes de cada estado. Y, por último, lo referente a secuestro, lo que puede derivar de situaciones relacionadas con su economía familiar y en otros casos por el encubrimiento de sus parejas o familiares.

Se sabe que muchas de las mujeres que se encuentran en este tipo de situaciones son indígenas, quienes, en muchos casos, no solo no saben leer y escribir, son pobres, madres o abuelas de familia, sino que, además, no hablan y no entienden español (no en todos los casos). Así, las mujeres indígenas son otra de las llamadas subcategorías importantes de reclusas en los centros penitenciarios femeniles y mixtos de nuestro país. Para casos como estos, en teoría, el Estado sí contempla leyes que garantizan los Derechos Humanos de aquellos y aquellas delincuentes que provienen de algún grupo étnico.

En el Art. 35 de la LNEP, de manera muy breve, contempla tres principales aspectos a seguir cuando se reciben casos de indígenas en los sistemas penitenciarios: El primero es que para determinar en qué Centro Penitenciario se ingresará a los individuos se tomará en cuenta el arraigo que éstos tengan con sus comunidades y la importancia que tenga para ellos ser ubicados cerca de sus lugares de origen. Lo segundo es que las autoridades deben de contar con interpretes certificados por el Instituto Nacional de Lenguas Indígenas, quienes faciliten la comunicación entre autoridades-acusados y, además, aseguren que los y las acusadas tengan claridad de los procesos que están enfrentando. 
Por otro lado, un tercer aspecto propuesto es que las autoridades penitenciarias no despojarán a los indígenas de sus usos y costumbres, además de que no se les obligará a adoptar nuevas. Respecto a esto, como veremos en el siguiente capítulo, en nuestro estudio de caso, a simple vista es cierto que las autoridades no imponen de manera directa cambios en la socialización de mujeres indígenas en condición de reclusión, pero es el mismo entorno y el resto de la población que habita en estos recintos, quienes promueven que las indígenas adopten un nuevo idioma, conductas y creencias, dejando de lado lo interiorizado desde sus comunidades. El hecho de no hacerlo, puede significar que éstas sean mayormente vulneradas, violentadas y sometidas por los otros.

Dentro de las cárceles femeniles y mixtas, no solo encontramos los mencionados perfiles de mujeres. Existen muchas condiciones que influyen en las vidas de las internas y que, por ende, tienen que desarrollar mecanismos distintos para su sobrevivencia dentro de reclusión. Por mencionar otras mujeres que quizás no son contempladas ampliamente en esta investigación, también existen mujeres con padecimientos crónicos como trastornos psicológicos, enfermedades generalizadas, enfermedades patológicas, discapacidades o necesidades especiales. Que si bien, el Estado sí contempla de manera breve en sus leyes, tampoco son ubicadas en sitios que cubran con lo necesario para estas mujeres.

En las áreas comunes encontramos mujeres con problemas psicológicos evidentes, puestas en medio del resto de la población y luchando por sobrellevar sus situaciones, esto es más común en las zonas femeniles de los recintos mixtos. En otras cárceles como las femeniles, se asignan pequeños anexos en los que se concentra a poblaciones con problemas de salud mental, lo cual se supone que está planeado para que las internas en esta condición reciban atenciones especiales, lo cual en la realidad no es garantizado. El resultado de estas medidas es que las internas en esta condición terminan con una interacción muy limitada con el resto de la población, ya que terminan apartadas y olvidadas en un mayor exilio que las demás.

Otra posible subcategoría es la de mujeres con preferencias sexuales distintas a las "normalizadas" socialmente. Tanto en cárceles femeniles como mixtas, también encontramos mujeres que sienten atracción y se relacionan sentimentalmente con personas de su mismo sexo. Éstas son ubicadas en los espacios comunes con el resto de la población. Sin embargo, allí adentro se enfrentan a actitudes de violencia y discriminación por parte de otras mujeres. 
La manera cómo interactúan y viven la vida en prisión implica el desarrollo de estrategias que les permitan enfrentar este tipo de comportamientos. Mientras que algunas otras prefieren no expresar sus preferencias abiertamente por temor a las reacciones del resto de las internas.

Para estos casos, el Estado aún no contempla como tal, leyes que beneficien a esta población, únicamente se les generaliza en los principios de no discriminación junto con otras diversidades de personas y que, principalmente compete a las labores de las autoridades a la hora de procesar a los individuos: "[Las personas privadas de su libertad deberán] recibir un trato digno del personal penitenciario sin diferencias fundadas en prejuicios por razón de género, origen étnico o nacional, sexo, edad, discapacidades, condición social, posición económica, condiciones de salud, religión, opiniones, preferencias sexuales, identidad de género, estado civil o cualquier otra que atente la dignidad humana" (LNEP, 2016: 6).

Así, podemos ver que dentro de las cárceles en donde habitan mujeres, es posible identificar una gran diversidad de estas. Por mencionar otras más, existen mujeres con problemas de drogadicción y/o alcoholismo. En estos casos, las autoridades las contemplan como personas con enfermedades psicológicas y, se supone, dentro de reclusión se les ofrecen pláticas, talleres y programas que pretenden erradicar este tipo de problemas. Respecto a esto, cabe decir que, los programas de atención a adicciones se promueven principalmente para las poblaciones de varones, las mujeres únicamente reciben pláticas semanales, lo que al parecer no ha dado buenos resultados. Dentro de las cárceles femeniles y mixtas, es muy común encontrarse mujeres con serios problemas de abuso de drogas y bebidas embriagantes, y ese estado es en el que viven día a día.

Hasta aquí, es evidente que dentro de los dos tipos de cárceles con población femenil, los grupos no se definen únicamente como mujeres que adoptan el estigma de delincuentes, sino que existe una amplia pluralidad de éstas. Recapitulando lo dicho en este apartado podemos encontrar: Mujeres de diferentes edades; con diferentes niveles de escolaridad y/o analfabetas; de distintas clases sociales; que son o no madres de familia; con problemas de salud, discapacidades o necesidades especiales; con problemas de adicción, ingresadas por diferentes tipos de delito y mujeres de diferentes grupos étnicos. Además, podemos mencionar algunos adicionales que en esta ocasión no son de relevancia para esta investigación tales como: mujeres con diferentes estados civiles antes de ser remitidas y 
durante la reclusión, de diferentes nacionalidades, y por su ocupación antes y durante el encierro.

Si conjuntamos toda la diversidad de mujeres existente en los centros penitenciarios femeniles y mixtos, podemos notar que existe un punto en el que las consecuencias de sus condiciones se entrecruzan y pueden llegar a resultar en cuestiones de vulneración de los grupos. En donde serán los otros (familia, amigos, autoridades y demás internas) quienes han de someter y dominar a los diferentes conjuntos de mujeres. Si recordamos lo propuesto en el capítulo 2, esto es algo que se ha vivido a lo largo de la historia de nuestro país y que al analizarlo dentro de los recintos carcelarios tenemos una importante representación de lo que sucede en nuestra sociedad actualmente.

En esta investigación lo argumentado se trata de identificar en un recinto carcelario mixto. Esto porque en la mayoría de los casos el espacio que ocupan las mujeres es sumamente pequeño a lo que se asigna para los varones. Además de que se considera que existen importantes diferencias en la vida de mujeres en recintos de este tipo con los que son únicamente femeniles, aun cuando muchas de las experiencias de las internas puedan tener ciertas similitudes entre sí. En estos últimos, el hecho de que el espacio sea específico para un solo género, hace que las principales problemáticas sean distintas a las de las áreas de los centros que son mixtos. Las cárceles de este tipo brindan más elementos de interés para esta investigación.

Es por esto que la cárcel mixta en donde se identificarán los elementos propuestos en los capítulos previos hasta aquí, se trata del Centro Penitenciario y de Reinserción Social "Santiaguito" en Almoloya de Juárez, Estado de México. Recinto en donde una vez que se localicen los componentes necesarios, se hace un comparativo de casos específicos de mujeres de diferentes condiciones que, inicialmente hemos de identificar en dos principales grupos: mujeres indígenas y mestizas. Y, a partir de la recaudación de sus diferentes testimonios, se obtiene lo necesario para identificar cómo es que se ven intervenidos los procesos de socialización de las mujeres desde su condición de género, raza, clase social y edad. Con lo que además se documentan los tipos de estrategias de sobrevivencia que desarrolla la diversidad de mujeres de este centro. 


\subsection{Centro Penitenciario y de Reinserción Social "Santiaguito", Almoloya de Juárez, Estado de México}

En el apartado 4.1 de este trabajo se mencionó que en México existen varios centros penitenciarios mixtos. Es decir, supuestamente, las poblaciones que habitan estos espacios se componen por varones y mujeres, los cuales son ubicados e instalados en áreas específicas según el sexo de cada individuo ${ }^{64}$. En nuestro país, muchos de estos recintos los encontramos en el Estado de México, en donde la mayoría de los Centros Penitenciarios pertenecen a la categoría "mixta". Además de que casi todos estos son dependientes del gobierno Estatal y solo unos cuantos del Federal. Y es en este estado en donde se ubica al Centro Penitenciario y de Reinserción Social (CPRS) "Santiaguito", lugar en donde se ha realizado el trabajo de campo con el que se pretende identificar las diferencias y desigualdades en los Procesos de Socialización y Estrategias de Sobrevivencia de mujeres indígenas y mestizas privadas de su libertad y con lo que posteriormente se analiza de manera comparativa los casos seleccionados.

Este Centro Penitenciario es uno de los 22 ubicados en el Estado de México, y tal como se ha adelantado, "Santiaguito" es un recinto mixto estatal. Cabe aclarar, que este suele ser confundido con el Centro Federal de Readaptación Social (CEFERESO) No. 1 "El Altiplano", debido a su ubicación, pues ambos se encuentran en el municipio de Almoloya de Juárez, Toluca, Estado de México. Se encuentran relativamente a una distancia corta uno del otro. Es por esto que es importante recalcar que son recintos diferentes, ocupados por poblaciones distintas que son acusadas por delitos de diversas magnitudes, categorías y niveles. El "Altiplano", según las normativas de nuestro país, es considerado una cárcel de "máxima" seguridad por sus características en las instalaciones y las "altas" tecnologías que lo componen y con las que se pretende mantener bajo control a delincuentes acusados de delitos del fuero Federal principalmente.

\footnotetext{
${ }^{64}$ Cabe decir que en este trabajo no se comparte totalmente la denominación de "mixtos" que se les otorga a estos recintos, ya que, como se describirá en el siguiente capítulo, a simple vista no son lugares constituidos para ser ocupados por ambos grupos de personas, sino que, más bien, parecen centros varoniles con pequeñas adaptaciones para la población femenil, lo que hace muy evidente importantes desigualdades hacia esta última.
} 
Una vez aclarado esto, retomando y profundizando más respecto a lo que refiere al Centro Penitenciario y de Reinserción Social "Santiaguito", hay que señalar que el territorio e instalaciones de este, según autoridades de la Dirección General de Reinserción Social (DGRS) del Estado de México, son las de mayor extensión a comparación con los demás centros penitenciarios de este estado. Además de que su ubicación se encuentra muy cercana a la entrada del municipio de Almoloya de Juárez y aproximadamente a unos 25 minutos del Valle de Toluca donde encontramos la Dirección General. Este centro lo podemos ver sobre la avenida principal hacia el municipio, y sus alrededores son tranquilos, además de que son pocas las construcciones y los comercios que se pueden observar cerca de la zona.

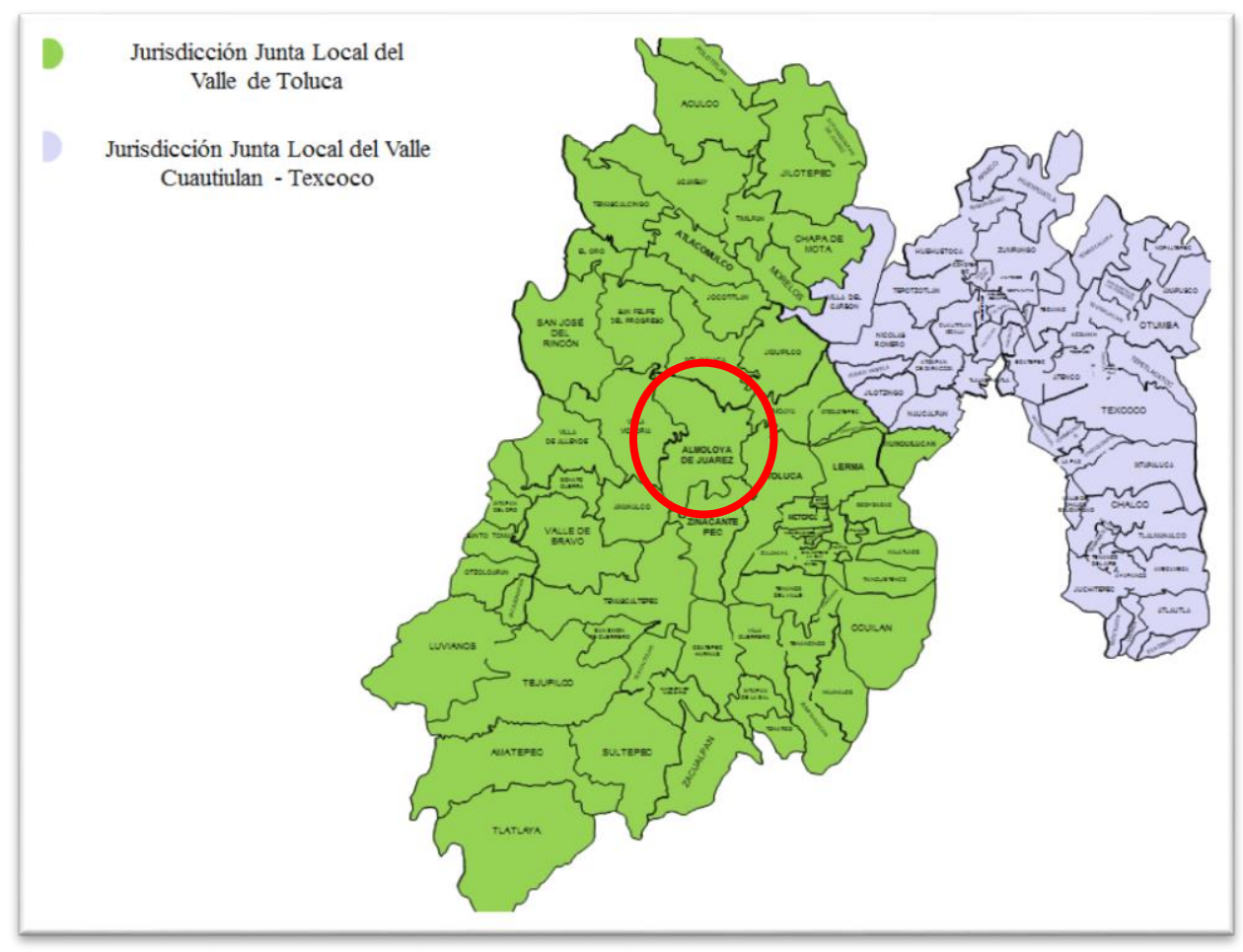

Fuente: http://juntatoluca.edomex.gob.mx/mapa_interactivo 


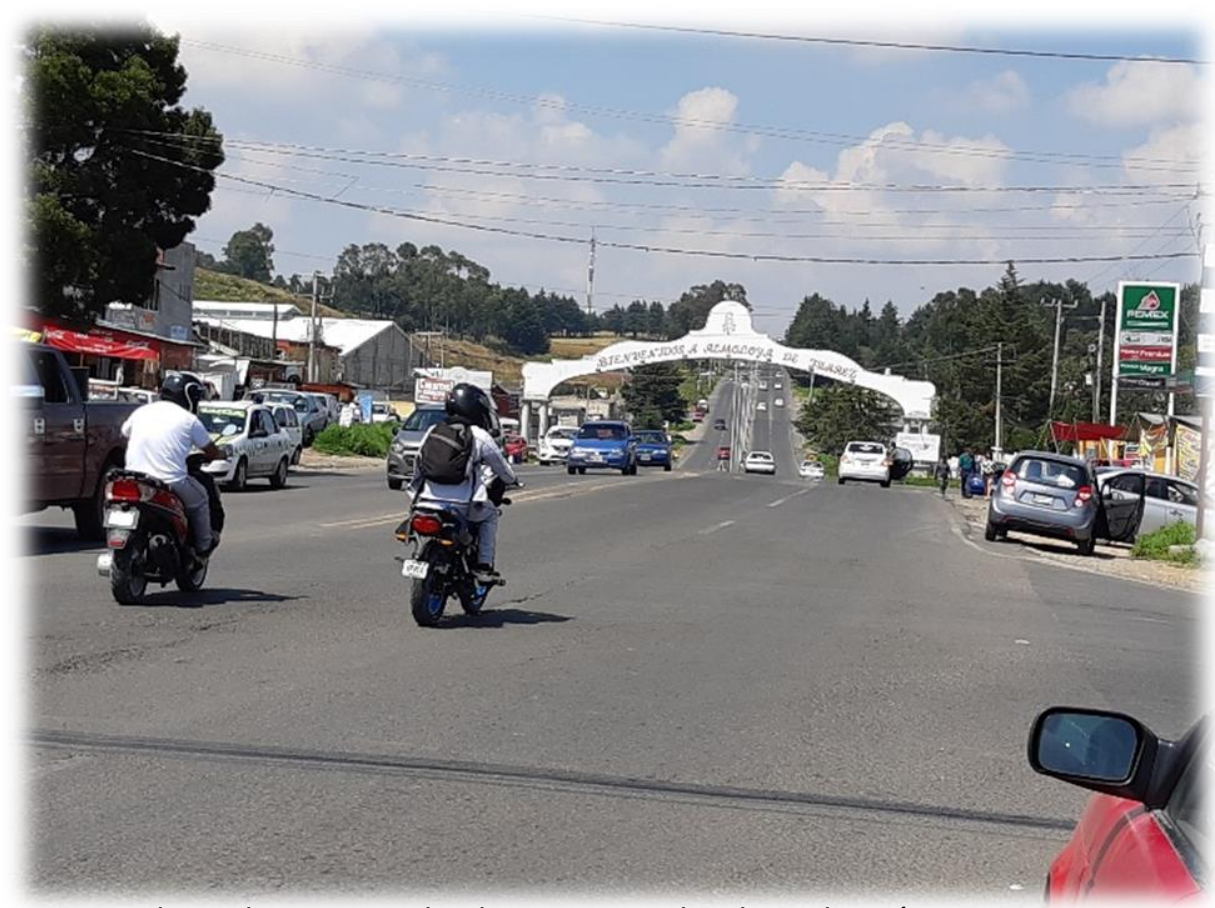

Foto de Archivo: Entrada al municipio Almoloya de Juárez

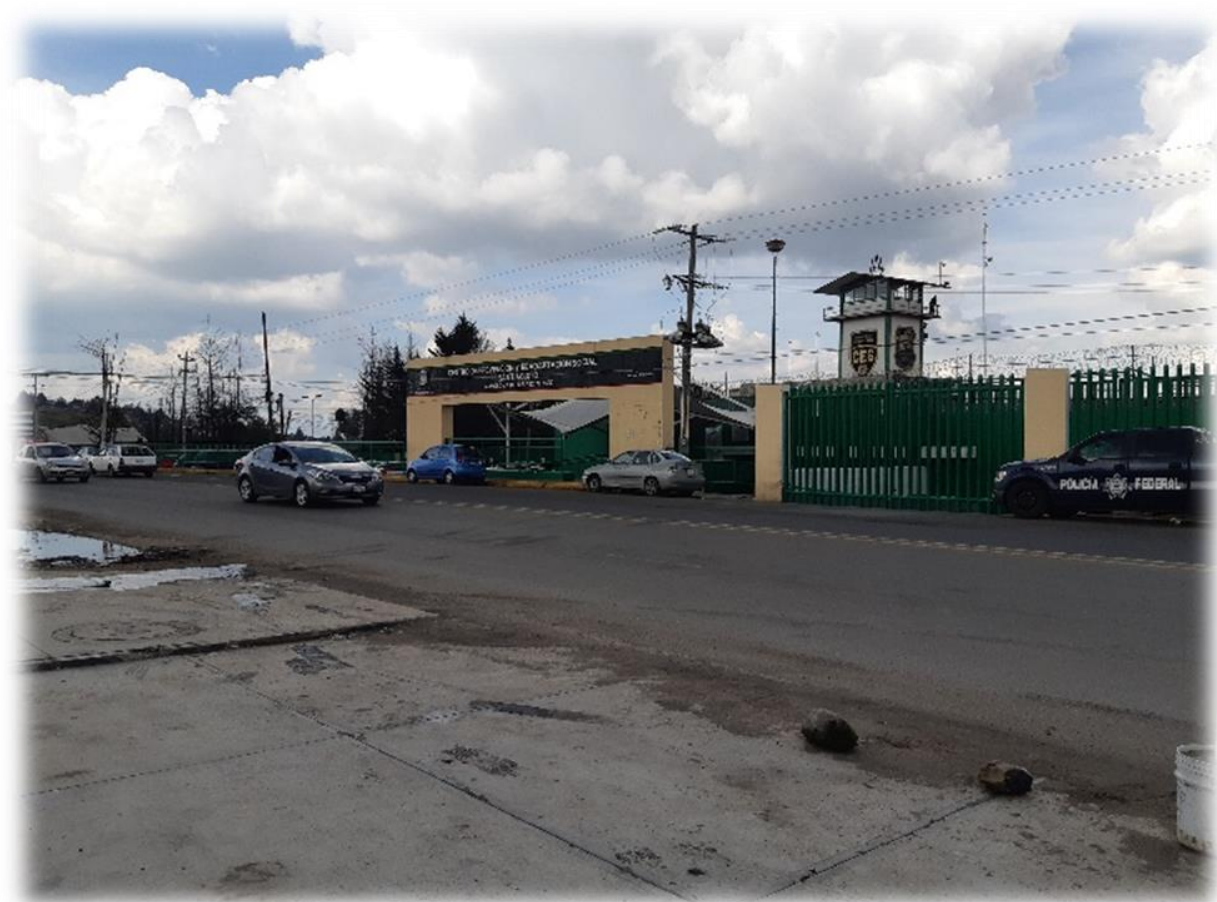

Foto de Archivo: Fachada del CPRS "Santiaguito" 
Los negocios que se encuentran cercanos son en su mayoría tiendas de abarrotes, lugares para la venta de alimentos, puestos de carretera de venta de comida y una gasolinera. Lo relevante de estos lugares es que han sido acondicionados para brindar servicios extraordinarios a los que se supone que están destinados. Por ejemplo, se ofrece el servicio de paquetería en el que por cantidades pequeñas de dinero las personas pueden dejar sus pertenecías en resguardo por algunas horas. Esto es una actividad común e importante para todos aquellos externos que requieren tener acceso a las instalaciones de "Santiaguito" para brindar algún tipo de actividad o realizar algún trámite o gestión jurídica. Es común que en muchas de estas ocasiones no se tenga en dónde dejar los objetos personales que son categorizados como prohibidos para el ingreso, ejemplo de esto son los dispositivos electrónicos (se explicará más a detalle en el siguiente capítulo).

Según las autoridades de los recintos carcelarios del Estado de México, se nota la importancia de este servicio principalmente los días de visita dentro de esta institución. Durante el tiempo que se destina para esta actividad, es llamativo ver que quienes hacen mayor uso de este tipo de servicio o de la compra de alimentos y que además se les puede ver haciendo largas filas para poder pasar algunas horas con sus familiares privados de la libertad, se trata de mujeres y a quienes esperan convivir con sus esposos, hermanos, padres e hijos. Es decir, en este suceso, es muy notoria una de las principales desigualdades presentes en el sistema carcelario de nuestro país, y que proviene del exterior. Esto es que son los varones quienes la mayoría de las veces reciben visitas, mientras que las mujeres no.

Las autoridades acentúan en muchas ocasiones esta situación, además de que ya la han normalizado, pues mencionan en diferentes ocasiones que es común ver que la espera de las mujeres para tener acceso comienza desde antes de las 6 de la mañana y que se termina concediendo la entrada después de dos a 4 horas (“Anónimo 2”, DGRS, 2018). Las asistentes a los días de visita provienen, en la mayoría de los casos de lugares aledaños al municipio de Almoloya de Juárez. Según los informantes clave de la DGRS, esto se debe al fácil acceso que tiene el lugar y de que aparentemente tiene una ubicación muy céntrica. Se supone, además, que gran parte de los internos que habitan "Santiaguito" residían en el Estado de México y es por esto que no es tan complicado para las familias el poder asistir semanalmente. 
En algunas conversaciones con estos informantes, se destacó que aun cuando la mayor parte de la población privada de la libertad son originarios de los pueblos cercanos a Almoloya de Juárez, también hay personas de otros estados e incluso cierta población extranjera, quienes reciben menos o ninguna visita, y más en el caso de las mujeres catalogadas como delincuentes. Para personal de la Dirección General de estos recintos, la lejanía con el municipio es una de las principales causas de que suceda esto, aunque también señalan algunas otras que abordaremos en el próximo capítulo. Mientras tanto, en cuanto al municipio en donde se ubica "Santiaguito", podemos decir que es reconocido por varios elementos; en primer lugar, por ser uno de los más grandes de los 125 que componen al Estado de México. Además, según parte de la historia de este sitio, se dice que cuenta con monumentos históricos muy importantes para la región y su población, tales como el Templo Colonial dedicado al arcángel San Miguel y el Monumento a los Héroes que conmemora a los llamados héroes de la Independencia. Pero resalta aún más por sus cárceles, comenzando por el ya mencionado CEFERESO "El Altiplano", lugar en donde se ha recluido a delincuentes de gran popularidad como a Joaquín Guzmán Loera (“El Chapo Guzmán”), uno de los máximos líderes del narco, uno de los más buscados durante muchos años no solo en nuestro país.

Con esto cabe señalar que también el CPRS "Santiaguito" es relevante para el gobierno mexicano, debido a la amplitud de sus instalaciones. Y, como se mencionó, a la zona en donde está ubicado, muy cercano a la Dirección General de Reinserción Social. En el caso de este centro, también se le ha popularizado por ser en éste en donde se ha ubicado a involucrados en casos que son muy controvertidos para el país. Por ejemplo, el de María Eulalia Guadalupe Buendía Torres (“La Loba de Chimalhuacán”), quien por varios años durante los 90s encabezó la invasión de muchos predios en el municipio de Chimalhuacán, Estado de México. Se dice que esta mujer protagonizó diversos hechos y abusos antes de ser detenida y sentenciada por las autoridades.

Sin embargo, desde el año 2000, su caso dejó de ser igual de sonado hasta hace algunos meses, pues se reportó que la mujer fue trasladada de "Santiaguito" a un hospital privado para ser atendida de lo que se presume se trató de COVID-19. Esta mujer murió en mayo de 2020 fuera del recinto penitenciario, lo que llamó la atención de diversos medios, ya que se 
destapó parte de lo que, durante estos tiempos de contingencia, parece algo alarmante: la manera cómo es aplicada la garantía de salud de las personas privadas de su libertad, descrita en apartados previos (Infobae $\left.{ }^{65}, 2020\right)$. Respecto a este caso, en muchos medios informativos, al cuestionar a las autoridades sobre la situación, han negado la veracidad lo ocurrido y la mala situación que enfrentan quienes se encuentran hacinados en este centro. No obstante, nuestros informantes clave afirmaron en julio de este mismo año lo ocurrido, además de lo deficientes que están siendo muchos de los servicios que deberían de estar garantizados.

Con esto podemos ver que, si bien en las cárceles del Estado de México puede haber casos sonados y que los involucrados, de alguna manera pueden llegar a conseguir ciertos "beneficios", existen otros que están en el anonimato debido a que son parte de poblaciones de clases sociales bajas, de diferentes razas o grupos étnicos y entre hombres y mujeres, y poblaciones derivadas. A partir de esto, en "Santiaguito" se puede decir que ocurren muchos hechos día a día en cada una de sus áreas. Gran parte de estos sucesos ya no son relevantes para quienes se encuentran a cargo, sin embargo, las experiencias de los internos, en este caso de las mujeres, dan cuenta de cómo todo esto influye de manera importante en la vida de los internos. Se pueden ver muchas diferencias y desigualdades que nacen del exterior y que impactan fuertemente en las personas.

Es poco lo que se puede decir de este recinto puesto que, como se mencionó, algunas de las desigualdades provienen del exterior. Por ejemplo, al querer retomar los antecedentes de "Santiaguito", lo primero que podemos destacar es que son un tanto ignorados, tanto que ni las mismas autoridades tienen conocimiento claro de ellos. Es por esto que, para saber algunos datos importantes fue necesario solicitarlos a la Secretaría de Seguridad Pública del Estado de México (SSPEDOMEX), pues es la única instancia que aparentemente cuenta con ellos. Esta institución señala que "Santiaguito" se construyó en el año de 1966 y se habitó un año después. La primera población en ocuparlo fue únicamente varonil, pues el motivo de su apertura de este fue la sobrepoblación de hombres privados de la libertad en otros recintos

${ }^{65}$ Infobae, disponible en: https://www.infobae.com/america/mexico/2020/05/24/murio-la-loba-dechimalhuacan-por-anos-lidero-la-invasion-de-terrenos-en-el-municipio-mexiquense/, Consultado:

20/septiembre/2020 
del estado, lo que hizo necesaria la creación de uno nuevo en donde se reubicara una parte del excedente de los demás Centros de Reinserción Social.

Se desconoce el momento exacto en el que se hicieron las adaptaciones para que "Santiaguito" recibiera población femenil y se convirtiera en un recinto "mixto". La SSPEDOMEX señala que no cuenta con información o estadísticas al respecto. Sin embargo, integrantes del personal interno, que ha laborado desde hace 26 años en el CPRS, menciona que cuando él comenzó a trabajar en este lugar, se estaba terminando de adaptar el área que ocuparían las mujeres, un espacio que era sumamente pequeño en comparación con lo asignado para la población varonil, se trató de una construcción de dos pisos (“dormitorio cinco") en la que se ubicaron aproximadamente unas 90 mujeres (Testimonio de “Anónimo", personal del Depto. De Industria Penitenciaria y Promoción del Empleo, 2018).

Conforme pasaron los años, la cantidad de ingresos de mujeres comenzaron a incrementarse, por lo que el espacio del dormitorio comenzó a ser insuficiente. Entonces es que se planea la construcción de un nuevo edificio en donde se pudiera ubicar el excedente de población que se estaba acumulando. Así, es que se inaugura el "dormitorio once” en donde se recibió una mayor cantidad de población femenil. Incluso se promovió que se hiciera traslados de otros centros penitenciarios del Estado de México. Igualmente, no se sabe mucho de las poblaciones que habitaron ambas áreas femeniles. Ni en la Dirección General de Reinserción Social, se cuenta con esta información.

Por otra parte, parte de lo que sí se sabe es que el dormitorio cinco quedó como espacio de castigo de mujeres con conductas que estuvieran fuera de las normas establecidas por las autoridades del lugar (Testimonio de “Anónimo", personal del Depto. De Industria Penitenciaria y Promoción del Empleo, 2018). Esta área es demasiado pequeña por lo que es difícil que las mujeres realicen diversas actividades como lo veremos en el siguiente capítulo. Las que se encuentran en la construcción "nueva”, tienen la posibilidad participar en talleres, pláticas y eventos. Además de que estar en este lugar les permite laborar en las ofertas laborales que se promueven para las mujeres privadas de su libertad en "Santiaguito".

Las áreas definidas en esta zona para las diversas actividades de las mujeres son pequeñas y de mala calidad, incluso, gran parte del patio principal no se encuentra pavimentado y está cubierto por tierra y pasto. En algunas partes de este terreno se ubican unas aulas que parecen 
improvisadas que es en donde se llevan a cabo varias de las actividades. Estos espacios construcciones de lámina. En el siguiente apartado se hace una descripción más detallada de los espacios que se encuentran en la zona externa al edificio principal que conforma el Dormitorio once. Además de que se destacará para qué suelen ser utilizados, en tanto a los diferentes talleres y labores que se promueven en el área femenil, sin contemplar al dormitorio cinco.

Respecto a esto, algo que no se puede ignorar de los componentes de "Santiaguito" es que, al igual que en otros recintos, las poblaciones que lo habitan no solo se pueden dividir en dos como generalmente se hace (hombres y mujeres), ya que dentro de las áreas femeniles y varoniles encontramos varias personas que se identifican con características más amplias las dos mencionadas. Por ejemplo: Población indígena, personas de la tercera edad, con enfermedades psicológicas, discapacidades físicas, extranjeros, personas con preferencias sexuales diversas y quienes pertenecen a clases sociales distintas. Por lo que, se supone, el sistema penitenciario de este CPRS, debería de garantizar las condiciones favorables para dar cumplimiento a los objetivos centrales de estos recintos (véase apartado 3 de este trabajo).

Y aunque, como se mencionó en apartados previos, en teoría, las principales leyes del sistema penitenciario mexicano sí contemplan a todos estos subgrupos, pero en la práctica difícilmente son aplicadas, ser parte de alguno de los grupos mencionados, sin duda, tiene un gran impacto en la vida de las personas privadas de su libertad. Es por ello que, acercándonos a nuestro estudio de caso, podemos identificar esta situación en un espacio tan pequeño como lo es el área femenil del CPRS “Santiaguito". En donde cada mujer ha de desarrollar sus diferentes estrategias para sobrevivir a las situaciones que se presentan durante el encierro según su género, raza, clase social, edad, etc., pues ninguna de estas mujeres se pretende generalizar, sino que más bien, se busca documentar desde las diferencias, lo que son cada una de éstas. 


\section{Mujeres en el CPRS de Almoloya de Juárez: análisis y comparativo de casos}

El significado de ser una mujer privada de su libertad en México es variado y complejo, según la perspectiva desde donde lo queramos ver. Actualmente son muchos los estudios que se han realizado acerca del tema, todos, desde diferentes ramas de las ciencias sociales, tales como: la antropología, la historia, el derecho, la comunicación/periodismo y desde la sociología. Cada análisis se ha enfocado en una o varias de las tantas problemáticas que de esto se desprende. Sin embargo, un elemento que comúnmente se comparte en los aportes de estas ciencias es una fuerte crítica hacia los componentes y aplicaciones del sistema carcelario "moderno" con el que, en teoría, se manejan la mayoría de los centros penitenciarios de nuestro país. $\mathrm{Y}$ es desde aquí de donde se desprenden muchas de las situaciones que las diferentes materias tienen interés por analizar.

Cada estudio referente a temas como estos se ha realizado desde un enfoque distinto, pretendiendo entender y documentar lo que específicamente se quiere investigar, dejando al descubierto muchas otras problemáticas. Por ejemplo, en el caso específico de mujeres en condición de confinamiento carcelario (como tema general), la herramienta de análisis que se emplea con mayor frecuencia es la perspectiva de género (véase apartado 3). Desde este enfoque se ha intentado mostrar que, a lo largo de la historia, las mujeres han sido presas de castigos que, si bien no eran de índole jurídica, sí lo eran social y cultural. Es decir, se destacan actos violentos resultantes del dominio y poder masculino, y las relaciones de subordinación y vulneración dadas en distintas sociedades, entre diferentes grupos de personas.

$\mathrm{Al}$ respecto, cabe enfatizar que, como se ha mencionado antes, la desigualdad que viven mujeres en situación de reclusión no solo es resultado de la condición de género, sino que puede ser desde muchas otras o desde el cruce de varias de estas. Es por esto que, más adelante, en este trabajo, se retoman elementos de la interseccionalidad vistos en el apartado 3.2. Lo que servirá de apoyo para analizar y comparar el impacto que tienen la condición de género, raza, clase social y edad en los diferentes procesos de socialización y las estrategias de sobrevivencia entre mujeres indígenas y mestizas privadas de su libertad, en un contexto específico como es el Centro Penitenciario y de Reinserción Social "Santiaguito". En donde las mujeres consideradas para este estudio son diversas; algunas tienen compatibilidad en 
ciertas condiciones, pero ninguna vive y enfrenta el encierro de la misma manera, puesto que ninguna es igual.

Entonces, actualmente ser una mujer privada de su libertad en México tiene fuertes implicaciones no solo en lo jurídico, sino en lo social, familiar, económico y psicológico de cada una. Desde una mirada general, cuando una mujer adquiere la calidad de reclusa, también es señalada automáticamente como delincuente o criminal, haya o no cometido alguna falta jurídica y social comprobable. Con esto, se sabe que la mayoría son mal vistas, juzgadas, excluidas y discriminadas en todos sus entornos o en la mayoría de estos. Lo que, en el caso de los varones, no siempre es así. Tal como se adelantó en el apartado 3.1 (páginas 116 y 117) con la exposición de breves testimonios de autoridades e internos (un hombre y una mujer) del CPRS "Santiaguito". A primera vista, pareciera que las diferencias y desigualdades han sido normalizadas para quienes tienen algún cargo en el sistema penitenciario y más aún para aquellos que son los implicados e implicadas.

En el Centro Penitenciario y de Reinserción Social de Almoloya de Juárez, como se comentó en el apartado previo, según cifras de 2019, existe un total de 3,138 personas privadas de la libertad de los cuales, solamente 343 son población femenil (SSPEDOMEX, 2019). Las mujeres en este centro son ubicadas en dos principales "dormitorios" que ocupan áreas muy pequeñas de todo lo que compone el recinto. A estos espacios se les conoce como "dormitorio once" y "dormitorio cinco"; el primero tiene una extensión un poco mayor a la del segundo y las instalaciones son más nuevas y un poco "más completas". El "dormitorio cinco", por su parte, fue el primero en ser construido y habitado por mujeres, ya que, desde 1966, "Santiaguito" fue por varios años cárcel varonil solamente.

Según autoridades de este recinto pasaron al menos cinco u ocho años desde que se construyó para que este se convirtiera en un centro "mixto" y se adaptara una pequeña área en donde se ingresó a mujeres procedentes de otras instituciones penitenciarias del Estado de México, en las cuales se presentaba una importante sobrepoblación. Es así que, "el dormitorio cinco” fue habitado por aproximadamente noventa mujeres inicialmente. Conforme la población de este espacio incrementó, en los años 2 miles se construye "el dormitorio once". Este es un edificio mucho más amplio a comparación del primero. "El once" es una construcción de dos pisos en donde se ubican varias celdas en cada una de las superficies, estas son espacios de cemento 
con iluminación casi nula y de una extensión de aproximadamente 4 x 4mtrs. Con esto, podemos ver que se trata de espacios demasiado pequeños para ser ocupados por entre siete u ocho mujeres en un mismo sitio. Esto es un importante problema que, como se verá en los próximos apartados, influye demasiado en la vida individual y grupal de las diferentes mujeres consideradas para el estudio caso.

Así, continuando con la descripción del área femenil de "Santiaguito", cabe destacar que, en el primer piso de esta cimentación, encontramos una pequeña biblioteca, que, se puede ver claramente que cuenta con una cantidad limitada de libros, los cuales son utilizados por aquellas mujeres que se encuentran realizando estudios escolares. Cada día, se ve ingresar a una cantidad pequeña de éstas, por lo que, al respecto, es importante decir que quienes hacen uso de este espacio, principalmente son mujeres jóvenes de entre veinte y cuarenta años, que aparentemente son el estándar de quienes están cursando algún grado escolar dentro de este centro penitenciario. En este primer piso, además de la biblioteca, encontramos más celdas que son de las mismas características a las mencionadas (Nota de campo de Calderón, 14 de diciembre de 2018).

Regresando con lo que compone la planta baja de este edificio, se observan dos pequeñas cocinas improvisadas en donde laboran algunas otras mujeres que habitan esta zona. A algunas de éstas se les puede ver haciendo tortillas a mano cocinadas en unos grandes comales, cuando la producción de este alimento está lista, se destinará a la venta con otros y otras internas ${ }^{66}$, y personal de este CPRS. Además, en esta planta baja, también encontramos una covacha acondicionada como tienda de abarrotes en la que, cabe mencionar que, desde una pequeña ventanita, un grupo reducido de mujeres privadas de la libertad son quienes se hacen cargo y tienen dominio total de la comercialización de los productos de primera necesidad que otras internas requieran, lo que se explica más ampliamente en los próximos apartados (Nota de campo de Calderón, 14 de diciembre de 2018).

Por otro lado, en el exterior de este edificio, hay un patio no muy grande, si lo comparamos con lo destinado para varones. Esta zona externa tiene piso de cemento y una gran parte es de tierra y pasto. Hay algunos pequeños juegos infantiles, que se supone son para la

\footnotetext{
${ }^{66}$ Productos como estos también son solicitados por el área varonil por los internos e incluso por los custodios, por lo que es una actividad común en el recinto.
} 
recreación de los menores que se encuentran bajo custodia de sus madres confinadas en este centro. Estos juegos pocas veces se observan ocupados por los niños. También en esta parte del área femenil, hay tres aulas de lámina de aluminio, estas se ocupan para diversas actividades, ya sean: laborales, de recreación o para la impartición de pláticas, cursos y talleres. Además, del otro lado de esta área de patio, encontramos zonas en donde las mujeres y sus hijos (quienes son madres privadas de la libertad), pasan el tiempo, conviven y juegan, mientras que otras que no tienen menores, se sientan en las banquetas o en el piso sin realizar ninguna actividad relevante o interactúan con otras mujeres, platicando, algunas fumando y compartiendo un cigarro. (Nota de campo de Calderón, octubre de 2018).

El "dormitorio once" tiene mayor cercanía con el área varonil, ambas zonas se encuentran separadas por un portón, un pasillo largo y una reja. Sin embargo, ambas poblaciones desarrollan la manera de interactuar. Los varones tienen la posibilidad de ir hasta el final de una de las canchas de futbol, la cual se encuentra junto al portón del área femenil, y aunque no se pueden ver cara a cara, logran entablar conversaciones. Las mujeres en otras ocasiones, se comunican con los varones a gritos, se recuestan boca abajo frente al portón y transmiten sus mensajes en voz muy alta de manera que los hombres que se encuentran del otro lado, detrás de la reja que separa ambas zonas, puedan escucharlas. Este tipo de interacción, generalmente se da entre parejas quienes ambos individuos se encuentran en confinamiento, ya sea que se hayan conocido antes del encierro o que comenzaran algún tipo de relación dentro de este recinto (los y las internas desarrollan estrategias para vincularse, aun cuando se encuentren en áreas separadas. Más adelante se describen estos medios).

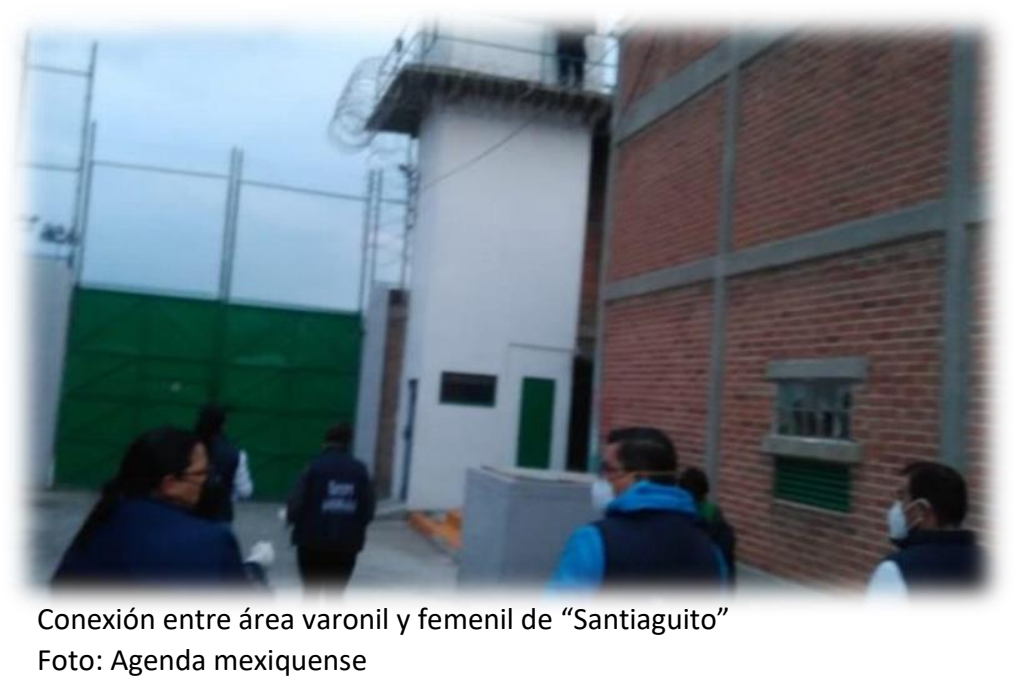


Así, en otros temas, con referencia a lo expuesto en el capítulo anterior sobre las garantías que, se supone, por ley deben de existir dentro de "Santiaguito y que, sin duda alguna, tienen un gran impacto en las vidas de las internas, es conveniente mencionar que cuando las mujeres tienen necesidad de recibir algún tipo de servicio extraordinario son sacadas del área femenil atravesando por una parte del área varonil. Esto, se debe a que en este recinto, hay servicios como la "clínica", capilla religiosa, área de visitas y espacios conyugales ${ }^{67}$ que se encuentran en el área de varones. Destacando lo evidentes que comienzan a ser algunas de las desigualdades que se van permeando entre las dos poblaciones y que surgen de la manera cómo se estructura y se aplica el sistema penitenciario en instituciones como esta. Además de la desequilibrada distribución espacial destinada para cada una de estas dos poblaciones ${ }^{68}$.

Si bien, con esto es importante acentuar que la mayoría de los centros penitenciarios habitados por ambas poblaciones, como tal no son cárceles mixtas -aunque así se les ha definido por las leyes del Estado-, sino que más bien, son instituciones varoniles con anexos femeniles. Esto, lo podemos ver justificado en servicios tales como los de salud, mujeres y hombres no poseen las mismas condiciones de acceso. Por ejemplo, si alguna mujer se enferma o siente algún malestar físico, tiene que solicitar a las autoridades que se le otorgue un permiso para ser llevaba a la "clínica". Existen ocasiones en que la autorización no es inmediata puede tardar hasta una semana, aun cuando existan casos en los que los malestares sean muy notorios y muestren la urgente necesidad de atenderlos. Cuando el permiso logra ser concedido, las mujeres deben de salir acompañadas por una o más custodias ${ }^{69}$. Si las personas que requieren consulta médica son más de una mujer, son llevadas en un mismo grupo con una mayor vigilancia (Nota de campo de Calderón, noviembre 2018).

Por otro lado, en casos como estos, los varones tienen mayor accesibilidad pues, al encontrar estos servicios en su área, ellos pueden asistir siempre que lo consideren necesario, no se ven obligados a informar como tal a las autoridades o solicitar autorización, y aunque deben de esperar algún tiempo para ser atendidos, y los servicios médicos no son de la mejor calidad, no tienen que pasar por las mismas gestiones que las mujeres. Incluso en la zona de "clínica”,

\footnotetext{
${ }^{67}$ Habitaciones utilizadas por los y las internas para tener privacidad con sus cónyuges o parejas dentro de los términos establecidos en las normas de este recinto carcelario.

${ }^{68}$ En este momento se destacan solo dos poblaciones que son las consideradas por la institución, ya que son los principales rubros de separación. En apartados posteriores se destacan otros casos.

${ }^{69}$ Personal femenino de guardia, custodia y vigilancia carcelaria.
} 
muchos individuos varones asisten con algún pretexto para “descansar”. Se colocan en la sala de espera y allí pasan algún tiempo lejos de los rayos del sol y del resto de sus compañeros. Aun cuando la construcción de servicios médicos se encuentra bajo vigilancia, se puede notar que muchos de los hombres que van a refugiarse allí, tienen buena relación con los guardias, por lo que no tienen ninguna represalia.

Ahora bien, hasta aquí, se han ido resaltando algunas de las más importantes y notorias diferencias entre el "dormitorio once” del área femenil y las áreas generales de la varonil, pero no todas las mujeres recluidas en este CPRS se encuentran confinadas en este dormitorio. Un pequeño porcentaje se encuentra en el "dormitorio cinco", se trata de aproximadamente 25 mujeres del total de la población femenil. Éstas son consideradas personas problemáticas y con mala conducta, por lo que son separadas y ubicadas en esta celda porque actualmente es un área de castigo.

En "la cinco" las mujeres tienen aún menores posibilidades de acceso a servicios y se les excluye de muchas actividades. Por ejemplo, cuando se trata de generar ingresos económicos, las internas que se encuentran en este dormitorio tienen menores posibilidades de comercializar algún tipo de producto que lleguen a producir. Mientras que las mujeres de "la once" venden alimentos y manualidades casi cada semana durante los días de visita. Las que se encuentran en el área de castigo, muchas veces no tienen autorización para salir a la zona de visitas. Además de que es más complicado que generen productos, pues difícilmente consiguen los materiales necesarios, y si los consiguen es a precios mucho más elevados de lo que ya de por sí los pagan las mujeres del dormitorio "normal". Otro hecho que es relevante entre ambas zonas son los talleres, pues según personal administrativo de este recinto, pocas veces se llegan a impartir algunos.

En otros ámbitos como el educativo, salud y religioso (algo que es importante para ciertas mujeres), en el dormitorio cinco las mujeres tienen aún más limitado el acceso. Como se ha descrito, estos servicios están ubicados en el área varonil, mucho más lejos del área cinco que de la once, por lo que, cuando alguna mujer requiere alguno de estos, también debe de solicitar formalmente una autorización, pero es común que quienes se encuentran en esta zona no siempre reciben respuesta satisfactoria y no se da atención a sus necesidades. Esto sucede aun cuando, como se vio en el capítulo previo, son garantías que, según las leyes, se 
deberían de cumplir, sin ningún tipo de discriminación o exclusión. Así, podría decirse que en el "dormitorio cinco", las mujeres se encuentran en un abandono mucho mayor al que de por sí, ya tienen por el hecho de ser "mujeres delincuentes”. Las mujeres del área de castigo, son etiquetadas más severamente que aquellas que se encuentran en el área "normal".

Sin embargo, aun con las notables diferencias de vida entre ambos espacios femeniles del CPRS “Santiaguito", es imposible generalizar a las mujeres que los habitan, puesto que todas son diferentes, muchas son procedentes de diferentes lugares, tienen orígenes étnico-raciales distintos, diferentes edades y pertenecen a clases sociales distintas. Sus niveles educativos tampoco son los mismos, algunas tienen elecciones o preferencias sexuales diversas y sus situaciones legales no son parecidas. Son juzgadas por diferentes delitos de los cuales, algunas reconocen firmemente haber cometido alguna falta a las leyes del Estado, mientras que otras aseguran no haber atentado en contra de nada ni de nadie. Es por esto que, en este momento podemos decir que, lo que se comparte principalmente entre éstas es el hecho de ser mujeres y tener la etiqueta social de delincuentes, pero la respuesta de cada una ante el impacto que tiene el sistema carcelario en sus vidas y sus procesos de socialización no es el mismo. Este depende, como se ha mencionado, de las diferentes condiciones o los diferentes cruces de estas, según sea el caso de cada mujer.

Por tal motivo en el siguiente apartado, comenzaremos a conocer la diversidad general de mujeres que se encuentran recluidas en el CPRS "Santiaguito", se describe un poco de cómo se perciben las diferencias y congruencias entre las mujeres consideradas para el estudio de caso. Con esto más adelante se analiza de forma comparativa la manera cómo se han ido interviniendo los procesos de socialización de estas mujeres y qué tipo de estrategias de sobrevivencia desarrollan según su condición de género, raza, clase social y edad. El análisis que se pretende documentar en este trabajo, se realiza desde el contraste de testimonios recaudados de mujeres de diferentes condiciones que participaron en un taller de creación de figuras con materiales reciclados, impartido del 12 de octubre al 14 de diciembre de 2018 en las instalaciones de este centro penitenciario. 


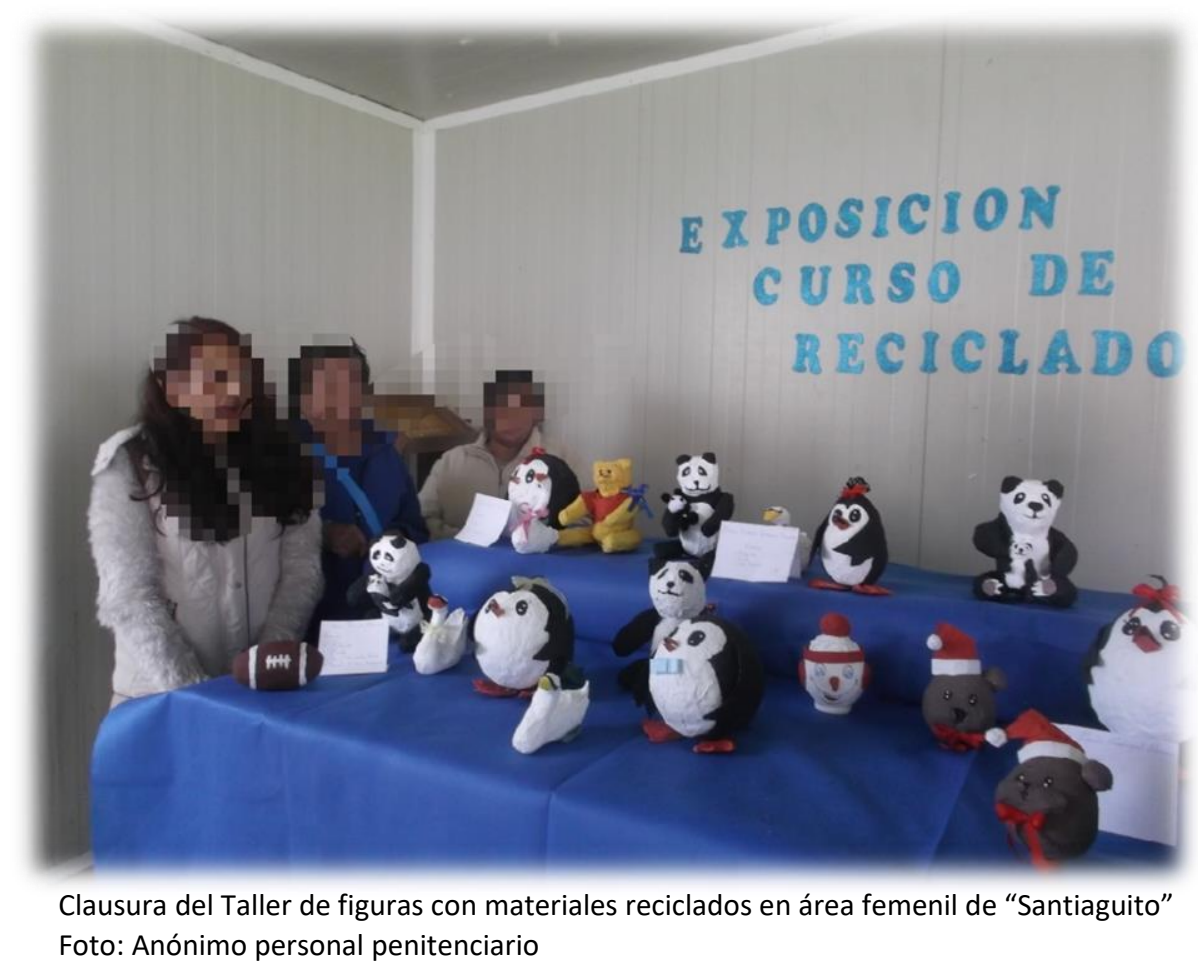

El registro de toda la información recopilada fue de manera memorística en dos diarios de campo, esto debido a las restricciones del sistema carcelario a la hora de ingresar a las instalaciones de "Santiaguito" y la Dirección General de Reinserción Social del Estado de México. En esta última, se pueden portar dispositivos electrónicos, pero está prohibido grabar audio y vídeo, así como capturar fotografías. Por otro lado, para tener acceso al CPRS, no está permitido el ingreso de celulares, grabadoras, computadoras o tabletas ${ }^{70}$. También, cabe decir que los testimonios obtenidos surgieron a partir de conversaciones informales con las internas. Además, se llevó un registro de lo contemplado durante el trabajo etnográfico y la observación no participante en varias zonas de este centro. Así, una vez hecha esta aclaración metodológica, se comienza a describir cómo es la diversidad de mujeres hacinadas en este recinto y algunos aspectos que son relevantes de su estadía en este lugar, con lo que se construirá el análisis comparativo que se quiere documentar.

\footnotetext{
70 Otras indicaciones para ingresar al CPRS "Santiaguito" son: vestimenta de colores que no sean beige, negro o azul marino, puesto que son los colores que usan los y las internas, y el personal de guardia y custodia. Además, en la entrada, el personal de vigilancia coloca en los brazos un sello con tinta negra y dos con tinta traslucida, los cuales son revisados en varios momentos durante la entrada y salida del penal. En la entrada hay que pasar por una revisión corporal en la que se compruebe que no se ingresa ninguno de los artículos prohibidos por la institución.
} 


\subsection{Diversidad de mujeres y su día a día en "Santiaguito": subordinación y exclusión en la reclusión}

En el Centro Penitenciario y de Reinserción Social "Santiaguito", existe una amplia diversidad de poblaciones privadas de su libertad. Las cuales no se pueden categorizar en dos grupos únicamente: hombres y mujeres, tal como generalmente lo hacen las autoridades de este recinto en donde más bien, se habla de algunas "subcategorías" de personas. Las cuales, en documentos oficiales de las oficinas generales de la institución, sí se contemplan diferentes "grupos", pero como se mencionó en el capítulo anterior, en la práctica estas poblaciones no se identifican tan fácilmente e incluso reciben un trato generalizado, ya sea dentro del área femenil o varonil, antes y durante los procesos penales. Si bien, solo algunas personas con discapacidades físicas notorias como la invalidez o con problemas mentales, sí son ubicados en áreas separadas al resto de los y las internas, pues son puestos en espacios en donde supuestamente se les brindan atenciones especiales, acordes con sus condiciones, ya sean médicas, laborales, jurídicas o psicológicas.

Mientras tanto, otras poblaciones como son: los adultos mayores, indígenas, extranjeros, homosexuales, de diferentes clases sociales y niveles académicos, por mencionar algunos solamente, son situados dentro de los espacios generales de este recinto, es decir en área varonil o femenil. Además, tampoco hay una separación notable entre tipos de delito o tipos de fuero. Aunque "Santiaguito" es un centro penitenciario estatal, existen muchas personas implicadas por crímenes como narcotráfico (fuero federal) que se encuentran en las mismas zonas de acusados de delitos considerados menores como, por ejemplo, robo a transeúnte (fuero común) ${ }^{71}$. Y, por ende, los procesos que siguen las personas privadas de la libertad, no son todos iguales. Si los vemos desde una perspectiva supuestamente "legal", estos se van a clasificar desde lo que se señala en las principales leyes nacionales y estatales con las que se rige esta institución (véase capítulo 4).

Sin embargo, en la realidad, cuando las personas tienen que enfrentarse a procesos penales, las diferencias comienzan a resaltar desde la condición de cada persona, ya sea por su género, clase social, raza, nacionalidad y grupo etario, o por varias de estas. Es así que, desde aquí, podemos decir que las situaciones que llevan a unos y otros a delinquir o a ser señalados

\footnotetext{
${ }^{71}$ Véase página 134 de este trabajo.
} 
como delincuentes, en muchos casos, depende de factores que provienen de sus entornos sociales y sus contextos de vida. Muchos implicados por los mismos tipos de delitos, aun cuando se trate de la misma gravedad, no son juzgados de la misma manera, puesto que algunos provienen de posiciones de mayor vulneración a comparación de otros. Esto es algo que, sin duda, podríamos identificar en muchos casos generales del CPRS "Santiaguito", pero que, en esta ocasión, solo se contemplan algunos de las áreas femeniles. Principalmente, del “dormitorio once", que es en donde se realizó la mayor parte del trabajo de campo para esta investigación.

En este dormitorio habita una gran diversidad de mujeres que aun cuando todas aparentemente comparten la misma condición de género, poseen otras determinantes que las colocan en posiciones distintas desde antes de su reclusión. En sus principales entornos, tales como la familia, son vistas y definidas de maneras distintas unas de otras. Es por esto que comenzaremos por decir que, dentro de esta área femenil se contemplan, inicialmente, dos principales grupos de mujeres, de los cuales se van a identificar otros más. Los primeros que hay que destacar son las mujeres mestizas, que, de manera general representan la mayoría de la población femenil de este centro penitenciario. Por otro lado, se considera a mujeres indígenas que son una muy notoria minoría en "Santiaguito". En el caso de estas últimas, las autoridades las identifican y contabilizan a partir de una caracterización que se puede considerar ambigua y limitada por los elementos que se contemplan para su determinación.

En este CPRS según datos de la Secretaria de Seguridad Pública del Estado de México (2019), de las trescientas cuarenta y tres mujeres privadas de su libertad solo cuatro son indígenas. De éstas, tres se encuentran actualmente en el "dormitorio once", mientras que la restante se encontraba en el área de castigo (dormitorio cinco) hasta febrero de 2019, fecha en que fue puesta en libertad. Para esta investigación, se trabajó y se hablará de siete casos de mujeres mestizas y tres de mujeres indígenas. Con dos de estas últimas la interacción se hizo dentro de las instalaciones de "Santiaguito". Mientras que, con la tercera, la convivencia se realizó en su domicilio ubicado en San Pedro Tlanixco, Estado de México, en el mes de abril de 2019, es decir, pocos meses después de su liberación. Las diez mujeres contempladas en esta investigación, compartieron en diversas conversaciones algunas de sus experiencias de vida antes de ser recluidas en este centro penitenciario. También hablaron de los delitos 
por los cuales se les imputa, y algunas de las motivaciones que las llevaron a cometer estos actos. Y, además, algo de lo más importante que comparten es una narrativa de cómo han vivido sus procesos en relación con las funciones e intervención de las autoridades correspondientes, a partir de la influencia de las condiciones de género, raza, clase social y edad.

Además, dentro de los testimonios de estas mujeres se describen el cómo han sido sus días dentro de este CPRS, destacando las relaciones que se constituyen con el resto de las internas y con parte del personal que labora en este recinto. En estas declaraciones, podemos identificar cómo es que, desde el momento de su llegada, se promueven relaciones de subordinación y poder. Estas, no solo provenientes desde el sistema carcelario y desde quienes, supuestamente, se encargan de aplicar las leyes, sino que, entre las mismas mujeres que habitan las áreas femeniles se constituyen importantes desigualdades en las que una gran minoría se posiciona en sitios de dominación y superioridad, no solo en el control de bienes y servicios, sino también de la vida de algunas de las internas. Del total de mujeres, la mayoría son colocadas en condiciones de más vulneración, exclusión, racismo y discriminación por diferentes motivos. Lo que, en combinación con otras situaciones del exterior, que siguen influyendo en los procesos de socialización de las mujeres, hacen que éstas desarrollen los diferentes mecanismos de sobrevivencia social que nos interesa comparar en este trabajo.

Así, comenzando a diferenciar las situaciones de mujeres indígenas y mestizas privadas de su libertad en "Santiaguito", Estado de México. Decir que las indígenas son quienes se encuentran en peores condiciones de vida o que se han enfrentado a sucesos más complicados que las demás internas durante sus procesos y en su día a día dentro de la institución, podría parecer bastante obvio. Puesto que, como se explicó en el apartado 2.1 de este trabajo, desde hace ya muchos años se han constituido grandes desigualdades hacia las poblaciones provenientes de los pueblos originarios, quienes en la mayoría de los entornos y a lo largo de la historia, han sido colocados en los peldaños más bajos de la escala social. Además de que, por características como el color de piel y su lengua materna, han sido excluidos, discriminados y violentados por otros que poseen un lugar de "superioridad" ante estos. Por lo tanto, en este centro penitenciario, la presencia de estas disparidades no son la excepción, pero podemos identificar casos en los que las estrategias de sobrevivencia de algunas 
indígenas, resultan un poco más efectivas que las de algunas mestizas que, por otro tipo de condiciones, son sometidas por grupos o individuos.

En el sistema carcelario actual el planteamiento de las diferencias por condición de raza, tiene importantes implicaciones en la vida de las mujeres privadas de la libertad, si comenzamos a contrastar las situaciones de indígenas y mestizas que, aun cuando sus respuestas ante las situaciones, también son determinantes de la posición en la que son puestas o la manera cómo son juzgadas, en nuestro estudio de caso, las diferencias comienzan a ser muy notorias, incluso, desde la percepción de las autoridades. Por ejemplo, uno de nuestros informantes clave dentro de la Dirección General de Reinserción Social del Estado de México, al preguntarle cómo es la situación de las mujeres privadas de su libertad en "Santiaguito", en términos generales, nos responde que:

La situación es de mucho abandono, la mayoría de las mujeres son olvidadas por sus familias, les dan la espalda porque no es bien visto que una mujer esté en la cárcel. A diferencia de los hombres que siempre tienen una mujer al pendiente de ellos. Además de que hasta parece que es normal ver que un hombre cometa algún delito (“Anónimo”, DGRS EDOMEX, 2018).

Según este testimonio, considerando que por condición de género las mujeres ya son vistas como parte de grupos en desventaja frente a los varones. Se le preguntó a la misma persona, entonces ¿cómo es la situación de las mujeres indígenas? Esto, pensando que en casos de este tipo se entrecruzan la condición de raza, género y clase social. El informante respondió:

En 'Santiaguito', hay muy poca población indígena, no se diga de mujeres, son muy poquitas, pero sí las hay. La situación que ellas enfrentan, sin que tenga dudas, te puedo decir que es mucho peor. A ellas las abandonan más. Considero que la sociedad las juzga más duro por las ideas que ya traen de sus pueblos. Además, sus familias suelen ser personas muy pobres y no tienen dinero para trasladarse a la cárcel para ir a verlas y llevarles algo. En estos casos, las familias o comen o van a otro lado para ir de visita. Ya depende las prioridades de los familiares. Pero yo te lo digo, difícilmente van a preferir gastar su poco dinero en ir a ver a alguien que no se portó bien, que les falló... (“Anónimo”, DGRS EDOMEX, 2018)

Lo expuesto por el informante respecto a la población indígena femenil del Centro Penitenciario y de Reinserción Social "Santiaguito", nos da cuenta de los estigmas con los que se señala a las poblaciones indígenas. Incluso, se podría decir que se recae en una victimización de estas poblaciones, enfatizando en las funciones de las familias y personas de los principales entornos de las mujeres. En testimonios como el anterior, también podemos destacar que las mismas autoridades omiten su participación en la promoción de las 
distinciones y desigualdades entre las poblaciones de mujeres indígenas y mestizas hacinadas en este centro. Por ejemplo, algo que es muy importante mencionar, es la manera como las autoridades penitenciarias de este estado hacen la diferenciación de uno y otro grupo, y con ello, la manera como aparentemente se llevarán a cabo sus procesos.

Al preguntar a otro de nuestros informantes clave de la DGRS ¿cómo distinguen a la población indígena de la mestiza?, nos respondió que:

Solo con que hablen alguna lengua indígena, ya con eso nosotros sabemos que son indígenas. También se les pregunta de dónde vienen, o sea, su lugar de nacimiento. Si nos dicen que provienen de una comunidad o de algún pueblo, pues ya los ponemos como indígenas. Aquí [en el Estado de México], generalmente vienen de los pueblos de los alrededores, pero hay algunos casos que vienen de otros lados. Si vienen de muy lejos, se busca la manera de reubicarlas cerca de su comunidad. Bueno, si ellas así lo quieren, se les dan las facilidades para su traslado (“Anónimo 1”, DGRS EDO MEX, 2018).

No obstante, como se explicó en el capítulo anterior, la realidad suele estar muy alejada de lo que las autoridades dicen promover. En el tema de cómo ubicar a las personas indígenas, la mayoría son ingresadas en los centros penitenciarios en donde se tenga más espacio y disponibilidad y, además, en el lugar más próximo de donde se le esté imputando por actos delictivos y no precisamente será lo más cerca de sus comunidades. Además, una vez ingresadas, si éstas solicitan sus traslados a recintos carcelarios aledaños a sus lugares de origen. Por ejemplo, si provienen de otros estados de la república, no siempre se atiende a sus demandas a la brevedad, ni tampoco reciben una respuesta satisfactoria al primer intento. Pueden pasar años antes de que se les reubique en otros centros o incluso, solo reciben una respuesta negativa a su petición.

Es así que, continuando con las diferencias resultantes del sistema penitenciario "moderno" entre mujeres indígenas y mestizas, cabe decir que la definición de ser indígena para las autoridades, como se expuso en el testimonio previo, no cubre muchos rubros. Hay casos en los que, si alguna indígena se identifica como tal por autodefinición, sin que hable alguna lengua originaria, es expuesta a un proceso penal que no contempla las garantías que, se supone, por ley deben de ser aplicadas hacia este tipo de poblaciones. En este trabajo, más adelante se exponen los testimonios de un caso como estos, mostrando el impacto que esto tuvo en la vida de reclusión de la mujer indígena, a diferencia de las otras dos que sí hablaban 
una lengua. Lo que no significa que estos dos casos hayan tenido un proceso adecuado, sino que, sus vidas tuvieron marcas distintas entre los diferentes casos de estas mujeres.

Respecto a todo esto, también se puede destacar que durante los procesos de mujeres de ambos grupos (indígenas y mestizas), existen dificultades que parten de la aplicación del sistema carcelario porque, como se irá exponiendo, en situaciones vividas por una gran mayoría de mujeres privadas de la libertad, influye el bajo nivel escolar. Muchas de éstas son analfabetas, algunas no saben leer y escribir o poseen bajos estudios escolares, lo que complica la comprensión de sus situaciones y la comunicación con las autoridades, personal penitenciario y demás población en reclusión. Mediante esto, es importante decir que no solo influye el hecho de que algunas no hablen español, como es el caso de muchas de las indígenas, sino que, el entendimiento de los términos jurídicos y legales, pueden tornarse muy complejos para las mujeres en general, dependiendo del grado escolar que éstas tengan.

Así, podemos agregar una de las principales condiciones que influye en la manera como las mujeres privadas de su libertad en el CPRS de Almoloya de Juárez, han de conducir sus vidas en confinamiento. Conforme se comiencen a exponer los testimonios de las mujeres que participaron en el trabajo de campo para esta investigación, se darán muestras de que las condiciones que constituyen a cada mujer determina fuertemente la manera como éstas se van adaptando a las circunstancias de la vida de encierro. Podemos resaltar, además, que no es lo mismo ser una mujer mestiza o indígena con nivel escolar alto o medio, que ser una mujer analfabeta. Pero también, podemos decir que hay otros aspectos que posicionan a las mujeres en niveles de desventaja en este recinto.

Si bien, en muchos entornos sociales como en el carcelario, el analfabetismo se suele relacionar con la pertenencia a una clase social baja. Las diferenciaciones por clase social, como se comentó en el apartado 2.2, representan una manera de segregar a las personas en diferentes grupos sociales, colocándolos en niveles distintos de las jerarquías sociales construidas según cada sociedad. Y, lo que ha de determinar la pertenencia de los individuos a cada peldaño de esta escala no solo se trata del poder adquisitivo, sino de algunos otros factores como el papel que desempeñan socialmente y que les concede la posibilidad de tener un dominio sobre los otros. En este sentido, dentro de recintos carcelarios como "Santiaguito", tenemos que, al igual que los elementos mencionados previamente, el nivel 
del cual son parte las mujeres imputadas interviene en la manera como éstas han de enfrentar sus procesos e incluso, en algunos casos es un factor clave del porqué llegan a cometer algún tipo de delito.

Es por esto que, en el caso de este trabajo, se destaca que, como en la mayoría de los ámbitos de la sociedad, en "Santiaguito" las mujeres que se posicionan en los lugares más altos de la jerarquía social de clases son una indiscutible minoría. Y, además, esto les concede el poder de dominar en muchos sentidos a la mayoría de las mujeres que se encuentran en niveles más bajos. Por ello, es importante resaltar que la mayoría de las mujeres que formaron parte del taller impartido para el trabajo de campo de esta investigación, son de clase social baja y, además, con pocos estudios escolares. Lo que ha influido en muchos de sus actos, en la manera como han tenido que enfrentar sus procesos legales y en el cómo viven su día a día dentro de este centro penitenciario, puesto que la mayoría de sus estrategias de sobrevivencia se dirigen principalmente a resolver conflictos económicos que de no hacerlo pueden llegar a generarles conflictos con los grupos de poder en el recinto.

En casos como estos el poder adquisitivo es importante para sobrellevar la vida en confinamiento. Dentro del CPRS "Santiaguito", es preciso decir que existe un control de productos, bienes, servicios y fuerza laboral, que está dominado por algunos internos, internas e incluso por personal penitenciario. Por lo que, muchas mujeres de otros grupos que son sometidas a este tipo de control, logran ingeniar métodos que les permiten generar ingresos mayores por su propia cuenta, con lo que, se podría decir, ellas compran un poco de "tranquilidad" y "seguridad". Otros tipos de mujeres que cuentan con ingresos provenientes del exterior no se ven obligadas a mejorar sus condiciones de vida en el mismo sentido económico que las demás. Sin embargo, en estos casos, algunas suelen ser vulneradas por otras condiciones, viviendo situaciones de violencia que no logran controlar tan fácilmente.

Así, profundizando un poco más en el tema de las clases sociales dentro de "Santiaguito", cabe decir que para las autoridades sí es importante la pertenencia de las mujeres en los diferentes niveles de la jerarquía social pues, indirectamente, señalan los beneficios que pueden llegar a tener integrantes de la población penitenciaria de clase social alta en todos los ámbitos de lo jurídico y penitenciario iniciando desde el momento en que los implicados comienzan a ser juzgados, en la forma en que se constituyen los procesos penales y durante 
la vida de privación de la libertad. Mientras que, por lo contrario, también se destacan las desventajas de ser de clase baja pues, claramente, los individuos en esta condición se enfrentan a situaciones mucho más complejas en el inicio, durante y al final de sus situaciones legales y que, cabe decir, tienen un mayor impacto en la vida de éstos que en la de los primeros.

Al respecto, se le preguntó a uno de nuestros principales informantes clave sobre la importancia de la pertenencia de las personas en situación de reclusión a las diferentes clases sociales, a lo que nos respondió que:

Las clases sociales sí influyen en todos los sentidos, porque, aunque nosotros no quisiéramos y no depende de nuestra área, quienes tienen más dinero o "palancas", pues no se ven tan afectados al momento de que son juzgados. Por ejemplo, si tienen más dinero o conocidos, se van a pagar su defensoría particular, si tienen que pagar alguna fianza, pues lo hacen y se van. Quienes no tienen esta posibilidad y que, además los dejan olvidados [sus familiares], van a solicitar apoyo de la defensoría de oficio que, aunque no quisiera decirlo, no siempre es buena, tiene limitaciones. Además, tú sabes, pasa en todos lados, con dinero..., pero en estos casos, hasta son más largos sus procesos y estando dentro, no se diga... sin dinero o conocidos, viven más violencia desafortunadamente... (“Anónimo 1", DGRS EDO MEX, 2018).

En "Santiaguito" específicamente uno de los mayores indicadores de desigualdad es el bajo nivel económico de la mayoría de las personas. Incluso, al caminar por las instalaciones se pueden percibir las malas condiciones. Cuando ingresan personas ajenas a la institución, es común que muchas mujeres privadas de la libertad (y varones, según sea el área de paso) se acerquen con insistencia y pidan alguna moneda $u$ ofrezcan alguno de los productos que realizan para la venta. Además, como se describió en el apartado anterior, algo muy evidente es que, debido a la pobreza de muchas de las personas, reciben una alimentación deficiente. Muchos internos en general no logran saciar sus necesidades alimentarias, y si bien, esta es una de las situaciones de mayor importancia a resolver, según lo señalan las autoridades, hay que destacar que son las mujeres quienes se observa que están en una mayor y constante búsqueda de trabajos y actividades que les posibiliten generar ingresos con lo cual puedan mejorar un poco su alimentación y condiciones de vida.

Sin embargo, no todas las mujeres muestran el mismo esfuerzo, cabe decir que, durante el trabajo etnográfico realizado en el CPRS de Almoloya de Juárez, se pudo observar la marcada división de grupos en el "dormitorio once". Son muchas las mujeres que se encuentran 
laborando fundamentalmente en actividades de cocina. En la planta baja del edificio principal, al pasar a la zona de celdas prácticamente en cada una de las entradas de estas, hay puestos improvisados de comida. Existe una enorme variedad de alimentos que las mujeres preparan para la venta o el intercambio de productos que se da con otras personas privadas de la libertad o con el mismo personal penitenciario. Por otro lado, en la parte exterior, también se puede ver un amplio grupo de mujeres de diferentes edades laborando en uno de los principales talleres ${ }^{72}$ impartido de manera fija en este centro penitenciario, se trata de la producción de artículos decorativos hechos con foamy ${ }^{73}$.

Además, en los pasillos y áreas comunes, también se puede ver a varias mujeres tejiendo o bordando algún producto. Las técnicas de tejido han sido aportadas por asociaciones como "La Cana ${ }^{74 "}$ que dentro de sus proyectos sociales, se encuentra la capacitación de mujeres en reclusión para la realización de diferentes artículos hechos con estambre con lo que tengan posibilidades de generar ingresos o intercambiar lo producido por artículos de primera necesidad e incluso, en algunos casos, son destinados como pago de "seguridad", pretendiendo escapar de ser posible blanco de actos de violencia. También hay mujeres que venden su fuerza de trabajo con aquellos que les solicitan algún servicio como el lavado de ropa. A muchas de éstas se les puede ver lavando a mano considerables cantidades de prendas de ropa, ya sea de varones o mujeres, puesto que este tipo de actividades se promueve en ambas áreas.

Son varias las maneras como los internos se relacionan para llegar a acuerdos como la ocupación en este tipo de trabajos, así como con quienes consumen los alimentos que las mujeres preparan. Una de las maneras más comunes con las cuales se desarrollan canales de

\footnotetext{
72 Este taller es una de las opciones que las mujeres tienen para laborar de manera "formal", puesto que perciben un sueldo por lo que producen. Esta oportunidad laboral es impartida por una empresa externa a la institución penitenciaria, pero que tiene un convenio con esta para la generación de empleos.

73 Se denomina FOAMY (goma EVA) al Etileno Acetato de Vinilo o simplemente llamado EVA por sus siglas en inglés (Ethylene Vinyl Acetate). También es conocido por su nombre comercial en inglés, "foamy" ("espumoso") que es el nombre utilizado en más de 30 países. Disponible en: https://www.manualidadesylabores.com/foamy-diccionario-de-manualidades-def-33

74 Es una empresa social que busca crear oportunidades para las personas que se encuentran en prisión, mediante la implementación de programas y talleres que tengan como objetivo su desarrollo personal, el trabajo y la capacitación para el mismo; con el fin de promover un proceso de reinserción que contribuya a romper el círculo de la reincidencia y la delincuencia. Esto se encuentra a cargo de un grupo de mujeres que buscan generar políticas eficaces para la debida reinserción social. Véase: https://www.facebook.com/lacanamx
} 
comunicación entre internos de ambas áreas es por medio de los custodios y custodias, quienes al recibir una parte de las ganancias generadas por estas actividades, suelen actuar como mensajeros $y$, a veces, conceden permisos extraordinarios en los que no se considera a las autoridades para que las mujeres puedan salir algunos minutos del "dormitorio once", dirigirse al área varonil y entregar todo aquello que les hayan solicitado. Es de esta manera como gran parte de las mujeres generan estrategias de sobrevivencia económicas y, además, de seguridad personal. Sin embargo, no todas las que ocupan las áreas femeniles realizan algún tipo de actividad laboral dentro de un régimen "legal” para sobrellevar su día a día de encierro.

Es así que en "Santiaguito" también se puede ver a muchas mujeres ejecutando actividades de ocio y vagancia. La mayoría de éstas, por lo que se pudo apreciar durante el trabajo de campo, suelen ser mujeres jóvenes a las que se les ve sentadas en las áreas comunes, tendidas en los pastos del patio principal, platicando entre ellas o pasando el tiempo dentro de sus celdas. Algunas de estas mujeres suelen mermar las situaciones de violencia hacia su persona, generando ellas mismas ambientes de intimidación hacia las demás. Muchas de estas mujeres arrebatan lo que las demás internas producen o son las que ofrecen seguridad a otras a cambio de algún producto, servicio o dinero en efectivo. Es decir, son parte de la población que mantiene dominio de ciertos elementos, personas y de la vida en reclusión. Sobre esto, se sabe que existen conjuntos de personas que ejercen poder sobre el resto de la población femenil, grupos tales conformados, en algunos casos, por integrantes de ambas poblaciones y personal penitenciario.

Estos grupos además de tener control de la tranquilidad y recursos de otras internas, también dominan y promueven negocios ilegales que sería inaceptable no mencionar en este trabajo, pues para algunas internas formar parte de estos, significa una manera de sobrevivir al confinamiento. Es por esto que, en este centro penitenciario, como en muchos otros de nuestro país, es común el funcionamiento de negocios como el narcotráfico y la prostitución, que no en todos los casos es promovido por las mismas internas, sino que el dominio puede surgir del área varonil, del exterior y de otros elementos no ajenos al sistema penitenciario. Todo esto es un tema muy delicado, el cual, dentro de "Santiaguito", por obvias razones no se habla abiertamente, pero tanto los y las internas, e integrantes del personal penitenciario, 
aunque en muy escasas ocasiones, durante el trabajo de campo mencionaron algo al respecto, una de nuestras informantes del personal administrativo, dijo lo siguiente:

La gente aquí busca moverse de diferentes formas, aquí se mueven muchos negocios. Lamentablemente mucha gente del narco emplea a algunos internos para que a su vez ellos manejen unos negocios. No te sabría decir cómo entran, pero me imagino, ya sabes... el dinero... [Por otro lado] sí hay prostitución, es como todo, es una manera fácil de ganar dinero, entonces sí hay quienes manejan a las mujeres. Nosotros luego ni cuenta nos damos, las cosas pasan como visitas conyugales. No sé más, pero sí pasan ese tipo de cosas (“Anónima”, personal administrativo del CPRS “Santiaguito", 2018).

Respecto a esto, cabe decir que se sabe que, si bien existen casos en los que las mujeres participan en este tipo de actividades por propia voluntad y que, incluso lo hablan abiertamente al no estar vinculadas con alguna red consolidada de prostitución o narcotráfico, sino que lo ven como una manera de ganarse la vida, aun cuando hay casos que esto mismo las coloque en posiciones de desprecio y rechazo por otras internas en el mismo centro. También hay otros casos en los que quienes son empleadas en estas ocupaciones, son mujeres de clase baja que no reciben visitas regulares de sus familiares y que, aparentemente no cuentan con otros medios que les permitan subsistir dentro de "Santiaguito". Además, algunas otras son forzadas por medio de la violencia de otros grupos a formar parte de estas actividades. Al respecto, como ya se ha mencionado, aunque es muy poco lo que las personas hacen referencia de la situación, es algo que no pasa desapercibido para nadie dentro de todas las áreas de este recinto.

Son muchos los medios que las mujeres emplean para dar frente a las situaciones que surgen cada día dentro de "Santiaguito". Algunas, por lo que mencionaron en parte de sus testimonios, muestran que las actividades que realizan dentro del centro penitenciario, en ocasiones son cercanas a lo que hacían antes de ser imputadas. Pero algunas otras, han cambiado sus labores desde lo que han aprendido allí adentro o desde las "oportunidades" que se les han presentado. En las diferentes actividades, podemos ver que se ubican mujeres de diferentes condiciones, cada una a partir de su género; clase social, junto con su nivel escolar y raza, es como van construyendo los medios con los cuales han de vivir en este recinto.

Esto es, según se expuso en el capítulo 1 de este trabajo, algunas mujeres sí presentan modificaciones muy notables en sus procesos de socialización, pero generalmente, en la 
mayoría de los casos, no son despojadas de lo que tienen interiorizado desde su nacimiento, a excepción de casos más específicos en donde las internas sí se ven obligadas a desprenderse de gran parte de estos elementos. El no hacerlo implicaría ser posicionadas en lugares de más vulneración, exclusión y violencia durante su situación penitenciaria. Entre este tipo de personas podemos destacar, inicialmente, a las mujeres indígenas que ingresan hablando su lengua materna, con usos y costumbres forjados y dedicadas a labores propias de sus comunidades y hogares.

En muchos casos - no en todos- éstas tienen que adoptar y adaptarse a nuevos elementos desde una manera mucho más drástica que en el caso de otras mujeres que principalmente se enfrentan a la lucha de sobrevivir a un día a día desde aspectos y características que para algunas es algo parecido a la vida del exterior. En referencia a esto, dos de las mujeres mestizas privadas de su libertad que formaron parte del taller para trabajo de campo, al preguntarles sobre cómo es vivir en "Santiaguito", respondieron:

Vivir aquí es como vivir en una vecindad. Cuando entras te das cuenta; unas mujeres están en los lavaderos, otras en cocina, otras en la tienda, otras andan de argüenderas. Es igual que afuera o algo parecido... Aquí sí hay peleas, es como todo, son pocas, no creas que siempre se están peleando, casi siempre son las más jóvenes, pero es como allá afuera ¿o qué tú nunca has visto a dos mujeres agarrarse de las greñas en la calle?... bueno, pues aquí es igual. Unas que son más gandallas que otras, no más que aquí pues, estamos encerradas y nos vemos las caras diario. A veces en los problemas sí se meten las custodias, pero no más es para separarse, las cosas no se calman no más así. Nunca falta que unas tengan problemas con otras, pero es como en un barrio de los de allá afuera (Azalia y Montes, mujeres privadas de la libertad, noviembre 2018).

Las mujeres que señalaron lo anterior, cabe decir que son del grupo de la tercera edad y, como mencionaron, debido a su edad tienen una percepción en donde se excluyen ellas mismas de los conflictos, considerando que son las más jóvenes quienes son participes de estos hechos. Muchas de las mujeres de la tercera edad, según autoridades de "Santiaguito", se han hecho parte de esta categoría dentro del recinto mientras cumplen con sus procesos y sentencias, pues varias de éstas tienen muchos años de haber sido ingresadas. Las mujeres en esta situación ya tienen una mejor adaptación a su entorno, pues incluso, han formado grupos con otras mujeres, lo cual hace un poco más sencillo sobrellevar el encierro. Sin embargo, existen otros casos en los que las mujeres han sido imputadas y ubicadas en este CPRS teniendo más de 60 años de edad cumplidos, lo que, según los estándares del sistema 
penitenciario del Estado de México, es uno de los principales rubros para ser identificadas y consideradas como parte del grupo de mujeres ancianas.

Las ingresadas como parte de esta categoría suelen ser posicionadas en lugares en donde se les vulnera, excluye y discrimina en diversos sentidos, esto surge desde su procesamiento y durante el confinamiento. Desde que adquieren la categoría de implicadas, se encuentran con dificultades a la hora de que el sistema penitenciario las ha de juzgar, debido a que, como se dijo en el capítulo anterior, no siempre se aplican las normatividades adecuadamente. Además, muchas veces las mujeres tienen complicaciones para entender sus situaciones jurídicas. Y, por otro lado, hay casos en los que durante el encierro suelen ser agredidas por mujeres con características distintas o que provienen de otras condiciones. Es por esto que, posiblemente, las diferencias etarias dentro del área femenil de "Santiaguito", son muy relevantes pues, aunque se trate de mujeres mestizas de una clase social media, la edad, representa una desventaja para muchas de estas.

En el caso de mujeres de la tercera edad, durante el trabajo etnográfico y el trabajo de campo realizados, se pudo notar que son uno de los grupos que tiene una mayor participación en las actividades que se promueven dentro de este recinto. Al igual que muchas otras mujeres, éstas dedican la mayor parte de su tiempo a producir artículos o alimentos que les posibiliten percibir algún tipo de beneficio -que no es necesariamente económico-. A muchas de estas mujeres se les ve frecuentemente en los pasillos tejiendo o dentro de las celdas preparando alimentos. Además, se puede notar una gran solidaridad y unión entre muchas de estas, pues suelen convivir y agruparse para realizar dichas actividades, y apoyarse en los momentos en que alguna o algunas de ellas se encuentran sometidas o vulneradas por algún tipo de violencia por parte de otras internas o personal penitenciario.

Muchas de estas mujeres, en ciertos casos comparten más que las actividades laborales, pues se ven identificadas por sus creencias religiosas, tipos de delitos por los que se les imputa, condiciones de salud, intereses generales y actividades realizadas antes del encierro. En cuanto a la situación de abandono de las que son parte de esta condición, no es igual para todas, pues a varias de éstas sí las visitan sus familias con mayor frecuencia. Generalmente a aquellas quienes han sido ingresadas recientemente son las que tienen mayor atención familiar. Mientras que, las que han envejecido dentro del recinto, en algún momento de sus 
vidas en confinamiento sus familias dejaron de asistir a la institución. Esto según las mismas internas puede ser por diferentes causas, la principal es que no tienen muchos familiares o por el hecho de que han sido olvidadas por su estigma de delincuentes, malas madres y malas mujeres.

Podría decirse que los grupos de mujeres de la tercera edad son de los que se ven mayormente influidos por el encierro, pues en muchos casos, como es en el de las indígenas, también se enfrentan al despojo o separación de algunos de los elementos interiorizados y arraigados desde su nacimiento. Aun con la unión que se puede observar entre las que son parte de este conjunto etario, es posible decir que el impacto que tiene el sistema carcelario y el entorno en ellas es muy notable. Puesto que son muchas las necesidades de las mujeres de la tercera edad que difícilmente se logran garantizar a la hora de ser imputadas, además de que la manera cómo se relacionan con el resto de las mujeres es muy distinto, puesto que se encuentran segregadas dentro de prisión y pocas veces logran pasar desapercibidas de actitudes de humillación y sometimiento.

Al respecto, dentro de "Santiaguito" se observa que la integración y la efectividad de las estrategias de sobrevivencia que desarrollan las distintas mujeres depende de más de un solo factor. En confinamiento, lo etario es un elemento que interviene en la calidad de vida de las mujeres, por lo que, en resumen, son el género, la raza, clase social y edad los componentes que determinan mucho de lo que constituye las situaciones de las diversas mujeres privadas de su libertad. Éstas pueden ser parte de más de una de estas condiciones, por lo que, según lo visto en el apartado 3.2 de este trabajo, desde la consideración de la interseccionalidad, podemos resaltar que las mujeres privadas de su libertad, son víctimas de opresiones múltiples por condiciones entrecruzadas. Algunas, como se ha venido diciendo, suelen ser el blanco de situaciones más complejas que otras, lo que no es resultado de una adhesión de características o elementos, sino de la intersección de éstos.

Más adelante iremos identificando lo anterior entre los casos aplicados para esta investigación. Además, veremos que existen muchas semejanzas de vida y de estrategias de sobrevivencia entre mujeres que no siempre comparten las mismas condiciones más que el hecho de ser mujeres. Es así que lo que se ha expuesto hasta aquí, desde una percepción generalizada, data de cómo se van identificando los diferentes grupos de mujeres dentro de 
"Santiaguito", destacando principalmente la relación de estos conjuntos con los elementos que en teoría constituyen al sistema penitenciario de nuestro país $y$, con los que aparentemente se rigen los centros penitenciaros del Estado de México. Sin embargo, como se ha podido notar, la perspectiva que tienen las autoridades respecto al manejo de las leyes y la manera como constituyen e idealizan los distintos grupos de personas privadas de su libertad muestran importantes sesgos, puesto que claramente se omiten muchos de los elementos que en la vida de los y las internas tiene fuertes implicaciones.

Es por esto que, contrastando lo que supuestamente debería de ser la realidad de las mujeres que habitan en este CPRS, podemos ver que las actoras narran hechos que se alejan de lo que se supone, sería el ideal de los sistemas penitenciarios. Prueba de esto, nos lo comparten la mayor parte de las diez mujeres consideradas en la muestra del estudio comparativo propuesto para este trabajo. Éstas como se comentó antes, las presentamos, inicialmente, de manera general en dos diferentes grupos: indígenas y mestizas. Por lo que cabe aclarar que en el Taller de figuras con materiales reciclados participaron de manera constante y voluntaria entre once y trece mujeres. De las cuales, fue evidente que solo dos son definidas indígenas desde las consideraciones de las autoridades de este centro penitenciario. Mientras que el resto son población mestiza (sin contemplar aun el caso de la mujer indígena que fue entrevistada después de ser puesta en libertad).

De todas las mujeres involucradas en el taller se seleccionaron únicamente nueve. La elección de las mestizas se hizo desde el rubro principal de que fueran quienes tuvieran una mayor participación y flexibilidad para hablar y compartir fragmentos de sus experiencias dentro del sistema penitenciario. Mientras que las indígenas fueron integradas automáticamente, por el hecho de que son la minoría de toda la población femenil en este recinto. Este proceso se planteó así debido a las restricciones de las autoridades, por lo que a las mujeres no se les pudo explicar a detalle que una de las intencionalidades de la actividad era recaudar sus testimonios y narrativas. Además de que se pretendía que la información que las actoras compartieran no se viera influida por el hecho de que tuvieran conocimiento del trabajo que se estaba realizando y con esto, se esperaba que lo que ellas compartieran fuera lo más sincero posible. 


\subsection{Reclusas de Almoloya de Juárez: el variado impacto en los procesos de socialización desde la condición de género, raza, clase social y edad}

Una vez expuesto lo anterior es importante empezar a identificar los casos que se compararán en este trabajo, por lo que, cabe señalar que primero se presenta a las siete mujeres mestizas seleccionadas y posteriormente se expondrán los casos de las tres mujeres indígenas que forman parte de esta investigación. En este apartado se pretende conocer un poco de lo que constituye la situación de cada una de las diez participantes, describiendo el cómo y por qué fueron recluidas en "Santiaguito", cómo ha sido el sistema penitenciario con ellas y cómo ha impactado de manera individual en sus vidas y en sus procesos de socialización, destacando sus diversas características. Es decir, se exponen los testimonios de las diez mujeres intentando mirarlas desde el cruce de sus diferentes condiciones, considerando que todos los casos viven de maneras muy distintas el ser una mujer privada de su libertad.

Comenzamos con el caso de "Lucrecia"75, quien es una mujer de aproximadamente 67 años, originaria del estado de Veracruz, la cual presenta problemas de audición y, por lo que se pudo notar, tiene algunas limitaciones de comprensión. Esta mujer platica que antes de ser imputada se dedicaba al hogar y en ocasiones vendía productos por catálogo a sus vecinas y conocidas, es viuda y vivía con uno de sus hijos y con la familia de éste. Ella no tiene estudios escolares avanzados, solo cursó hasta sexto de primaria, por lo que, aunque sí sabe leer y escribir, tiene algunas dificultades para entender varios elementos de su situación legal. A esta mujer se le acusó del delito de secuestro, es decir, pertenece al fuero común.

"Lucrecia" se define a sí misma como inocente de lo que se le imputa, según lo señala, recibió una acusación injustificada por parte de vecinas del lugar en donde residía. Al preguntarle por qué la recluyeron en el estado de Toluca y no en Veracruz, respondió que tiene familia en el Estado de México, por lo que ella iba de visita con éstos cuando fue aprehendida. Respecto a esta situación, las autoridades mencionaron que, pese a que se le encontró culpable durante su proceso, ella siempre ha declarado ser inocente y desconocer por qué se le señaló a ella. La mujer ya está sentenciada a quince años de confinamiento y su proceso duró dos años. Actualmente lleva siete años habitando en "Santiaguito". De manera

\footnotetext{
${ }^{75}$ Por petición de las autoridades se ha cambiado el nombre real de la mujer.
} 
generalizada, su relación con las demás internas no es muy buena, lo que fue fácil de percibir durante el trabajo etnográfico y desde las críticas emitidas por otras internas hacia ella.

Algo que se destaca de la situación de la mujer es que ella sí recibe visitas frecuentes de sus familiares, además de que éstos le hacen percibir un ingreso económico semanal. Incluso, según lo menciona, cuando ella requiere de más dinero para comprar materiales de alguna actividad a la que ella se esté integrando, se los hace saber y el día que la visitan suelen entregarle lo necesario. Esta mujer participa en la mayoría de los talleres manuales que se les imparten dentro de prisión, pero no produce ningún producto para la venta, sino que, lo creado suele entregárselo a su familia a manera de obsequios. Como actividad laboral dentro de prisión, ella vende dulces y golosinas a las demás internas y personal penitenciario. La mujer dice que generalmente no vende mucho, pero que sí suele generar ciertos ingresos extras. También menciona que algunos de estos artículos los intercambia por productos como cigarros y, a veces, bebidas embriagantes.

Es relevante decir que esta mujer reconoce y hace mención de que presenta problemas de alcoholismo, por lo que semanalmente acude a pláticas de ayuda y superación de adicciones que se imparten en el área femenil de este CPRS, pues cabe decir que, en esta zona, las mujeres no cuentan con programas de desintoxicación como el CICA, que se promueve únicamente en el área varonil. Respecto a esto, es importante señalar que los problemas de adicciones en las personas privadas de su libertad es uno de los más comunes en la mayoría de las instituciones carcelarias, ya sean: federales, estatales o municipales. Pero en el Estado de México, en varios de los recintos carcelarios, se promocionan programas de atención a adicciones, principalmente en los recintos y áreas varoniles. En los que son femeniles solo se dan platicas, similares a las de los grupos de "Alcohólicos Anónimos"76 (AA) de la vida del exterior.

\footnotetext{
${ }^{76}$ Alcohólicos Anónimos ${ }^{\circledR}$ es una comunidad de hombres y mujeres que comparten su mutua experiencia, fortaleza y esperanza para resolver su problema común y ayudar a otros a recuperarse del alcoholismo. El único requisito para ser miembro de AA es el deseo de dejar la bebida. Para ser miembro de AA no se pagan honorarios ni cuotas; nos mantenemos con nuestras propias contribuciones.

AA no está afiliada a ninguna secta, religión, partido político, organización o institución alguna; no desea intervenir en controversias, no respalda ni se opone a ninguna causa.

Nuestro objetivo primordial es mantenernos sobrios y ayudar a otros alcohólicos a alcanzar el estado de sobriedad. Véase: https://aamexico.org. $\mathrm{mx/}$
} 
Por esto es importante hacer la aclaración de que en muchos de los casos que se presentan en este trabajo, las mujeres viven dentro de "Santiaguito" con algún tipo de adicción. Así, una vez hecho este importante paréntesis, se presenta a la siguiente mujer contemplada para esta investigación, se trata de "Bianca", mujer mestiza de 70 años, oriunda del municipio de Toluca. Actualmente, tendría un año y ocho meses recluida en este recinto. Sin embargo, en julio de 2020, dos de los informantes clave de la Dirección General de Reinserción Social del Estado de México, comunicaron de manera personal el fallecimiento de esta mujer a causa de la mala atención médica que recibió para tratar lo que aparentemente fue SARS-CoV-2 (COVID-19). Aun con la noticia de su fallecimiento, se retoma su caso, puesto que, durante el trabajo de campo, fue una de las mujeres con mayor presencia y participación en las actividades.

Hasta antes de su fallecimiento, "Bianca" continuaba en espera de una sentencia. A esta mujer se le acusaba del delito de invasión y robo de propiedad privada. Al igual que en el caso anterior ella se declaraba inocente ante dicha acusación. En cuanto a qué se dedicaba antes de ser recluida, ella comentó: "Pues mira, yo gracias a dios estaba en mi casa, yo no trabajaba ya. Mi esposo tiene una pensión y no más para los dos. Vivíamos solitos, no era para lujos, pero ahí nos alcanzaba para comer y nuestras cosas, no le pedíamos nada a nadie. Mis hijos ya cada quien, por su lado, sí nos veían, pero no estaban con nosotros" ("Bianca", 2018). La mujer era madre de cuatro hijos, de los cuales, en esos momentos, dos también se encontraban internos en el CPRS de Lerma en el Estado de México. A estos se les imputó por la misma transgresión que a nuestra actora.

Esta mujer sí recibía visitas cada semana, una de sus hijas era quien recurría cada domingo al recinto para llevarle dinero, productos de higiene y de uso diario, además de comida. Dentro de "Santiaguito", "Bianca" no laboraba de manera formal u obligada, puesto que no consideraba que fuera tan necesario generar ingresos extras a los recibidos de su hija. No obstante, sí estaba produciendo artículos tejidos con estambre, puesto que le gustaba mucho esta actividad, era algo que ya tenía aprendido desde antes de ser confinada. Algunos de los objetos producidos, los había regalado a los hijos de las mujeres que habitaban con sus bebés en esos momentos, otras cosas se las entregaba a su hija durante las visitas, y otras cuantas 
se los daba a otra de sus compañeras para que ésta las vendiera durante los días de visita, compartiendo con ella el dinero obtenido por los artículos.

Durante el periodo que se llevó a cabo el taller, la mujer platicó que buscaba integrarse a la mayor cantidad de actividades manuales que se les impartieran, ya que deseaba pasar el menor tiempo posible en su celda, debido a que, desde su consideración por ser nueva era violentada de diferentes formas por otras internas de menor edad, incluso de algunas de otra nacionalidad. A esta mujer se le preguntó qué es lo peor que había pasado desde que llegó a este recinto, por lo que narró algunas de sus experiencias en las que se destaca la gran vulneración y violencia que vivió debido a su condición etaria:

Las compañeras de celda [han sido lo peor], hay unas que son malas, se adueñan de todos los espacios. De por sí las celdas son chiquitas y ellas lo ocupan todo. Yo no más me dejan un rinconcito debajo de mi cama, ahí en una esquinita pongo mi ropa y mi agua, si la pongo en otro lado luego hasta me las avientan. Luego ellas [señaló a otra de las mujeres] me hacen favor y me guardan unas cosas...

Cuando apenas llegué, me pusieron en una celda con una hondureña, era bien canija. Un día me aventó mis cosas afuera de la celda y me dijo que me durmiera en el piso o a ver a dónde. Yo me puse a llorar y no sabía qué hacer, se acercaron otras y le dijeron que no se pasara conmigo, que ya estoy grande y se calmó poquito. Ya después pedí que me cambiaran de celda. En donde estoy no me corren, pero yo no tengo espacio, no más mi rincón. No puedes decir nada, mejor me callo porque no quiero que me hagan nada ("Bianca, 2018).

Para sobrellevar las situaciones de violencia esta mujer habló de su integración con mujeres de su mismo grupo etario para mantenerse ocupada a lo largo del día. En ella se pudo observar que, al ser poco tiempo el que tenía de haber llegado a este centro, su adaptación no era muy buena ante las situaciones que había que enfrentar cada día, ella vivía con miedo y en constante incertidumbre de lo que pasaría al día siguiente. Intentar mantenerse oculta era una de las opciones que ella destacaba en diversas ocasiones. Su relación con el resto de las mujeres de su mismo grupo etario parecía ser buena, puesto que se integraba en las actividades que se promovían por parte de las mismas internas para generar una mayor convivencia. En el caso de "Bianca", se veía buena aceptación por parte de las demás mujeres de su edad, situación que no se vio en el caso de "Lucrecia", a quien se le excluye por su dificultad de entender algunas cosas. 
Continuando con el caso de la señora "Bianca" hay que decir que tenía estudios de nivel básico, pues solo concluyó la secundaria, por lo que sí sabía leer y escribir. Sin embargo, mencionó en diversas ocasiones que tenía problemas a la hora de entender su situación. Su familia contrató defensoría particular para atender su caso, por lo que la mujer comentó que su abogado procuraba explicarle lo mejor posible lo que ocurría en cada una de sus audiencias, aunque a ella no siempre le quedaba claro y después su hija le explicaba. Muchas veces habló de su tristeza y desesperación por recuperar su libertad, además de que en diversas ocasiones decía que ella pensaba que para el siguiente año (2019) ella resultaría exonerada del delito que se le acusaba. En muchas de sus narrativas, expresaba lo difícil que estaba siendo el tener que vivir en este recinto, incluso desde su proceso de detención:

...Me agarraron en la calle, yo no sabía ni qué pasaba. Me dijeron que porque me habían demandado unos que nos habían quitado un terreno que era de mi esposo, dijeron que mis hijos y yo casi matamos al hijo del fulano ése. Entonces yo salí y ya me estaban esperando, me gritaron y me subieron al carro, pero me apretaban feo porque yo no quería. A mí me dio mucho miedo, yo no más lloraba y me encomendaba a dios. Imagínate, a mi edad tener que pasar esto... (la mujer lloraba mientras narraba esto) ... ("Bianca", 2018).

En diversas ocasiones esta mujer expresó un fuerte valor por sus creencias religiosas, era tanto que, se podría decir, era una de sus prioridades. Dentro de "Santiaguito", esto era una manera de refugiarse y huir de lo que estaba viviendo:

...Aquí está la capillita, ¿ya la viste?, nosotras tenemos que pedir permiso para que nos dejen ir, porque de este lado no hay, pero yo sí voy cuando se puede, voy a rezarle a diosito, voy a pedirle que me cuide y me ayude a salir de aquí. Le pido por mis hijos, que me los cuide y me los proteja, yo no los puedo ver, pero dice mi hija que están bien sus hermanos... bueno, qué me puede decir, ¿verdad?, yo solo ruego que se acabe esta pesadilla... ("Bianca", 2018).

Con las narrativas de esta mujer se pudo comprender que, con cada caso, durante la reclusión, las situaciones de vida pueden variar, no solo desde las principales condiciones contempladas en esta investigación (raza, género, clase social y edad), sino que hay otros factores como el tiempo que las actoras llevan habitando el recinto carcelario. Sin embargo, son muchos los contrastes respecto a esto, por ejemplo, tenemos un tercer caso de mujer mestiza que, relativamente, no llevaba ni mucho ni poco tiempo en este CPRS. Se trata de "Luna", quien, a diferencia de las mujeres mencionadas antes, es muy joven. Actualmente tiene treinta y un años, es originaria de Temascaltepec, Estado de México. Concluyó sus estudios de nivel 
medio superior, sabe leer y escribir. Ella requirió defensoría de oficio, puesto que no recibe ningún tipo de apoyo familiar para enfrentar su situación.

“Luna” está acusada por el delito de secuestro, según lo que nos comparte, su ex pareja sí participaba en este tipo de crimen. Sin embargo, ella no tenía conocimiento claro de la situación. Al momento de que alguien señaló a su ex esposo como parte del crimen organizado, él decidió señalarla a ella como responsable intelectual de los delitos, además de entregarla con las autoridades. La mujer tiene dos hijos con el sujeto, por lo que al momento de ser ingresada a "Santiaguito", él decidió alejar a los niños de ella y de su familia. Los padres de "Luna", por su parte, decidieron olvidarla, mostrándose decepcionados de ella: "Mis papás dijeron que yo dejaba de ser su hija y pues no vienen, ya ni se acuerdan de mí" ("Luna”, 2018). Mientras que la única persona que la visita esporádicamente es su hermana. Esta mujer dice que la ve prácticamente una vez al año "No, nadie viene. Casi cada año viene mi hermana, ella dice que viene cada Navidad, ijajaja!” (“Luna”, 2018).

Actualmente esta mujer tiene cinco años de estar privada de su libertad. Tiene una sentencia de setenta años, puesto que se le acusó de más de un secuestro. Ella, a diferencia de las dos mujeres anteriores, no recibe ingresos del exterior, por lo que labora en diversas actividades dentro del CPRS. Cuando hay oportunidad, se hace parte del reciclado de botellas, actividad que es remunerada por la institución carcelaria. Este trabajo se trata de que las mujeres seleccionen de entre grandes cargas de basura inorgánica, todos los envases de pet que encuentren y los coloquen en grandes bolsas para que posteriormente se les reutiliza en el taller de plásticos, que es una parte del recinto en donde otras internas producen bolsas negras de plástico que después se destinan para la venta en el exterior.

"Luna", también participa en el taller de productos de foamy, actividad que, señala, es de sus preferidas, puesto que a ella le gustan mucho las manualidades. Además, por su cuenta también diseña y crea figuras de fieltro, labor que realizaba desde antes de su confinamiento. Todos los productos que produce son destinados para la venta durante los días de visita. Ella tiene un acuerdo con los custodios para que, aunque no reciba visitas, le permitan salir a comerciar con sus productos. Además, es relevante mencionar que durante los años que lleva interna, se vinculó con un individuo del área varonil, quien actualmente es su pareja. Con éste tuvo un hijo, el cual ha pasado sus primeros años en confinamiento junto con su madre. 
Ella menciona que el tener pareja en esta situación, le parece una de sus mejores decisiones, puesto que ambos trabajan dentro del recinto para sobrellevar la vida.

"Luna" no muestra mucho interés por relacionarse con el resto de las internas, dice que desde antes de estar en "Santiaguito", era una persona solitaria: “...yo no convivo mucho, no me gusta, siempre he sido así. Te digo que yo me dedico a mis cosas, casi no salgo y no hablo con nadie, menos cuando está mi bebé. Con las que luego hablo más es con las señoras más grandes, como con la abuela (Señora "Azalia"), ellas me ayudan con mi bebé y luego me apoyan con cositas" (“Luna”, 2018). Esta mujer, como podemos ver, suele tener una mejor convivencia con las mujeres de la tercera edad que con las que son más jóvenes, lo que durante el trabajo etnográfico fue muy evidente. Además de que ella, al igual que las mujeres de mayor edad, considera que son las jóvenes quienes generan la mayor parte de los conflictos y peleas que se viven en el área femenil de este CPRS, por lo que ella procura no hacerse parte de estos hechos.

Ante la consideración de que la violencia y conflictos proviene en mayor medida de las mujeres de menor edad, tenemos otro caso de una mujer joven participe de nuestro trabajo de campo. Esta cuarta mujer mestiza es "Daniela", ella actualmente tiene treinta y cinco años de edad y lleva tres años y medio privada de la libertad, es originaria del estado de Toluca y posee estudios de nivel medio superior concluidos. Antes de ser imputada, laboraba en un minisúper y se dedicaba al hogar y a su familia. Aún no ha sido sentenciada, por lo que continua en calidad de procesada. Ella pertenece al fuero común, se le imputa por el delito de robo a tienda de autoservicio. Su defensoría legal es de oficio, de la cual, tiene muchas críticas, ya que considera que el abogado a cargo de su situación, no le ha dado buenos resultados. En diferentes ocasiones compartió su preocupación y desesperación por tener respuesta a su conflicto. La mujer mencionó varias veces el delito por el que se le imputa con duda e indiferencia, pero nunca negó el haber cometido el saqueo del que se le acusa.

Esta mujer, además, es madre de dos niñas; una de nueve años y la otra de ocho. "Daniela" nos comparte que sus hijas desconocen el hecho de que ella está recluida, su esposo y padres son quienes se hacen cargo de las menores, pero han ocultado las razones por las que su madre no está con ellas. La historia que se le ha compartido a las niñas es que la mujer migró hacia otro lugar para laborar. "Daniela" procura llamar una o dos veces por semana a sus 
hijas, manteniendo la promesa de volver pronto con ellas. Además, ésta recibe visitas cada semana de sus familiares, algunas ocasiones ve a su esposo y otras a sus padres, quienes hasta el momento en que se realizaba el trabajo de campo, no la habían olvidado, ni estaba siendo duramente estigmatizada como sucedió en el caso anterior.

"Daniela" expresó muchas veces el apoyo que mantenía de sus familiares, sin embargo, tenía un gran deseo por abandonar el CPRS, ya que, en ocasiones, se encontraba conflictuada por situaciones que le estaba tocando presenciar dentro de su celda con sus compañeras (estaba siendo testigo de actos de ilegalidad como la venta de drogas y estupefacientes dentro del recinto). Además de que, debido a esto, había estado recibiendo amenazas e intentos de ser violentada fisicamente. Ella dice que hasta el momento se ha protegido de algunas agresiones por medio de violencia física, es decir, ha tenido varios enfrentamientos con otras mujeres. Al respecto ella dijo: "aquí, desde que llegas te vas dando cuenta de que te van a querer agarrar de su pendeja, y sí pasa, si te dejas, pero si les contestas y te les enfrentas te dejan en paz un rato. Muchas veces es mejor ponerse a hacer algo, así ya no te ven en todo el día..." (“Daniela", 2018).

Esta mujer, al igual que en los casos previos, vemos que el mantenerse ocupada la mayor parte del día es una buena manera de alejarse de los conflictos. Además, a comparación con el caso de "Bianca", es muy notorio que la edad sí determina uno de los mayores conductos de vulneración, pues para "Daniela" su juventud representa una ventaja para defenderse de los conflictos. Es por esto que, junto con los testimonios de esta interna se recaudaron los de otra mujer mestiza joven. Su seudónimo es "Elisa", quien actualmente tiene veintisiete años de edad, es madre soltera de un niño de cuatro años. Al momento que se realizaba el trabajo de campo, ella tenía solo tres meses de haber sido recluida y tampoco tenía sentencia, se encontraba enfrentando su proceso. Se le imputa por delitos contra la salud (narcotráfico), ella se declara culpable del acto, sin embargo, al hacerlo, nos comparte un poco de lo que la impulsó a vender diferentes tipos de drogas. Según lo menciona, fue su situación económica y presión por parte de sus padres para que ella generara mayores ingresos y tratara de asegurar una mejor calidad de vida para su hijo lo que, según ella, la llevó a esta actividad.

Esta mujer se encontraba desempleada, viviendo en la casa de sus padres, no aportaba dinero para los gastos del hogar y, aunque en varias ocasiones buscó un empleo, no tuvo mucha 
suerte. "Elisa", atribuye esto a su bajo nivel escolar, pues solo tiene secundaria trunca. Al encontrarse en esta situación tuvo la "oportunidad" de participar como "camello"77 en el mercado de la droga, por lo que comenzó a dedicarse a esta actividad. Sin embargo, fue muy poco el tiempo el que se ocupó en esto, aproximadamente a los siete meses de comenzar, fue detenida por las autoridades. No describe el momento de su captura como un hecho muy violento, pero que sí le generó un gran temor por pensar en que su hijo se quedaría solo, pues ella ya se encontraba consciente de que sería recluida por un buen tiempo. Mientras ella se encuentra en "Santiaguito", sus padres se hacen cargo del pequeño niño.

En cuanto a las visitas, ella no las recibe con frecuencia, sus padres acuden al recinto una vez cada tres o cuatro meses. "Elisa" dice que es así debido a que su familia no cuenta con dinero suficiente para hacerlo, pese a que viven en el mismo estado. La mujer señala que prefiere que el poco dinero con el que cuentan se destine a solventar los gastos de su hijo. Por lo que, en reclusión, ella se emplea en diferentes actividades. Como en el caso de "Luna", también participa en el reciclado de botellas de pet y el taller de figuras de foamy. Además, ella se ofrece para actividades como las mencionadas en este apartado, tales como lavar ropa de otros internos, limpiar sus celdas o, en ocasiones, ayuda a las mujeres que se dedican a preparar alimentos. Cabe decir que "Luisa", desde el poco tiempo de haber sido ingresada, ha procurado tener una buena relación y cercanía con las mujeres de la tercera edad, pues, según explica, el pasar más tiempo con ellas, la favorece en varios sentidos. Lo que se describe mejor en el próximo apartado.

Una de las mujeres del grupo de mayor edad que le concede a "Luisa" y a otras internas ciertos "beneficios", se trata de la que aquí identificaremos como la "señora Azalia", ésta es nuestro sexto caso a comparar. "Azalia” tiene aproximadamente sesenta y siete años, no quiso decirnos su edad exacta y algunos otros elementos de su vida personal, sin embargo, durante las conversaciones hubo ocasiones en las que destacaron algunos de estos detalles. Esta mujer no es de Toluca, ella radicaba en la Ciudad de México, meses antes de su detención es que

\footnotetext{
77 El empleo de "camello" como sinónimo de traficante de drogas a pequeña escala tiene su origen en una picaresca que se extendió entre los vendedores de los años veinte del siglo pasado. Cuando intuían una situación de peligro o la posibilidad de ser descubiertos por la policía, los traficantes escondían la mercancía debajo de sus ropas, generalmente en la espalda, a la altura de la cintura. De ahí que empezaran a ser conocidos como camellos. Véase: https://www.muyinteresante.es/cultura/arte-cultura/articulo/ipor-que-alos-traficantes-se-les-llama-camellos
} 
se mudó al Estado de México y fue ahí en donde la capturaron las autoridades. Lo que se sabe acerca de su situación es que ella pertenece al fuero federal, pues se le acusa de varios delitos catalogados de "cuello blanco" "78 entre estos algunos fraudes empresariales y lavado de dinero. Durante el trabajo de campo, no se supo cuántos años llevaba habitando en "Santiaguito", la mujer solo comentó en varias ocasiones que ya tenía muchos años ahí e incluso señalaba que allí terminaría sus días.

Las autoridades de este centro nos compartieron que la sentencia de esta mujer es de ochenta años, por lo que, por obvias razones ella ya no aspira a salir en libertad algún día. En las conversaciones con ella, se pudo notar que la mujer a diferencia de las demás mujeres tanto del mismo grupo etario como de las más jóvenes, no muestra desesperación, ni deseos de cambiar su situación. Además, ella menciona que el estar privada de la libertad le ha dado varias lecciones:

Mira, yo ya estoy aquí y me pasó esto por algo. La verdad yo nunca fui una buena persona, le hice daño a muchas personas, nunca tuve humildad y compasión hacia los otros, nunca me nacía ayudar a los demás. Ya ahora que estoy aquí es diferente, trato de compartir lo que tengo con algunas de las mujeres que veo que lo necesitan. Que si tienen hambre, yo preparo y se los regalo, también a los muchachos, muchos no tienen. Entonces yo me apuro en el día para hacerles de comer, ahorita eso es mi preocupación del diario, darles su taco. A "Luna", por ejemplo, luego sí le doy un dinero para que encargue la leche de su bebé, porque luego no tiene y el chamaco qué culpa tiene. Ahora cuando voy a la capilla, le digo a dios que tomo esto como una lección de todo lo que no hice, pues sí, ya para qué lo veo como castigo, mejor doy de lo que tengo... (“Azalia", 2018)

Esta mujer frecuentemente hizo mención de varios de los conflictos que se viven dentro del área femenil de "Santiaguito" y de rumores que le llegaban de sucesos en el área varonil: "Aquí seguido hay problemas, pero también es cosa de allá arriba [de las autoridades], no nos resuelven nada, entonces muchos se hacen justicia por su cuenta. A nosotras lo que nos conviene es estar lo más calmadas posible, distraernos en nuestras cosas y no meternos. Entonces así le hacemos, luego nos juntamos con las chicas en mi celda y ahí nos ponemos

\footnotetext{
78 Delitos de guante blanco o de cuello blanco es el nombre que se les da a aquellos delitos que se realizan sin derramar directamente sangre (por lo que se les llama de guante blanco) aunque suele ser derramada la sangre por sicarios empleados o subordinados. También se denominan "delitos de cuello blanco" debido a que el delito o crímenes realizado por una persona con un estatus socioeconómico alto. Los delitos de cuello blanco más comunes son: el tráfico de influencias, el fraude, el lavado de dinero, el cohecho, el vaciamiento de empresas, la quiebra fraudulenta, la malversación de fondos económicos; la delincuencia organizada. Véase: https://ala.org.es/wp-content/uploads/2016/10/03-Delitos-de-cuello-blanco-2015-CP.pdf
} 
a hacer manualidades como estas [las figuras del taller]" ("Azalia", 2018). La mujer describió a mayor detalle los conflictos y quiénes suelen ser los más involucrados, sin embargo, se describirán más adelante con lo que se destacan varias de las estrategias de sobrevivencia que desarrollan las mujeres de las diferentes condiciones.

Dentro de este recinto la "señora Azalia" se encuentra muy unida con otra mujer del grupo de la tercera edad, quien es el séptimo caso de mujeres mestizas que se presenta en este trabajo. La mujer es apodada "Montes", su edad aproximada es de sesenta y cuatro años, ésta, al igual que "Azalia", no quiso compartir muchos detalles de su vida personal. Esta mujer está acusada por delito de secuestro, tiene ya varios años en el recinto y no tiene pretensiones de salir en libertad. En varias ocasiones mencionó estar muy acostumbrada a la vida de encierro: "esta es mi vida ahora, así que no hay de otra. Unos viven allá afuera, y yo vivo en este residencial, ijajaja!, es como todo, hay que ganarse la vida, no importa en dónde, hay que hacerlo" ("Montes", 2018). Esta mujer suele pasar la mayor parte del tiempo con "Azalia", la ayuda en las actividades que esta última realiza como en la preparación de la comida que entrega a algunos de los internos en condiciones más desfavorables. "Montes" recibe remuneración económica por su colaboración con la otra mujer.

Nuestra actora narra en diferentes ocasiones los conflictos que se generan con mayor frecuencia en el recinto, pero los compara con hechos que ocurren en la vida diaria del exterior. Muchas veces hace referencia de que vivir en la cárcel es como estar en barrios peligrosos, porque en estos también se promueven sucesos como la venta de drogas, peleas y conflictos entre grupos, robos e inseguridad y corrupción. Además, su percepción de las actividades diarias también es cercana a la de afuera, como la venta de los productos diseñados por mujeres. Esta también es algo que ella realiza, crea artículos hechos con estambre y sale los fines de semana a las áreas de visita para intentar comercializarlos. Menciona tener un acuerdo con las custodias, que, a cambio de cierta cantidad de dinero, le permiten salir, pues generalmente ella no recibe visitas de ningún familiar.

Por otra parte, ella también comercializa con los productos que otras mujeres generan y que no suelen salir a vender los fines de semana. La mujer describe los días de visita como fines de semana "normales", en donde la gente convive con sus familias en mercados y tianguis. Dice: "hay puestos de comida, de artesanías, cositas de madera, figuritas. Otras personas 
caminan entre la gente ofreciendo sus productos, mientras otros comen con sus familias en las mesitas. No es muy distinto a lo que tú podrías ver a fuera, solo que aquí ya sabes que estás encerrada..." (“Montes”, 2018). Además, ella señala que el hecho de participar en actividades como estas y pasar tiempo con "Azalia”, la ha hecho que todos la conozcan; hombres y mujeres privados de la libertad, personal penitenciario y hasta familiares de otros internos. Lo cual ella considera algo bueno, porque así se evita ser molestada por las demás, pues considera que brinda mucho apoyo a sus compañeras.

A partir de estos siete casos presentados podemos ir destacando algunas de las maneras como las mujeres van sobreviviendo a la vida de confinamiento. Vemos que, sin duda, la edad sí determina la condición de algunas de estas mujeres, pero en otros casos no es la edad, sino el poder adquisitivo o prestigio y relaciones lo que las posiciona en situaciones de menor desventaja. Hasta aquí, aun no se presentan los casos de las mujeres indígenas que, si bien tienen algunas similitudes a las de las mestizas, también se destacan importantes diferencias, principalmente cuando se trata de los primeros años de reclusión. Esto no significa que en la exposición de los casos de las indígenas vamos a encontrar los peores escenarios, pues cabe destacar que incluso, entre este tipo de mujeres existen muchas diferencias, según factores como el entorno, tiempo de confinamiento, tipo de delito y autodefinición racial. Además de que la influencia del sistema penitenciario muestra claros efectos en la vida de las diferentes mujeres, sean cuales sean las condiciones de éstas.

Así, una vez dicho lo anterior, la primera mujer indígena contemplada en este trabajo es "Nidia", mujer indígena originaria de Pinotepa, Oaxaca. Ella es parte del pueblo mixteco de esta región. Ésta tiene aproximadamente cuarenta y ocho años de edad, es viuda, puesto que su marido falleció dentro del CPRS "Santiaguito" mientras se encontraba cumpliendo su sentencia. Actualmente esta mujer tiene dieciséis años recluida y se encuentra sentenciada a veintidós años de prisión. Sin embargo, desde 2018 se encuentra tramitando lo que se llama la "libertad anticipada", esto es un "beneficio" que las personas privadas de la libertad pueden solicitar cuando les faltan pocos años para terminar de cumplir su condena. Para poder hacer el trámite, es importante que los sujetos cumplan con ciertos requisitos, hayan tenido un buen comportamiento durante los años de confinamiento, además de acumular puntos participando en diversas actividades promovidas en este centro. 
"Nidia" considera que ha cumplido con todo lo solicitado y mantiene la esperanza de recibir una respuesta favorable a su solicitud. La condena que ella está pagando se debió a la acusación del delito de secuestro, el cual, de alguna manera, reconoce haber cometido junto con su difunto esposo. Él es quien participaba en este tipo de transgresión, ya que a esto se dedicaba. Ella tenía conocimiento de la situación, pero nunca denunció y en ocasiones apoyó en algunas cuestiones como preparar alimentos para quienes se encontraban privados de la libertad. Los primeros años de su confinamiento, no los vivió en "Santiaguito", puesto que a ella se le ingresó primero en el CPRS de Ixtlahuaca, Estado de México. En este, pese a que llevaba ya algunos años viviendo en el municipio de Toluca, aun hablaba su lengua materna (mixteco) y solía usar algunas prendas características de su comunidad. Esto, según lo narra, sí le generó conflictos con otras internas:

...cuando llegas a un lugar nuevo, eres desconocida y te miran raro, mira, de arriba abajo [señalando que así la veían], hasta con desprecio. Yo llegué primero al de Ixtlahuaca y no sabía ni qué hacer, no tenía nada, luego te digo que no sabía hacer muchas cosas, peor tantito. No sabes cómo vas a estar, luego ves que todo te quieren cobrar y uno sin dinero, hasta te pones a llorar. Sientes que el mundo se te acaba. No te puedes acercar a nadie, cada quien ve por su bien, qué te van a estar ayudando.

...luego, si te escuchan hablar tu idioma, te hacen burla y te agarran como su juguete, te dicen india y hasta te pegan porque no les sabes contestar. Sí, si no te creas, son malas las personas, pero yo mejor lo que hice fue aprender el español, sí, me metí a la escuela, aunque se reían de mí, pero veme ya aprendí...

...Ya luego te das cuenta que, si trabajas, si le echas ganas, si aprovechas todo lo que dan, ves que no es el fin del mundo, pero si eres floja, si no le buscas, ahí sí se vienen los problemas, hasta problemas con otras. Mejor echarle las ganas... ("Nidia", 2018).

Actualmente ella se encuentra habitando en "Santiaguito" desde hace 6 años, en este recinto las cosas parecen ser distintas porque llegó hablando español y sabiendo leer y escribir, cosas que antes no sabía. Su vestimenta ha cambiado, dejó de usar aquellos elementos que conservaba de su comunidad. Además, desde que se encontraba en el anterior CPRS, ella comenzó a trabajar en conjunto con otra mujer indígena (Matilde), a quien conoció dentro de prisión. A ambas las trasladaron juntas al centro penitenciario de Almoloya de Juárez. De manera conjunta, laboran día a día en su actividad principal que es hacer bolsas bordadas, servilleteros y fundas para almohadas. "Nidia" dice que ese tipo de cosas le causaban pereza cuando se encontraba en su comunidad pese a que es algo que se suele hacer mucho. Por esto, nunca aprendió a hacerlo, ella prefería dedicarse a trabajar fuera de su comunidad como 
empleada doméstica. Cuando se casó, su esposo le pidió dejar de trabajar y tiempo después se fueron a vivir al estado de Toluca, en donde surgió todo el conflicto que la llevó a vivir a su vida en confinamiento.

Según lo que ella menciona el estar en reclusión no le parece que sea algo del todo malo, ya que en su comunidad ella no habría aprendido a leer y a escribir, ni continuaría con sus estudios como actualmente lo hace. Cuando se le preguntó si en estos momentos vive actos de violencia, respondió que no, que se lleva bien con la mayoría de las mujeres, además de que ella se dedica casi todo el día a realizar diversas actividades, por lo que difícilmente tiene tiempo de convivir con las otras mujeres. Sus productos, al igual que en casos anteriores de mestizas, los comercializa principalmente los días de visita. También tiene acuerdos con el personal penitenciario para poder salir del dormitorio once y poder ofertar los artículos producidos.

"Nidia" señala que no le va mal con la venta de sus productos, además de que en ocasiones también prepara tamales oaxaqueños y muchas personas los consumen: “...Yo haría más seguido tamalitos, son los verdaderos, verdaderos oaxaqueños, pero aquí es bien difícil conseguir las cosas. No, si las tienes que encargar antes para que te las consigan y que no te las den tan caras, luego sí se mandan las de la tienda, porque ya ves que no se pueden meter harinas y esas cosas que porque no vayan a ser droga" ("Nidia", 2018). Así, como se mencionó en el apartado anterior, en varios de los testimonios compartidos por estas mujeres, se muestra un poco del dominio que tienen algunas otras mujeres en los productos que se comercializan dentro del CPRS, por lo que, en el caso de esta mujer, en ocasiones se muestra como una limitante para laborar en más actividades.

Para su compañera y socia en la vida de reclusión las cosas se tornan de una manera muy similar, pues como ya se mencionó, trabajan en conjunto casi todo el tiempo. Ambas asisten a la escuela y además a todos los talleres que se imparten dentro del recinto. Es importante decir que las actividades que les llaman más la atención a ambas son aquellos que promueven la creación de empleos y de microempresas, pues las dos mujeres comentaron que planean crear alguna empresa cuando sean puestas en libertad. La compañera de "Nidia", se trata de "Matilde", es una mujer indígena de al menos cuarenta y cinco años de edad, también es proveniente del estado de Oaxaca, de la zona mixteca de Juxtlahuaca. Ella también hablaba 
mixteco y fue trasladada del CPRS Ixtlahuaca a "Santiaguito". Esta mujer tiene veinte años recluida, está acusada del delito de secuestro y sentenciada a cuarenta y dos años de prisión. "Matilde" reconoce haber participado en el delito, al igual que "Nidia", lo hizo apoyando a su pareja con quien vivía desde algunos años en el estado de Toluca. Dice que terminó su relación con este individuo cuando fueron recluidos en Ixtlahuaca, por lo que actualmente ya no sabe nada de él. La vida en reclusión para ella sí representó un problema al principio, puesto que platica haber vivido situaciones de violencia por parte de otras internas. Fue golpeada algunas ocasiones y enfrentaba constantes burlas por su lengua materna. Esta mujer también decidió estudiar dentro de prisión para aprender a leer, escribir y hablar español. Incluso, algo que llama mucho la atención de sus testimonios es que ella considera que ya no es indígena por todo lo que ha aprendido dentro de prisión:

...Ya no soy como antes porque ahora sé más cosas y me valgo por mí. Pero hay que trabajar mucho... ya tampoco hay quien me moleste, como te digo, todo el día estoy ocupada, luego yo ya no hago las cosas que hacía antes, yo ya dejé de ser indígena. Ahora yo ya soy como las demás, yo hablo el español bien... Sí les platico [a las demás internas] luego que yo sé hablar mixteco, pero luego no me creen, ya cuando les enseño se ríen y ya. Te digo, yo sí he aprovechado todo, ahí vamos viviendo ("Matilde", 2018).

Al parecer, para esta mujer la situación no se torna del todo mala, pues al igual que en el caso anterior, considera haber recibido beneficios estando en reclusión. Si bien, esto se puede justificar desde el hecho de que después de muchos años de vivir en este centro penitenciario, ya poseen una mejor adaptación. En ambos casos, cabe señalar que no se encuentran del todo olvidadas por sus familias, pues, aunque no reciben visitas semanales, sí las tienen una vez cada mes. Esto, se podría decir, representa un impacto positivo en sus vidas, siendo que en diferentes ocasiones hablan de planes a futuro de que en conjunto puedan crear su propia empresa y mejorar la calidad de vida de ellas y sus familias.

Ambas son madres, "Nidia" incluso, tiene nietos, con los cuales dice hablar vía telefónica en varias ocasiones y considera que con todo lo aprendido durante el confinamiento, ella también puede compartirles conocimientos a los niños. Esta mujer tiene cinco hijos, uno de treinta y cuatro, otro de treinta y dos, de treinta y uno, veintinueve años y la más pequeña de catorce años. Ésta última, cabe señalar, fue concebida y nacida dentro del CPRS, pero no pasó su infancia en el confinamiento, puesto que la familia de la mujer se la llevaron a las 
pocas semanas de haber nacido. Por otro lado, "Matilde" tiene solo dos hijos; uno de diecinueve y otro de doce años. Ambos viven con los padres y familiares de la mujer, pues señala que sus padres siempre le han brindado apoyo pese a la situación que está enfrentando.

Estos dos casos llaman mucho la atención, puesto que el panorama, a diferencia de algunos de los anteriores no parece ser del todo malo. Las estrategias que estas mujeres han desarrollado, les han funcionado, aun cuando se destaca el desprendimiento que tienen de gran parte de lo interiorizado desde su proceso de socialización primaria. Si bien, el esfuerzo que ellas han realizado para sobresalir dentro del CPRS ha sido bastante, pero su percepción de cómo funciona el sistema penitenciario para ellas es algo positivo aun cuando sí notan muchas de las deficiencias de este, pero destacan que hay aspectos que son buenos mientras se les aproveche. Además de que, su manera de trabajo conjunta y su identificación entre ellas por sus orígenes, ha sido favorable dentro de este recinto.

Si comparamos las situaciones de ambas mujeres con los siete previos, vemos que el enlace de sus condiciones de género, raza y clase sí ha tenido un impactado muy notable, pero de una manera que podríamos decir que ha sido favorable. Puesto que, a partir de sus intersecciones, es que han desarrollado estrategias de sobrevivencia, en su mayoría, distintas a las de las mestizas. Sin embargo, no podemos dejar de lado que las edades de estas dos mujeres, también tienen mucho que ver para que logren evadir ciertas actitudes de violencia y vulneración dentro de la institución. Además de que, en sus casos, las autoridades sí contaron con traductores que hablaran mixteco, lo que favoreció hasta cierto grado el seguimiento y entendimiento de sus procesos, aun cuando éstos duraron siete años para el caso de "Nidia" y tres años para el de "Matilde".

Ante esto, hay que resaltar que sí son muchas las diferencias que podemos encontrar dentro toda de la diversidad de mujeres que habitan en "Santiaguito", y como se ha dicho en varias ocasiones, la vida no es igual para ninguna de las que habitan en este centro penitenciario. Puesto que, en todos los casos aun cuando encontramos muchas similitudes en las condiciones de las mujeres, existen aspectos específicos que hacen que sus situaciones se tornen de manera distinta. Además de que, a partir de algunas de las características de las mujeres, las autoridades actúan de manera distinta. Por ejemplo, entre los casos de mujeres indígenas, podemos ver que las situaciones se pueden presentar muy distintas aun cuando se 
comparte la condición racial, de clase y de género. Es por esto que presentamos el último de nuestros diez casos, del cual se destacan elementos importantes de los cuales se constituye esta investigación.

Inicialmente, cabe decir que este último caso es muy significativo para esta investigación, pues fue por el cual se despertó el deseo por hacer trabajo de campo en el Centro Penitenciario y de Reinserción Social “Santiaguito” en Almoloya de Juárez. Así, el nombre real de la mujer indígena es Dominga González ${ }^{79}$ quien vivió una polémica situación, se trató de seis indígenas nahuas de la comunidad de San Pedro Tlanixco, del municipio de Tenango del Valle, Estado de México a quienes se les privó de la libertad en este CPRS. De este grupo de personas cinco son hombres y solo una mujer. Fueron acusados de secuestrar, torturar y asesinar a un empresario español, quien presuntamente, pretendía apropiarse de las reservas de agua del poblado de donde son originarios, lugar en donde se tiene un fuerte arraigo por sus tradiciones, costumbres y sobre todo un enorme respeto por la naturaleza.

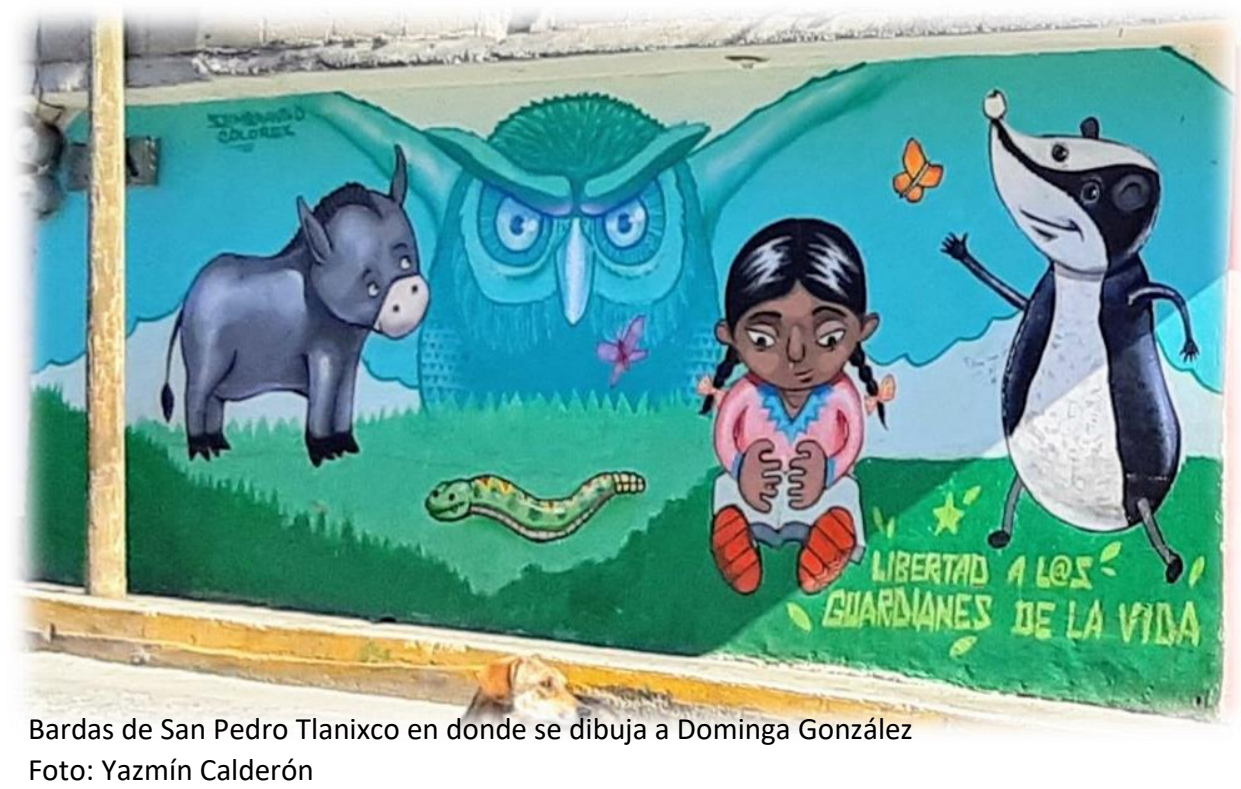

La detención de la mujer fue violenta y arbitraria tres años después del fallecimiento del empresario. El proceso de la mujer duró mucho más tiempo que el de todas las expuestas antes (mestizas e indígenas), puesto que pasaron diez años hasta que recibió una sentencia de

\footnotetext{
${ }^{79}$ Se usa su nombre real, ya que se le entrevistó fuera del recinto carcelario y ella dio autorización de mencionar su nombre.
} 
cincuenta años de prisión. Al momento de su aprehensión, ella se encontraba convaleciente de una cirugía en los ovarios, por lo que no estaba en óptimas condiciones. El momento de su detención, según lo comparten sus familiares y ella, fue uno de los peores que han vivido a lo largo de sus vidas:

[Fue] bien fea, bien fea, porque, yo me dormía en este lugar [se refiere al cuarto en el que estábamos en ese momento. Ahora lo utilizan como cocina]. los treinta y cinco coches de judiciales que vinieron, porque eran treinta y cinco coches que vinieron, de judiciales y venían así [haciendo señas de que eran muchos], pero muchisisísimos judiciales que venían en los coches, se volaron la casa, la barda...

...[No presentaron orden de detención], no más se brincaron, se brincaron. No quisieron presentar nada. Entonces, estee, me, estee, venían todos encapuchados y... y yo la verdad, estee. Cuando a mí me sacan, dice mi cuñada, porque ps a mí no me dejaron voltear para ver, dice que mi mamá, estee, se quiso salir y que la agredieron muy feo, muy feo [comenzó a llorar]... y ps, la verdad es muy triste, pagar un delito que no cometimos [se quedó callada] (Dominga González, 2019).

Además, describe agresiones físicas a la hora de que las autoridades comenzaron a recaudar sus testimonios y declaraciones:

...me pasaron allá en Toluca en un cuarto muy feo, muy feo. Era de adobe, yo sé que era de abobe, porque se veía todo bien viejo. Y ahí decían que si yo no decía dónde estaba Rey Pérez, dónde estaba Alejandro (otros de los implicados), que me iban a violar... Entonces entraba uno, y entraba otro, todos encapuchados. Entraba uno y entraba otro, y ps yo la verdad me daba miedo, porque... yo le pedía mucho a Dios que no me pegaran, que porque, estee, porque yo no tenía mucho que me habían operado... (Dominga González, 2019)

El área que la mujer describe es conocido por el personal penitenciario como las "catacumbas", y se encuentra en una zona que funciona como túnel, el cual conecta el recinto carcelario con los juzgados de este mismo. Según las autoridades, durante el trabajo de campo, explicaron que en este lugar ya no se lleva a los internos para nada desde hace aproximadamente unos 15 años, solo se usa como vía para ingresar al área de juzgados sin tener que pasear a los implicados por fuera del recinto. Mediante lo expuesto por Dominga, se sabe que en realidad hasta hace al menos once años aún seguía en funcionamiento esta parte de las instalaciones del CPRS. Con lo que, podemos destacar el contraste entre lo que dicen las autoridades y lo que se practica en algunos casos.

Por otro lado, también se sabe que una vez que la mujer fue confinada, se le ubicó en el área de castigo de "Santiaguito" (dormitorio cinco). Allí vivió once años, compartiendo el espacio 
con una población de mujeres muy pequeña. La mujer describe con pena la situación que vivió en este dormitorio, pues en varias ocasiones fue agredida físicamente por otras internas. Además, señala que ella no solía salir de su celda de manera que intentaba pasar desapercibida de sus agresoras. Para lograr sobrellevar esta situación, familiares de Dominga decidieron comprar seguridad y protección para ella, pagándole a una de las mujeres que parecía tener una posición de dominio ante las demás.

Así, la gente de Tlanixco, juntaba dinero para poder cubrir este gasto y para poderle llevar algo en efectivo semanalmente. También se le entregaban artículos de higiene personal, por lo que durante sus años en reclusión no laboró dentro de la institución con la finalidad de generar recursos económicos extraordinarios por su propia cuenta. Sin embargo, sí se dedicaba a actividades como el bordado de productos de tela. Ella a diferencia de las internas del dormitorio once, no comercializaba directamente sus productos dentro de "Santiaguito, sino que cada semana que recibía la visita de sus familiares se los entregaba para que éstos los pudieran vender en su comunidad o en los pueblos de los alrededores y el dinero recaudado se utilizaba para seguir buscando la libertad y exoneración de esta mujer y de los cinco hombres también implicados.

Por otro lado, Dominga no sabe leer ni escribir, pero tampoco habla alguna lengua indígena, sino que se comunica en español, lo cual, si lo contrastamos con lo expuesto líneas arriba, es uno de los principales elementos con los que las autoridades determinan si un individuo es o no indígena y es desde esta determinación que se les da una atención "personalizada" o diferenciada a la de las personas mestizas. Es así que, en el caso específico de Dominga, durante todo el proceso se le negaron muchas de las garantías que deberían de ser otorgadas. Ella asegura y defiende ser indígena, lo hace con orgullo y por autodeterminación:

...yo soy indígena nahua... ya no hablamos eso [nahua], porque nos discriminaban los maestros por hablar nahua, nuestro idioma. Entonces, para los que éramos jóvenes se fue quitando todo eso en la comunidad, porque lo veían malo los de juera. Y ps yo, yo todavía tengo una hermana que sí habla todavía, pero yo ya no me tocó, pero aquí la mayoría somos indígenas. Yo sí soy indígena y yo se los decía porque mis abuelos, mis papás y todos somos indígenas nahuas y sabemos que eso somos... (Dominga González, 2019).

En este caso podemos ver cómo se enmarcan importantes diferencias si hacemos una comparación solo entre los tres casos de indígenas. Mientras que "Nidia" y "Matilde" hablan 
de una importante integración y participación a las actividades del recinto, Dominga estuvo excluida en todo momento de estas. Además, las primeras dos mujeres pese a haber enfrentado en algún momento situaciones de violencia, esto no ha perdurado, puesto que, se podría decir que al tener una alianza entre ellas ha hecho que queden fuera de varios actos de vulneración. Mientras que González tuvo que pagar por algo de seguridad y no tuvo la oportunidad de cambiar su vida de manera "positiva" al estar dentro del CPRS como lo mencionan las otras dos indígenas.

Es importante destacar en la diferenciación de estos tres casos que, mientras Dominga defiende con fuerza sus orígenes nahuas y su condición indígena, "Matilde" y "Nidia", incluso, dicen haber dejado de serlo por el solo hecho de que han dejado atrás muchos de los elementos propios de sus comunidades. Estas notables diferencias, podemos ver que se comienzan a permear desde los estándares calificativos con los que las autoridades categorizan a las poblaciones femeniles. Además, desde los procesamientos comienzan a notarse muchos de los sesgos que conforman a los sistemas penitenciarios hacia mujeres de diferentes tipos, tal como se expuso en el apartado 3.2 de este trabajo.

Hay casos en los que se dejan fuera componentes importantes en la definición y atención de los casos, lo que lleva a un desconocimiento de la manera precisa y justa para dar atención a situaciones en las que son muchos y diversos los cruces de las condiciones de las mujeres imputadas. En el caso de Dominga en cada audiencia las autoridades negaban su procedencia indígena, destacando solo algunas de sus condiciones, tales como su bajo nivel escolar y su condición de mujer: "usted no es indígena, lo que es usted es ignorante porque no sabe leer y escribir, pero eso no la hace indígena. Usted entiende muy bien el español...” (Dominga González, 2019).

Intentando hacer un contraste de este caso con el de las siete mestizas, también podemos encontrar que la influencia de la condición de raza, clase social y nivel escolar ha tenido un impacto mayor que en el caso de las mujeres más jóvenes o de aquellas que tienen un mayor poder adquisitivo. Sin embargo, otras mujeres de mayor edad como "Bianca", también fue puesta en altos niveles de vulneración por su condición etaria. En este caso, al igual que en el de Dominga, esta mujer contaba con apoyo externo por parte de sus familiares, lo que no la libró de muchas de las situaciones que estaba viviendo dentro de reclusión. En ambos casos 
y para el resto de las internas y autoridades, podemos decir que la relación de todas sus condiciones las colocó en niveles de mucho mayor vulneración que las de otras mujeres.

Es así que, continuando con el caso de Dominga, se pueden destacar otros elementos como la limitante en el acceso a ciertas actividades y servicios que ya se ha mencionado antes. Por ejemplo, cuando se impartió el Taller de figuras con materiales reciclados, a ella no se le integró. Según las autoridades, porque ella era una mujer violenta y conflictiva. Por otro lado, esta mujer hace mención de que tampoco se le daba atención médica cuando lo requería, pocas veces le concedían las solicitudes para ser llevada a servicios médicos. Podemos decir que, de por sí ya es difícil el acceso a ciertos servicios para las internas del dormitorio once, para quienes habitan el cinco es aún más limitado.

Con referencia a esto, en alguna ocasión, una de nuestras informantes clave de la dirección interna de "Santiaguito", mencionó que las mujeres que se encontraban en el área de castigo, no solían tener participación en la mayoría de las actividades, pues estas solo se imparten en mayor medida en el dormitorio "normal". En el caso de la última mujer indígena todos estos elementos muestran un impacto distinto al de las dos anteriores, viendo que el contexto de cada una de estas es distinto desde la manera como son vistas en sus entornos y de esto ha dependido el nivel de acceso de unas y de otras. Lo que también es muy claro en el caso de las mujeres mestizas en donde no es la raza desde donde se les vulnera, sino que más bien, son algunas otras de sus condiciones las que representan un mayor peso y determinan que estas sean puestas en posiciones en donde los medios que desarrollan para sobrellevar las situaciones de su día a día son muy distintos unos de otros.

Todo lo expuesto hasta aquí sobre las diez participantes que se consideran en este comparativo de casos, solo es una parte de lo que nos compartieron, se trata de los aspectos más generales de las actoras y mayormente vinculados a lo que es el imaginario de un sistema penitenciario "moderno" y parte del efecto que perciben las mujeres hacinadas en este centro. No obstante, en el siguiente apartado, se profundizan un poco más sus testimonios, destacando que desde el impacto que tienen este sistema, el entorno de privación de la libertad y del exterior en la vida de cada una de las mujeres, tiene como resultado según la intersección de sus distintas condiciones el desarrollo de las diferentes estrategias de sobrevivencia específicas y acordes para cada caso con lo que éstas viven su confinamiento. 


\subsection{Producto de una múltiple opresión en el área femenil de "Santiaguito": comparativo de casos y estrategias de sobrevivencia de mujeres indígenas y mestizas}

En el apartado previo, se expusieron de una manera un poco general los diez casos de mujeres privadas de su libertad con los que se realiza el análisis central de este trabajo. Se trata de siete mestizas (de las que se desprenden subgrupos) y tres indígenas. Además, se destacó parte del impacto e influencia que tiene el sistema penitenciario en varios aspectos de la vida de las mujeres, considerando momentos de sus aprehensiones, procesamientos y

confinamiento. Con lo expuesto fueron bastante evidentes muchas de las diferencias y desigualdades que se generan a partir de las condiciones de género, raza, clase social y edad de cada una de las mujeres. Varias de éstas comparten algunas características como el hecho de ser mujeres, delincuentes, madres y pertenecer a la misma clase social.

Sin embargo, estos elementos no se presentan solos, sino que en cada caso de mujeres se entrecruzan con otras condiciones. Lo que genera que sus circunstancias de vida sean muy distintas unas de otras. A algunas se les ha colocado en lugares de mayor vulneración que de otras. Además, son algunos casos específicamente en los que se notan mayores alteraciones en sus procesos de socialización, puesto que hay quienes han sido más alejados de lo interiorizado durante sus etapas de vida, mientras que otras conservan la mayor parte de lo socializado. Es a partir de todas estas intervenciones y las distintas características de las diez mujeres privadas de su libertad cuando éstas desarrollan los mecanismos de sobrevivencia que nos interesa documentar en este trabajo.

Recapitulando con lo visto en el apartado 1.2, podemos entender a las estrategias de sobrevivencia como acciones con las que se persigue un beneficio individual, pero para lograrlo el individuo puede apoyarse de otros sujetos. Para ser sobreviviente, la relación con los otros no siempre será de colaboración conjunta, sino que se puede tratar de actividades en las que se orille a los otros a actuar en bien de lo que se desea lograr. Son diversas las estrategias que las personas pueden llegar desarrollar según sus contextos, entornos, necesidades y características. En lo general, es importante señalar que este concepto suele ser utilizado más comúnmente es estudios de la economía campesina y casi siempre hace mayor referencia a aspectos que se relacionan con la generación de un aumento de recursos 
económicos o bienes. Sin embargo, hay que recalcar que en realidad se les pueden dar muchas otras connotaciones si las miramos desde otras perspectivas como desde la social.

En este trabajo las estrategias de sobrevivencia que se van a documentar y comparar son las que se generan dentro del Centro Penitenciario y de Reinserción Social "Santiaguito" por las diez mujeres que conforman nuestro estudio de caso, tomando en cuenta que estos mecanismos son el resultado de lo que cada una de las actoras ha vivido desde sus diversas condiciones sociales. Los principales tipos de estrategias de sobrevivencia que se destacan en esta investigación son: el uso de la fuerza física, la imposición de temor, el uso de carisma, convencimiento y persuasión no violentos, el camuflaje, unión y apoyo grupal, y las de índole económicas. Cabe señalar que cada una de las participantes no desarrolla solo un tipo de estrategias, sino que para sobrevivir pueden llegar a depender de varias de estas.

Así, podemos comenzar con uno de los principales medios para sobrevivir en confinamiento que se destacó en varias de las narrativas de las diez mujeres, se trata de la conformación de grupos y trabajo en conjunto. Si bien, no todas las mujeres prefieren unir su trabajo y tiempo con otras internas, se pudo ver que en el caso de las mujeres del grupo de la tercera edad es algo común y que aparentemente les trae resultados positivos. En los casos de "Azalia” y "Montes", ambas mujeres mestizas del mismo grupo etario, quien recibe un mayor beneficio con este tipo de unión, indudablemente es "Montes", pues al ser de una clase social baja, con prácticamente nulas visitas familiares e interacción con factores del exterior, es por medio del poder adquisitivo de la primera mujer, que esta otra logra mejorar su calidad de vida dentro de "Santiaguito".

Por ejemplo, en aspectos no solo económicos, si hacemos referencia a una de las principales deficiencias del sistema penitenciario mexicano como es la calidad alimentaria, "Montes" sí consume lo otorgado por la institución, pero cuando esto no es de su agrado, ella se alimenta de lo que prepara junto con la señora "Azalia" e incluso cuenta con recursos que le permiten satisfacer algunos de sus gustos:

...Han estado pasando cosas, hay problemas con los de arriba, además de los atrasos de los pagos a las mujeres que trabajan aquí, los servicios han sido muy malos, la comida muy mala y prohibiciones de todo en el área varonil, allá con los chicos. Nos han estado dando casi puro huevo, hasta como crudo, aguado, aguado, yo así no me lo trago. Nosotras (señalando a 
“Azalia") nos hacemos algo y ya le invitamos, aunque sea un taquito a las chicas. No, si hasta parece que le están dando de comer a los perros... ("Montes", 2018).

Si bien, muchas de las mujeres que no tienen relación con internas con mejores posiciones económicas y que se encuentran en situaciones más desfavorables, en cuanto a la cuestión alimentaria no tienen otra opción más que consumir la comida que se prepara por parte de la institución, así sea muy mala. Sin embargo, como podemos percibir con el testimonio anterior, varias de las mujeres consideradas en este estudio de caso, se han vinculado con la señora "Azalia", recibiendo también algún tipo de apoyo o beneficio que les favorece para sobrevivir en "Santiaguito".

Sin embargo, no solo las mujeres de la tercera edad son cercanas a "Azalia", sino que, si recordamos algo de lo expuesto en el apartado previo, "Luna" que es una mujer joven, madre de un pequeño niño, suele recibir dinero o productos para su hijo por parte de la mujer de la tercera edad. Por esta situación, "Luna" prefiere estar alejada de las que son de su mismo grupo etario y convivir más con las que son mayores. Se podría decir en este caso que la convivencia con las mujeres de la tercera edad, principalmente con "Azalia" es una doble estrategia de sobrevivencia. Por un lado, recibe beneficios materiales de vez en cuando y por otro, es una manera de evitar los conflictos que según lo mencionaron varias de las participantes, surgen principalmente de la población más joven.

Otros casos en los que una de las principales estrategias de sobrevivencia es la conformación de vínculos o grupos es en los de las dos mujeres indígenas procedentes del estado de Oaxaca: "Matilde" y "Nidia". Éstas, como se describió líneas arriba, desde que se conocieron en el CPRS de Ixtlahuaca comenzaron a trabajar en conjunto y a participar en la mayor cantidad posible de talleres y actividades, tales como el asistir a la escuela, pues ambas se han propuesto metas conjuntas sobre la creación de alguna empresa que las favorezca económicamente a ellas mismas y en donde puedan integrar a otras mujeres de sus familias o de sus comunidades de origen. Estos deseos, parten del hecho de que en sus primeros años de reclusión vivieron momentos de violencia y humillaciones debido a que no sabían hablar español, no sabían leer y escribir y solo podían comunicarse en mixteco.

En referencia a esto "Nidia" comentó que: "se siente bien feo que se burlen de ti o que te quieran pegar porque te ven diferente... no te creas, eso no no más pasa en estos lugares. 
Luego cuando sales a la calle sí te gritan cosas por cómo te vistes, porque te ven pobre. Entonces si yo le enseño a las demás a ser diferentes, ya no les va a volver a pasar que las maltraten" ("Nidia", 2018). Si bien, en estos casos vemos que las estrategias de estas mujeres indígenas son pensadas no solo para la sobrevivencia y subsistencia dentro de prisión, sino que hablan de resultados a futuro y en conjunto con sus comunidades. Para estas mujeres, la unión que han forjado durante todos los años que llevan recluidas, además, las ha ayudado a “dejar de ser indígenas" y consideran que eso debe de ser promovido en sus pueblos.

Es así que, este “dejar de ser indígena”, es algo que llama mucho la atención dentro de esta investigación, puesto que, si lo vemos desde un sentido de autodefinición, éstas sí estarían soltando el estereotipo de ser mujer indígena por decisión propia, aun cuando fue el entorno el que las motivó a separarse de la mayor parte de los rasgos característicos de sus comunidades. No obstante, dentro del sistema penitenciario las dos mujeres siguen siendo catalogadas de esta manera. Incluso, una de nuestras informantes clave del personal penitenciario de este centro, mostró que en su oficina mantiene anclada en una de sus paredes una lista en la que aparecen los nombres de cada uno de los internos (hombres y mujeres) señalados como indígenas desde los rubros de caracterización que se explicaron antes.

La misma informante, hizo referencia de que estas mujeres al ser indígenas, son de las personas que se esfuerzan y trabajan más. Señaló que, por lo general, las poblaciones mestizas suelen ser más flojas y conformistas (“Anónima”, 2018). Es por esto que el hecho de ver la fuerte unión de estas mujeres también las ha favorecido ante las autoridades del recinto, logrando ser reconocidas y cuando éstas tienen alguna petición dentro del recinto, que no dependa de las autoridades generales del sistema penitenciario del Estado de México, suelen tener apoyo y facilidades.

Cuando el taller se comenzó a impartir, nuestra informante clave dentro de la Dirección interna del CPRS, mencionó con mucho agrado que las dos mujeres son muy accesibles siempre a la hora de participar en actividades. Así, también podemos destacar que, en estos casos, además de estrategias de sobrevivencia de trabajo en conjunto, las mujeres hacen uso de su carisma para no ser subordinas por el resto. No obstante, comparando estos casos con el de la otra mujer indígena que pasó sus días en el dormitorio cinco (área femenil de castigo), vemos que ella no tuvo posibilidades de generar un lazo con otras internas, sino que enfrentó 
su situación dentro del recinto ella sola, aun cuando ésta no tuvo las mismas oportunidades, cabe resaltar que, a diferencia de las otras dos mujeres, Dominga tuvo un mayor apoyo del exterior.

Hasta aquí, podemos ver que es claro el contraste que hay entre los casos de indígenas, entendiendo que en los tres, el sistema penitenciario ha impactado de manera muy fuerte en la vida de las mujeres, podemos decir que "Nidia" y "Matilde" presentan mayores cambios en sus procesos de socialización. Si bien, no podemos respaldar la propuesta de un proceso de resocialización o socialización terciaria (véase apartado 1.1.3 de este trabajo), sí podemos decir que el separarse de sus usos y costumbres, y adaptarse a lo "propio" de su entorno, representa otra de los tipos de estrategias de sobrevivencia más notables en esta investigación: "el camuflaje". Pero en estos casos no hablamos de un ocultamiento, sino del encubrimiento de los elementos que componen su condición indígena, adaptándose a su entorno urbano y mestizo.

Por otro lado, comparando esto con el caso de Dominga González, vemos en ella que una de sus estrategias para sobrevivir, también es la del "camuflaje", pero en su caso, su intención sí era pasar desapercibida del resto. Por esto, ella prefería no salir de su celda con frecuencia, mientras menos la notaran las demás, no estaría siendo expuesta a actos de abuso y de violencia. En este caso, la mujer no intentó soltar su identidad indígena, sino que en todo momento decidió mostrar orgullo por sus orígenes:

...como yo no me metía con nadie. Yo ni convivía con las internas, ni con nadie. Yo siempre era sola, sola, y pues solamente la señora que, estee, yo no sabía que mi hermano le pagaba cada ocho días para que ella me cuidara, porque, si yo iba a lavar, estee, comenzaban a decirme de cosas... Yo agarraba, no más salía a lavar, la señora me cuidaba mientras. Terminaba, yo me metía y ya agarraba y estee, me metía a la celda y ya no salía en todo el día. Casi todos los días yo me la pasaba en la celda (Dominga González, 2019).

Mientras las dos primeras indígenas pasan la mayor parte de sus días ocupadas en actividades fuera de sus celdas, Dominga prefería no salir. En estos casos, vemos, además que, pese a que las tres mujeres se encontraban en el mismo recinto, sus entornos no fueron los mismos y por lo tanto sus oportunidades de acceso tampoco eran compatibles. Mientras que para unas el encierro se ve como una oportunidad de crecimiento y como un medio para "dejar de ser indígena", la otra lo consideró lo peor que le pudo haber sucedido. 
En los casos de "Matilde" y "Nidia, las autoridades brindan una atención más solidaria, mientras que, en el caso de Dominga, era el mismo personal penitenciario el que promovía actitudes de violencia: “. ..todos eran malos, las custodias eran bien malas... un día que, estee, una custodia me castigó, quince días tenía yo que barrer diario. Quince días yo a las siete de la mañana ya tenía que estar con la escoba barriendo, sino, llegaba y me amenazaba" (Dominga González, 2019). Podemos ver hasta aquí, con lo expuesto sobre estos cinco casos (dos mestizas y tres indígenas), que son evidentes que las diferencias que se promueven en el recinto no solo son entre la división del entorno por género, sino que, entre las áreas de mujeres hay condiciones desiguales que no pueden ser enfrentadas de la misma forma.

Vemos entonces que las estrategias de sobrevivencia como las expuestas, que implican la agrupación o unión con otros, parece que en este recinto son medios con los que se obtienen resultados favorables si se le vincula además con algún otro tipo de estrategias que derivadas según las condiciones de cada una de las mujeres. Por ejemplo, volviendo al caso de "Luna", además de tener un vínculo con las mujeres mayores, decidió tener una relación afectiva con un individuo del área varonil, quien es el padre de su pequeño hijo. La mujer menciona que el hecho de tener una pareja sentimental la aleja de actitudes de violencia y subordinación por parte de otras internas. Además de que, para ella, su pareja es su equipo para juntos ganarse la vida, es decir, para generar recursos económicos con los cuales poder subsistir día a día:

Yo tengo pareja aquí, entre los dos nos apoyamos, aunque nos vemos poco, luego es difícil, no te dejan salir a la visita, pero cuando sí se puede, nos vemos. Juntamos nuestro dinero y como sea así ya es más fácil salir adelante, luego él tiene más, luego tiene menos o yo... está difícil, pero así salimos... Como las demás saben que tengo mi esposo pues también ya no se meten conmigo porque saben que yo le puedo avisar y se armarían los problemas, entonces mejor ya ni se meten conmigo... ("Luna", 2018).

Desde la connotación de protección y seguridad de la idea de tener pareja dentro de prisión, esta mujer destaca lo funcionales que resultan las alianzas dentro del CPRS. Puesto que al ser una persona que no recibe visitas frecuentes, que no percibe ningún recurso del exterior e incluso ha sido olvidada y rechazada por sus familiares, ella ha constituido a través de la unión con otros una nueva familia, una nueva vida. Para "Luna", aun cuando conserva el deseo de salir en libertad, considera que el encierro en el que se encuentra no es del todo malo por estas razones "si yo estuviera afuera, no tendría a mi bebé y él es mi todo. Ni sé qué 
voy a hacer cuando ya no me lo dejen tener aquí...” (“Luna”, 2018). Es así que, en este caso podemos destacar que al ser ésta una mujer joven, mestiza, privada de la libertad y pobre, su principal medio de sobrevivencia es la unión, pero también podríamos destacar que al igual que otras de las mujeres, emplea lo que aquí le denominamos "camuflaje”.

La idea que se quiere dar con este término es que, con este tipo de estrategias de sobrevivencia, las mujeres pretenden pasar desapercibidas del resto de las internas para evitar el conflicto. Lo que, podemos decir, es otro de los mecanismos más comunes empleados por las mujeres privadas de su libertad. Sin embargo, en este trabajo, este medio, lo encontramos como prioritario en dos casos principalmente, uno es el de "Bianca", mujer mestiza de la tercera edad con poco tiempo de haber sido confinada y el segundo es el que ya expuso líneas arriba, el de Dominga González, mujer indígena nahua. En el apartado previo se destacó que en estas dos mujeres se percibe una mayor vulneración, violencia y exclusión. Una principalmente por su condición etaria y la otra por el hecho de ser indígena. Ambas, aunque en diferente grado, pasaron por procesos muy violentos y durante su encierro en diferentes ocasiones fueron agredidas por otras internas, lo que inicialmente las llevó a evadir el conflicto, ocultándose o tratando de no hacerse notar.

Otras de las mujeres que también hicieron referencia a actuar de manera desapercibida en ciertas ocasiones, fueron "Daniela" y "Elisa". Si recordamos lo expuesto en el capítulo anterior, estas dos mujeres son mestizas, jóvenes y madres de familia. La primera, tiene un mayor apoyo y atención familiar, mientras que la segunda por cuestiones económicas, se ha visto abandonada por sus padres. Las dos mujeres, a diferencia de las anteriores, no suelen estar unidas con otras con el fin de sobrevivir. Si bien, procuran tener una buena relación con las demás, no trabajan en equipo con nadie. Sin embargo, ellas mencionaron haber presenciado circunstancias ilegales dentro del recinto y en sus celdas. Ante esto, "Daniela" dijo: "Sí, yo lo que hago es ponerme a hacer cosas, aprovechar lo que nos dan, mantenerme ocupada y si veo algo, hago como que no lo veo. Ya luego también te vas dando cuenta con quiénes puedes convivir y con quiénes no, pero es mejor sola. Aquí todos estamos solos ("Daniela, 2018).

Por su parte, "Elisa” aconseja brevemente: "Dicen aquí: "Ver, oír y callar", eso es lo primero que aprendes aquí y si lo haces, no te pasa nada, es lo que yo hago ahora...” (“Elisa”, 2018). 
Estas mujeres más que ocultarse como en el caso de "Bianca" y de Dominga, no tratan de ocultarse, pero sin de ser discretas y guardar silencio ante las situaciones. Sin embargo, "Daniela" dice que cuando esto no funciona y alguien intenta agredirla, entonces ella responde con violencia para calmar las situaciones, según uno de sus testimonios mostrado en el apartado anterior: "aquí, desde que llegas te vas dando cuenta de que te van a querer agarrar de su pendeja, y sí pasa, si te dejas, pero si les contestas y te les enfrentas te dejan en paz un rato. Muchas veces es mejor ponerse a hacer algo, así ya no te ven en todo el día” (“Daniela", 2018).

En el caso de "Luna", pese a que procura mantenerse alejada de los conflictos y de quienes los generan, mencionó que hay ocasiones en las que otras mujeres se acercan a ella para generar algún tipo de conflicto, la respuesta que tiene ante estas situaciones es por el mismo medio de violencia que se exprese hacia su persona. Señaló que ella no se deja maltratar, que considera que debe defenderse y defender a su bebé, si es necesario, porque en ese momento su pareja no encuentra con ellos para protegerlos "Luna", 2018). Es por esto que se destaca otra de las principales estrategias de sobrevivencia propuestas en este trabajo, la del uso de la fuerza física.

Aun cuando se piensa que las peleas y agresiones provienen en mayor medida de la población mestiza joven, podemos decir que no siempre es así. Ejemplo de esto es lo que narró la señora "Lucrecia", quien ha tenido algunos problemas con "Azalia": "Son canijas, pero yo trato de no seguirles la corriente, no más sí nos hemos hecho de palabras como con ella [señaló a la señora Azalia], pero ya estamos viejas y mejor nos calmamos, no nos han tenido que separar o llevar a ningún lado" ("Lucrecia”, 2018). Esta mujer indicó que frecuentemente tiene algún tipo de discusión con alguna mujer, puesto que muchas veces suele recibir un trato grosero cuando ella tiene algún tipo de acercamiento con ellas. Esta mujer, al igual que "Daniela" y "Elisa", no suele vincular y colaborar con nadie.

En relación con los conflictos, cabe mencionar que la repuesta de las autoridades ante dichas situaciones de peleas es la aplicación de un programa denominado "mediación penitenciaria". Se lleva a los o las implicadas a un edificio que se encuentra cercano al área de visitas. Además, se invita a uno o dos de los posibles testigos del conflicto para que actúe como “mediador". Hace que ambos expongan su versión del conflicto y posibles soluciones a este. 
La idea es que en ese momento conversen sobre lo que ocurrió y traten de resolverlo de manera "civilizada". Para autoridades de la DGRS esto es algo muy interesante que aleja de más violencia a los sujetos.

No obstante, aunque la propuesta suene como algo muy apropiado, algunas mujeres del área femenil once mencionaron que era algo gracioso para ellas porque al final no resolvían nada. Los involucrados aparentaban llegar a un punto de acuerdo, pero en otros momentos, se buscaba la solución al conflicto desde la violencia física y verbal. Podemos ver que, aunque las autoridades muestran medios que son parte de un imaginario de técnicas funcionales que pretenden disminuir los actos de violencia, no siempre son efectivos, pues las aplicaciones son limitadas. Es por razones como estas que las internas e internos terminan desarrollando sus propios mecanismos de defensa ante las situaciones de peligro que se les presentan. Si bien, estos no siempre son efectivos y suele ocurrir que durante las peleas haya lesionados o personas que pierdan la vida, sí suelen representar medidas más efectivas que las supuestas del sistema penitenciario.

Así, podemos decir que otra estrategia de sobrevivencia también es la imposición del miedo o la intimidación. Este medio no es empleado por ninguna de nuestras participantes directamente, pero sí suelen identificarlo y mencionarlo. Cuando "Bianca" narró las agresiones vividas por parte de una interna de nacionalidad hondureña, dijo que ella no entendía por qué algunas mujeres eran así, que "a todo mundo quieren pegarle, pues qué les quita uno. No más lo que hacen es que uno les tenga miedo y ya luego te quieren estar quitando tus cosas. Así hay varias, no te creas..." ("Bianca”, 2018). En otros casos, en una conversación con la señora “Azalia” y "Montes”, se señaló que ellas consideran que muchas de las mujeres jóvenes de ahí, no son malas personas, pero que quizá por miedo de ser ellas quienes reciban las agresiones, prefieren convertirse como las agresoras ("Azalia” y "Montes", 2018).

Dentro de las áreas femeniles de "Santiaguito", las relaciones de opresión, subordinación y violencia, cabe decir, no solo provienen de las demás internas, sino que, como se destacó antes, también suelen ser reproducidas por parte del personal penitenciario, ya sea autoridades, custodias y custodios. Es por esto que se puede identificar en la mayoría de los testimonios de mujeres privadas de su libertad, tanto mestizas como indígenas, suelen llegar 
a acuerdos, principalmente económicos con personas en estas posiciones, con la finalidad de recibir facilidades en algún tipo de situación. Tal como para la comercialización de los productos que éstas crean en las diferentes actividades promovidas en el recinto.

Además, con estos acuerdos es que muchas de las mujeres suelen comunicarse con individuos del área varonil puesto que se constituyen redes en donde, en muchas ocasiones, los custodios se convierten en mensajeros. Llevan de una zona a otra algún producto y hasta recaditos que se envían las personas privadas de su libertad. Esto, podríamos considerarlo como una estrategia de sobrevivencia del tipo de "persuasión y convencimiento". Por medio de sobornos, las mujeres logran que se les concedan algunos permisos, como aquellas que no reciben visitas frecuentes, pero sí salen cada fin de semana solo para comercializar sus productos y los de algunas otras compañeras. En estos casos podemos ubicar a varias de nuestras participantes, como es a "Luna", "Montes" y a las indígenas "Nidia" y "Matilde".

Otra de las estrategias de sobrevivencia muy destacada dentro del dormitorio once de "Santiaguito" son las que refieren a los aspectos económicos. De estas podemos encontrar muchas variantes, pues las mujeres no las reproducen exactamente de la misma forma. Por ejemplo, aquellas que venden su fuerza de trabajo, ya sea en la preparación y venta de comida, no trabajan de la misma manera que las que se dedican a lavar prendas de ropa ajena o aquellas que cortan el cabello, mucho menos de las que se dedican actividades ilegales como el narcotráfico y la prostitución. De la mayoría de estas actividades, no tenemos ningún caso en la investigación, solo de los de preparación de comida y de actividades como la creación de artículos manuales.

Sin embargo, se puede hacer mención del resto de las actividades, puesto que desde el trabajo etnográfico y la observación no participante durante el trabajo de campo se pudieron percibir algunas de estas actividades. Como se expuso antes, algunas de las mujeres que generan mayores ingresos son aquellas que se ocupan en actividades ilegales. Mientras que el resto genera una menor cantidad de dinero. En otros casos, y destacando nuevamente a los de las mujeres que laboran en conjunto con otras, podemos ver que como se ha venido diciendo, la combinación de varias de las estrategias de sobrevivencia llega a causar efectos más favorables en las mujeres en lo que respecta a los aspectos económicos. 
Esto lo podemos ver en los casos de "Nidia" y "Matilde" o en los casos de "Azalia" y "Montes", mientras que en los demás casos se ven obligadas a trabajar aún más si es que no reciben algún tipo de apoyo del exterior. Como es el caso de "Elisa", de quien su situación económica no es nada buena debido al olvido familiar que está viviendo y a la situación de adaptación que estaba enfrentando durante el trabajo de campo, pues recordemos, llevaba muy pocos meses de haber sido confinada en "Santiaguito". El resto de las mujeres que se encuentran en una situación de individualidad, aunque podría ser poco, pero reciben apoyo de sus familiares más directos o como en el caso de "Luna", de su colectividad con su actual pareja.

Es preciso destacar que, en el caso de Dominga, podemos ver que la situación se presentó de manera muy diversa. Desde los primeros momentos de su detención, en ella el impacto de los sistemas carcelarios fue muy distinto, incluso de aquellas quienes comparten su condición racial. El hecho de haber sido ubicada durante la mayor parte del tiempo en el área de castigo del CPRS de Almoloya de Juárez, vemos que la llevó a vivir situaciones de mayor peligro y violencia de lo ocurrido con la mayoría de las mujeres que se encuentran en el dormitorio once. Además, las estrategias de sobrevivencia de esta mujer, también suelen ser diferenciadas de lo que son las de las demás. Las de ésta dependieron principalmente de su comunidad y familiares, por lo que totalmente no fueron un desarrollo personal.

Por otro lado, el caso de la mujer mestiza "Bianca", también se diferencia enormemente del resto de los de los de las demás mujeres. Esta mujer sí interactuaba con las mujeres de su mismo grupo etario, sin embargo, no generó vínculos fuertes con alguna o algunas de estas con el fin de producir beneficios personales. En este caso, al igual que en el de Dominga, vemos que vivió una mayor subordinación y violencia por parte de grupos o personas dominantes en de este recinto. Las estrategias de sobrevivencia de la mujer, también son distintas a las de las demás, pero vemos que, al igual que en el caso de la indígena nahua, dependen de sus familiares, en este caso, de su hija.

Las diferencias y similitudes de las estrategias de sobrevivencia de las diez mujeres contempladas para esta investigación, cabe decir que son el resultado de sus diferentes condiciones. Aunque encontramos algunas de estas que son muy parecidas en ciertos casos, también encontramos diferencias en la aplicación y en el resultado obtenido de cada una. No 
a todas las mujeres les funcionan de la misma forma los mecanismos de sobrevivencia. Pues algunas poseen características que suelen ser mayormente vulneradas. Lo vemos en estos últimos dos casos expuestos, se trata de una mujer indígena y una mestiza, que, además, podemos destacar que son las que se encontraron en peores condiciones. Mientras que las demás mujeres tuvieron elementos que favorecieron que sus estrategias resultaran funcionales. 


\section{Reflexiones finales}

El tema que se aborda en este trabajo es extenso, pues de éste mismo se pueden desprender otras problemáticas relevantes en tanto a los sistemas carcelarios. Tal como se expuso en el primer capítulo de este trabajo, las características del sistema penitenciario mexicano conservan aún muchos rasgos de lo que eran las primeras instituciones carcelarias. Los castigos que se imponen ahora, siguen lastimando en gran medida a las poblaciones que se les confina en este tipo de recintos. Con esto no se pretende dar la idea de que los delincuentes no deberían de recibir un castigo por su actuar anómalo, sino que es importante revisar desde

el fondo las estructuras que componen a los sistemas penitenciarios y la manera cómo se imponen las sanciones, buscando que se puedan lograr cabalmente los objetivos que se plantea este sistema descritos en el capítulo cuatro de este trabajo.

La documentación de este análisis permite ver que las medidas que se promueven en el sistema penitenciario mexicano por donde las miremos, no favorecen el sentido de la reinserción y readaptación social, pues es común ver a personas que cumplen sus sentencias y vuelven a la vida de delito y conflicto. Pero también, cabe destacar que hay casos en los que las personas reciben este tipo de castigo injustamente. Probablemente, quienes se encuentran en estas circunstancias son sujetos/as que han sido posicionados en lugares de distintos tipos de vulneración y que, como consecuencia se ven mayormente intervenidos por el sistema y por el entorno, no solo el carcelario, sino de lo proveniente del exterior.

Así, siendo más específicos en casos de mujeres en general, privadas de la libertad, la situación que enfrentan unas y otras es claramente distinto. Como se pudo notar a lo largo de este trabajo, algo que es completamente relevante es que no se puede victimizar a las indígenas como se suele hacer en muchos estudios, en los que, al hablar de este tipo de mujeres, muestran los peores escenarios y las más deplorables condiciones de vida. Y aunque sí se destacan muchos de los esfuerzos de este tipo de mujeres, no se suele mostrar que hay otros sectores que pueden llegar a posicionarse en las mismas condiciones aun cuando no se trate de indígenas. En nuestro estudio de caso, algo evidente fue que incluso una mestiza debido a su edad, se enfrenta a situaciones más complicadas que dos de las indígenas consideradas en este trabajo. 
Otro aspecto que es importante resaltar es el hecho de que entre las indígenas las diferencias también son marcadas, lo que podemos atribuir, en primera instancia, a la manera en que impacta este sistema penitenciario en cada mujer desde que inician sus procesos, puesto que desde la manera como se les señala y sus condiciones, es que depende gran parte del trato que han de recibir y de las circunstancias que han de enfrentar. Para entender mejor este tipo de situaciones, sin duda alguna, analizar los casos desde la consideración de la interseccionalidad, es un elemento clave.

Pero para poder emplear esta perspectiva, es importante entender cómo estas diferenciaciones sociales se han ido constituyendo y han ido colocando a los individuos en diferentes posiciones de las jerarquías sociales. Es por esto que lo expuesto en el capítulo dos de este trabajo significó una importante guía para mirar nuestro estudio de caso desde una perspectiva más completa dentro de un entorno específico como lo es el Centro Penitenciario y de Reinserción Social "Santiaguito". Sin hacer este recorrido, es mucho más complejo identificar el impacto que hay en los procesos de socialización y las estrategias de sobrevivencia desarrolladas por las mujeres privadas de su libertad.

El CPRS de Almoloya de Juárez como parte del sistema penitenciario mexicano es representativo de lo que ocurre en diferentes entornos de la sociedad. Por ejemplo, al ver la ausencia de la debida aplicación de las leyes con las que se supone que se mueve el sistema penitenciario de México, aunque parece obvio, en la realidad es algo que impacta por lo deficiente que puede llegar a ser. Y más que por eso, por la manera en que éste afecta a muchas de las personas que se encuentran privadas de su libertad. Así, con la realización de este trabajo, resaltaron de una forma aplicada las limitantes que se promueven por este sistema. Lo que trastoca el interés de personas que tienen interés en estudiar las problemáticas de estos entornos. Tal fue nuestro caso, que aún con las dificultades que implicó acceder a diferentes recintos, terminó aportando importantes enseñanzas.

Desde un sentido personal dentro de la investigación social, el acceso al CPRS, también cambió mucho la imagen que se tenía estereotipada sobre las personas en situación de reclusión. Generalmente, se les llega a imaginar como sujetos y sujetas violentos e intimidantes. Sin embargo, la realidad no es así, pues quienes habitan allí son personas comunes y corrientes, humanos que viven y sienten, y que se encuentran en una larga lucha 
por adaptarse y conformarse con lo que les toca presenciar. A algunos otros, deja de importarles su condición porque al final de cuentas, para ellos, el exterior es peor. Por lo que se hace mención de que, en esta investigación, se tuvo experiencia de trabajo de campo no solo con mujeres, sino con algunos varones del programa CICA. Estos, cabe resaltar, también compartieron algunas de sus experiencias, de las cuales también existe un registro importante, pese a que no se contemplaron como eje central de este trabajo.

En estas últimas reflexiones, es preciso decir que de la interacción con los varones también se pudieron detectar elementos que favorecieron el análisis de esta investigación como las diferencias en las condiciones de vida de unos y de otras. Las evidentes distinciones espaciales, laborales y de recreación que hay entre las dos áreas (femenil y varonil), son algo que ayuda a entender las desigualdades por condición de género, además de las de raza, clase y edad.

Además, a simple vista, en todos los espacios de "Santiaguito", se puede ver la pobreza y marginalidad que vive la mayoría. Lo que, sin duda alguna, es un marcado reflejo de lo que también encontramos en el exterior, en la vida cotidiana y que ya ha sido "normalizado" en nuestra sociedad mexicana. Dentro de las cárceles como en el exterior todo esto son situaciones de tristeza y preocupación, pues en ninguno de los dos, las personas que viven en estas condiciones difícilmente tienen manera de cambiar su destino, pues son muchos los factores que intervienen en la vida de los sujetos.

Por ejemplo, dentro de las cárceles en el contexto actual (2020), con la emergencia sanitaria, se tuvieron que promover diferentes prohibiciones dentro de las instituciones carcelarias con la finalidad de evitar la propagación del virus y, supuestamente erradicarlo. Lo cual no sucedió, los informantes clave de la DGRS del Estado de México, describieron en conversaciones informales un escenario bastante malo, en el que incluso, como se comentó en el último capítulo de este trabajo, cobró la vida de la señora "Bianca" que tristemente anhelada salir en libertad muy pronto. Esta mujer jamás imaginó que acabaría sus días dentro de este lugar, viviendo no solo desesperación y sufrimiento por el encierro, sino padecer graves y desgastantes síntomas de una letal enfermedad.

En casos como estos, dentro de reclusión, es obvio que se siguen marcando las desigualdades de las que se ha hablado en esta investigación: género, clase social, raza y edad. Las mujeres 
con recursos económicos mayores podrán acceder a un mejor servicio de salud a comparación con aquellas que no cuentan con dinero suficiente ni siquiera para subsistir. Además, esta situación también complica el desarrollo de las estrategias de sobrevivencia económicas que se destacaron en este trabajo. En estos momentos, aquellas que se dedican a vender sus productos durante los días de visita, no tienen oportunidad de hacerlo, pues no está permitida la entrada de familiares al recinto y por tanto, no hay manera de generar ingresos de esta manera.

Esto es importante mencionarlo, debido a que según lo que se explicó en el último apartado, el entorno define mucho de las condiciones de vida de las mujeres. Ahora, una situación que proviene del exterior es la que impide que muchas de estas mujeres realicen sus actividades con normalidad y que su sobrevivencia siga el curso que estas mujeres ya se habían planteado. Lo que seguramente, estará promoviendo que se desarrollen nuevas estrategias de sobrevivencia, pues en estos tiempos no solo se trata de sobrellevar las condiciones de vida, sino de cuidarse y salvarse de una letal enfermedad con lo poco que hay.

Este análisis queda abierto a nuevas problemáticas como la que se acaba de mencionar. Pues, descrito un poco del panorama que se vive actualmente, podemos señalar que en el caso de mujeres como la indígena Dominga, que logró obtener su libertad antes de la emergencia sanitaria, en su comunidad no corre los mismos riesgos que las otras dos que siguen privadas de la libertad y que de las mestizas en la misma situación. Por lo que, en este caso, Dominga no se ve en la necesidad de desarrollar nuevas estrategias de sobrevivencia, a diferencia de las demás.

En estos difíciles momentos sociales, gran parte de lo planteado en este trabajo, probablemente se torna diferente, por lo que sería importante considerar cómo se viven estas problemáticas como un nuevo eje de análisis. Además de que queda el deseo de buscar otros tipos de justicias que pudieran aplicarse a las poblaciones vulnerables como las indígenas. Por mencionar algún tipo, sería bueno analizar a las llamadas justicias indígenas o comunitarias, en contraste con las justicias ordinarias, temas que se estudiarán más adelante. 


\section{Bibliografía}

AMARILES, Erica, 2007. Alcances actuales del proceso de resocialización en las cárceles masculinas del área metropolitana. Universidad de San Buenaventura. Medellín.

ARIÑO, Antonio y Serra, Inmaculada, 2005. Cultura y Socialización, en García, Ferrando: Pensar nuestra Sociedad Global. Fundamentos de sociología. Valéncia, Tirant Lo Blanch. Págs. 113-128.

ARNETT, J., 1995. Broad and narrow socialization: The family in the context of a cultural theory, en: Simkin, Hugo y Becerra Gastón, 2013. El proceso de socialización. Apuntes para su exploración en el campo psicosocial. Ciencia, Docencia y Tecnología. Universidad Nacional de Entre Ríos Concepción del Uruguay, Argentina.

ARREDONDO, Martha y González, José, 2013. Las Estrategias de Sobrevivencia de los Pobres: Un repaso a su Estudio en las Ciencias Sociales (concepto, perspectivas teóricas y acciones que implican). Revista Realidades, UANL, México.

BARRY, Kathleen, 1984. International Feminism: Networking against Female Sexual Slavery (Nueva York: International Women's Tribune Center. En RICH, Adrienne, 1985. La Heterosexualidad Obligatoria y la Existencia Lesbiana. Revista Feminista. Nosotras que nos queremos tanto. Madrid. Disponible en: http://www.caladona.org/grups/uploads/2014/02/rich-a-heterosexualidad-obligatoriarevista_nosotras_n_3_11_1985.pdf

BÉNARD, Silvia, 1998. La consolidación de un estado nacional mexicano: democracia o nacionalismo. Revista Caleidoscopio, Núm. 3, Universidad Autónoma de Aguascalientes, Aguascalientes, México.

BERGER, Peter y Lukmann, Thomas, 1999. La construcción social de la realidad. Amorrortu Editores, Argentina.

BETHER, Lorraine. The Infynity of Conscious Pain. En RICH, Adrienne, 1985. La Heterosexualidad Obligatoria y la Existencia Lesbiana. Revista Feminista. Nosotras que nos queremos tanto. Madrid. Disponible en:

http://www.caladona.org/grups/uploads/2014/02/rich-a-heterosexualidad-obligatoriarevista_nosotras_n_3_11_1985.pdf 
BRISEÑO, Marcela, 2006. Garantizando los Derechos Humanos de las Mujeres en Reclusión. INMUJERES/ PNUD. Ciudad de México. Disponible en: http://cedoc.inmujeres.gob.mx/documentos_download/100793.pdf

CANETTI, Elias, 2013. Masa y poder. Alianza Editorial. Madrid.

CEA[R], 2009. Heteronormatividad. Género y Asilo. Euskadi, España. Disponible en: https://diccionario.cear-euskadi.org/heteronormatividad/

CONWAY, Jill, Bourque, Susan y Scott, Joan, 2018. El Concepto de Género. En LAMAS, Martha, 2018. El Género. La construcción cultural de la diferencia sexual. Pp. 41-52, CIEG, UNAM. México.

COSTA, Ana Paula y De Juan, Sabino, 2010. Socialización y ambientes virtuales. Educación y futuro: revista de investigación aplicada y experiencias educativas. España.

COMISIÓN NACIONAL DE SEGURIDAD (CNS), 2016. Cuaderno mensual de Información Estadística Penitenciaria Nacional. Secretaría de Gobernación, México.

CURIEL, Ochy, 2013. La Nación Heterosexual. Análisis del discurso jurídico y el régimen heterosexual desde la antropología de la dominación. Primera Edición. Brecha Lésbica y en la Frontera. Bogotá, Colombia

DELPHY, Christine, 1970. L'ennemi principal. En CURIEL, Ochy, 2013. La Nación Heterosexual. Análisis del discurso jurídico y el régimen heterosexual desde la antropología de la dominación. Primera Edición. Brecha Lésbica y en la Frontera. Bogotá, Colombia

DE MEndiZABAL, Miguel; Mora, José; Otero, Mariano; Molina, Andrés; Whetten, Nathan; Palerm, Ángel; Stavenhagen, Rodolfo y González, Pablo, 1985. Las clases Sociales en México. Los grandes problemas nacionales. Nuestro Tiempo, S. A., México.

DÍAZ, Lina, 2007. Algunas consideraciones sobre el castigo. Una perspectiva desde la sociología. Derecho penal y criminología. Universidad Externado, Colombia. 
DUQUE, Joaquín y Pastrana, Ernesto, 1973. Las estrategias de supervivencia económica de las unidades familiares del sector urbano: una investigación exploratoria, Santiago de Chile, FLACSO. En Vargas, Mónica, 1996. Estrategias de sobrevivencia, alternativas económicas y sociales de la unidad campesina. Papeles de Población. Universidad Autónoma del Estado de México, Toluca. P.p. 39-50.

DURKHEIM, Émile. 1899-1900. Dos Leyes de la evolución Penal. Francia, Journal Sociologique. Pp. 71-90.

DURKHEIM, Émile, 1992. Las formas elementales de la vida religiosa. Ediciones Akal universitaria. Madrid.

DURKHEIM, Émile, 2007. La división del trabajo social. Sexta edición, Colofón. México.

ERRÁZURIZ, Margarita y Urzúa, Raúl, 1984. Estrategias de sobrevivencia en economías campesinas: el rol de la mujer. Biblioteca CEPAL, Santiago de Chile.

ESTEVA, Gustavo, 1988. “Vivir o Sobrevivir” en Las sociedades rurales hoy. Zepeda Patterson. El Colegio de Michoacán-CONACYT, Michoacán. En Vargas, Mónica, 1996. Estrategias de sobrevivencia, alternativas económicas y sociales de la unidad campesina. Papeles de Población. Universidad Autónoma del Estado de México, Toluca. P.p. 39-50.

FINQUIELEVICH, Susana, 1993. "Estrategias de supervivencia en las ciudades Latinoamericanas" en Pobreza un tema impostergable. Nuevas respuestas a nivel mundial. Centro Latinoamericano de Administración para el Desarrollo. Programa de las Naciones Unidas. En Vargas, Mónica, 1996. Estrategias de sobrevivencia, alternativas económicas y sociales de la unidad campesina. Papeles de Población. Universidad Autónoma del Estado de México, Toluca. P.p. 39-50.

FLORESCANO, Enrique, 1996. Etnia, Estado y Nación. Taurus, México.

FOUCAULT, Michel, 1998. La verdad y las formas jurídicas. Gedisa, Barcelona.

FOUCAULT, Michel. 2009. Vigilar y castigar. Nacimiento de la prisión. México, Siglo XXI editores. 
GARCIADIEGO, Javier, 2014. El Porfiriato (1874-1911) en VON, Gisela, 2014. Historia de México. Fondo de Cultura Económica. México

GARLAND, David, 1999. Castigo y sociedad moderna. Un estudio de teoría social. México, Siglo XXI editores.

GOFFMAN, Erving. 2012. Estigma. Buenos Aires, Amorrortu. Pp.13-34.

GOLUBOV, Nattie, 2016. Interseccionalidad. En Moreno, Hortensia y Alcántara, Eva, 2016. Conceptos clave en los estudios de género. PUEG, UNAM, México.

GUILlAMONDEGUI, Raúl, 2010. Resocialización y Semilibertad. Análisis Legal, Jurisprudencial y Criminológico. B de F, Buenos Aires.

GUILLAUMIN, Colette, 1992. Práctica de poder e idea de naturaleza. En CURIEL, Ochy, 2013. La Nación Heterosexual. Análisis del discurso jurídico y el régimen heterosexual desde la antropología de la dominación. Primera Edición. Brecha Lésbica y en la Frontera. Bogotá, Colombia.

GUTIÉRREZ, Alicia, 2009. Educación y reproducción social: el abordaje de las estrategias escolares en el marco de un análisis relacional de la pobreza, en Seminario Internacional "Bourdieu, educación y pedagogía", Instituto para la Investigación Educativa y el Desarrollo Pedagógico, Bogotá. En Arredondo, Martha y González, José, 2013. Las Estrategias de Sobrevivencia de los Pobres: Un repaso a su Estudio en las Ciencias Sociales (concepto, perspectivas teóricas y acciones que implican). Revista Realidades, UANL, México.

HILL, Patricia, 1991. Black Feminist Tought. Knowledge, Consciousness, and the politics of empowerment, Nueva York y Londres, Routledge. En Moreno, Hortensia y Alcántara, Eva, 2016. Conceptos clave en los estudios de género. PUEG, UNAM, México.

HILL, Patricia, 2012. Feminismos Negros una Antología. Mercedes Jabardo y Traficantes de Sueños, Madrid. 
HOOKS, bell, 2004. Mujeres negras. Dar forma a la teoría feminista, en Otras impropiables, Traficantes de Sueños, Madrid. En JABARDO, Mercedes, 2012. Feminismos negros. Una antología. Traficantes de Sueños. Madrid.

HOOKS, bell, 2017. El feminismo es para todo el mundo. Traficantes de Sueños. Madrid.

INEGI, 2019. Censo Nacional de Gobierno, Seguridad Pública y Sistema Penitenciario Estatales 2019. México. Disponible en: https://www.inegi.org.mx/programas/cngspspe/2019/default.html\#Documentacion

JABARDO, Mercedes, 2012. Feminismos negros. Una antología. Traficantes de Sueños. Madrid.

LAMAS, Martha, 2000. Diferencias de sexo, género y diferencia sexual. Escuela Nacional de Antropología e Historia, México. Disponible en: https://www.redalyc.org/pdf/351/35101807.pdf

LAMAS, Martha, 2016. Género. En Moreno, Hortensia y Alcántara, Eva, 2016. Conceptos clave en los estudios de género. PUEG, UNAM, México.

LAMAS, Martha, 2018. El Género. La construcción cultural de la diferencia sexual. CIEG, UNAM. México

LARA, María, 1988. "El papel de la mujer en el campo: nuevas estrategias" en las sociedades rurales hoy. Zepeda Patterson. El Colegio de Michoacán- CONACYT. Michoacán. En Vargas, Mónica, 1996. Estrategias de sobrevivencia, alternativas económicas y sociales de la unidad campesina. Papeles de Población. Universidad Autónoma del Estado de México, Toluca. P.p. 39-50.

LAHIRE, Bernard, 2007. Infancia y adolescencia: de los tiempos de socialización sometidos a constricciones múltiples. Revista de Antropología Social. Universidad Complutense de Madrid, España.

LENIN, Vladimir, 1996. Una gran iniciativa, en Marx y Engels, Editorial Progreso. Moscú. LNEP, 2016. Ley Nacional de Ejecución Penal. Cámara de Diputados. México 
LÓPEZ, Arturo y Helí, Díaz, 2015. Economía campesina y estrategias de sobrevivencia. El caso de las mujeres indígenas de Santa Lucía Miahuatlán, Oaxaca. $2^{\circ}$ Congreso de Investigación y Vinculación para el Desarrollo. UNSIS. Oaxaca, México.

LÓPEZ, Carlos, 2008. Sangre y temperamento: Pureza y mestizajes en las sociedades de castas americanas. En Saberes Locales; Ensayos sobre historia de la ciencia en América Latina. El Colegio de Michoacán, México

LUCAS, Antonio, 1986. El proceso de socialización: un enfoque Sociológico. Revista Española de Pedagogía, año XLIV, no. 173. Universidad Compultense de Madrid, España.

LUCAS, Antonio, 1976. Hacia una teoría de la comunicación de masas. MEC, Madrid.

LUGONES, María, 2008. Colonialidad y Género. Tabula Rasa, núm. 9, Bogotá, Colombia.

LUGONES, María, 2013. Conferencia ofrecida por María Lugones en el Coloquio Internacional "Reconocer las superficies de nuestras hendiduras. Cartografiar el Sur de nuestros Feminismos". IDAES/UNSAM. Bs As, 15 y 16 de julio, 2013. En BIDASECA, Karina, 2014. Los peregrinajes de los feminismos de color en el pensamiento de María Lugones. Revista Estudos feministas, Brasil.

MARTÍNEZ, Patricia, 2014. La resocialización del delincuente. Universidad Jaime I, España.

MASSA, Laura, 2010. Estrategias de reproducción social y satisfacción de necesidades. Parte I: Controversias conceptuales, polémicas prácticas, Revista Perspectivas Sociales vol. 12, Universidad Autónoma de Nuevo León/Universidad de Tennessee, pp.103- 140. En Arredondo, Martha y González, José, 2013. Las Estrategias de Sobrevivencia de los Pobres: Un repaso a su Estudio en las Ciencias Sociales (concepto, perspectivas teóricas y acciones que implican). Revista Realidades, UANL, México.

MENDOZA, Breny, 2001. La desmitologización del mestizaje en Honduras, en: Mesoamérica 42. California. En CURIEL, Ochy, 2013. La Nación Heterosexual. 
Análisis del discurso jurídico y el régimen heterosexual desde la antropología de la dominación. Primera Edición. Brecha Lésbica y en la Frontera. Bogotá, Colombia.

OAKLEY, Ann, 1977. La mujer discriminada: Biología y Sociedad. Tribuna Feminista. Ed. Debate, Madrid. En Stolke, Verena, 2004. La mujer es puro cuento: la cultura del género. Estudos Feministas. Brasil. Disponible en: https://www.redalyc.org/pdf/381/38112205.pdf

OCHOA, Karina, 2020. Una mirada crítica a la perspectiva de género desde las coordenadas de otros feminismos. Revista Intersticios. Filosofía, Arte, Religión. Año 25, Número 52. Universidad Intercontinental. México.

OLIVEIRA, Orlandina, 1991. Presencias y ausencias femeninas. En Oliveira, Orlandina (Coordinadora), Trabajo, poder y sexualidad. El Colegio de México. PIEM. México. ONODC, 2015. Las Reglas Mínimas de las Naciones Unidas para el Tratamiento de os Reclusos (Las Reglas Nelson Mandela). ONU, Ciudad del Cabo, Sudáfrica.

PETRUS, Antonio, 1992. Hacia una pedagogía comunitaria de la pedagogía penitenciaria. Colección Humanidades, Barcelona.

PETRUS, Antonio, 1996. El desafio de la educación social. La educación social en la sociedad del bienestar. Colección Humanidades, Barcelona.

POWELL, T.G, 1972. Los liberales, el campesino indígena y los problemas agrarios durante la Reforma. Historia Mexicana, Colmex. México. Disponible en: https://historiamexicana.colmex.mx/index.php/RHM/article/view/2977/2484

QUIJANO, Aníbal, 2014. Cuestiones y horizontes. De la Dependencia HistóricoEstructural a la Colonialidad/ Descolonialidad del Poder. Clacso, Buenos Aires.

RICH, Adrienne, 1980. La Heterosexualidad obligatoria y la existencia lesbiana. En CURIEL, Ochy, 2013. La Nación Heterosexual. Análisis del discurso jurídico y el régimen heterosexual desde la antropología de la dominación. Primera Edición. Brecha Lésbica y en la Frontera. Bogotá, Colombia

RICH, Adrienne, 1985. La Heterosexualidad Obligatoria y la Existencia Lesbiana. Revista Feminista. Nosotras que nos queremos tanto. Madrid. Disponible en: http://www.caladona.org/grups/uploads/2014/02/rich-a-heterosexualidad-obligatoria$\underline{\text { revista_nosotras_n_3_11_1985.pdf }}$ 
RITCHER, Juan, 2010. ¿Es la cárcel el castigo más acorde a nuestros tiempos?, Universidad Católica de Chile, Chile. Pp. 279-291.

ROCHER, G., 1980. Introducción a la Sociología, p. 133, Barcelona en Lucas, Antonio, 1986. El proceso de Socialización: Un enfoque Sociológico, Revista Española de Pedagogía, España.

RUBIN, Gayle, 1975. El tráfico de mujeres: notas sobre "la economía política” del sexo, en: LAMAS, Martha, 2018. El género. La construcción cultural de la diferencia sexual. CIEG, UNAM. México

SALINAS, Claudia, 2014. Las cárceles de mujeres en México: Espacios de opresión patriarcal. Revistas de Ciencias Sociales de la Universidad Iberoamericana. Ibero, México.

SIMKIN, Hugo y Becerra Gastón, 2013. El proceso de socialización. Apuntes para su exploración en el campo psicosocial. Ciencia, Docencia y Tecnología. Universidad Nacional de Entre Ríos Concepción del Uruguay, Argentina.

TALANCÓN, Jaime, 2009. La violencia política. Revista de la Facultad de Derecho de México. Vol. 59, Núm. 251. México. Disponible en: http://www.revistas.unam.mx/index.php/rfdm/article/view/60880

TONKONOFF, Sergio, 2012. Las funciones sociales del crimen y el castigo. Una comparación entre la perspectiva de Durkheim y Foucault. Revista Sociológica, México. Pp. 109-142.

TORRADO, Susana, 1980, Sobre los conceptos de estrategias familiares de vida y proceso de reproducción de la fuerza de trabajo: Notas teórico-metodológicas, CEUR, Buenos Aires, Argentina. En Arredondo, Martha y González, José, 2013. Las Estrategias de Sobrevivencia de los Pobres: Un repaso a su Estudio en las Ciencias Sociales (concepto, perspectivas teóricas y acciones que implican). Revista Realidades, UANL, México. 
VACCA, Lucrecia, 2012. Una Crítica Feminista al Derecho a partir de la noción de Bipoder de Foucault. Revista Páginas de Filosofía, No. 16. Pp. 60-75. Universidad de Buenos Aires, Argentina

VALLEJO, Daniela y Herrera Ximena, 2016. Factores psicosociales que promueven la resocialización en la cárcel de Villa Hermosa, Cali, Colombia. Universidad de Buenaventura, Santiago de Cali.

VARGAS, Mónica, 1996. Estrategias de sobrevivencia, alternativas económicas y sociales de la unidad campesina. Papeles de Población. Universidad Autónoma del Estado de México, Toluca. P.p. 39-50.

VILLAVERDE, Noemí, 2016. Angela Davis, mujeres y cárcel. Revista Mito No. 30. México. Disponible en: http://revistamito.com/angela-davis-mujeres-y-carcel/

VIVEROS, Mara, 2016. La interseccionalidad: una aproximación situada a la dominación. Debate Feminista. Universidad Nacional de Colombia, Bogotá, Colombia.

VII Censo General de Población, 1960. Dirección General de Estadística. México. En DE MENDIZABAL, Miguel; Mora, José; Otero, Mariano; Molina, Andrés; Whetten, Nathan; Palerm, Ángel; Stavenhagen, Rodolfo y González, Pablo, 1985. Las clases Sociales en México. Los grandes problemas nacionales. Nuestro Tiempo, S. A., México.

WEBER, Max, 2012. Economía y Sociedad. Fondo de Cultura Económica. Décimo octava reimpresión, México

WITTIG, Monique, 1992. El pensamiento heterosexual y otros ensayos. Editorial EGALES, Barcelona.

\section{Sitios web consultados:}

Association for Women's Rights in Development. Disponible en: https://www.awid.org/sites/default/files/atoms/files/nterseccionalidad_una_herramien 
ta_para_la_justicia_de_genero_y_la_justicia_economica.pdf. Consultado 14 de julio de 2020

Comisión Nacional de los Derechos Humanos, México. Disponible en: http://www.cndh.org.mx/Que_son_Derechos_Humanos . Consultado: 1 de junio de 2019

Diccionario Social. Enciclopedia jurídica online. México. Disponible en: https://diccionario.leyderecho.org/procesado/ . Consultado: 5 de octubre de 2019

Diccionario de Oxford en español. Disponible en:

https://es.oxforddictionaries.com/definicion/sobrevivencia. Consultado: 15 de julio de 2018

Diccionario Panhispánico de Dudas del Diccionario de la Real Academia Española (DRAE). Disponible en: http://lema.rae.es/dpd/?key=Sobrevivir. Consultado: 15 de julio de 2018

Diccionario del Español Jurídico de la Real Academia Española. Disponible en: https://dej.rae.es/lema/establecimiento-penitenciario . Consultado: 25 de octubre de 2019

Diccionario Definición De. Disponible en: https://definicion.de/menu . Consultado: 28 de febrero de 2019

FORMACIONMZC. ¿Qué es la interseccionalidad? Subtitulada en español. Disponible en: https://www.youtube.com/watch? $\mathrm{v}=\mathrm{hBaIhlmM30w}$. Visto: 26 de septiembre de 2020

GIMENO, Beatriz, s/a. Heteronormatividad. Lengua de Signos Española. Disponible en: http://glosario.pikaramagazine.com/glosario.php?lg=es\&let=h\&ter=heteronormativid ad . Consultado: 13 de abril de 2020

Google sites, Ley Lerdo. Disponible en: https://sites.google.com/site/laepocadejuarezysusreformas/-leyes/ley-lerdo .

Consultado: 5 de marzo de 2019 
IMCO: Justicia Penal, Justicia Transparente. Disponible en: https://imco.org.mx/justiciapenal/blog/definicion/prision-preventiva/ . Consultado: 29 de mayo de 2019

Infobae América. Disponible en:

https://www.infobae.com/america/mexico/2020/05/24/murio-la-loba-dechimalhuacan-por-anos-lidero-la-invasion-de-terrenos-en-el-municipio-mexiquense/ . Consultado: 20 de septiembre de 2020

Organización de los Estados Americanos. Folleto delito e infracciones administrativas, 2001. Disponible en:

http://www.oas.org/udse/cd_educacion/cd/Materiales_conevyt/VPLD/delitos.PDF .

Consultado: 10 de julio de 2019

Real Academia Española. Diccionario Español Jurídico. Disponible en: https://dej.rae.es/lema/procesar . Consultado: 5 de octubre de 2019

Real Academia Española. Definición de Patriarcado. Disponible en: https://dle.rae.es/patriarcado . Consultado: 7 de marzo de 2020

Semanario Judicial de la Federación. Disponible en: http://sjf.scjn.gob.mx/SJFSist/Documentos/Tesis/299/299329.pdf . Consultado: 17 de octubre de 2019

Significados, definición de Latifundio. Disponible en: https://www.significados.com/latifundio/ . Consultado: 12 de abril de 2019

PASIONLATINAMONTREAL, 2015. Sojourner Truth discurso: ¿Acaso no soy mujer? Disponible en: https://www.youtube.com/watch?v=fu9vjEmGFjU . Consultado: $30 / 09 / 2020$

SSP Edo. Méx., Subsecretaría de Control Penitenciario. Disponible en: http://sseguridad.edomex.gob.mx/subsecretaria_control_penitenciario . Consultado: 19 de septiembre de 2018

TRIGLIA, Adrián, 2020. La teoría feminista de Simone de Beauvoir: ¿qué es la mujer? Un resumen de los principios fundamentales de esta importante filosofa y escritora 
feminista. Psicología y mente. Barcelona. Disponible en: https://psicologiaymente.com/social/teoria-simone-beauvoir

\section{Entrevistas y testimonios.}

Conversación con “Azalia” y "Montes”, mujeres mestizas tercera edad, privadas de su libertad. Dormitorio once, Centro Penitenciario y de Reinserción Social "Santiaguito", Estado de México, noviembre, 2018.

Testimonio de "Bianca", mujer mestiza tercera edad, privada de su libertad. Dormitorio once, Centro Penitenciario y de Reinserción Social "Santiaguito", Estado de México, noviembre, 2018.

Testimonio de Dominga González, mujer indígena, ex convicta. Dormitorio cinco, Centro Penitenciario y de Reinserción Social “Santiaguito”, Estado de México. Entrevistada en San Pedro Tlanixco, Estado de México, abril, 2019.

Testimonio de "Enrique", hombre mestizo joven privado de su libertad. Área varonil, centro Penitenciario y de Reinserción Social “Santiaguito”, Estado de México, 2018.

Testimonio de "Luna", mujer mestiza joven privada de su libertad. Área femenil, Dormitorio once. Centro Penitenciario y de Reinserción Social "Santiaguito", Estado de México, 2018.

Testimonio de "Matilde", mujer indígena mixteca, privada de su libertad. Área femenil, Dormitorio once. Centro Penitenciario y de Reinserción Social "Santiaguito", Estado de México, 2018.

Testimonio de "Nidia", mujer indígena mixteca, privada de su libertad. Área femenil, Dormitorio once. Centro Penitenciario y de Reinserción Social "Santiaguito", Estado de México, 2018.

Testimonio de "Anónimo", personal del Depto. De Industria Penitenciaria y Promoción del Empleo, Almoloya de Juárez, Estado de México, noviembre 2018. 
Testimonio de “Anónimo 1" de la Dirección General de Reinserción Social del Estado de México (DGRS EDOMEX), Toluca, Estado de México, 19 de marzo de 2019.

Testimonio de “Anónimo 2", de la Dirección General de Reinserción Social del Estado de México, Toluca, Estado de México, 1 de octubre de 2018.

Testimonio de "Anónima", Personal Administrativo del Centro Penitenciario y de Reinserción Social (CPRS) “Santiaguito”, Almoloya de Juárez, Estado de México, 12 de octubre de 2018.

SSPEDOMEX, 2019. Solicitud de Información No. 00096/SEM/IP/2019, Toluca, Estado de México. 